\title{
The influence of pain-related fear on pain perception: attention as a possible mediator
}

Citation for published version (APA):

Roelofs, J. (2004). The influence of pain-related fear on pain perception: attention as a possible mediator. [Doctoral Thesis, Maastricht University]. Universiteit Maastricht. https://doi.org/10.26481/dis.20040610jr

Document status and date:

Published: 01/01/2004

DOI:

10.26481/dis.20040610jr

Document Version:

Publisher's PDF, also known as Version of record

\section{Please check the document version of this publication:}

- A submitted manuscript is the version of the article upon submission and before peer-review. There can be important differences between the submitted version and the official published version of record.

People interested in the research are advised to contact the author for the final version of the publication, or visit the DOI to the publisher's website.

- The final author version and the galley proof are versions of the publication after peer review.

- The final published version features the final layout of the paper including the volume, issue and page numbers.

Link to publication

\footnotetext{
General rights rights.

- You may freely distribute the URL identifying the publication in the public portal. please follow below link for the End User Agreement:

www.umlib.nl/taverne-license

Take down policy

If you believe that this document breaches copyright please contact us at:

repository@maastrichtuniversity.nl

providing details and we will investigate your claim.
}

Copyright and moral rights for the publications made accessible in the public portal are retained by the authors and/or other copyright owners and it is a condition of accessing publications that users recognise and abide by the legal requirements associated with these

- Users may download and print one copy of any publication from the public portal for the purpose of private study or research.

- You may not further distribute the material or use it for any profit-making activity or commercial gain

If the publication is distributed under the terms of Article $25 \mathrm{fa}$ of the Dutch Copyright Act, indicated by the "Taverne" license above, 
THE INFLUENCE OF PAIN-RELATED FEAR ON PAIN PERCEPTION: ATTENTION AS A POSSIBLE MEDIATOR 
Coverdesign: Renate Meijers

Publisher: $\quad$ Unigraphic Maastricht

Financial support for the printing of this thesis has been kindly provided by Winnock, The Netherlands.

(C) Jeffrey Roelofs, Maastricht 2004

ISBN 90-5681-197-5 


\section{THE INFLUENCE OF PAIN-RELATED FEAR ON PAIN PERCEPTION: ATTENTION AS A POSSIBLE MEDIATOR}

\section{PROEFSCHRIFT}

ter verkrijging van de graad van doctor aan de Universiteit Maastricht, op gezag van de Rector Magnificus, Prof. mr. G. P. M. F. Mols

volgens het besluit van het College van Decanen, in het openbaar te verdedigen op donderdag 10 juni 2004 om 16.00 uur

door

Jeffrey Roelofs 
Promotor:

Prof. dr. M. A. van den Hout

Co-promotores:

Dr. M. L. Peters

Dr. J. W. S. Vlaeyen

Beoordelingscommissie:

Prof. dr. A. Arntz (voorzitter)

Prof. dr. G. Crombez (Universiteit Gent, België)

Prof. dr. S. Morley (University of Leeds, United Kingdom)

Dr. J. Patijn

Dr. A. J. M. Schmidt 
“Pijn voert je terug naar de essentie van het wezenlijke zijn. Pijn laat je herinneren aan de hulpeloosheid van dat kleine mensje dat je was toen je ter wereld kwam. Je moest (ook hier had je geen enkele zeggenschap over) uit die warme, veilige, vertrouwde wereld waarin je je ontwikkeld had tot dat mensje om je te gaan ontwikkelen tot de mens die je nu bent. Pijn dwingt je om weer die veilige, vertrouwde wereld te verlaten. Opnieuw dat geboorteproces te doorstaan maar nu de andere kant op. Terug naar je zuivere wezen. Leren leven met de talenten die werkelijk van jou zijn. Leren leven met de onveranderlijke eenzaamheid die daaruit voortvloeit. Afleggen. Loslaten. Opnieuw ontwikkelen. Het doet verrekte pijn!"

Maria Scheres 



\section{CONTENTS OF THE THESIS}

CHAPTER 1 INTRODUCTION

\section{CHAPTER 2 EXPERIMENTAL STUDIES ON THE ROLE OF PAIN-RELATED FEAR} IN SELECTIVE ATTENTIONAL PROCESSING OF PAIN-RELATED STIMULI ........21

2.1 The modified Stroop paradigm as a measure of selective attention towards painrelated stimuli among chronic pain patients: A meta-analysis.

2.2 Selective attention for pain-related information in healthy individuals: The role of pain and fear ..........................................................................................................................

2.3 The modified Stroop paradigm as a measure of selective attention towards painrelated information in patients with chronic low back pain

2.4 An examination of word relevance in a modified Stroop task in patients with chronic low back pain

2.5 Selective attention and avoidance of pain-related stimuli: A dot-probe evaluation in a pain-free population .....

2.6 The role of fear of movement and (re)injury in selective attentional processing in chronic low back pain patients

\section{CHAPTER 3 THE INFLUENCE OF A MANIPULATION OF ATTENTIONAL FOCUS}

ON THE PAIN EXPERIENCE

3.1 Does fear of pain moderate the effects of attentional focusing and distraction on cold pressor pain in pain free individuals?

3.2 Electronic diary assessment of pain-related fear, attention to pain, and pain intensity in chronic low back pain patients.

\section{CHAPTER 4 PSYCHOMETRIC PROPERTIES OF SELF-REPORT MEASURES OF PAIN VIGILANCE AND FEAR OF PAIN}

4.1 Dutch version of the Pain Vigilance and Awareness Questionnaire: Validity and reliability in a pain-free population

4.2 The Pain Vigilance and Awareness Questionnaire (PVAQ): Further psychometric evaluation in fibromyalgia and other chronic pain syndromes............................................145

4.3 Psychometric evaluation of the Pain Anxiety Symptoms Scale (PASS) in chronic pain patients.

4.4 The Tampa Scale for Kinesiophobia: Further examination of psychometric properties in patients with chronic low back pain and fibromyalgia .....

4.5 The Fear of Pain Questionnaire: Further psychometric examination in a non-clinical sample. 



\section{CHAPTER 1 \\ Introduction}



Non-specific low back pain is a common disease in most western industrialized countries. In a comprehensive review of the epidemiological literature on chronic low-back pain in these countries, Andersson (1999) reported that 70-85\% of all people have back pain at some time in life. The annual prevalence of back pain ranges from $15 \%$ to $45 \%$, with point prevalences averaging $30 \%$. A recent study conducted in the Netherlands reported a comparable point prevalence rating $(27 \%)$ of chronic low back pain (Picavet \& Schouten, 2003). Most patients with back pain recover quickly. Overall, $60-70 \%$ recover by 6 weeks and $80-90 \%$ by 12 weeks. Recovery after 12 weeks is slow and uncertain. Fewer than half of those individuals disabled for longer than 6 months return to work and, after 2 years of absence from work, the return-towork rate is close to zero (Spitzer et al., 1987). The identification of mechanisms underlying the process of recovery of back pain is of paramount importance. The 'fear-avoidance' model has been proposed as a good candidate to explain why some individuals do and others do not recover from an acute pain incident. Before describing this model in more detail, a brief overview of pain theories is provided. The 'fear-avoidance' model is then discussed followed by an in depth discussion of the role of hypervigilance in the maintenance of chronic low-back pain. Finally, an outline of the thesis is provided in which the research question is presented.

\section{Theories of pain}

Until recently, theoretical formulations of the pain experience have been unidimensional in focus, either conceptualizing pain as a purely affective experience, or as a purely sensory experience (Craig, 1989). Aristotle, for example, considered pain an affect that was the obverse of pleasure. In his view, pain served a signal function, like other emotional states, so that the experience of pain was a cue to escape or remove the eliciting stimulus (Hardy et al., 1952). Apparently, pain continued to be seen as an affect until the 17th century, when sensory-specificity theories of pain began to predominate, which considered pain to be a specific sensation independent of other sensations. Descartes' dualistic theory of human experience can be seen as seminal in the development of sensory-specificity pain theory. In this view, pain is reduced to an activation of specific pain receptors and fibers, which project pain impulses through a spinal pain pathway to a pain center in the brain. The psychological experience of pain was virtually equated with peripheral injury. For Descartes, only higher-order cognitive functions such as reason were distinct from these mechanistic principles (Heidbreder, 1933).

The general thinking in the 19th century was that the mind had at least physical correlates if not physical substance. In 1842, Muller published his "doctrine of specific nerve energies" which provided physiological support for the notion that all sensations, including pain, could be understood as either unique energies transmitted along dedicated neural routes, or electrical phenomena, which although transmitted on common neural routes, was projected on to localized brain tracts. In either case, Muller tied psychological phenomena to bodily processes (Muller, 1842). In the late 19th century, a physician named Von Frey partialled the cutaneous 
sensation into four characteristics: touch, cold, warmth, and pain, each with a modality-specific cutaneous receptor for which some physiological evidence had been found (Boring, 1942).

\section{The contribution of psychological factors in pain theory}

In spite of the generalized historical ascendancy of sensory-specificity pain theories, there have been several early writers who have suggested that an adequate explanation of the pain experience requires equal consideration of both sensory and affective factors. For instance, Marshall (1894) proposed that affective and sensory systems operate in parallel during painful stimulation. Similarly, Strong (1895) recognized that negative affect is an inseparable consequence of pain. By the midtwentieth century, it was becoming apparent that sensory-specificity theories could not provide a full explanation for certain pain-related phenomena, such as: a) the highly variable relationship between extent of injury and intensity of pain, $b$ ) the observation that innocuous stimuli can sometimes provoke intense pain, c) the lack of relationship between the location of an injury and the location of pain, and d) the presence of chronic pain for which no anatomical basis can be found.

To account for these apparent anomalies, a number of multidimensional theories have been proposed, all of which share the general assumption that physiological factors and psychological factors, such as the personal meaning of painful sensations, beliefs about the likelihood of pain, and attention to (or distraction from) noxious events, must interact in order to provide a full account of all pain-related phenomena. Another opponent to the early specificity pain theories has been pattern theory, which postulates that there is no separate system for perceiving pain, and the receptors for pain are shared with other senses, such as touch. Individuals feel pain when certain patterns of neural activity exceed a threshold as a function of intensity and frequency of stimulation (e.g., Weddell, 1955; Sinclair, 1955). However, several pattern theories have been put forward all being generally vague and inadequate (Melzack, 1993). Nevertheless, pattern theories have set the stage for the gate control theory by moving the field in the direction of the spinal cord and away from the periphery as the exclusive answer to pain.

The gate-control theory, first proposed by Melzack and Wall in 1965, and elaborated in subsequent publications (Melzack \& Casey, 1968; Melzack \& Torgerson, 1971; Melzack \& Wall, 1988) proposed that nociceptive input may be controlled by a "gating" mechanism involving presynaptic as well as postsynaptic inhibition in the dorsal horn substantia gelatinosa of the spinal cord. After passing through this gating mechanism, painful stimulation is projected onto a sensorydiscriminative channel and a motivational-affective channel. These channels are assumed to operate in parallel, and may be interactively influenced by higher-order central nervous system processes, which allow for cognitive processing and evaluation of the pain experience. Thus, the gate-control theory clearly takes a biopsychological perspective by proposing a physiological mechanism by which psychological factors can affect people's experience of pain. 
Since the advent of the gate control theory of pain, psychological factors have been widely admitted to play a crucial role in the formation of the experience of pain. Although the gate control theory recognized the importance of psychological factors, the precise way in which they exerted their influence was not specified, apart from their proposed ability to moderate the spinal gate through descending efferent fibers. The impetus provided by the gate control theory to the psychology of pain has been enormous and several theoretical perspectives have been developed, of which the cognitive-behavioral framework account is the dominant one. The cognitivebehavioral framework subsumes several propositions, the central one being that an individual's emotions and behavioral activity in response to an event are influenced by their cognitive appraisal and interpretation of that event. One model that has received increased attention lately is the 'fear-avoidance' model of chronic low back pain.

\section{The 'fear-avoidance' model of chronic low back pain}

Consistent with research in anxiety that has demonstrated that anxiety may be maintained by avoidance of fear-eliciting stimuli, Philips (1987) has suggested that chronic pain sufferers may learn to avoid stimuli that they have associated with the initiation or exacerbation of their pain symptoms. In avoiding these stimuli, they reduce the likelihood of increased pain symptoms, which may in turn reinforce their anxiety by rewarding their avoidance behavior. Thus, a vicious circle is created in which avoidance behavior reinforces avoidance beliefs, which maintains anxiety. The central concept in the so-called 'fear-avoidance' models is pain-related fear (Lethem et al., 1983). 'Confrontation' and 'avoidance' are postulated as the two extremes in a continuum of responses to this fear, of which the former leads to the reduction of fear over time. The latter, however, leads to the maintenance or exacerbation of fear, possibly generating a phobic state. According to Waddell et al. (1993), disability in chronic low back pain patients is correlated more strongly with fear avoidance than with physical pathology. In the last decade, an increasing number of investigations have corroborated and refined the fear-avoidance model. A more cognitively oriented model of pain-related fear in chronic low back pain, which is based on the work of Lethem (1983), Philips (1987) and Waddell et al. (1993), is presented in figure 1-1. This cognitive-behavioral model posits a behavioral mechanism whereby fear of movement/(re)injury might contribute to the maintenance of chronic pain (Vlaeyen et al., 1995a; Vlaeyen et al., 1995b; Vlaeyen \& Linton, 2000). The model starts with the acute phase of the injury. At that point, if pain is interpreted as threatening, possibly through the cognitive process of catastrophizing, pain-related fear evolves. This leads to avoidance behaviors and hypervigilance to bodily sensations, which maintains a chronic pattern of disability, disuse and depression. Both depression and disuse are known to be associated with decreasing pain tolerance and hence promote the painful experience. The pain experiences fuel the cycle of increasing fear and avoidance. In contrast, non-catastrophizing patients have low levels of pain-related 
fear, and are more likely to rapidly confront daily activities, thus leading to fast recovery. In the next section, the concept of hypervigilance is further explored.

Figure 1-1: Fear avoidance model of chronic low back pain (Adapted from Vlaeyen E Linton, 2000)

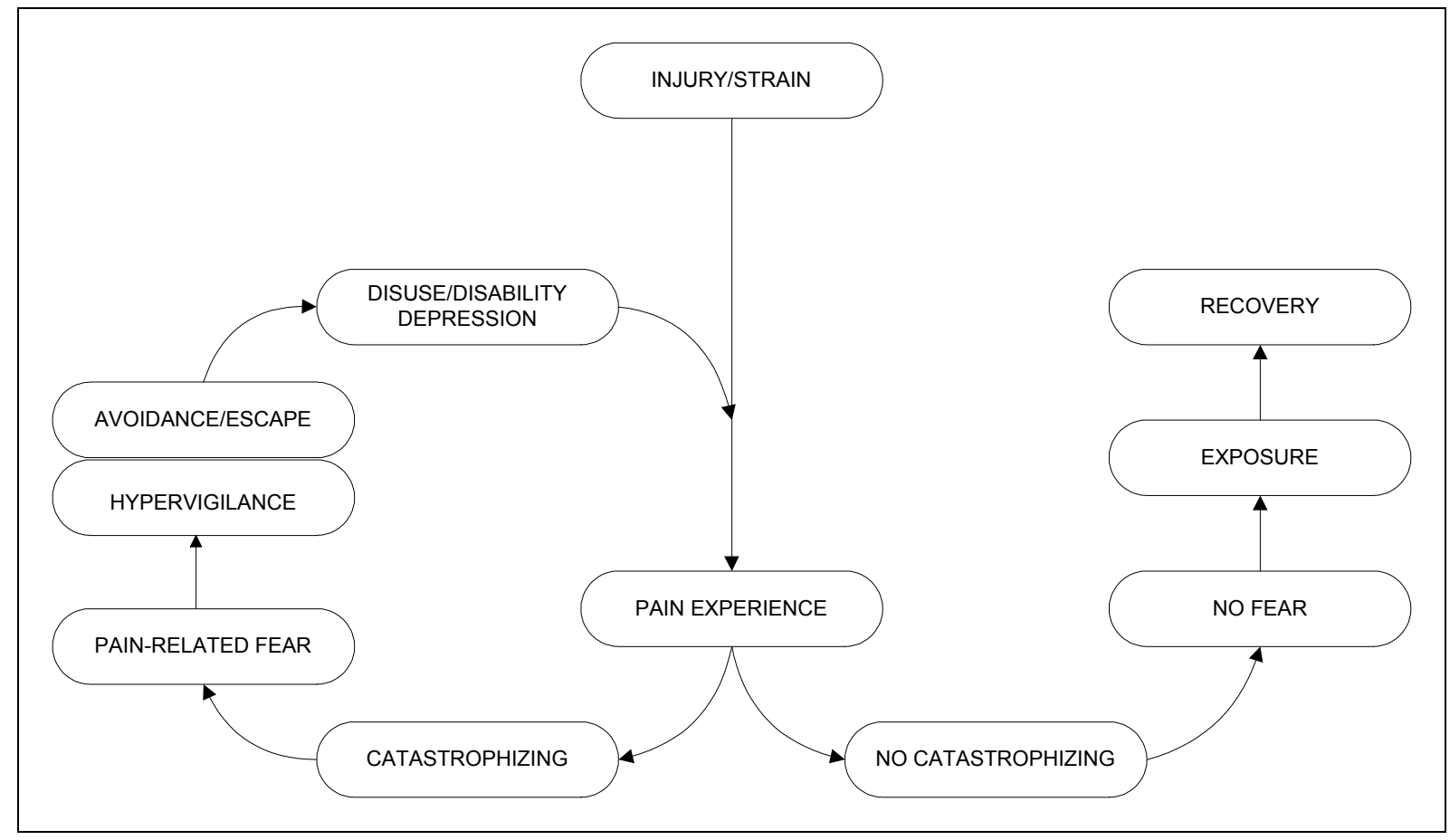

\section{Hypervigilance}

According to the fear-avoidance model outlined in the previous section, hypervigilance may play an important role in the maintenance of back pain. The term 'vigilance' was first introduced in the psychological literature by Mackworth (1950). He considered vigilance as a predisposition to attend to certain classes of events. Chapman (1978) applied the concept of (hyper)vigilance to somatic sensations. The hypervigilant patient is convinced that noxious somatic sensations mean something bad and as a consequence, the patient keeps a constant, sometimes exaggerated, vigil for the sensations. In this view, hypervigilance can be conceptualized as a perceptual habit of scanning the body for noxious somatic sensations. It is also important to recognize that hypervigilance to noxious somatic sensations is directly related to the threat value of pain. That is, individuals who are convinced that noxious signals from the body mean something dangerous are especially prone to develop a constant scanning of the body for threatening sensations. This conceptualization of hypervigilance is closely related to the view of Watson and Pennebaker (1989). In their seminal paper, these authors argued that the relation between negative affectivity (i.e., the disposition to experience negative affect and low mood) and somatic complaints is best explained by a hypervigilance to somatic information in individuals with high levels of negative affectivity. The construct of hypervigilance has also been of importance in accounting for 
unexplained symptoms and complaints in chronic low back pain (Vlaeyen \& Linton, 2000), hypochondrias (Barsky \& Klerman, 1983), fibromyalgia (McDermid et al., 1996), and irritable bowel syndrome (Chang et al., 2000).

From a functional perspective, hypervigilance is viewed within the need of an organism to behave in a purposeful and coherent way (Allport, 1989). Attentional engagement serves the purpose of survival. Failure to shift attentional engagement to environmental threats is hazardous and possibly fatal. In line with Allport (1989), a cognitive-affective model of the interruptive function of pain has been developed by Eccleston and Crombez (1999). According to this model, the interruption of pain is mediated by its threat value. Pain-related characteristics implicated in interruption are the intensity, novelty, and predictability of a threatening pain stimulus and the degree to which an individual catastrophizes about pain and has a high somatic awareness. Eysenck (1992) has provided one of the most elaborated accounts of the role of attention to threat in anxiety and fear. In his view, hypervigilance to threat is not restricted to an attentional scanning mechanism but may rather become manifest in different ways, depending on the temporal imminence of the threat. The following example clarifies this:

Jane is very afraid of spiders. Her boy friend is coming for diner tonight and she wants everything to be perfect. She has to get a bottle of wine from the cellar. Only the thought of descending the cellar stairs makes her afraid. This thought makes her vigilant towards several irrelevant stimuli in the environment (general hypervigilance). When she actually goes downstairs, she scans the environment on the presence of spiders, which may result in a rapid detection of a spider. Attention will be drawn automatically to the spider (specific hypervigilance), and once it is detected, she will have serious difficulty in both disengaging attention from the spider and directing it to other stimuli such as the label on the wine bottles.

Individuals who are afraid of spiders may eventually become hypervigilant for spiders and spider-related stimuli. In the case of chronic low back pain patients, individuals displaying high levels of pain-related fear may become particularly hypervigilant for pain signals from the body. In this context, Mogg and Bradley (1998) have suggested a non-linear relationship between the level of threat and the attentional bias of threat. As long as the threat value is below a certain threshold, individuals will switch attention away from threat and continue to pursue their goals. Hypervigilance to threat, often expressed in terms of attentional bias, occurs when the threat value exceeds a certain threshold. 


\section{Outline of the thesis}

The fear-avoidance model assumes that pain-related fear affects the pain experience indirectly via avoidance behavior and subsequent disuse, disability and depression. In this thesis, an additional route is proposed, namely that pain-related fear influences pain intensity via hypervigilance (see figure 1-2).

Figure 1-2: Modified fear-avoidance model of chronic low back pain.

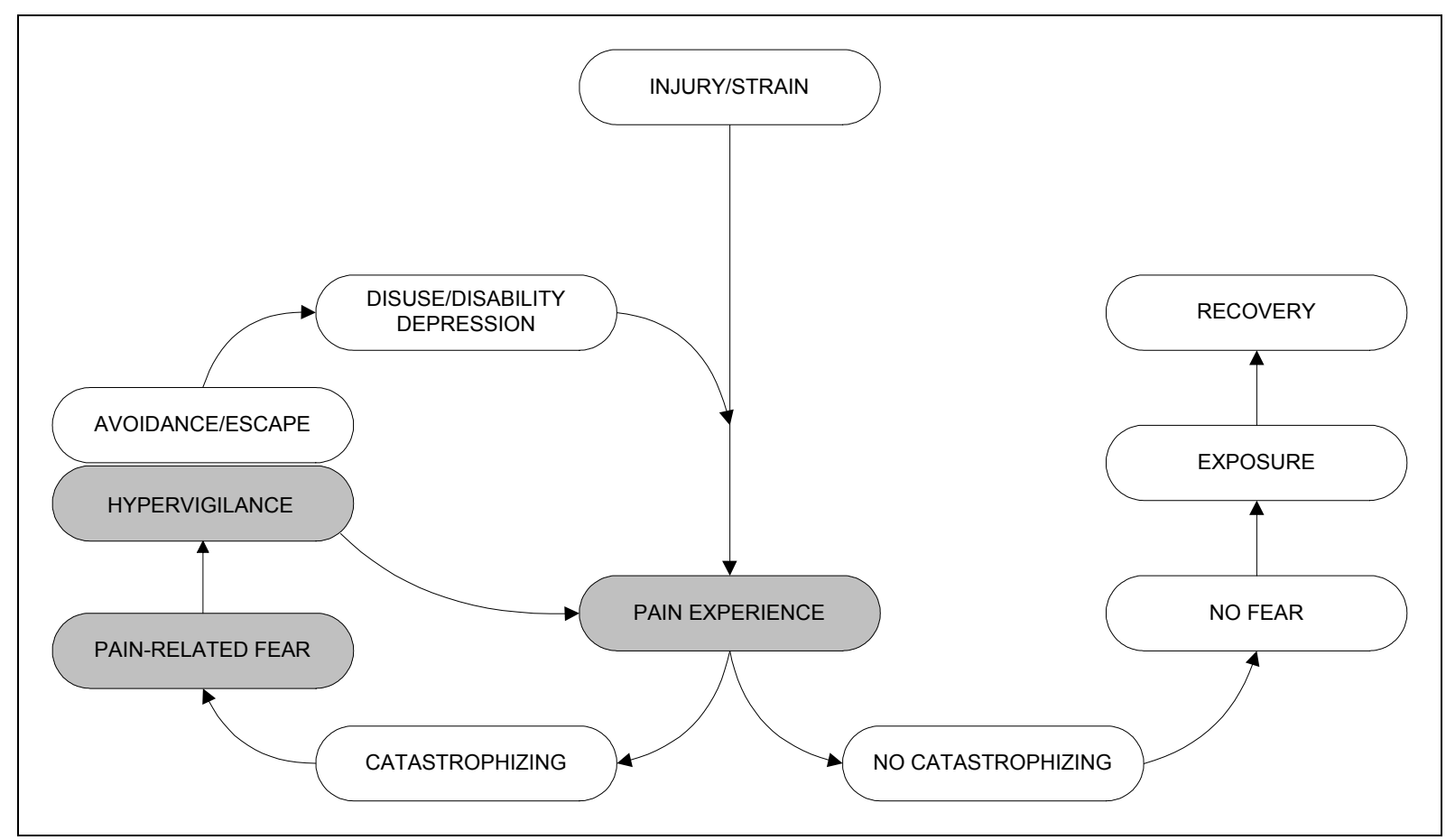

Evidence for hypervigilance as a mediator between pain-related fear and pain intensity comes from a series of experimental studies that have shown that fear may either increase or decrease the pain experience, depending on the focus of attention. More specifically, attention is directed to pain and pain is experienced as more intense when the experienced fear is related to pain. In contrast, attention is distracted from pain and pain is experienced as less intense when fear is related to another source of threat (Janssen \& Arntz, 1996; Arntz et al., 1994; Arntz \& De Jong, 1993; Arntz et al., 1991).

The research question of this thesis involved examining the degree to which hypervigilance mediates the relation between pain-related fear and the pain experience. In examining this, a prerequisite would be to demonstrate an association between pain-related fear and hypervigilance. In chapter 2, a series of experimental studies is presented, most of which examined hypervigilance, operationalised as selective attentional processing, as a function of pain-related fear in pain patients and experimental analogues in pain-free individuals. Elaborating on the experimental studies examining the mediating role of hypervigilance in the relation between painrelated fear and pain intensity mentioned in the previous section, two studies are presented in chapter 3 in which the effect of a manipulation of attention to pain on 
the pain experience was examined. The moderating effect of pain-related fear on the relation between attention to pain (manipulated) and the pain experience was also investigated in both studies. The first study was an experimental study in which pain-free individuals underwent a pain test (cold pressor test) thereby providing an experimental way of investigating the relations between pain-related fear, vigilance (manipulated), and the pain experience. In the second study presented in chapter 3 , pain-related fear, hypervigilance, and the pain experience were measured in daily life of pain patients, using an experience sampling methodology. In addition to examining temporal relationships between pain-related fear, hypervigilance, and pain intensity, this study attempted to manipulate attention to pain to examine the influence of this manipulation on pain intensity and to examine whether the effect of the manipulation depended on the level of pain-related fear (i.e., whether painrelated fear moderated the relation between attention to pain and the pain experience). In chapter 4, a series of studies was presented aimed at establishing reliability and validity of self-report measures of pain vigilance and pain-related fear in pain patients and pain-free individuals. Chapter 5 presents a discussion of the findings from the previous chapters.

\section{REFERENCES}

Andersson, G. B. J. (1999). Epidemiological features of chronic low-back pain. Lancet, 354, 581-585.

Allport, A. (1989). Visual attention. In: M. I. Posner (Ed.), Foundation of cognitive science (pp. 631-682). Hillsdale, NJ: Erlbaum.

Arntz, A., Dreessen, L., \& Merckelbach, H. (1991). Attention, not anxiety, influences pain. Behaviour Research and Therapy, 29, 41-50.

Arntz, A., \& De Jong, P. J. (1993). Anxiety, attention and pain. Journal of Psychosomatic Research, 37, 423-431.

Arntz, A., \& Dreessen, L., \& De Jong, P. J. (1994). The influence of anxiety of pain: Attentional and attributional mediators. Pain, 56, 307-314.

Barsky, A. J., \& Klerman, G. L. (1983). Overview: Hypochondrias, bodily complaints, and somatic styles. American Journal of Psychiatry, 140, 273-283.

Boring, E. G. (1942). Sensation and perception in the history of experimental psychology. New York: Appleton Century Crofts.

Chang, L., Mayer, E. A., Johnson, T., Fitzgerald, L. Z., \& Naliboff, B. (2000). Differences in somatic perception in female patients with irritable bowel syndrome with and without fibromyalgia. Pain, 84, 297-307.

Chapman, C. R. (1978). Pain: The perception of noxious events. In R. A. Sternbach (Ed.), The psychology of pain (pp. 169-202). New York: Raven Press.

Craig, K. D. (1989). Emotional aspects of pain. In P. D. Wall \& R. Melzack (Eds.). Textbook of pain (pp. 220-230). Edinburgh: Churchill Livingstone. 
Eccleston, C., \& Crombez, G. (1999). Pain demands attention: a cognitive-affective model on the interruptive function of pain. Psychological Bulletin, 125, 356-366.

Eysenck, M. W. (1992). Anxiety: the cognitive perspective. Hillsdale: Lawrence Erlbaum Associates.

Hardy, J., Wolff, H., \& Goodell, H. (1952). Pain sensations and reactions. Baltimore: Williams \& Wilkins.

Heidbreder, E. (1933). Seven psychologies. Englewood Cliffs: Prentice Hall.

Janssen, S. A., \& Arntz, A. (1996). Anxiety and pain: Attentional and endorphinergic influences. Pain, 66, 145-150.

Lethem, J., Slade, P. D., Troup, J. D. G., \& Bentley, G. (1983). Outline of a fearavoidance model of exaggerated pain perceptions. Behaviour Research and Therapy, 21, 401-408.

McDermid, A. J., Rollman, G. B., \& McGain, G. A. (1996). Generalized hypervigilance in fibromyalgia: Evidence of perceptual amplification. Pain, 66, 133-144.

Mackworth, N. H. (1950). Researches in the measurement of human performance. Medical Research Council Special Report Series, 268.

Marshall, H. R. (1894). Pain, pleasure, and aesthetics. London: Macmillan.

Melzack, R., \& Wall, P. D. (1965). Pain mechanisms: A new theory. Science, 150, 971979.

Melzack, R., \& Casey, K. L. (1968). Sensory, motivational, and central control determinants of pain: A new conceptual model. In D. Kenshalo (Ed.), The skin senses. Springfield: Thomas.

Melzack, R., \& Torgerson, W. S. (1971). On the language of pain Anaesthesiology, 34, 50-59.

Melzack, R., \& Wall, P. D. (1988). The challenge of pain. London: Penguin

Melzack, R. (1993). Pain: past, present and future. Canadian Journal of Experimental Psychology, 47(4), 615-629.

Muller, J. (1842). Elements of physiology. London: Taylor.

Mogg, K., \& Bradley, B. P. (1998). A cognitive-motivational analysis of anxiety. Behaviour Research and Therapy, 36, 809-848.

Philips, H. C. (1987). Avoidance behaviour and its role in sustaining chronic pain. Behaviour Research and Therapy, 25, 273-279.

Picavet, H. S. J., \& Schouten, J. S. A. G. (2003). Musculoskeletal pain in the Netherlands: prevalence, consequences and risk groups, the DMC3-study. Pain, 102, 167-178.

Sinclair, D. C. (1955). Cutaneous sensation and the doctrine of specific energy. Brain, 78, 584-614.

Spitzer, W. O., LeBlanc, F. E., Dupuis, M., Abenhaim, L., Bloch, R., Bombardier, C., et al. (1987). Scientific approach to the assessment and management of activity-related spinal disorders: a monograph for clinicians. Report of the Quebec Task Force on Spinal Disorders. Spine, 12, S1-S59.

Strong, C. A. (1895). The psychology of pain. Psychological Review, 2, 69-80. 
Vlaeyen, J. W. S., Kole-Snijders, A. M. J., Boeren, R. G. B., \& Van Eek, H. (1995a). Fear of movement/(re)injury in chronic low back pain and its relation to behavioral performance. Pain, 62, 363-373.

Vlaeyen, J. W. S., Kole-Snijders, A. M. J., Rotteveel, A., Ruesink, R., Heuts, P. H. T. G. (1995b). The role of fear of movement/(re)injury in pain disability. Journal of Occupational Rehabilitation, 5, 235-252.

Vlaeyen, J. W. S., \& Linton, S. J. (2000). Fear-avoidance and its consequences in chronic musculoskeletal pain: a state of the art. Pain 85, 317-332.

Waddell, G., Newton, M., Henderson, I., Somerville, D., \& Main, C. (1993). A FearAvoidance Beliefs Questionnaire (FABQ) and the role of fear-avoidance beliefs in chronic low back pain and disability. Pain, 52, 157-168.

Waddell, G. (1998). The Back Pain Revolution. London: Churchill Livingstone.

Watson, D., \& Pennebaker, J. W. (1989). Health complaints, stress, and distress: Exploring the central role of negative affectivity. Psychological Review, 96, 234-254.

Weddell, G. (1955). Somesthesis and chemical senses. Annual Review of Psychology, 6, 119-136. 



\section{CHAPTER 2}

Experimental studies on the role of pain-related fear in selective attentional processing of painrelated stimuli 



\subsection{THE MODIFIED STROOP PARADIGM AS A MEASURE OF SELECTIVE ATTENTION TOWARDS PAIN-RELATED STIMULI AMONG CHRONIC PAIN PATIENTS: A META-ANALYSIS*}

\section{ABSTRACT}

Although the modified Stroop paradigm is considered to be a prominent paradigm for investigating selective attention in emotional disorders, relatively few studies have applied this paradigm to examine selective attention in chronic pain patients. Moreover, the results from these studies are not robust. The purpose of this article is to review the evidence for attentional bias in chronic pain patients, by means of a meta-analysis. Data from five studies were pooled and summarized into a mean difference (MD). Significant MD estimations (in milliseconds) were found for both sensory pain words $(\mathrm{MD}=26.7 ; 95 \% \mathrm{CI} 10.0-42.9)$ and affective pain words $(\mathrm{MD}=28.1 ; 95 \% \mathrm{CI} 0.4-55.8)$. Meta regression analysis indicated that methodological quality did not significantly affect the pooled MD estimation for both sensory pain words and affective pain words. Thus, the results from the present meta-analysis on studies applying the modified Stroop paradigm, suggest that chronic pain patients selectively attend to both pain sensory and pain affective stimuli. Furthermore, the MD estimation did not depend upon the methodological quality tentatively indicating that even though studies differed in methodology, the results were rather consistent. Implications of the results are discussed.

\footnotetext{
* Roelofs, J., Peters, M. L., Zeegers, M. P. A., Vlaeyen, J. W. S. (2002). The modified Stroop paradigm as a measure of selective attention towards pain-related stimuli among chronic pain patients: a metaanalysis. European Journal of Pain, 6, 273-281.
} 


\section{INTRODUCTION}

During the past decade, researchers in experimental psychopathology have increasingly relied upon cognitive psychology to account for emotional disorders, in particular depression and anxiety disorders. According to cognitive theory, people with these disorders process information differently as compared to people without these disorders. This implies that an individuals' affective status is associated with cognitive biases that favor the processing of information congruent with the affective state. Research in many syndromes, which has mainly been inspired by Beck's schema theory (Beck, 1976; Beck et al., 1986) and Bower's network theory (Bower, 1981; Bower, 1987), has identified biases in attention, memory and interpretation. Research into information processing has also been applied to chronic pain patients. There is good reason to assume that chronic pain patients exhibit a recall bias towards pain-related stimuli (Pincus et al., 1993; Pincus et al., 1998; Pincus, 1998) and that interpretation bias takes place in pain patients (Pincus et al., 1994; Pincus et al., 1996; Pincus, 1998). However, the possible existence of an attentional bias towards pain-related information remains unclear. In general, attentional bias can be defined as selective attention to (specific) concern-related information. Attentional bias towards pain may serve the purpose of early detection of potentially dangerous painrelated stimuli.

One paradigm for investigating attentional bias has been the modified Stroop paradigm. Generally, in a modified Stroop paradigm categories of emotionally salient and neutral words are presented in different colors. Response times of patients to name the color of each word are measured. Typically, color naming is slowed down when words are threatening and relevant to the patients' concern, whereas no response delay is found with neutral words. Selective attention can be expressed in terms of interference, which is calculated by subtracting the color naming time of neutral words from the color naming time of concern-related words.

A relatively small number of studies regarding attentional bias applying a modified Stroop in chronic pain patients have been carried out. One of the first studies was performed by Pearce and Morley (1989). The results from this study indicated that pain patients displayed greater interference on pain-related sensory and affective words when compared to healthy controls. Thus, patients with chronic pain tended to show selective attention towards cues related to the expression of pain. However, depression was associated with a general delay in response times thereby contaminating the effect of pain on the observed attentional bias.

Boissevain (1994) further investigated the interaction between pain and depression by comparing performance on the Stroop task between four groups: depressed pain patients, non-depressed pain patients, pain free depressed patients and pain- and depression- free controls. The results of this study support the presence of an attentional bias in pain patients: both pain groups were slower to name words from the sensory category than the neutral and positive categories. 
Pincus et al., (1998) conducted two successive experiments to investigate the presence of attentional bias in chronic pain patients. The first study attempted to replicate the study of Pearce and Morley (1989). The second study described a more detailed examination of the effects of anxiety and depression in relation to attentional bias. Neither experiment provided evidence for an attentional bias towards pain stimuli in chronic pain patients when compared to a healthy control group. However, the interference score was influenced by measures of anxiety and depression rather than by pain itself.

A subsequent study using the modified Stroop paradigm found that patients with chronic pain but not healthy volunteers had delayed color-naming latencies to both sensory and affective words (Snider et al., 2000). Additionally, delayed colornaming latencies to pain words was partly associated with high pain-specific cognitive anxiety (as measured with the Pain Anxiety Symptoms Scale (PASS; McCracken et al., 1992) and with lower levels of anxiety sensitivity (as measured with the Anxiety Sensitivity Index (ASI; Reiss et al., 1986).

The empirical evidence that chronic pain patients display attentional bias towards pain-related information is not robust. In addition, previous studies appear to have some theoretical and methodological inadequacies. Consequently, there is a need for a critical review of this area in the hope of summarizing and integrating the current literature. The purpose of the present study is to systematically review studies in chronic pain patients applying a modified Stroop paradigm, by means of a meta-analysis which provides a quantitative summary estimate (mean difference) of whether chronic pain patients selectively pay attention to pain-related information (i.e. display attentional bias). In the present meta-analysis, the impact of the methodological quality of the individual studies on the mean-difference effect size is estimated. Finally, some concluding remarks and directions for future research are provided.

\section{MATERIALS AND METHODS}

\section{Search strategy and inclusion criteria}

Studies were identified through a computerized Pubmed (Medline), PsycInfo and Current Contents search up to July 2001. Furthermore, an intensive search on the worldwide web was performed in order to identify articles, abstracts or posters that may refer to the existence of Stroop studies that have been conducted in chronic pain patients. The keywords used in all search strategies were Stroop, chronic pain, selective attention and attentional bias. Additionally, references in relevant publications were further examined and experts in the field were inquired.

Five articles and one unpublished dissertation were identified (Pearce \& Morley, 1989; Boissevain, 1994; Duckworth et al., 1997; Pincus et al., 1998; Crombez et al., 2000; Snider et al., 2000). Each study had to provide sufficient information to estimate a mean difference (MD) (i.e., mean response latencies and standard 
deviations for each group for both sensory pain, affective pain and control words). With regard to the study by Boissevain, only the group consisting of non-depressed pain patients and the pain- and depression free control group were taken into account in the present meta-analysis. The study of Duckworth et al. (1997) did not provide mean response latencies. The response latencies could not be provided by the authors. In addition, in order to calculate a MD, a control group is necessary. In the study of Crombez and colleagues (2000) no control group was included. Both studies were therefore omitted from the analysis. The study of Pincus and colleagues (1998) consisted of two successive experiments which have been taken as two separate studies in the current review, leaving a total number of five studies for further analysis (Pearce \& Morley, 1989; Boissevain, 1994; Pincus et al., 1998 a; Pincus et al., 1998 b; Snider et al., 2000).

\section{Data collection}

In order to identify possible sources of heterogeneity, information on study characteristics was collected. Information regarding study design (publication year, study size, country), measuring instrument (computerized versus non-computerized Stroop task), source of pain patients and minimum duration of pain complaints were listed. In addition, the methodological quality of each study was systematically assessed by two authors (JR and JWSV) independent of each other using a list of predefined criteria (see appendix 1-1). Each item was scored one (rating 'yes') or zero (rating 'no' or 'don't know'). The range of the quality score was between zero and ten. Disagreements were solved by consulting one of the other authors (MLP).

\section{Statistical Analysis}

A common way to examine publication bias is by visually inspecting a precisionbased funnel plot asymmetry (Egger et al., 1997). In addition, the degree of asymmetry can be quantified by using Egger's unweighted regression asymmetry test (Egger et al., 1997). Due to the small number of studies in the present review, publication bias could not be examined adequately. In order to estimate a pooled mean difference (MD), an individual MD was computed for each study. Therefore, for both sensory pain and affective pain words, an interference score was computed within each study, which was defined as the difference in response times (RT) between sensory or affective words and neutral words. This was done for the chronic pain patients as well as for the healthy controls. By subtracting the interference score in the control group from the interference score in the pain group, a mean-difference was computed for pain sensory words and pain affective words separately. In formula:

$$
\begin{aligned}
& \text { Interference }_{(\text {sensory/affective) }}=\mathrm{RT}_{(\text {sensory/affective) }}-\mathrm{RT}_{(\text {neutral })} \\
& \mathrm{MD}_{(\text {sensory })}=\text { interference }_{(\text {sensory; chronic pain group) }}-\text { interference }_{(\text {sensory; control group) }} \\
& \mathrm{MD}_{(\text {affective) })}=\text { interference }_{(\text {affective; chronic pain group })}-\text { interference }_{(\text {affective; control group) }}
\end{aligned}
$$


In order to compute a 95\% confidence interval (CI) for each individual MD, the standard error, reflected by the square root of the variance, is needed. The variance of the MD (VAR) is defined as the sum of the variance in each group (chronic pain group and control group) divided by its study size (n). The variance in each group is equal to the variance of a difference score (pain words versus neutral words within each group). The formula for a difference score (dif) is defined as the sum of the variance for both the pain words and the neutral words minus two times the covariance. In formula for both sensory and affective pain words:

$\operatorname{VAR}(M D)=\left(\operatorname{VAR}_{(\text {chronic pain group })} / \mathrm{n}\right)+\left(\operatorname{VAR}_{(\text {control group })} / \mathrm{n}\right)$

To compute both $\mathrm{VAR}_{\text {(chronic pain group) }}$ and $\mathrm{VAR}_{\text {(control group): }}$

$$
\operatorname{VAR}_{(\text {dif })}=\operatorname{VAR}_{(\text {pain words) }}+\operatorname{VAR}_{(\text {neutral words })}-2{ }^{*} r^{*} \mathrm{SD}_{(\text {pain words) }}{ }^{*} \mathrm{SD}_{(\text {neutral words) }}
$$

In the formula, $\mathrm{r}$ refers to the correlation between (sensory or affective) pain words and neutral words. These correlations were not provided in the individual papers but were obtained from the authors, except for the studies of Pincus et al. (1998). A pooled correlation coefficient was estimated for the Pincus et al. studies, based on the correlations from the other studies and the studies by Duckworth et al. (1997) and Crombez et al. (1999). One remark with regard to the type of Stroop studies is in order. Two studies used a non-computerized Stroop task, which consisted of presenting cards with sensory pain words, affective pain words and neutral words in a fixed order. The time to complete each card was measured. In order to compute a MD and a 95\% CI, response times were transformed into mean response latencies by dividing the total response times by the amount of stimuli used within each word category.

A pooled MD and its $95 \%$ CI were estimated according to both a fixed and a random effects model using the STATA statistical software package (STATA corporation, 1999). In a fixed effects model, all studies are assumed to estimate the same underlying 'fixed' effect. Differences between studies are completely due to sampling error. According to a random effects model, each study is assumed to estimate its own underlying effect thereby allowing for variability between studies. In the absence of (statistical) heterogeneity, both models produce asymptotically the same estimates (Zeegers et al., 2000). Furthermore, the fixed effects model unfortunately assumes that inference can be made only to the studies that are included in the meta-analysis. Only the random effects model allows for generalisability. On the other hand, a random effects model may not be appropriate because no random sampling was used to obtain the studies that could have been performed. The results from both a fixed and a random effects analysis are presented. If the MD estimations of both models do not differ substantially, the fixed effects model is interpreted. In addition, an indication of statistical heterogeneity is obtained by the Q-test. However, since there are only five studies in the meta- 
analysis, the Q-test has low power and should be interpreted cautiously. The between-study variance was estimated iteratively, using the empirical Bayes method. Meta-regression analysis can be used to identify possible sources of clinical and methodological heterogeneity and was used in the present study to investigate the impact of the methodological quality of the individual studies on the pooled MD (i.e. whether methodological quality is an effect modifier). If the magnitude of the pooled MD depends upon the methodological quality of the studies (i.e. methodological quality is a significant effect modifier), then the pooled MD should be estimated separately according to each category of the effect modifier.

\section{RESULTS}

\section{Study characteristics}

Table 2-1 displays study characteristics, which may account for heterogeneity between studies.

Table 2-1: Study characteristics of five studies concerning attentional bias in chronic pain patients using the modified Stroop task, ordered by year of publication

\begin{tabular}{|c|c|c|c|c|c|c|}
\hline $\begin{array}{l}\text { First } \\
\text { author }\end{array}$ & $\begin{array}{l}\text { Publication } \\
\text { year }\end{array}$ & Country & $\begin{array}{l}\text { Measuring } \\
\text { instrument }\end{array}$ & Source of pain patients & $\mathrm{N}_{\mathrm{e}} / \mathrm{N}_{\mathrm{c}}{ }^{*}$ & $\begin{array}{l}\text { Duration } \\
\text { of pain } \\
\text { complaints }\end{array}$ \\
\hline Pearce & 1989 & UK & non-computerized & $\begin{array}{l}\text { chronic pain patients } \\
\text { (not specified) }\end{array}$ & $16 / 16$ & 1 year \\
\hline Boissevain & 1994 & Canada & non-computerized & $\begin{array}{l}\text { various types of pain } \\
\text { patients }\end{array}$ & $15 / 15$ & 6 months \\
\hline Pincus (a) & 1998 & UK & non-computerized & $\begin{array}{l}\text { chronic pain patients } \\
\text { (not specified) }\end{array}$ & $20 / 20$ & 6 months \\
\hline Pincus (b) & 1998 & UK & computerized & $\begin{array}{l}\text { chronic pain patients } \\
\text { (not specified) }\end{array}$ & $17 / 17$ & 6 months \\
\hline Snider & 2000 & Canada & computerized & $\begin{array}{l}\text { chronic back and/or } \\
\text { neck pain }\end{array}$ & $33 / 33$ & 3 months \\
\hline
\end{tabular}

Note: ${ }^{*} N_{e}=$ number of patients; $N_{c}=$ number of healthy controls

\section{MD estimation}

Table 2-2 shows the MD estimations and their 95\% CI for both sensory and affective pain words for each study. In addition, the pooled MD and its 95\% CI for both a fixed and a random effects model are presented. Figure 2-1 summarizes the MD and their $95 \%$ CI for each study and the pooled MD estimation in a graphical way. 
Table 2-2: Mean Difference (MD) estimation and their 95\% confidence interval (CI)

\begin{tabular}{lclcl}
\hline First author & $\mathrm{MD}_{\text {(sensory) }}$ & $95 \% \mathrm{Cl}_{\text {(sensory) }}$ & $\mathrm{MD}_{\text {(affective) }}$ & $95 \% \mathrm{Cl}_{\text {(affective) }}$ \\
\hline Pearce & 102.4 & {$[26.0 ; 178.0]$} & 108.6 & {$[12.8 ; 195.4]$} \\
Boissevain & 42.0 & {$[-3.0 ; 96.0]$} & 36.0 & {$[-0.8 ; 72.8]$} \\
Pincus (a) & 41.6 & {$[-9.8 ; 93]$} & -30.6 & {$[-84.7 ; 23.5]$} \\
Pincus (b) & 4.0 & {$[-46.9 ; 54.9]$} & 32 & {$[-19.4 ; 83.4]$} \\
Snider & 18 & {$[-3.4 ; 39.4]$} & 29 & {$[3.75 ; 46.25]$} \\
Pooled (fixed) & 26.5 & {$[10.0 ; 42.9]$} & 28.0 & {$[11.9 ; 44.2]$} \\
Pooled (random) & 31.5 & {$[7.6 ; 55.4]$} & 28.1 & {$[0.4 ; 55.8]$} \\
\hline
\end{tabular}

Figure 2-1: Forest plots for sensory and affective pain words displaying Mean Differences and their $95 \%$ CI for individual studies and the pooled estimation

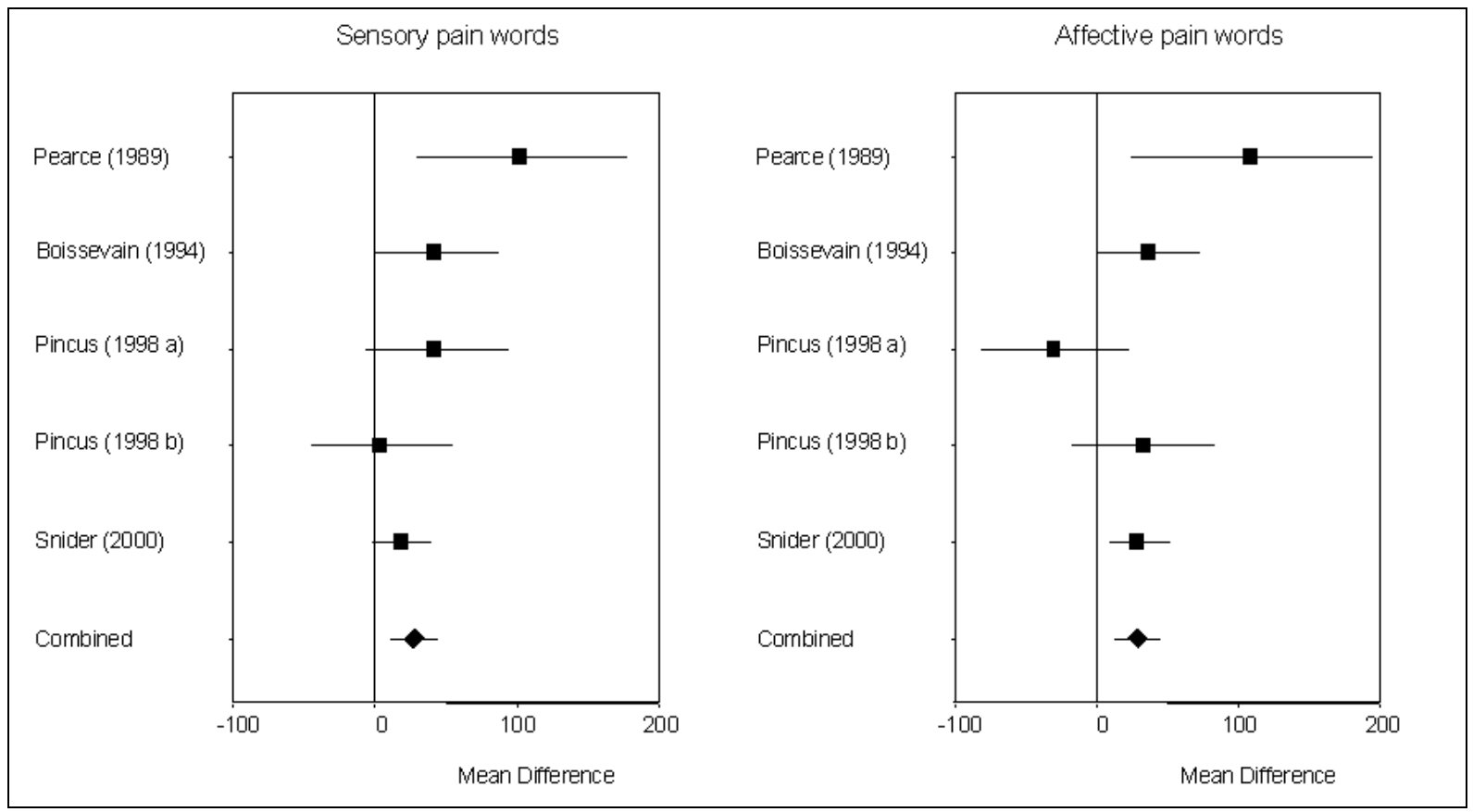

As both the fixed effects model and the random effects model yield comparable MD estimation for sensory pain words as well as for affective pain words, the fixed effects model is interpreted for both word categories. In addition, the $Q$-value was $6.20(p=0.185)$ for sensory pain words and $8.31(p=0.079)$ for affective pain words, tentatively indicating the absence of statistical heterogeneity. According to table 2-2, for sensory pain words a MD of 26.5 was found (95\% CI 10.0-42.9; $\mathrm{p}=0.002)$ and for affective pain words a MD of 28.0 was found (95\% CI 11.9-44.2; $\mathrm{p}=0.001)$. With regard to the methodological quality of each study, table 2-3 shows the ratings for each study. Inter-rater agreement measured by kappa was 0.91, indicating very good strength of agreement (Altman, 1997). Metaregression analysis indicated that methodological quality of the various studies did not significantly affect the pooled MD estimation for both sensory pain words $(p=0.058)$ and for affective pain words $(p=0.557)$. 
Table 2-3: Ratings of methodological quality of each study.

\begin{tabular}{llllll}
\hline & Pearce (1989) & $\begin{array}{l}\text { Boissevain } \\
(1994)\end{array}$ & $\begin{array}{l}\text { Pincus } \\
(1998 \mathrm{a})\end{array}$ & Pincus (1998 b) & Snider (2000) \\
\hline Inclusion criteria & 1 & 1 & 1 & 1 & 1 \\
Exclusion criteria & 0 & 1 & 0 & 0 & 1 \\
Type of patients & 0 & 1 & 0 & 0 & 1 \\
Matching patients & 1 & 1 & 1 & 1 & 0 \\
Environment & 0 & 0 & 0 & 0 & 1 \\
Computerized Stroop & 0 & 0 & 0 & 1 & 1 \\
Matching words & 1 & 1 & 1 & 1 & 1 \\
Depression & 0 & 1 & 1 & 1 & 1 \\
Anxiety & 0 & 0 & 1 & 1 & 1 \\
Statistical analysis & 1 & 1 & 1 & 1 & 1 \\
\hline Total quality score & 4 & 7 & 6 & 7 & 9 \\
\hline
\end{tabular}

\section{DISCUSSION}

The purpose of the present study was to review by means of a meta-analysis whether chronic pain patients display attentional bias towards pain-related information on a modified Stroop task. The results can be summarized as follows: (a) significant MD estimations (in milliseconds) were found for both sensory pain words $(\mathrm{MD}=26.7 ; 95 \% \mathrm{CI} 10.0-42.9)$ and affective pain words $(\mathrm{MD}=28.1 ; 95 \% \mathrm{CI}$ 0.4-55.8) (b) a meta regression analysis to examine whether the methodological quality of the various studies influenced the MD's, did not reach statistical significance for both sensory pain words and affective pain words. Thus, although the various studies differed with regard to the methodological quality, the MD estimations for both sensory pain words and affective pain words tentatively indicated a rather consistent pattern. The MD estimations provided in table 2-2 allow researchers to compute power and sample sizes. One may choose either the combined MD or, in a more conservative way, the MD provided by Pincus et al. (1998 b).

Recently, Pincus and Morley (2001) proposed a so-called 'enmeshment model' to account for evidence regarding attention, interpretation and recall biases in chronic pain patients. According to this model, biases in information processing in chronic pain are the result of overlap between three schemata: pain, illness and self. With frequent repeated or continued experience of pain, the pain schema becomes enmeshed with illness and self-schemata. The extent of the enmeshment and the salient content of the schema determine the bias. A fundamental assumption is that all pain patients selectively process sensory-intensity information. The results from the present meta-analysis are consistent with this assumption. The pooled data suggest that chronic pain patients selectively attend to sensory stimuli. Moreover, chronic pain patients also selectively attend to affective pain words. 
Lately, research into information processing bias in chronic pain patients has shifted from investigating the role of pain itself to the role of depression and anxiety (pain-related fear in particular). The influence of mood state (i.e. depression and anxiety) on the observed MD cannot be investigated in the present meta-analysis but should be examined within each study instead. Some studies have indeed found some support that an attentional bias can also be accounted for as arising from mood state (Pincus et al., 1998; Snider et al., 2000), whereas others have not (Pearce \& Morley, 1989; Boissevain, 1994). Depression has been found to be associated with a general delay in color naming latencies on a Stroop. The role of anxiety (or painrelated fear) however, is less clear. However, according to the cognitive theory of anxiety, the most important function of anxiety is facilitating the early detection of potentially dangerous stimuli (Eysenck, 1992). Therefore, anxiety represents a shift into a mode of hypervigilance, such that the person scans the environment for any threatening stimulus, particularly those that have been associated with threat-related stimuli. This is also called specific hypervigilance. Highly anxious individuals also tend to pay attention to any irrelevant (neutral) stimuli. This is called general hypervigilance. In the case of chronic pain, one may wonder whether chronic pain patients with pain-related fear display an attentional bias (i.e. are hypervigilant) to pain-related information. According to the fear-avoidance model as proposed by Vlaeyen (Vlaeyen et al., 1995; Vlaeyen \& Linton, 2000) pain-related fear may induce a state of hypervigilance (i.e. increased attention for pain and other somato-sensory signals). Thus, it may be proposed that only a subgroup of chronic pain patients, namely those with pain-related fear, display an attentional bias. Some evidence for this has been found in a study of Peters and colleagues, in which pain-related fear appeared to be associated with superior detection of weak electrical stimuli (Peters, et al., 2000) and in a study of Crombez and colleagues (Crombez et al., 1999), in which attentional interference (measured by a numerical interference test) in forty chronic pain patients was found to be best predicted by the interaction between pain severity and pain-related fear.

Some limitations of the present meta-analysis need further addressing. First, only five articles could be identified. Although considerable effort has been put into identifying all suitable studies for the present meta-analysis, the presence of unpublished studies cannot be completely ruled out. If the results from these unpublished studies do not support the idea that chronic pain patients may exhibit an attentional bias towards pain related information, the pooled estimation in the present study might be an overestimation of the "true estimation". Second, the assessment of the methodological quality could not be blinded, as both raters were familiar with the individual articles. Although most criteria were to be rated in an objective manner, some degree of subjectivity might have been associated with the assessment of the methodological quality. Third, although significant MD estimations were found for both sensory pain words and affective pain words, it should be borne in mind that the fixed effects model does not allow extrapolation of 
the results obtained in the present meta-analysis. A random effects model, which yielded comparable results allows for generalization.

Some doubts have been expressed whether the modified Stroop-paradigm is a pure measure of attentional bias or some other information processing (e.g., preoccupation with word meaning) or motor response (e.g., production of appropriate verbal response). The modified Stroop paradigm might therefore be a measure of more general information processing bias instead of pure attentional bias.

The dot-probe paradigm, another widely used technique to investigate attentional bias, may overcome these limitations. The dot-probe is assumed to represent a more direct test of allocation of visual attention thereby eliminating interpretations of results that are associated with stages of information processing unrelated to attention and to the production of a response. Using a dot-probe procedure with a mixture of sensory pain and affective pain words selected from the MPQ, Asmundson et al. (1997) found no evidence for an attentional bias in chronic pain patients. However, when the patients were divided on the basis of their scores on a measure of anxiety sensitivity (i.e. the proneness to experience fear in response to anxiety-related sensations), those with low anxiety sensitivity shifted attention away from pain-related stimuli whereas those with high anxiety sensitivity attended equally to pain and neutral stimuli. The observation that low anxiety-prone individuals become more avoidant of threat is in line with the interaction hypothesis concerning attentional biases, which suggest that when state anxiety or stress increases, high trait anxious individuals become more vigilant, whereas low trait anxious individuals become more avoidant of threat (Mogg \& Bradley, 1998).

Keogh et al. (2000) investigated in healthy volunteers whether individuals high in fear of pain would selectively attend towards pain-related information using a dot-probe paradigm. Participants were allocated to three groups based on their scores on the Fear of Pain Questionnaire (FPQ: McNeil \& Rainwater, 1998). Furthermore, selectivity of the attentional bias was investigated by including social threat words and positive words. The results from this study suggested that those with high fear of pain exhibited a selective attentional bias towards pain-related information, compared to those classified as low in fear of pain. No attentional effects were found for social-threat words or for positive words. Similar results were found in a subsequent dot-probe study in which individuals were selected on the basis of physical anxiety sensitivity (Keogh et al. 2001). Those high in physical anxiety were found to exhibit a selective attentional bias for physically threatening material. However, other studies applying a dot-probe paradigm have failed to find evidence for attentional bias in individuals high on pain-related fear (Keogh \& Cochrane, 2002).

In conclusion, this study reviewed by means of a meta-analysis whether chronic pain patients selectively attend to pain-related information using a modified Stroop paradigm. The meta-analysis indicated that chronic pain patients selectively attend to sensory pain words and affective pain words as measured by a modified Stroop paradigm. However, in the light of the limitations, in particular the small 
number of studies included in the present meta-analysis, one can only impute moderate confidence to the MD estimations. The conclusion from the metaregression analyses, showing that methodological quality does not influence the MD estimations can only be drawn tentatively. Taken together, employing a modified Stroop paradigm has yielded evidence for attentional bias towards pain-related words. However, future research should open up the way to other paradigms (i.e., dot-probe), which may offer a more rigorous test of attentional bias thereby possibly yielding more robust effects.

\section{ACKNOWLEDGEMENTS}

The authors would like to express their greatest gratitude to Gordon Asmundson, Michael Boissevain, Geert Crombez, Danielle Hale, Stephen Morley and Tamar Pincus for their assistance in preparing this manuscript.

Appendix 1-1: Criteria list for the assessment of the methodological quality.

\begin{tabular}{lll}
\hline 1 & Were the inclusion criteria specified? & Yes/no/don't know \\
2 & Were the exclusion criteria specified & Yes/no/don't know \\
3 & Was the type of pain patients described? & Yes/no/don't know \\
4 & Were controls matched? & Yes/no/don't know \\
5 & Did controls share the same (medical) environment? & Yes/no/don't know \\
6 & Was a computerized version of the Stroop task administered? & Yes/no/don't know \\
7 & Were words matched? & Yes/no/don't know \\
8 & Were levels of depression adequately assessed? & Yes/no/don't know \\
9 & Were levels of anxiety (or pain-related fear) adequately assessed? & Yes/no/don't know \\
10 & Was the statistical analysis appropriate? & Yes/no/don't know \\
\hline
\end{tabular}

Note: 'yes' is rated as one point whereas 'no' and 'don't know' are rated as zero.

\section{REFERENCES}

Altman, D. G. (1997). Practical statistics for medical research. London: Chapman \& Hall.

Asmundson, G., Kuperos, J., \& Norton, G. (1997). Do patients with chronic pain selectively attend to pain-related information? Preliminary evidence for the mediating role of fear. Pain, 72, 27-32.

Beck, A. T. (1976). Cognitive therapy and the emotional disorders. New York: International Universities Press.

Beck, A. T., Emery, G., \& Greenberg, R. C. (1986). Anxiety disorders and phobias: a cognitive perspective. New York: Basic Books.

Boissevain, M. D. (1994). Information processing in chronic pain: the role of depression. Unpublished thesis. University of Western Ontario, Canada. 
Bower, G. H. (1981). Mood and memory. American Psychologist, 36, 129-148.

Bower, G. H. (1987). Commentary on mood and memory. Behaviour Research and Therapy, 25, 443-456.

Crombez, G., Eccleston, C., Baeyens, F., Van Houdenhove, B., \& Van de Broeck, A. (1999). Attention to chronic pain is dependent upon pain-related fear. Journal of Psychosomatic Research, 47(5), 403-410.

Crombez, G., Hermans, D., \& Adriaensen, H. (2000). The emotional stroop task and chronic pain: What is threatening for chronic pain sufferers? European Journal of Pain, 4(1), 37-44.

Duckworth, M. P., Iezzi, A., Adams, H. E., \& Hale, D. (1997). Information processing in chronic pain disorder: A preliminary analysis. Journal of Psychopathology and Behavioural Assessment, 19(3), 239-255.

Egger, M., Davey Smith, G., Schneider, M., \& Minder, C. (1997). Bias in meta-analysis detected by a simple, graphical test. British Medical Journal, 315, 629-634.

Eysenck, M. W. (1992). Anxiety: The cognitive perspective. Hove: Erlbaum.

Keogh, E., Ellery, D., Hunt, C., \& Hannent, I. (2000). Selective attentional bias for pain-related stimuli amongst pain fearful individuals. Pain, 91, 91-100.

Keogh, E., Dillon, C., Georgiou, G., \& Hunt, C. (2001). Selective attentional biases for physical-threat in physical anxiety sensitivity. Journal of Anxiety Disorders, 15, 299315.

Keogh, E., \& Cochrane, M. (2002). Anxiety sensitivity, cognitive biases and the experience of pain. Journal of Pain, 3, 320-329.

McCracken, L. M., Zayfert, C., \& Gross RT. (1992). The Pain Anxiety Symptoms Scale: Development and validation of a scale to measure fear of pain. Pain, 50(1), 67-73.

McNeil, D. W., \& Rainwater, A. J. (1998). Development of the Fear of Pain Questionnaire-III. Journal of Behavioral Medicine, 21, 389-410.

Mogg, K., \& Bradley, B. P. (1998). A cognitive-motivational analysis of anxiety. Behaviour Research and Therapy, 36, 809-848.

Pearce, J., \& Morley, S. (1989). An experimental investigation of the construct validity of the McGill Questionnaire. Pain, 39, 115-121.

Peters, M., Vlaeyen, J. W. S., \& Van Drunen, C. (2000). Do fibromyalgia patients display hypervigilance for innocuous somatosensory stimuli? Application of a body scanning reaction time paradigm. Pain, 86, 283-292.

Pincus, T., Pearce, S., McClelland, A., \& Turner-Stokes, L. (1993). Self-referential selective memory in pain patients. British Journal of Clinical Psychology, 32, 365374.

Pincus, T., Pearce, S., McClelland, A., Farley, S., \& Vogel, S. (1994). Interpretation bias in responses to ambiguous cues in pain patients. Journal of Psychosomatic Research, 38(4), 347-353.

Pincus, T., Pearce, S., \& Perrott, A. (1996). Paint patients' bias in the interpretation of ambiguous homophones. British Journal of Medical Psychology, 69(3), 259-266.

Pincus, T., Fraser, L., \& Pearce, S. (1998). Do chronic pain patients 'stroop' on pain stimuli? British Journal of Clinical Psychology, 37, 49-58. 
Pincus, T. (1998). Assessing psychological factors in chronic pain - a new approach. Physical Therapy Review, 3, 41-45.

Pincus, T., \& Morley, S. (2001). Cognitive processing in chronic pain: a review and integration. Psychological Bulletin, 127, 599-617.

Reiss, S., Peterson, R. A., Gursky, D. M., \& McNally, R. J. (1986). Anxiety sensitivity, anxiety frequency and the prediction of fearfulness. Behaviour Research and Therapy, 24, 1-8.

Snider, B. S., Asmundson, G. J., \& Wiese, K. C. (2000). Automatic and strategic processing of threat cues in patients with chronic pain: a modified stroop evaluation. Clinical Journal of Pain, 16(2), 144-154.

STATA Corporation, 4905 Lakeway Drive, College Station, Texas 77845, USA. (1999).

Vlaeyen, J. W. S., Kole-Snijders, A., Boeren, R., \& Van Eek, H. (1995). Fear of movement/re(injury) in chronic low back pain and its relation to behavioral performance. Pain, 62, 363-372.

Vlaeyen, J. W. S., \& Linton, S. J. (2000). Fear-avoidance and its consequences in chronic musculoskeletal pain: a state of the art. Pain, 85, 317-332.

Zeegers, M. P., Heisterkamp, S. H., Kostense, P. J., Van der Windt, D. A., \& Scholten R. J. (2000). The practice of systematic reviews. VII. Pooling the results of observational studies. Nederlands Tijdschrift voor Geneeskunde, 144, 1393-1397. 


\title{
2.2 SELECTIVE ATTENTION FOR PAIN-RELATED INFORMATION IN HEALTHY INDIVIDUALS: THE ROLE OF PAIN AND FEAR*
}

\begin{abstract}
The aim of this study was to investigate whether pain itself or pain-related fear is crucial in eliciting attentional bias towards pain-related information in healthy individuals. The results from two successive experiments provide evidence that attentional bias does not take place as a function of pain-related fear or as a function of pain per se. Attentional bias for pain words was neither found to be related to trait variables like anxiety, depression, catastrophizing, fear of pain, and pain vigilance. Implications of the results are discussed and directions for future research are provided.
\end{abstract}

${ }^{*}$ Roelofs, J., Peters, M. L., \& Vlaeyen, J. W. S. (2002). Selective attention for pain-related information in healthy individuals: the role of pain and fear. European Journal of Pain, 6, 331-339. 


\section{INTRODUCTION}

Since the rise of cognitive psychology, the investigation of information processing biases in emotionally disturbed patients (e.g., eating disorders, several anxiety disorders, and depression) has become increasingly popular. This research has mainly been inspired by Beck's schema theory (Beck, 1976; Beck et al., 1986) and Bower's network theory of the relationship between emotion and cognition (Bower, 1981; Bower 1987). Although some important conceptual differences between both theories exist, both suggest that an individual's affective status is associated with cognitive biases (e.g., memory bias, interpretation bias, and attentional bias), which favor the processing of information congruent with the affective state (De Ruiter \& Brosschot, 1994). During the last decade, research into information processing has also been applied to chronic pain patients. In a short review, Pincus (1998) concluded that there is good reason to assume that chronic pain patients exhibit a recall bias towards pain-related stimuli and that interpretation bias takes place in pain patients. The possible existence of an attentional bias towards pain-related information, however, remains unclear.

One paradigm for investigating attentional bias has been the modified Stroop paradigm. In a modified Stroop paradigm, categories of emotionally salient words (i.e., pain-related words) and neutral words are presented in different colors. Response times of patients to name the color of each word are measured. Typically, compared to neutral words, color naming is slower when words are threatening and relevant to the patients' concern. Recently, we conducted a meta-analysis of Stroop studies in chronic pain patients (Roelofs et al., 2002). The primary aim of the metaanalysis was to determine whether chronic pain patients show an attentional bias for pain-related words. Five papers were identified (Pearce \& Morley, 1989; Boissevain, 1994; Pincus et al., 1998 (consisting of two studies); Snider et al., 2000) through a thorough search of databases and the worldwide web. Data from these five studies were pooled and summarized into a mean difference (MD). Significant MD estimations were found for both sensory and affective pain words, indicating selective attention to sensory and affective pain words. The results from the metaanalysis are in line with the recently proposed enmeshment model, which assumes that all pain patients would selectively process sensory-intensity information (Pincus \& Morley, 2001).

An important issue that needs further addressing is whether the observed attentional bias as measured with a modified Stroop paradigm in chronic pain patients is due to pain per se or pain-related fear. In fact, it may be that only a subgroup of chronic pain patients, namely those with pain-related fear, would display an attentional bias. According to the fear-avoidance model as proposed by Vlaeyen (Vlaeyen et al., 1995; Vlaeyen \& Linton, 2000), pain-related fear may induce a state of hypervigilance (i.e., increased attention for pain and other somato-sensory signals). Some evidence for this has been found in a study of Peters and colleagues, 
in which pain-related fear appeared to be associated with superior detection of weak electrical stimuli (Peters et al., 2000) and in a study of Crombez and colleagues (Crombez et al., 1999), in which attentional interference (measured by a numerical interference test) was found to be best predicted by the interaction between pain severity and pain-related fear. Additional evidence that attentional bias is more related to fear than to pain per se comes from the study of Snider et al. (2000) who found that delayed color-naming latencies to pain words in a modified Stroop task was associated with high pain-specific cognitive anxiety and with lower levels of anxiety sensitivity and from the study of Pincus et al. (1998) who performed a modified Stroop task in chronic pain patients and concluded that attentional bias could best be accounted for as arising from mood state rather than from pain itself.

Another paradigm for investigating attentional bias has been the (visual) dotprobe paradigm. In a dot-probe paradigm, two words (an emotional word and a neutral word) appear on a screen and one of these words is replaced by a small dot. Participants have to react to this dot by indicating the location, which it appeared in. Using a dot-probe paradigm, Asmundson et al. (1997) found no evidence for an attentional bias in chronic pain patients. However, when the patients were divided on the basis of their scores on a measure of anxiety sensitivity (i.e., the proneness to experience fear in response to anxiety-related sensations), those with low anxiety sensitivity shifted attention away from stimuli to pain whereas those with high anxiety sensitivity responded similarly to dot-probe regardless of the location of presentation. Although it should be born in mind that anxiety sensitivity is a conceptually different construct than trait anxiety, this result is in line with the interaction hypothesis concerning attentional biases, which suggest that when state anxiety or stress increases, high trait anxious individuals become more vigilant, whereas low trait anxious individuals become more avoidant of threat (Mogg \& Bradley, 1998).

Taken together, increasing evidence seems to support the supposition that attentional bias may be present in highly fearful pain patients or that it may depend on individual differences in ones proneness to experience fear in response to anxietyrelated sensations (i.e., anxiety sensitivity). However, one of the main issues in this field is the need to understand the relationship between pain per se and associated emotional status, especially anxiety/fear. The present study offers a significant contribution to this issue by independently manipulating both fear and pain in healthy volunteers. This way, it is investigated whether pain itself or pain-related fear is the crucial factor in attentional bias. The present study consists of two successive experiments. Experiment One was set up to further explore whether pain itself (experimentally induced) or whether pain-related fear predicts an attentional bias towards pain-related information. Thus, both pain and fear were experimentally induced whereas previous studies have examined clinical pain and trait fear of pain in chronic pain patients. Only an experimental manipulation allows one to study pain and fear separately. It was hypothesized that pain-related fear is a better predictor of attentional bias than experimentally induced pain per se. Moreover, it 
was explored whether attentional bias was related to trait variables as measured by various questionnaires. A recent study by Keogh et al. (2001a) found evidence for selective attention towards pain-relevant material in healthy volunteers who scored high on a questionnaire measuring pain-related fear. The results from Experiment One did not confirm the hypothesis that pain-related fear is crucial in predicting attentional bias. A post-hoc analysis suggested that, in contrast to our expectation, pain itself may have elicited an attentional bias. Since this effect of pain only occurred when the two fear groups were omitted from the analysis, Experiment Two was set up to further investigate the role of pain in relation to attentional bias.

\section{EXPERIMENT ONE}

\section{METHODS}

\section{Participants}

Eighty healthy University students (61 females, 19 males; mean age $21.2 \pm 2.3$ years; range 18 - 28 years) voluntarily took part in this study. All participants signed an informed consent in which the experimental design was explained. Participants were unaware of the hypothesis and were unfamiliar with the modified Stroop task. In addition, all participants verbally reported the absence of any pain during the experiment. The Ethics Committee of the Maastricht University approved the experimental protocol.

\section{Design}

Participants were randomly assigned to one of four groups in which pain and fear were independently manipulated (i.e., group 1: pain and fear; group 2: pain only; group 3: fear only; group 4: no pain, no fear). Pain was induced by a muscle-ischemia procedure, which involved reducing blood flow to the muscles of the arm (see procedure). Fear of pain was induced by informing participants that they could receive a painful electric shock during the Stroop task. None of the participants actually received the electric shock. Group 4 served as a control group.

\section{Materials}

A computerized version of a modified Stroop task was used containing 5 pain words and 5 neutral words, which were presented four times in four different colors (yellow, red, green, and blue). Each pain word was matched with one neutral word on the number of syllables and word length. In a pilot study 15 participants underwent the muscle-ischemic pain test to select the most appropriate pain words from the McGill Pain Questionnaire (Melzack, 1975). Furthermore, it was investigated whether pain was maintained during the trial (a small insignificant increase in pain intensity was observed during the pain trial). The neutral words also 
formed a word category (writing desk items). Word order was randomized with the constraints that no word would appear twice in succession and that no color would appear for more than two times consecutively. Table 2-4 presents the pain words and the neutral words.

Table 2-4: Stimuli (pain and neutral words). Dutch equivalents in parenthesis.

\begin{tabular}{ll}
\hline Pain words & Neutral words \\
\hline 1. Pain (pijn) & 1. Eraser (gum) \\
2. Stab (pijnscheut) & 2. Felt pen (viltstift) \\
3. Burning (branderig) & 3. Pen tray (pennenbak) \\
4. Pricking (prikkend) & 4. Note pad (kladblok) \\
5. Cramping (krampend) & 5. Adhesive tape (plakband) \\
\hline
\end{tabular}

A dot was displayed for $500 \mathrm{msec}$ to alert the participant to the upcoming word, which was immediately followed by the word itself which remained present until the participant named its color or with a maximum duration of $3000 \mathrm{msec}$. The response times of the color naming were recorded by a voice key. Incorrect responses (i.e., wrong color, coughing) were coded by the experimenter. The Stroop task lasted approximately three minutes (without practice). Presentation of words and recording of response times were controlled by MEL software.

At the beginning of the experiment, all participants completed a battery of questionnaires, i.e., Dutch versions of the Pain Vigilance and Awareness Questionnaire (PVAQ; McCracken, 1997), the State-Trait Anxiety Inventory (STAI; Spielberger et al., 1970), the Pain Catastrophizing Scale (PCS; Sullivan et al., 1995), the Zung depression scale (Zung, 1965), and a self-translated version of the Fear of Pain Questionnaire (FPQ; McNeil \& Rainwater, 1998). In addition, visual analogue scales (VAS) were used to check whether fear of pain was successfully induced. The end points of the VAS were labeled 'no fear' (left) and 'very fearful' (right).

\section{PROCEDURE}

\section{Pain induction}

After completing the questionnaires, participants in both pain groups (groups 1 and 2) were told that the effect of mild pain in relation to an attention-demanding task was studied. They were further told that they would undergo the muscle ischemic pain test. The ischemic pain test was administered twice. The logic behind repeating the pain procedure was twofold. First, any affective reaction associated with the pain procedure during the first trial could be minimized. Second, the first trial served as a test to see whether participants were able to sustain the pain procedure for several minutes so that they were able to perform the modified Stroop task during the second trial. Pain induction was accomplished by wrapping the cuff of a 
sphygmomanometer around the dominant forearm, inflating it, and maintaining the pressure at a level well above a systolic blood pressure of $160 \mathrm{~mm} \mathrm{Hg}$ (Turk et al., 1983). While the pressure was maintained, participants performed handgrip exercises on a dynamometer, which caused a painful sensation. Participants were instructed to indicate their pain threshold. After reaching the pain threshold, the handgrip exercises stopped and the pain had to be maintained for at least three minutes. Thereafter, the cuff was deflated. Next, the pain procedure was administered for the second time and participants completed the modified Stroop task. During the Stroop task the pain procedure was continued. VAS fear ratings were measured in both pain groups before the first (baseline) and before the second pain procedure by individuals in both pain groups.

\section{Fear manipulation}

To induce fear of pain, participants in the groups 1 and 3 were told that they could receive an intense electric shock during the Stroop task. Therefore, two large electrodes were attached to the forearm (dominant side) and the experience of a noxious electrical stimulus was verbally explained by using words synonymous with those used in the Stroop task. In addition, a video was shown in which a male student model received an electrical stimulus after which he displayed pain behavior and a strong withdrawal reflex.

\section{STATISTICAL ANALYSES}

\section{Manipulation check}

To check whether the manipulation of fear was successful, only for groups 1 (pain + fear) and 2 (pain), a difference score was computed which compared levels of fear (as measured on a visual analogue scale) for the first pain procedure to the fear of pain for the second pain procedure. In a similar way, a difference score was computed which compared levels of pain for both pain trials. An independent samples t-test was used to test whether the difference scores in levels of fear between both groups differed significantly. A one-samples t-test was performed to test whether levels of pain between both pain trials differed significantly within both groups.

\section{Data reduction and analysis of the Stroop task}

For the Stroop color-naming task, average reaction times to color naming for both word categories were calculated. Incorrect responses were removed, as were outliers (defined as a reaction time deviating more than 3 standard deviations from each individual mean reaction time). In addition, reaction times below $200 \mathrm{msec}$ were also removed. Repeated measures analysis of variance was used containing one withinsubjects factor (word category) and two between-subjects factors (pain and fear). It was expected that an interaction effect of fear $x$ word category would be found, but 
that the interaction between pain $x$ word category would not reach statistical significance.

Additionally, an interference score was computed, defined as latency to pain words minus latency to neutral words, to examine by means of regression analysis whether trait variables, such as anxiety or depression, in isolation or in combination with the experimental manipulations (pain and fear induction) affected the interference score. Predictors in the regression analyses were pain, fear (both coded as dummies), the interaction between pain and fear, and in separate analyses the scores on the STAI, PCS, Zung and FPQ in isolation and in interaction with both the pain and fear manipulation. To prevent artificial collinearity, the independent variables involved in an interaction term were centered (using -1,1 coding for dichotomous variables and subtracting the overall mean for continuous variables) before computing the interaction terms.

\section{RESULTS}

\section{Manipulation check}

Table 2-5 presents mean levels of fear and pain for group 1 and 2 for both pain trials. The increase in fear (as measured on the VAS) before test 1 to test 2, intended as a manipulation check, showed that the mean increase of fear in group 1 (pain and fear) was $19.1 \mathrm{~mm}$. and in group 2 (pain only) $3.0 \mathrm{~mm}$. This difference in mean levels of fear was statistically significant $(\mathrm{t}(38)=3.34, \mathrm{p}<0.01)$. As expected, no statistically significant difference was found for mean levels of pain within the two groups $(\mathrm{t}(39)=-1.72, \mathrm{p}=0.094)$.

Table 2-5: Mean levels of fear and pain (in mm. and measured on VAS) and standard deviations (in parenthesis) for group 1 and 2.

\begin{tabular}{lllll}
\hline & Fear (trial 1) & Fear (trial 2) & Pain (trial 1) & Pain (trial 2) \\
\hline Group 1 (pain + fear) & $17.1(14)$ & $36.2(24)$ & $64.0(20.3)$ & $56.6(22.3)$ \\
Group 2 (pain only) & $22.2(19)$ & $25.2(23)$ & $74.7(11.2)$ & $72.8(9.5)$ \\
\hline
\end{tabular}

Note: Trial 1 refers to the first pain induction trial and trial 2 refers to the second pain induction trial.

\section{Analysis of modified Stroop task}

Table 2-6 shows mean response times for both pain-related words and neutral words for each of the four groups. No differences were found between the four groups in the number of errors (total percentage of errors was $1.9 \%$ ). 
Table 2-6: Mean Stroop response times (ms.) and standard deviations (in parenthesis) for pain and control words for each group.

\begin{tabular}{lll} 
& pain & neutral \\
\hline Group 1 (pain + fear) & $586(73)$ & $582(70)$ \\
Group 2 (pain only) & $588(100)$ & $565(86)$ \\
Group 3 (fear only) & $609(68)$ & $601(84)$ \\
Group 4 (no pain, no fear) & $559(81)$ & $554(82)$ \\
\hline
\end{tabular}

Repeated measures analysis of variance showed a statistically significant main effect $(\mathrm{F}(1,76)=7.37, \mathrm{p}=0.008)$ for word category (i.e., pain versus neutral). No significant interactions were found between word category and fear $(F(1,76)=1.30$, $\mathrm{p}=0.26)$ and word category and pain $(\mathrm{F}(1,76)=0.99, \mathrm{p}=0.32)$. Furthermore, the three-way interaction between word category, pain and fear was not statistically significant $(\mathrm{F}(1,76)=2.33, \mathrm{p}=0.13)$. Thus, naming the color of pain words was slowed down compared to neutral words in all groups, irrespective of the pain and fear manipulation.

Using regression analysis to account for variance in the interference scores, measures of pain vigilance (PVAQ) interacted significantly with the fear manipulation $(\beta=-0.23, p=0.046)$. Simple effects analysis showed a significant positive association $(\beta=0.389, \mathrm{p}=0.012)$ between pain vigilance and the interference scores in the non-fear groups, whereas in the fear groups pain vigilance did not predict interference. On the other hand, depression (Zung) and trait-anxiety (STAI) showed an interaction with the pain manipulation $(\beta=0.267, p=0.017$ and $\beta=0.233$, $p=0.046$ respectively). A significant negative association $(\beta=-0.349, p=0.029)$ between depression and the interference scores in the non-pain groups was found. This negative association between depression and the interference scores was not found in the pain groups. Furthermore, simple effects analysis concerning traitanxiety did not yield a significant effect. Surprisingly, no significant association between fear of pain (FPQ) or one of its subscales and the interference score was observed, as was previously reported by Keogh et al. (2001a). Table 2-7 displays a correlation matrix for all questionnaires.

Table 2-7: Correlation matrix in which the associations between different questionnaires are depicted.

\begin{tabular}{llllll}
\hline & PVAQ & STAI-S & STAI-T & PCS & ZUNG \\
\hline STAI-S & 0.17 & & & & \\
STAI-T & $0.33^{* *}$ & $0.59^{* *}$ & & & \\
PCS & $0.48^{* *}$ & $0.45^{\star *}$ & $0.48^{* *}$ & & \\
ZUNG & $0.26^{*}$ & $0.63^{* *}$ & $0.83^{* *}$ & $0.43^{* *}$ & \\
FPQ & $0.45^{* *}$ & 0.20 & $0.39^{* *}$ & $0.46^{* *}$ & $0.32^{* *}$ \\
\hline
\end{tabular}

Note: PVAQ = Pain Vigilance and Awareness Questionnaire; STAI-S = State version of the State Trait Anxiety Inventory; STAI-T = Trait version of the State Trait Anxiety Inventory; PCS = Pain Catastrophizing Scale; Zung = measure of depression. ${ }^{*} p<0.05$ level (2-tailed), ${ }^{* *} p<0.01$ level (2-tailed). 
In sum, the results from the first experiment did not confirm the hypothesis that pain-related fear is a better predictor of attentional bias for pain words than pain per se. However, contrary to this hypothesis, a post-hoc comparison of the response times for pain and neutral words in the pain group and the control group (reaction times are shown in table 3) revealed a significant interference effect in the pain group $(t(38)=5.56, p=0.047)$. Thus, some support for pain as a predictor of attentional bias was found in the first experiment. In addition, it was found that pain vigilance (PVAQ) was positively associated with the interference scores in the non-fear groups only.

\section{EXPERIMENT TWO}

Experiment Two was set up to further test whether pain per se and pain vigilance accounted for the interference effect. In the second experiment the fear manipulation was omitted, leaving two groups, a pain group that underwent the ischemic pain test and a control group. It was predicted that only participants in the pain group would display selective attention towards pain related words.

\section{METHODS}

\section{Participants}

Forty healthy University students (35 females, 5 males; mean age $22.2 \pm 1.7$ years; range 18 - 26 years), voluntarily took part in Experiment Two. As in Experiment One all participants signed an informed consent. Participants were unfamiliar with the first experiment, the hypothesis and the modified Stroop task. All participants verbally reported the absence of pain during the experiment.

\section{Design}

Experiment One showed an overall main effect of word category (i.e., naming the color of pain words was slowed down compared to neutral words in all groups). In retrospect, this may be explained by the fact that all participants were aware of taking part in a pain experiment, which may have activated their pain network before and during the experiment. This way, all groups were more or less equally primed at the beginning of the experiment. However, the most optimal design to demonstrate an attentional bias is recruiting the control group without any reference to anything related to pain at all. Therefore, participants in the control group were asked to complete a few questionnaires and to perform a computer task. The further procedure and statistical analysis of the modified Stroop task was identical to the first experiment omitting the fear manipulation. 


\section{Materials}

The Stroop task was identical to the one used in Experiment One. In addition, the same questionnaires were completed by each participant.

\section{Procedure}

After completing the questionnaires, participants in the pain group performed the Stroop task while enduring the ischemic pain, whereas those in the control group only performed the Stroop task. Debriefing of all participants (including those from the first experiment) took place by letter after the second experiment.

\section{Statistical analyses}

Similar to Experiment One, incorrect responses, outliers and reaction times below 200 msec. were removed from the analyses. Repeated measures analysis of variance with word category as the within-subjects factor and pain as the between-subjects factor was used to test the hypothesis that pain itself is a predictor of an attentional bias towards pain related information. In addition, similar to Experiment One, regression analysis was used to examine whether person characteristics (as measured by questionnaires) predicted the interference score.

\section{RESULTS}

\section{Analysis of modified Stroop task}

Table 2-8 displays mean response times of the Stroop task for both pain words and neutral words for each group. No differences between both groups were found in the number of errors (total percentage of errors was 1.5\%). Repeated measures analysis of variance did not show a significant effect of word category $(F(1,38)=3.51$, $\mathrm{p}=0.069$ ). Furthermore, no significant interaction effect of word category and pain was observed $(F(1,38)=0.006, p=0.937)$. Additionally, regression analysis showed that none of the person characteristics (as measured by questionnaires) in isolation or in interaction with the pain manipulation was predictive of the interference effect.

Table 2-8: Mean Stroop response times (ms.) and standard deviations (in parenthesis) for pain and control words for each group.

\begin{tabular}{lll}
\hline & pain & Neutral \\
\hline Group 1 (pain) & $546(75)$ & $535(69)$ \\
Group 2 (no pain, no fear) & $624(97)$ & $614(74)$ \\
\hline
\end{tabular}




\section{GENERAL DISCUSSION}

The results from Experiment One did not confirm the hypothesis that pain-related fear is a better predictor of an attentional bias towards pain-related information than pain per se. Contrary to the hypothesis, a post-hoc analysis, which compared the interference scores from the pain group to those from the control group, revealed a significant interaction effect between pain and word category (i.e., participants in the pain group showed more interference when compared to participants in the control group). The observation that the induction of fear did not lead to an attentional bias and that the effect of pain was only present in the pain group and not in the pain plus fear group, may suggest that fear has confounded the effect of paying selective attention to pain words as a function of pain itself. In line with this confounding effect of the fear manipulation, a simple effect analysis showed a significant positive association between measures of pain vigilance (PVAQ) and the interference score in the pain group and the control group. Thus, those participants in the non-fear groups showing high levels of pain vigilance also display more interference (i.e. slower in naming the color of pain words compared to neutral words). Other studies, in which fear has been experimentally induced, have also failed in attempting to induce an attentional bias (Van den Hout et al., 1998; Kroeze \& Van den Hout, 2001). Furthermore, naming the color of pain words was slowed down compared to neutral words in all groups, irrespective of the pain and fear manipulation. This may indicate that the valence and arousal components of the pain words might have been responsible for the general delay in responding to pain words. That is, in non-clinical samples pain cues presented by a modified Stroop task may capture attention of everybody equally.

Experiment Two was set up to further investigate to what extent pain itself may predict an attentional bias and whether the overall slower color naming of pain words could be replicated. The results from Experiment Two did not show an effect of the pain manipulation on the interference scores. Similar as in Experiment One, although statistically insignificant, both groups tended to slow down color naming pain words compared to neutral words. A secondary aim of both experiments was to explore whether the interference effect was related to trait variables in isolation or in combination with the experimental manipulation. The previous reported association between self-reported fear of pain and attentional bias in healthy individuals (Keogh et al., 2001a) was not replicated in Experiment One. However, significant interaction effects between pain vigilance and manipulated fear and between depression and pain on the interference scores were observed in Experiment One. These observed effects of pain vigilance and depression could not be replicated in Experiment Two. Whether depression is associated with an attentional bias for negative information is a controversial issue. It is generally assumed that depressed individuals do not automatically orient their attention towards negative information in the environment. However, once such material has come into the focus of their attention, 
they might have greater difficulty in disengaging from it. That is, depression may be primarily associated with a bias in those processes involved in the maintenance of attention to negative information, rather than with a bias in initial automatic orienting (Mogg \& Bradley, 1998).

Some discussion is needed concerning the limitations of this study. First, the attentional system provides the mechanism for detecting and monitoring environmental and interoceptive stimuli, which are relevant of the motivational state of the organism. In this study, an interference score on the Stroop was taken as a measure of attentional bias, which is in turn considered to be a measure of hypervigilance. Hypervigilance in the context of pain can be defined as an increased attention towards (internal) bodily sensation (i.e., pain). However, an interference score obtained from a Stroop only indicates that attention is drawn away from the color-naming task. Where exactly the attention is going to is in fact unknown. Moreover, some debate exists as to whether the modified Stroop paradigm is a pure measure of attentional bias or whether it is related to some other biases in information processing. Second, the function of attentional bias is based on evolutionary origins. An important function of fear is to facilitate the detection of danger in the environment and to help the organism respond promptly and effectively to threatening situations. It has been shown that color-naming interference effect of threat-related stimuli can disappear in fearful individuals when they are tested in close temporal or physical proximity to their phobic object or situation, such as snake phobic tested in the presence of a snake (Mathews \& Sebastian, 1993). In the present study, pain was present when performing the Stroop task, which may have suppressed any attentional effect. Third, although the pain words were carefully selected in a pilot study, the possibility that the words were not relevant for each participant's pain experience cannot be ruled out. Thus, the absence of an attentional bias could also be due to the selection of appropriate pain words. This implies that in studying attentional bias in general, emotional stimuli should be matched to an individuals' current concerns. Fourth, with regard to the specificity of the fear induction, VAS scales only assessed fear instead of fear of pain (i.e., anchors were 'no fear' and 'very fearful'). In addition, the modified Stroop task did not include another threat word category against which to compare response latencies to the pain words. Without this word category, it cannot be equivocally stated that slower responses to pain threat are specific to pain (i.e., that slower responses would not have occurred to other threat words unrelated to pain). Fifth, the present study did not examine the effect of gender on selective processing of pain-related threat cues, which is an important issue (see Stewart et al., 1998). In addition, the sample in experiment 1 was predominantly female. The fear induction procedure in which a male model was used may have confounded the fear manipulation. Finally, a possible limitation of the present study is that participants completed (pain-related) questionnaires at the beginning of the experiment. There is some evidence that the order of presentation of questionnaire measures can indeed prime participants towards particular Stroop words (see Lundh \& Czyzykow-Czarnocka., 2001). 
In conclusion, the results from both experiments suggest that neither pain itself, nor pain-related fear lead participants to selectively pay attention to pain words. Attentional bias for pain words was neither found to be related to trait variables like anxiety, depression, catastrophizing, fear of pain, and pain vigilance. However, the absence of support for attentional bias in the present studies, does not exclude that pain-related fear might be an important determinant of attentional bias in chronic pain patients, having more long-lasting and more elaborative pain schemata. For studying attentional processes, a dot-probe paradigm may be superior since it is considered to be a more direct measure of visual attention. In addition, stimulus material should be matched to an individuals' current concerns (see Riemann \& McNally, 1995). Although three studies applying a dot-probe paradigm (Asmundson et al., 1997; Keogh et al., 2001a: Keogh et al., 2001b) found (some) evidence for selective information processing, one study did not (Keogh \& Cochrane, 2002). Attentional bias in pain might be a subtle phenomenon that proves difficult to replicate. Future research into information processing in pain patients should not only focus on refining the measurement of attentional processes but should also investigate memory processes and interpretation processes.

\section{REFERENCES}

Asmundson, G., Kuperos, J., \& Norton, G. (1997). Do patients with chronic pain selectively attend to pain-related information? Preliminary evidence for the mediating role of fear. Pain, 72, 27-32.

Beck, A. T. (1976). Cognitive therapy and the emotional disorders. New York: International Universities Press.

Beck, A. T., Emery, G., \& Greenberg, R. C. (1986). Anxiety disorders and phobias: a cognitive perspective. New York: Basic Books.

Boissevain, M. D. (1994). Information processing in chronic pain: the role of depression. Unpublished thesis. University of Western Ontario, Canada.

Bower, G. H. (1981). Mood and memory. American Psychologist, 36, 129-148.

Bower, G. H. (1987). Commentary on mood and memory. Behaviour Research and Therapy, 25, 443-456.

Crombez, G., Eccleston, C., Baeyens, F., Van Houdenhove, B., \& Van den Broeck, A. (1999). Attention to chronic pain is dependent upon pain-related fear. Journal of Psychosomatic Research, 47(5), 403-410.

De Ruiter, C., \& Brosschot, J. F. (1994). The emotional stroop interference effect in anxiety: attentional bias or cognitive avoidance? Behaviour Research and Therapy, 32, 315-319.

Keogh, E., Ellery, D., Hunt, C., \& Hannent, I. (2001a). Selective attentional bias for pain-related stimuli amongst pain fearful individuals. Pain, 91, 91-100. 
Keogh, E., Dillon, C., Georgiou, G., \& Hunt, C. (2001b). Selective attentional biases for physical-threat in physical anxiety sensitivity. Journal of Anxiety Disorders, 15, 299-315.

Keogh, E., \& Cochrane, M. (2002). Anxiety sensitivity, cognitive biases and the experience of pain. Journal of Pain, 3, 320-329.

Kroeze, S., \& Van den Hout, M. A. (2001). Can selective attention for bodily information be induced by fear? Behavioural and Cognitive Psychotherapy, 29, 235239.

Lundh, L. G., \& Czyzykow-Czarnocka, S. (2001). Priming of the emotional stroop effect by a schema questionnaire. An experimental study of test order. Cognitive Therapy and Research, 25(3), 281-289.

Mathews, A., \& Sebastian, S. (1993). Suppression of emotional Stroop effects by fear arousal. Cognition and Emotion, 7, 517-530.

McCracken, L. M. (1997). "Attention" to pain in persons with chronic pain: A behavioral approach. Behavior Therapy, 28(2), 271-284.

McNeil, D. W., \& Rainwater, A. J. (1998). Development of the Fear of Pain Questionnaire-III. Journal of Behavioral Medicine, 21, 389-410.

Melzack, R. (1975). The McGill Pain Questionnaire: Major properties and scoring methods. Pain, 1, 277-299.

Mogg, K., \& Bradley, B. P. (1998). A cognitive-motivational analysis of anxiety. Behaviour Research and Therapy, 36, 809-848.

Pearce, J., \& Morley, S. (1989). An experimental investigation of the construct validity of the McGill Pain Questionnaire. Pain, 39, 115-121.

Peters, M. L., Vlaeyen, J. W. S., \& Van Drunen, C. (2000). Do fibromyalgia patients display hypervigilance for innocuous somatosensory stimuli? Application of a body scanning reaction time paradigm. Pain, 86, 283-292.

Pincus, T. (1998). Assessing psychological factors in chronic pain - a new approach. Physical Therapy Review, 3, 41-45.

Pincus, T., Fraser, L., \& Pearce, S. (1998). Do chronic pain patients 'stroop' on pain stimuli? British Journal of Clinical Psychology, 37, 49-58.

Pincus, T., \& Morley, S. (2001). Cognitive-processing bias in chronic pain: A review and integration. Psychological Bulletin, 127, 599-617.

Riemann, B. C., \& McNally, R. J. (1995). Cognitive processing of personally relevant information. Cognition and Emotion, 9, 325-340.

Roelofs, J., Peters, M. L., Zeegers, M. P. A., \& Vlaeyen, J. W. S. (2002). The modified Stroop paradigm as a measure of selective attention towards pain-related stimuli amongst chronic pain patients: a meta-analysis. European Journal of Pain, 6, 273281.

Snider, B. S., Asmundson, G. J., \& Wiese, K. C. (2000). Automatic and strategic processing of threat cues in patients with chronic pain: a modified stroop evaluation. Clinical Journal of Pain, 16(2), 144-54.

Spielberger, C. D., Gorsuch, R. L., \& Lushene RE. (1970). State-Trait Anxiety Inventory. Palo Alto: Consulting Psychologists Press. 
Stewart, S. H., Conrod, P. J., Gignac, M. L., \& Pihl, R. O. (1998). Selective processing biases in anxiety-sensitivity men and women. Cognition and Emotion, 12(1), 105133.

Sullivan, M. J. L., Bishop, S. R., \& Pivik, J. (1995). The pain catastrophizing scale: development and validation. Psychological Assessment, 7, 524-532.

Turk, D., Meichenbaum, D., \& Berman, W. (1983). Pain and behavioral medicine: A cognitive-behavioral perspective. New York: Guilford.

Van den Hout, M. A., Arntz, A., Janssen, S., De Jong, P., \& Pool, K. (1998). No threat related processing bias in low trait-anxious high state-anxious novice parachuters. Cognitive Therapy and Research, 22, 125-135.

Vlaeyen, J. W. S., Kole-Snijders, A., Boeren, R., \& Van Eek, H. (1995). Fear of movement/(re)injury in chronic low back pain and its relation to behavioral performance. Pain, 62, 363-372.

Vlaeyen, J. W. S., \& Linton S. J. (2000). Fear-avoidance and its consequences in chronic musculoskeletal pain: a state of the art. Pain, 85, 317-332.

Zung, W. W. K. (1965). A self-rating depression scale. Archives of General Psychiatry, 12, 63-70. 


\title{
2.3 THE MODIFIED STROOP PARADIGM AS A MEASURE OF SELECTIVE ATTENTION TOWARDS PAIN-RELATED INFORMATION IN PATIENTS WITH CHRONIC LOW BACK PAIN $^{*}$
}

\begin{abstract}
The present study assessed, by means of a modified Stroop paradigm, whether highly fearful patients with chronic low back pain pay selective attention to words related to movement and injury. Two groups of patients (High Fear and Low Fear) were included based on their scores on the Tampa Scale for Kinesiophobia (TSK), a measure of fear of movement/(re)injury. A control group was recruited by means of advertisement in a local newspaper. Repeated measures analysis of variance was conducted to examine whether highly fearful pain patients pay more selective attention to movement and injury words, compared to patients with low levels of pain-related fear and controls. The results from the present study do not support the proposition that highly fearful patients with chronic low back pain selectively pay attention to words related to injury and movement. Limitations of the modified Stroop paradigm are discussed as well as the need for the application of alternative methods such as the dot-probe paradigm.
\end{abstract}

\footnotetext{
* Roelofs, J., Peters, M. L., \& Vlaeyen, J. W. S.(2003). The modified Stroop paradigm as a measure of selective attention towards pain-related information in patients with chronic low back pain. Psychological Reports, 92, 707-715.
} 


\section{INTRODUCTION}

Research into biases of information processing (i.e., memory, interpretation, attention) has predominantly involved the area of emotional disorders (e.g., depression, several anxiety disorders, eating disorders). This research has mainly been inspired by Beck's schema theory (Beck, 1976; Beck et al., 1986) and Bower's network theory of the relationship between emotion and cognition (Bower, 1981, 1987). Recently, the domain of attentional processes in the area of chronic pain is in full expansion (see for two excellent reviews Eccleston \& Crombez, 1999 and Pincus \& Morley, 2001). Consequently, information processing concepts have also been applied to the field of chronic pain. According to the cognitive behavioral model of chronic low back, information processing, in particular attentional processing, is assumed to play an important role in acute pain becoming chronic pain (Vlaeyen \& Linton, 2000).

The modified Stroop paradigm may serve as an indirect measure of selective attention towards bodily sensations and pain. In a modified Stroop paradigm categories of emotionally salient and neutral words are presented in different colors. Response times of patients to name the color of each word are measured. Typically, color naming is slowed down when words are threatening and relevant to the patients' concern, whereas no response delay is expected for neutral words. Selective attention can be expressed in terms of interference, which is calculated by subtracting the color naming time of neutral words from the color naming time of concernrelated words (i.e., words related to pain). Recently, we conducted a meta-analysis on Stroop studies in chronic pain patients (Roelofs et al., 2002). Data from five studies (i.e., Pearce \& Morley, 1989; Boissevain, 1994, Pincus et al., 1998 (consisting of two studies); Snider et al., 2000) were pooled and summarized into a mean difference (MD). Significant estimations of MD's were obtained for both sensory and affective pain words indicating that pain patients selectively pay attention to both sensory and affective pain words.

Based on the results from the meta-analysis, two important issues need further addressing. First, it is important to examine whether the observed Stroop interference effects in chronic pain patients, measured with a modified Stroop paradigm, goes beyond the words for sensory and affective pain. In order to find Stroop interference effects, Riemann and McNally (1995) have suggested that stimulus words should be matched to an individual's current concerns. With respect to patients with chronic low back pain, pain-related fear and, more specifically, fear of (re) injury and fear of moving is associated with self-reported disability (Crombez et al., 1999). Thus, in addition to sensory and affective pain words, words related to injury and movement in a modified Stroop task may also strongly represent a patients' current concerns. Second, it is important to investigate whether any Stroop interference effect is dependent upon the level of fear patients experience. According to the cognitive theory put forward by Eysenck (1992), the most important function 
of anxiety is the early detection of potentially threatening stimuli. Thus, the Stroop interference effect may be larger in highly anxious patients compared to patients with lower levels of anxiety.

The aim of the present study is to examine whether highly fearful patients with chronic low back pain selectively attend to words related to injury and movement. Patients high and low in fear of injury were selected based on the scores on the Tampa Scale for Kinesiophobia (TSK: Miller et al., 1991) which is a self-report measure of fear of re(injury) and fear of movement. We expected that patients scoring high on the TSK would experience more difficulty with color naming both movement and injury words (as it may be more relevant to their personal concerns) compared to patients scoring low on the TSK. Therefore, we hypothesized that patients scoring high on the TSK would display greater interference on both injury and movement words as compared to patients scoring low on the TSK, and that healthy controls should not show any significant interference. Interference is defined as the response latency to pain words minus latency to neutral words. Furthermore, we investigated to what extent personality characteristics (as measured by various questionnaires) would be significantly associated with the interference scores of both injury and movement words.

\section{METHODS}

\section{Participants}

Low back pain patients were recruited throughout several pain clinics in the Southern area of The Netherlands. The inclusion criteria for the present experiment were nonspecific complaints about back pain for a duration of at least three months and age between 18 and 65 years. The selection of patients was based on a previously established TSK-distribution (see Peters et al., 2002). Patients scoring below 37 (bottom third of the distribution) were considered as Low Fear while patients scoring above 43 (top third of the distribution) were considered as High Fear. A total number of 36 participants were included, each group having 18 patients. A comparable control group consisting of 21 healthy participants was recruited by means of an advertisement in a local newspaper. The three groups did not differ significantly on mean age but did differ significantly on the mean educational level (rated on an 11point scale), highly fearful patients being less educated than controls and patients low in pain-related fear (see table 2-9). The High Fear group and Low Fear group did not differ with regard to reported pain duration (see table 2-9) and (analgesic) medication use $\left(\chi^{2}=1.49, \mathrm{p}=0.47\right)$. All patients and controls signed a written informed consent and the Ethics Committee of the Maastricht University Hospital approved the experimental protocol. 
Table 2-9: Descriptive statistics of the questionnaires and levels of pain intensity.

\begin{tabular}{|c|c|c|c|c|c|c|c|c|}
\hline & \multicolumn{2}{|c|}{ High fear $(n=18)$} & \multicolumn{2}{|c|}{ Low fear $(n=18)$} & \multicolumn{2}{|c|}{ Controls $(n=21)$} & \multirow[t]{2}{*}{$F\left(o r t^{2}\right)$} & \multirow[t]{2}{*}{$p$-value } \\
\hline & Mean & SD & Mean & SD & Mean & SD & & \\
\hline Age (years) & 45.2 & 10.0 & 46.4 & 10.9 & 50.0 & 7.6 & 1.4 & 0.264 \\
\hline Education & 5.5 & 1.9 & 6.4 & 2.3 & 7.3 & 2.1 & 3.7 & 0.032 \\
\hline $\begin{array}{l}\text { Pain duration } \\
\text { (months) }\end{array}$ & 12.9 & 9.1 & 10.6 & 10.8 & & & 0.48 & 0.491 \\
\hline Pain intensity & 60.9 & 26.9 & 41.9 & 33.0 & & & 3.4 & 0.074 \\
\hline (m)TSK & 49.2 & 6.4 & 28.6 & 5.1 & 37.0 & 5.4 & 45.7 & $<0.001^{*}$ \\
\hline BVS & 17.4 & 4.9 & 12.7 & 6.8 & 14.7 & 5.5 & 4.0 & $0.024^{* *}$ \\
\hline PVAQ & 45.7 & 11.4 & 29.4 & 9.0 & & & 22.7 & $<0.001$ \\
\hline PASS & 65.4 & 32.4 & 35.9 & 20.5 & & & 10.7 & 0.002 \\
\hline PCS & 21.5 & 9.9 & 10.3 & 6.1 & & & 16.8 & $<0.001$ \\
\hline
\end{tabular}

Note: Education is rated on a 11-point scale (with 11 being highest educated); Pain intensity is measured on a 100 mm. VAS; $(\mathrm{m})$ TSK = (modified) Tampa Scale for Kinesiophobia; BVS = Body Vigilance Scale; PVAQ = Pain Vigilance and Awareness Questionnaire; PASS = Pain Anxiety Symptoms Scale; PCS = Pain Catastrophizing Scale. * TSK scores differed significantly for all conditions except for Low Fear and Controls. ${ }^{* *}$ BVS scores differed significantly only for High Fear and Low Fear.

\section{Materials}

A computerized version of the modified Stroop task was used containing six Dutch words related to injury (i.e., operatie, hernia, invalide, verlamd, rolstoel, and uitval, which can be translated into English as operation, hernia, invalid, paralyzed, wheelchair, and loss of function respectively) and six Dutch words related to movement (i.e., tillen, buigen, vallen, springen, rennen, and voetballen, which can be translated into English as lifting, bending, falling, jumping, running, and playing football respectively). Words were selected based on the TSK that includes items referring to fear of movement (e.g., 'It is really not safe for a person with a condition like mine to be physically active') and fear of (re)injury (e.g., 'Pain always means I have injured my body'). Each pain word was matched with one neutral word on the number of syllables and word length, leaving a total number of 24 words in the Stroop task. As each word was presented in four different colors, the total number of trials was 96. Word order was randomized with the constraints that no word would appear twice in succession and that no color would appear for more than two times consecutively. A battery of Dutch questionnaires was completed. The Tampa Scale for Kinesiophobia (TSK; Miller et al., 1991; Dutch version: Vlaeyen et al., 1995) is a self-report measure of fear of (re)injury and fear of movement and consists of 17 items rated on a four-point scale. Anchors are labeled 'strongly agree' and 'strongly disagree'. Control participants filled in a slightly modified version of the TSK (mTSK), specially adapted for use in samples of non-patients (Vlaeyen \& Crombez, 1998). The Body Vigilance Scale (BVS; Schmidt et al., 1997; Dutch version: Peters \& Vlaeyen, 1996) measures vigilance for bodily sensations and consists of four items of which the first three are scored on a ten-point scale. The fourth item consists of 16 non-specific body symptoms (i.e., palpitations, dizziness), which are rated on a six- 
point scale. Different anchor points are used for the BVS items and a total score is obtained by averaging the scores on the last item and summing this up with the scores on the first three items. Only pain patients filled in the Pain Vigilance and Awareness Questionnaire (McCracken, 1997; Dutch version: Crombez \& Vlaeyen, 1998), the Pain Catastrophizing Scale (PCS; Sullivan et al., 1995; Dutch version: Crombez \& Vlaeyen, 1996), and the Pain Anxiety Symptoms Scale (PASS; McCracken et al., 1992). The PVAQ is a measure of pain vigilance (e.g., "I focus on sensations of pain"). The PVAQ consists of 16 items rated on a 6-point scale from never to always. The PCS is a self-report measure of catastrophizing related to pain (e.g., "I keep thinking how badly I want the pain to stop"). The PCS contains 13 items rated on a 4point scale (anchors labeled 'not at all' and 'all the time'). The PASS is a 40-item, 6point scale questionnaire measuring fear and anxiety behaviors related to pain (e.g., "Pain sensations are terrifying", "I try to avoid activities that cause pain"). Anchors are labeled 'never' and 'always'. In addition, all patients scored the present (back) pain on a $100 \mathrm{~mm}$ VAS scale anchored 'no-pain' and 'extreme pain'. Questionnaire scores are presented in table 2-9.

\section{Procedure}

After signing an informed consent, all patients and control participants completed the set of questionnaires (see materials). Subsequently, all patients and controls were asked to perform the modified Stroop task. In the modified Stroop task, a dot was displayed for $500 \mathrm{~ms}$. to alert the participant to the upcoming word, which was immediately followed by the word itself, which remained present until the participant named its color (with a maximum duration of $3000 \mathrm{~ms}$ ). The response times of the color naming were recorded by a voice key. Incorrect responses (i.e., wrong color, coughing) were coded by the experimenter. The modified Stroop task lasted approximately six minutes (without practice). Presentation of words and recording of response times were controlled by MEL software (Schneider, 1995).

\section{Statistical analyses}

For the modified Stroop task, average reaction times to color naming responses were calculated for the different word categories separately. Incorrect responses were removed, as were outliers (defined as a reaction time deviating more than 3 standard deviations from each individual mean reaction time). In addition, reaction times below $200 \mathrm{~ms}$. were also removed. Repeated measures analyses of variance was conducted with Word Category (Movement and matched Neutral words vs. Injury and matched Neutral words) and Word Valence (Movement and Injury words vs. matched Neutral words) as within-subjects factors and Group (High Fear vs. Low Fear vs. Control) as between-subjects factor. A significant interaction between Group and Word Valence was expected.

To examine the association of various personality characteristics (measured by questionnaires) on the interference score, correlational analyses were conducted. To prevent spurious findings due to type I error, alpha was set to 0.01 . 


\section{RESULTS}

\section{The modified Stroop task}

Table 2-10 shows mean response times for words related to injury, movement, and their matched neutral (control) words. No differences were found between the three groups in the number of errors (total percentage of errors was less than $5 \%$ ).

Table 2-10: Mean response times ( $m s$.) and standard deviations (SD) for all word categories across all groups.

\begin{tabular}{lllllll}
\hline & \multicolumn{2}{l}{ High fear group $(\mathrm{n}=18)$} & \multicolumn{2}{l}{ Low fear group $(\mathrm{n}=18)$} & \multicolumn{2}{l}{ Control group $(\mathrm{n}=21)$} \\
\hline & Mean & SD & Mean & SD & Mean & SD \\
\hline Injury words & 731 & 128 & 682 & 118 & 652 & 104 \\
Neutral words (injury) & 737 & 100 & 693 & 114 & 678 & 120 \\
Movement words & 709 & 102 & 683 & 119 & 658 & 110 \\
Neutral words (movement) & 715 & 110 & 665 & 99 & 657 & 116 \\
\hline
\end{tabular}

Note: Neutral words (injury) refer to the neutral words matched with injury words and Neutral words (movement) refer to neutral words matched with movement words. Neural words were matched to Injury words and Movement words with respect to number of syllables and worth length.

Repeated measures analysis of variance showed a statistically significant interaction effect between Word Category and Word Valence $(\mathrm{F}(2,54)=7.95$, $\mathrm{p}=0.007)$. No significant interaction was found between Group and Word Valence $(\mathrm{F}(2,54)=1.80, \mathrm{p}=0.18)$ and between Group, Word Valence, and Word Category $(\mathrm{F}(2,54)=1.87, \mathrm{p}=0.17)$. To examine the interaction between Word Category and Word Valence, further post-hoc paired samples t-tests were conducted for Movement words and Injury words separately. Differences in response latencies for Movement words and the matched Neutral words were statistically nonsignificant across all three groups $(t(56)=0.96, p=0.34)$. For Injury words, response latencies for these words were shorter than that for the matched neutral (control) words across all three groups $(t(56)=-2.64, p=0.011)$.

Pearson correlation coefficients between self-report measures of personality characteristics and the interference scores (i.e., Movement, Injury) ranged from - 0.14 to 0.39 and were all non-significant (i.e., p-values well above 0.01 ).

\section{DISCUSSION}

The present study investigated whether patients with chronic low-back pain selectively attend to words related to injury and movement, employing a modified Stroop paradigm. Pain patients were selected on the basis of their scores on the TSK (measure of fear of (re)injury and movement) and two fear groups were formed (i.e., High Fear and Low Fear) as well as a control group. The High Fear group was 
expected to show a larger Stroop interference effect to these word stimuli compared to the Low Fear group and the control group. A significant interaction was found between Word Category and Word Valence. Post-hoc analysis indicated that only response latencies for Injury words were significantly different from latencies for the matched Neutral words. This indicates that naming the color of injury words was, quite counterintuitively, speeded up compared to neutral words in all three groups. Taken together, the results from the present study do not provide evidence that selective attention to words related to injury and movement takes place as a function of fear of (re)injury and/or movement as measured with a modified Stroop task. Unlike words related to sensory and affective pain, words related to movement and injury may perhaps not capture the patients' current concerns adequately enough. A previous study conducted by Crombez, Hermans, and Adriaensen (2000) addressed an almost identical hypothesis in patients with chronic low back pain but also failed to find that patients with high pain-related fear display a heightened Stroop interference to back-related words.

An alternative paradigm to investigate selective processing bias is the (visual) dot-probe paradigm. Generally, in a visual dot-probe paradigm, two words (an emotional word and a neutral word) appear on a screen and one of these two words is replaced by a small dot. Participants have to react to this dot by indicating the location at which it appeared. In a dot-probe task, speeding up the probe detection when the dot replaces the emotional word and a delay in detection when the dot replaces the neutral word is considered to be indicative of selective attentional processing. Only one study has used a visual dot-probe paradigm in chronic pain patients (Asmundson et al., 1997). Although the results from this did not directly provide evidence for selective attentional processing, dividing the patients on the basis of their scores on the Anxiety Sensitivity Index (ASI; Reiss et al., 1986), indicated that patients low in anxiety sensitivity shifted attention away from stimuli related to pain. Individuals high on anxiety sensitivity responded similarly to the probes regardless of the location of presentation. Keogh, Ellery, Hunt, and Hannent (2001a) conducted a visual dot-probe study in healthy University students selected on the basis of their scores on the Fear of Pain Questionnaire (FPQ; McNeill, \& Rainwater, 1998). Individuals high on pain-related fear were found to pay selective attention to pain-related words compared to those classified as medium and low in fear of pain. No evidence for selective attention was found for either social threat words or positive words. In a further study, Keogh, Dillon, Georgiou, and Hunt (2001b) selected healthy University students on the basis as to whether they were high or low in their anxious concern for physical sensations (i.e., a subscale of the ASI). The results from this study indicated that those scoring high on this subscale, selectively paid attention to words related to physical threat, whereas those scoring low on the this subscale, were found to avoid such material. Again, no selective attention effects were found for social threat-related and positive words.

In sum, the modified Stroop paradigm as a measure of selective attentional processing in pain patients does not seem to be a robust measure (i.e., the Stroop- 
effect seems to be difficult to replicate). Future studies should further investigate the usefulness and sensitivity of the visual dot-probe paradigm as a measure of attentional processing bias in chronic pain patients. Further, the role of the emotional state (i.e., pain-related fear, anxiety sensitivity disposition), which has been found to be associated with selective attention towards concern-related words, should be further investigated.

\section{REFERENCES}

Asmundson, G., Kuperos, J., \& Norton, G. (1997). Do patients with chronic pain selectively attend to pain-related information? Preliminary evidence for the mediating role of fear. Pain, 72, 27-32.

Beck, A. T. (1976). Cognitive therapy and the emotional disorders. New York: International Universities Press.

Beck, A. T., Emery, G., \& Greenberg, R. C. (1986). Anxiety disorders and phobias: a cognitive perspective. New York: Basic Books.

Boissevain, M. D. (1994). Information processing in chronic pain: the role of depression. Unpublished thesis. University of Western Ontario, Canada.

Bower, G. H. (1981). Mood and memory. American Psychologist, 36, 129-148.

Bower, G. H. (1987). Commentary on mood and memory. Behaviour Research and Therapy, 25, 443-456.

Crombez, G., \& Vlaeyen, J. W. S. (1996). The Pain Catastrophizing Scale: unpublished authorized Dutch/Flemish translation.

Crombez, G., \& Vlaeyen, J. W. S. (1998). The Pain Vigilance and Awareness Questionnaire: unpublished authorized Dutch/Flemish translation.

Crombez, G., Vlaeyen, J. W. S., Heuts, P. H. T. G, \& Lysens, R. (1999). Pain-related fear is more disabling than pain itself: evidence on the role of pain-related fear in chronic back pain disability. Pain, 80, 329-339.

Crombez, G., Hermans, D., \& Adriaensen, H. (2000). The emotional stroop task and chronic pain: what is threatening for chronic pain sufferers? European Journal of Pain, 4(1), 37-44.

Eccleston, C., \& Crombez, G. (1999). Pain demands attention: a cognitive-affective model of the interruptive function of pain. Psychological Bulletin, 125, 356-366.

Eysenck, M. W. (1992). Anxiety: the cognitive perspective. Hillsdale: Lawrence Erlbaum Associates.

Keogh, E., Ellery, D., Hunt, C., Hannent, I. (2001a). Selective attentional bias for painrelated stimuli amongst pain fearful individuals. Pain, 91, 91-100.

Keogh, E., Dillon, C., Georgiou, G., \& Hunt, C. (2001b). Selective attentional bias for physical-threat in physical anxiety sensitivity. Journal of Anxiety Disorders, 15, 299315.

McCracken, L. M., Zayfert, C., \& Gross, R. T. (1992). The Pain Anxiety Symptoms Scale: development and validation of a scale to measure fear of pain. Pain, 50, 67-73. 
McNeill, D. W., \& Rainwater, A. J. (1998). Development of the Fear of Pain Questionnaire-III. Journal of Behavior Medicine, 21, 389-410.

McCracken, L. M. (1997). "Attention to pain in persons with chronic pain: a behavioral approach. Behavioral Therapy, 28, 271-284.

Miller, R. P., Kori, S. H., \& Todd, D. D. (1991). The Tampa Scale. Unpublished report. Tampa: FL.

Pearce, J., \& Morley, S. (1989). An experimental investigation of the construct validity of the McGill Pain Questionnaire. Pain, 39, 115-121.

Peters, M. L., \& Vlaeyen, J. W. S. (1996). The Body Vigilance Scale: unpublished Dutch translation.

Peters, M. L., Vlaeyen, J. W. S., \& Kunnen, A. M. W. (2002). Is pain-related fear a predictor of somatosensory hypervigilance in chronic low back pain patients? Behaviour Research and Therapy, 40, 85-103.

Pincus, T., Fraser, L., \& Pearce, S. (1998). Do chronic pain patients 'Stroop' on pain stimuli? British Journal of Clinical Psychology, 37, 49-58.

Pincus, T., \& Morley, S. (2001). Cognitive-processing bias in chronic pain: a review and integration. Psychological Bulletin, 127(5), 599-617.

Reiss, S., Peterson, R. A., Gursky, D. M., \& McNally, R. J. (1986). Anxiety sensitivity, anxiety frequency and the prediction of fearfulness. Behaviour Research and Therapy, 24(1), 1-8.

Riemann, B. C., \& McNally, R. J. (1995). Cognitive processing of personally relevant information. Cognition and Emotion, 9, 325-340.

Roelofs, J., Peters, M. L., Zeegers, M. P. A., \& Vlaeyen, J. W. S. (2002). The modified Stroop paradigm as a measure of selective attention towards pain-related stimuli among chronic pain patients: a meta-analysis. European Journal of Pain, 6(4), 273281.

Schmidt, N. B., Lerew, D. R., \& Trakowski, J. K. (1997). Body vigilance in pain disorder: evaluating attention to bodily perturbations. Journal of Consulting and Clinical Psychology, 65, 214-220.

Schneider, W. (1995). MEL professional: User's guide. Pittsburgh: Psychology Software Tools Inc.

Snider, B. S., Asmundson, G. J., \& Wiese, K. C. (2000). Automatic and strategic processing of threat cues in patients with chronic pain: a modified Stroop evaluation. Clinical Journal of Pain, 16(2), 144-154.

Sullivan, M. J. L., Bishop, S. R., \& Pivik, J. (1995). The Pain Catastrophizing Scale: development and validation. Psychological Assessment, 7, 624-532.

Vlaeyen, J. W. S., Kole-Snijders, A. M. J., Boeren, R. G. B., Van Eek, H. (1995). Fear of movement/(re)injury in chronic low back pain and its relation to behavioral performance. Pain, 62, 363-372.

Vlaeyen, J. W. S., \& Crombez, G. (1998). The modified Tampa Scale of Kinesiophobia: for its use in non-pain samples. Unpublished Dutch/Flemish translation.

Vlaeyen, J. W. S., \& Linton, S. J. (2000). Fear-avoidance and its consequences in chronic musculoskeletal pain: a state of the art. Pain, 85, 317-332. 


\title{
2.4 AN EXAMINATION OF WORD RELEVANCE IN A MODIFIED STROOP TASK IN PATIENTS WITH CHRONIC LOW BACK PAIN*
}

\begin{abstract}
The present study examined the role of idiosyncratic relevance of sensory pain words in a modified Stroop task applied to chronic low back pain patients. Thirty chronic low back pain patients completed the modified Stroop task as well as a set of selfreport measures aimed to asses pain-related fear, trait anxiety, pain catastrophizing, pain vigilance, and pain intensity. The modified Stroop task comprised 33 sensory pain words of which the relevance towards current concerns (referred to as 'personal relevance') was rated afterwards by each participant on a 7-point Likert scale. An interaction between self-reported pain-related fear and personal relevance was expected to account for Stroop reaction times on sensory pain words. More specifically, personal relevance was expected to be associated with larger reaction times especially in highly fearful patients. Results from multi-level analyses did not confirm this hypothesis. Furthermore, none of the other self-report measures accounted for reaction times in isolation or in interaction with personal relevance. Results of the present study are discussed and directions for future research are provided.
\end{abstract}

\footnotetext{
* Roelofs, J., Crombez, G., Peters, M. L., Vlaeyen, J. W. S., \& Verschuere, B. An examination of word relevance in a modified Stroop task in patients with chronic low back pain. (manuscript submitted).
} 


\section{INTRODUCTION}

Research into biases in information processing has predominantly involved the area of emotional disorders such as depression, eating disorders, and several anxiety disorders. This research, inspired by Beck schema theory (Beck, 1976; Beck et al., 1986) and Bower's network theory of the relation between emotion and cognition, (Bower, 1981, 1987), has revealed biases in memory, interpretation and attention. Recently, investigation of information-processing biases has also been applied to the field of chronic pain. In an extensive review, Pincus and Morley (2001) concluded that there is strong evidence for the presence of memory bias and interpretation bias towards pain-related stimuli in pain patients. There was only limited evidence for selective attention towards pain-related stimuli in chronic pain patients. However, a recent meta-analysis (Roelofs et al., 2002) has shown that chronic pain patients indeed selectively pay attention towards pain stimuli (i.e., sensory and affective pain words) as measured with a modified Stroop task.

In a modified Stroop task, categories of emotionally salient and neutral words are presented in different colors. Response times of patients to name the color of each word are measured. Typically, color naming is slowed down when words are relevant to the patients' concern, whereas no response delay is expected for neutral words. Although the overall conclusion of the meta-analysis on Stroop studies was that chronic pain patients selectively pay attention to pain-related words, not all studies included in the meta-analysis have found support for selective attention towards pain-related words. One reason for the failure to find the expected attentional effects may be that words are for many patients not relevant for their pain and therefore do not capture the current concerns of pain patients. The importance of using words in a modified Stroop task that accurately tap current concerns (referred to as 'personal relevance' from here) has been stressed in several studies conducted in different anxiety disorders (see Williams et al., 1997 for an overview).

Another reason may be that not all pain patients show a specific interference effect. In line with the view of Eccleston and Crombez (1999) and Vlaeyen and Linton (2000), it is reasonable to hypothesize that especially those patients who catastrophize about their pain or who are fearful about their pain will display an increased attention to pain or pain-related information. The modified Stroop task may serve as an indirect way of measuring selective attention for pain-related words that represent patients' pain.

The present study offers a first attempt to examine the extent to which personal relevance account for Stroop reaction times in chronic low back pain patients. Drawing on studies that have examined current concerns in the modified Stroop task, we hypothesized that an interaction between pain-related fear and personal relevance would be present, such that Stroop effects are most likely to be found to words that are highly relevant to patients' concerns, especially in high fearful patients. The specificity of pain-related fear in predicting Stroop reaction 
times was investigated by examining whether a measure of trait anxiety interacted with personal relevance in accounting for Stroop reaction times. As pain catastrophizing is theoretically closely related to pain-related fear, we also examined whether pain catastrophizing would interact with personal relevance of Stroop words in predicting Stroop reaction times. Current pain intensity in interaction with personal relevance in accounting for Stroop reaction times was also examined. Finally, we examined to what extent these self-report measures and personal relevance in isolation, accounted for Stroop reaction times.

\section{METHODS}

\section{Participants}

Thirty patients with chronic low back pain (19 females, 11 males) were recruited from two Belgian pain clinics of the University hospital of Ghent and the University hospital of Leuven at 'Pellenberg'. The inclusion criteria for the present experiment were nonspecific complaints about back pain for a duration of at least six months, age between 18 and 65, and to have mastered Dutch language. Written informed consent was obtained for each participant before the start of the experiment.

\section{Materials and procedure}

Each participant completed a computerized version of the modified Stroop task, which contained 33 Dutch sensory pain words derived from the McGill Pain Questionnaire (Melzack, 1975; Dutch version: Van der Kloot \& Vertommen, 1989). Each word was presented in four different colors (i.e., red, yellow, blue, green) leaving a total number of 132 trials. Each word was presented with a maximum duration of $2000 \mathrm{~ms}$. and response times of the color naming were recorded by a voice key. Inter-stimulus time was 3000 ms. Incorrect responses (i.e., wrong color, coughing) were coded by the experimenter. As each word appeared four times, mean reaction times were calculated. The Stroop task lasted approximately 8 minutes (without practice). Recording of presentation time was controlled by a Turbo Pascal timer.

At the end of the experiment, all participants were requested to complete a set of questionnaires, which had to be sent back to the experimenter by mail. The extent to which these words were personally relevant to the pain experience and captured current concerns, was measured by a 7-point Likert scale with anchors labeled 'not at all applicable' and 'very applicable to my pain'. The Tampa Scale for Kinesiophobia (TSK: Miller et al., 1991; Dutch version: Vlaeyen et al., 1995), which is a self-report measure of fear of (re)injury (e.g., "Pain always means I have injured my body") and fear of movement (e.g., "It is really not safe for a person with a condition like mine to be physically active") has 17 items to be rated on a 4-point Likert scale. Anchors are labeled 'strongly agree' and 'strongly disagree'. The trait version of the State-Trait Anxiety Inventory (STAI: Spielberger et al., 1970; Dutch version: Van der Ploeg et al., 
1980) is a 20-item inventory of trait anxiety (e.g., "I feel nervous"). Items are rated on a 4-point scale ranging from 'almost never' to 'almost always'. The Pain Catastrophizing Scale (PCS: Sullivan et al., 1995; Dutch version: Van Damme et al., 2002) is a self-report measure of catastrophizing related to pain (e.g., "I keep thinking how badly I want the pain to stop"). The PCS contains 13 items rated on a 4-point Likert scale with anchors labeled 'not at all' and 'all the time'. The Pain Vigilance and Awareness Questionnaire (PVAQ: McCracken, 1997; Dutch version: Roelofs et al., 2003) is a measure of pain vigilance (e.g., "I focus on sensations of pain"). The PVAQ consists of 16 items rated on a 6-point scale with anchors ranging from 'never' to 'always'. Current pain intensity was measured with a $100-\mathrm{mm}$. visual analogue scale with anchors labeled 'no pain' and 'the worse imaginable pain'.

\section{Statistical analyses}

Multilevel analysis (MLA) was used to analyze the Stroop data. MLA can be used for repeated measures and nested data. Personal relevance of Stroop words was rated by each participant. In this respect, participants comprised the highest (first) level while relevance ratings of the 33 sensory pain words comprised the second level. These relevance ratings (second level) were thus nested within participants (first level). In contrast to traditional statistical tests such as ordinary least squares regression techniques, MLA accounts for intra-class correlation in the data (i.e., relevance ratings within patients may be stronger interrelated compared to ratings between patients). MLA also has the advantage that it can deal with occasional missing data. In nine subsequent analyses, the predictors of reaction time of the sensory pain words (dependent variable) were scores on the TSK, STAI, PCS, pain intensity (PainVAS) in isolation and in combination with relevance ratings of sensory pain words. Relevance as a predictor of reaction time in isolation was also examined. To decrease the likelihood of spurious findings due to type I error, alpha was set to 0.01 for MLA. Data were analyzed using the mixed model analysis option in SPSS version 11.0 .

\section{RESULTS}

Table 2-11 presents descriptive statistics of the questionnaire scores and Pearson correlation coefficients between the various measures. Mean pain duration and age are also depicted. As expected, all self-report measures related to pain (i.e., TSK, PCS, PVAQ, PainVAS) were moderately intercorrelated. Trait anxiety (STAI) was moderately associated with pain-related fear (TSK) and pain catastrophizing (PCS) but not with pain vigilance (PVAQ) and pain intensity (PainVAS). Age was positively associated with pain-related fear (TSK) and trait anxiety (STAI). Two remarks need further addressing. First, two patients did not return the questionnaires to the experimenter and three patients only completed part of the questionnaires. Thus, the sample size in the analyses varied from 25 to 30 depending 
on the available data. Second, females scored significantly higher on measures of pain-related fear (TSK: $\mathrm{p}=0.008$ ), trait anxiety (STAI: $\mathrm{p}=0.022$ ), and pain catastrophizing (PCS: $\mathrm{p}=0.048$ ). Word relevance ratings showed sufficient spread (mean $=3.06 ; \mathrm{SD}=2.22$; range 1 to 7 ).

The results of MLA on the Stroop data are depicted in table 2-12. All tested models controlled for gender and age, which did not significantly predict response times (data not shown). The intra-class correlation coefficient was 0.67, indicating that MLA is the appropriate technique for analysis rather than ordinary regression techniques. As can be seen in table 2-12, the expected interaction between TSK scores and personal relevance ratings of sensory pain words (model 6) was not confirmed in the present study. Further, none of the other predictors significantly accounted for reaction times of sensory pain words.

Table 2-11: Descriptive statistics and correlational analyses.

\begin{tabular}{|c|c|c|c|c|c|c|}
\hline & \multicolumn{2}{|c|}{ Descriptive statistics } & \multicolumn{4}{|c|}{ Correlational analyses } \\
\hline & Mean & SD & TSK & STAI & PCS & PVAQ \\
\hline TSK & 40.7 & 7.1 & - & & & \\
\hline STAI & 40.8 & 9.1 & $0.65^{* *}$ & - & & \\
\hline PCS & 22.8 & 8.7 & $0.63^{* *}$ & $0.52^{* *}$ & - & \\
\hline PVAQ & 42.6 & 9.6 & $0.47^{*}$ & 0.30 & $0.58^{* *}$ & - \\
\hline Pain intensity & 48.2 & 24.9 & $0.57^{* *}$ & 0.12 & $0.47^{*}$ & $0.52^{*}$ \\
\hline Pain duration & 75.6 & 86.9 & 0.35 & 0.14 & 0.07 & 0.19 \\
\hline Age & 41.2 & 11.6 & $0.45^{*}$ & $0.40^{*}$ & 0.15 & 0.08 \\
\hline
\end{tabular}

Note: TSK = Tampa Scale for Kinesiophobia; STAI = trait version of the State-Trait Anxiety Inventory; PCS = Pain Catastrophizing Scale; Pain duration in months; age in years. ${ }^{*} p<0.05,{ }^{* *} p<0.01$.

Table 2-12: Multilevel analyses of Stroop data.

\begin{tabular}{lccccc}
\hline Predictor(s): & Beta & SE & $95 \%$ Cl (Beta) & t-value & p-value \\
\hline Model 1: TSK & 0.26 & 0.21 & $-0.17 ; 0.69$ & 1.26 & 0.22 \\
Model 2: STAI & 0.18 & 0.19 & $-0.21 ; 0.58$ & 0.95 & 0.35 \\
Model 3: PCS & 0.27 & 0.18 & $-0.10 ; 0.63$ & 1.52 & 0.14 \\
Model 4: Pain intensity & 0.07 & 0.17 & $-0.29 ; 0.43$ & 0.39 & 0.70 \\
Model 5: Relevance & -0.02 & 0.02 & $-0.06 ; 0.02$ & -1.02 & 0.31 \\
Model 6: Relevance X TSK & -0.05 & 0.14 & $-0.32 ; 0.23$ & -0.33 & 0.75 \\
Model 7: Relevance X STAI & -0.06 & 0.11 & $-0.27 ; 0.15$ & -0.57 & 0.57 \\
Model 8: Relevance X PCS & -0.08 & 0.07 & $-0.22 ; 0.06$ & -1.07 & 0.28 \\
Model 9: Relevance X Pain intensity & -0.09 & 0.06 & $-0.20 ; 0.03$ & -1.44 & 0.15 \\
\hline
\end{tabular}

Note: TSK = Tampa Scale for Kinesiophobia; STAI = trait version of the State-Trait Anxiety Inventory; PCS = Pain Catastrophizing Scale. All tested models controlled for gender and age. 


\section{DISCUSSION}

The present study examined whether reaction times of color-naming sensory pain words were influenced by the extent to which these words represented patients current concerns (relevance) in isolation and in interaction with scores on self-report measures of pain-related fear (TSK), trait anxiety (STAI), pain catastrophizing (PCS), and pain intensity (visual analogue scale). The effects of these measures in isolation on Stroop reaction times were also investigated. Results showed that the hypothesized interaction between relevance and scores on the TSK was not confirmed in the present study. Further, neither self-report measures in isolation or in interaction with relevance, nor relevance itself, were predictive of reaction times.

The results from the present study are in contrast to studies that have investigated the role of current concerns in anxiety disorders in applying the modified Stroop task (see Williams et al., 1997). Some methodological differences between the present study and studies that have addressed similar research questions in anxiety disorders warrant attention. First, the study design of the present study differs from studies examining current concerns in anxiety disorder. In the present study, relevance of words to current concerns was rated afterwards and was taken into account in the multi-level analyses. Studies conducted in the field of anxiety disorders have predominantly relied on a priori independently varying the degree of specific relevance to personal concern of the word stimuli. Second, as only sensory pain words were used, and one cannot rule out that other word stimuli such as affective pain words might have tapped current concerns in a more precise way. However, the recently proposed 'enmeshment model' by Pincus and Morley (2001) to account for evidence regarding attentional, interpretation, and memory biases in chronic pain patients has the fundamental assumption that pain patients would selectively process sensory intensity information. Third, the function of showing selective attention to threat related words that are related to patients' current concerns is to avoid its possible occurrence. It has been shown that selective attention for threat related stimuli can disappear in fearful individuals when they are tested in close temporal or physical proximity to their phobic object or situation, such as snake phobic tested in the presence of a boa constrictor (Mathews \& Sebastian, 1993). One could argue that in participants who actually experienced pain, the expected effects on reaction times for relevant sensory pain words does not occur. However, a recent Stroop study in pain patients showed that interference effects were significantly predicted by pain intensity (Crombez et al., 2000).

In conclusion, the present study could not find evidence for the proposition that word relevance predicted reaction times as measured with the modified Stroop task in chronic low back pain patients. Taking the mixed results of previous Stroop studies into account, the best conclusion that can be drawn at this point is that the Stroop task does not seem to be a robust measure of demonstrating interference effects in chronic low back pain patients. It is possible that these interference effects 
are small effects that may not be present in all pain patients. Future studies should apply alternative paradigms such as the dot-probe task as a measure of selective attentional processing in chronic low back pain patients. It is possible that word stimuli are not emotionally salient enough to produce selective attentional processing. Therefore, not only words but also pictures should be included and these stimuli should preferably be chosen idiosyncratically.

\section{ACKNOWLEDGEMENTS}

We are grateful to Murielle Verschuere for collecting data in the present study.

\section{REFERENCES}

Beck, A. T. (1976). Cognitive therapy and the emotional disorders. New York: International Universities Press.

Beck, A. T., Emery, G., \& Greenberg, R. C. (1986). Anxiety disorders and phobias: a cognitive perspective. New York: Basic Books.

Bower, G. H. (1981). Mood and memory. American Psychologist, 36, 129-148.

Bower, G. H. (1987). Commentary on mood and memory. Behaviour Research and Therapy, 25, 443-456.

Crombez, G., Hermans, D., \& Adriaensen, H. (2000). The emotional stroop task and chronic pain: what is threatening for chronic pain sufferers? European Journal of Pain, 4, 37-44.

Eccleston, C., \& Crombez, G. (1999). Pain demands attention: a cognitive-affective model of the interruptive function of pain. Psychological Bulletin, 125, 356-366.

McCracken, L. M. (1997). Attention to pain in persons with chronic pain: a behavioral approach. Behavior Therapy, 28, 271-284.

Mathews, A., \& Sebastian, S. (1993). Suppression of emotional Stroop effects by fear arousal. Cognition and Emotion, 7, 517-530.

Melzack, R. (1975). The McGill Pain Questionnaire: major properties and scoring methods. Pain, 1, 277-299.

Miller, R. P., Kori, S., \& Todd, D. D. (1991). The Tampa Scale. Unpublished report, Tampa, FL.

Pincus, T., \& Morley, S. J. (2001). Cognitive-processing bias in chronic pain: a review and integration. Psychological Bulletin, 127, 599-617.

Roelofs, J., Peters, M. L., Zeegers, M. P. A., \& Vlaeyen, J. W. S. (2002). The modified Stroop paradigm as a measure of selective attention towards pain-related stimuli among chronic pain patients: a meta-analysis. European Journal of Pain, 6, 273-281.

Roelofs, J., Peters, M. L., McCracken, L. M., \& Vlaeyen, J. W. S. (2003). The Pain Vigilance and Awareness Questionnaire (PVAQ): further psychometric evaluation in fibromyalgia and other chronic pain syndromes. Pain, 101, 299-306. 
Spielberger, C. D., Gorsuch, R. L., \& Lushene, R. E. (1970). State-Trait Anxiety Inventory. Palo Alto: Consulting Psychologists Press.

Sullivan, M. J., Bishop, S. R., \& Pivik, J. (1995). The Pain Catastrophizing Scale: development and validation. Psychological Assessment, 7, 624-632.

Van Damme, S., Crombez, G., Bijttebier, P., Goubert, L., \& Van Houdenhove, B. (2002). A confirmatory factor analysis of the Pain Catastrophizing Scale: Invariant factor structure across clinical and non-clinical populations. Pain, 96(3), 319-324.

Van der Ploeg, H. M., Defares, P. B., \& Spielberger, C. D. (1980). Handleiding bij de Zelf Beoordelingsvragenlijst (ZBV). Lisse: Swets \& Zeitlinger.

Van der Kloot, W. A., Vertommen H. (1989). De MPQ-DLV. Een standaard Nederlandstalige versie van de McGill Pain Questionnaire. Achtergronden en handleiding. Lisse: Swets \& Zeitlinger.

Vlaeyen, J. W. S., Kole-Snijders, A. M. J., Boeren, R. G. B., \& Van Eek, H. (1995). Fear of movement/(re)injury in chronic low back pain and its relation to behavioral performance. Pain, 62, 363-372.

Vlaeyen, J. W. S., \& Linton, S. J. (2000). Fear-avoidance and its consequences in chronic musculoskeletal pain: a state of the art. Pain, 85, 317-332.

Williams, J. M. G., \& Watts, F. N., MacLeod, C., \& Mathews, A. (1997). Cognitive psychology and the emotional disorders ( $2^{\text {nd }}$ Edition). Chichester: John Wiley \& Sons. 


\title{
2.5 SELECTIVE ATTENTION AND AVOIDANCE OF PAIN-RELATED STIMULI: A DOT-PROBE EVALUATION IN A PAIN-FREE POPULATION*
}

\begin{abstract}
The present study investigated selective attention and avoidance of pain-related stimuli by applying a dot-probe paradigm to healthy University students. The study consists of two successive experiments. The first experiment, a direct replication of a previous study, failed to find evidence for the presence of attentional bias towards pain-related words in highly fearful individuals compared to those who are low in pain-related fear. A second experiment was set up to examine whether avoidance of pain stimuli was influenced by presentation time of word pairs and to investigate the effects of gender on processing pain-related stimuli. The results from the second experiment showed that presentation time of words, fear of pain scores, and gender in isolation or in interaction with each other did not significantly influence attention to and avoidance of pain-related stimuli. Implications of the results are discussed and directions for future research are provided.
\end{abstract}

\footnotetext{
${ }^{*}$ Roelofs, J., Peters, M. L., Van der Zijden, M., Thielen, F. G. J. M., \& Vlaeyen, J. W. S. (2003). Selective attention and avoidance of pain-related stimuli: a dot-probe evaluation in a pain-free population. Journal of Pain, 4(6), 322-328.
} 


\section{INTRODUCTION}

Research in information processing bias has mainly involved the area of emotional disorders (e.g., several anxiety disorders, eating disorders, depression). Inspired by Beck's schema theory (Beck, 1976; Beck et al., 1986) and Bower's network theory of the relation between cognition and emotion (Bower, 1981; Bower 1987), biases in attention, memory, and interpretation have been identified. Research in information processing bias has also been applied to the field of chronic pain. In an extensive review, Pincus and Morley (Pincus \& Morley, 2001) reported firm evidence for memory bias and interpretation bias towards pain-related stimuli in chronic pain patients. However, empirical evidence for attentional bias towards pain-related information is weak.

One prominent paradigm for investigating attentional bias has been the modified Stroop paradigm. Generally, in a modified Stroop paradigm categories of emotionally salient and neutral words are presented in different colors. Response times to name the color of each word are measured. Typically, the color naming of words relevant to one's concern is slowed down compared to neutral words. Thus, the content of the emotional words interferes with color naming. This interference effect is expected to be larger in emotionally disturbed patients as compared to healthy controls. To date, few studies have applied a modified Stroop paradigm to investigate selective attention towards pain-related words in chronic pain patients (Boissevain, 1994; Pearce \& Morley, 1989; Pincus et al., 1998; Snider et al., 2000), and yielded inconsistent results. To account for these inconsistent findings, we recently conducted a meta-analysis on the aforementioned Stroop studies (Roelofs et al., 2002a). Data from these studies were pooled and summarized into a mean difference (MD). The results from the meta-analysis showed significant MD's for both sensory and affective pain words, indicating that pain patients selectively pay attention to these pain-related words compared to neutral words. In addition, meta-regression analysis indicated that the MD's were not influenced by methodological quality of the individual studies. Recently, processing of accident-related and pain-related words has been investigated in motor vehicle accident survivors using a modified Stroop paradigm (Beck et al., 2001). Results indicated that participants with comorbid posttraumatic stress disorder and pain showed response delays in color naming both accident and pain-related words, whereas participants with pain alone showed delays to pain words only.

Another influential paradigm for investigating attentional bias has been the (visual) dot-probe paradigm. Generally, in a visual dot-probe paradigm, two words (an emotional word and a neutral word) appear on a screen and one of these two words is replaced by a small dot. Participants have to react to this dot by indicating the location, which it appeared in. Chronic pain patients are expected to be faster to respond to probes that replace pain words than neutral words, in comparison with healthy controls. This speeding up of response time in pain patients is considered as 
indicative of attentional bias. Few studies have investigated the dot-probe paradigm as a measure of attentional bias in chronic pain patients. Asmundson et al. (1997) applied a dot-probe task to a group of 19 pain patients and 22 healthy controls, consisting of a mixture of pain-sensory and pain-affective words selected from the McGill Pain Questionnaire (Melzack, 1975). No evidence was found for an attentional bias. However, when the patients were divided on the basis of their scores on a measure of anxiety sensitivity (i.e., the proneness to experience fear in response to anxiety-related sensations), those with low anxiety sensitivity shifted attention away from stimuli to pain whereas those with high anxiety sensitivity responded similarly to dot-probe regardless of the location of presentation. Keogh and co-workers have conducted four dot-probe studies in pain-free individuals. In the first study (Keogh et al., 2001a), a visual dot-probe task was applied including physical threat-related, social threat-related, and positive words. Participants were selected on the basis as to whether they were high or low in their anxious concern for physical sensations (based on scores on the physical anxiety sensitivity subscale of the Anxiety Sensitivity Index [Reiss et al., 1986]). The results from this study indicated that those high in physical anxiety sensitivity, selectively paid attention only to physical threatrelated words whereas those low in physical anxiety sensitivity were found to avoid such material. The second study (Keogh et al., 2001b), investigated whether individuals high in fear of pain would selectively attend towards pain-related words as measured with a dot-probe task. Participants were allocated to three groups (low, medium, and high fear of pain) based on their scores on the Fear of Pain Questionnaire (McNeil \& Rainwater, 1998). The results from this study showed that only the high fear of pain group selectively paid attention towards pain-related information, compared to those classified as medium and low in fear of pain. No attentional effects were found for either social-threat words or positive words. However, in two further dot-probe studies in healthy individuals, no evidence was found for selective attention towards pain-related stimuli as a function of anxiety sensitivity (Keogh et al., 2002) or fear of pain (Keogh et al., 2003).

Taken together, dot-probe studies have produced mixed results in examining to what extent selective attention towards pain-related words is associated with emotional state such as anxiety sensitivity or pain-related fear. The present study consists of two experiments. The first experiment attempts to replicate the findings by Keogh and colleagues (2001b) in a pain-free population of Dutch University students. We hypothesized that high fearful individuals selectively pay attention to pain-related words compared to low fearful individuals. In contrast to our expectation, the results from the first experiment did not support this hypothesis. Experiment two was set up to examine whether selective attention to and avoidance of pain stimuli was influenced by presentation time of word pairs and to investigate the effects of gender on processing pain-related stimuli. 


\section{EXPERIMENT ONE}

\section{MATERIALS AND METHODS}

\section{Participants}

Ninety female University students (mean age $=19.9$ years, $\mathrm{SD}=1.7$ years, range 18 26 years) were sampled from a predominantly female population $(\mathrm{n}=272)$ of University students who completed a set of questionnaires. Only females were included in experiment one as the number of males was very small. Participants verbally reported the absence of any pain during the experiment. All participants signed a written informed consent in which part of the experimental design was explained. Participants were unfamiliar with the hypothesis and the dot-probe task. Full debriefing took place immediately after the end of the experiment and results from the experiment were sent by mail after completion of the study. The experimental protocol was in line with the regulations of the Ethics Committee of Maastricht University.

\section{Design}

As the largest effects in the study from Keogh and colleagues (2001b) were found between the high fearful participants and the low fearful individuals, two equally sized groups were created based on the scores on the FPQ. In order to enlarge the contrast between individuals with regard to the level of pain-related fear, only individuals below the $25^{\text {th }}$ percentile $\left(\mathrm{FPQ}\right.$ scores $<62$ ) and above the $75^{\text {th }}$ percentile (FPQ scores > 85) were asked to participate.

\section{Materials and procedure}

At the beginning of the experiment, all participants completed a battery of Dutch questionnaires. The Pain Vigilance and Awareness Questionnaire (PVAQ; McCracken, 1997; Crombez et al., 1998) is a measure of pain vigilance (e.g., "I focus on sensations of pain") containing 16 items rated on a 6-point scale anchored 'never' and 'always'. PVAQ total scores range from 0 to 80. The Anxiety Sensitivity Index (ASI; Reiss et al., 1986) is a 16-item questionnaire that measures an individual's fear of the symptoms of anxiety (e.g., "Unusual body sensations scare me"), rated on a five-point scale anchored 'very little' to 'very much'. ASI total scores range from 0 to 64. The Pain Catastrophizing Scale (PCS; Crombez \& Vlaeyen, 1996; Sullivan et al., 1995; Van Damme et al., 2002) is a self-report measure of catastrophizing related to pain and contains 13 items rated on a 4-point scale (e.g., "I keep thinking how badly I want the pain to stop"). PCS total scores range between 0 and 52 and anchors are labeled 'not at all' and 'all the time'. The Zung (Zung, 1965) is a self-report measure of depression (e.g., "I feel downhearted, blue, and sad"), consisting of 20 items rated on a 4-point scale anchored 'none or little of the time' to 'most or all of the time'. Zung total scores 
range from 20 to 80 . For all questionnaires, higher scores reflect higher levels of the underlying person characteristic that the questionnaire presumes to measure.

After completing the questionnaires all participants completed a computerized version of the visual dot-probe task, containing the same words translated into Dutch, which were used in the study of Keogh et al. (2001b). Consistent with their study, three word categories were used: pain-related, social threat and positive. Word pairs were created by matching each word with a neutral word. In addition, a set of neutral word pairs was generated to act as filler items. All word pairs were matched on the number of syllables and word length. Participants were initially presented with a fixation cross in the center of a computer screen for $500 \mathrm{~ms}$. Two words were presented: one above and one below this fixation point. After a further $500 \mathrm{~ms}$, both words were removed and in the location of one of the words a small dot appeared. Participants were required to indicate via a response box whether the dot appeared in the upper or the lower location. For each word group, there were four different presentation conditions. The emotional word could be presented to either the upper or lower location and the dot could replace the emotional word or the neutral word, which was randomly controlled by the computer. Within each word pair group, these four possible presentations occurred in a randomized fashion. As soon as a response had been made, or after $3000 \mathrm{~ms}$., the dot was erased. After 500 ms. the next trial began.

\section{Data reduction and statistical analyses}

For each word group, average reaction times for all four different presentation conditions were calculated. Incorrect responses, as well as outliers (defined as a reaction time deviating more than 3 standard deviations from each individual mean reaction time) were removed. In order to investigate the dot-probe data, a bias-index was computed for each word group according to the following formula (see Keogh et al., 2001b):

$$
\begin{aligned}
& \text { Bias-index }=((\text { eudl }- \text { eldl })+(\text { eldu }- \text { eudu })) / 2 \\
& e=\text { emotional word; } d=\text { dot; } u=\text { upper position; } I=\text { lower position }
\end{aligned}
$$

A positive score on these indexes indicates a selective attentional bias towards the location of the emotional word (i.e., vigilance), whereas a negative score indicates a bias away from such material (i.e., avoidance). A repeated measures analysis of variance was performed containing bias indices (pain-related, social threat, and positive) as within-subjects factor and fear group (high fear vs. low fear) as betweensubjects factor. To directly compare a specific pain-related bias with both a general threat and a general emotionality bias, pain-related, social threat, and positive bias indices were analyzed within the same analysis. Furthermore, the extent to which the bias index of pain was influenced by personality characteristics (i.e., questionnaire scores) was investigated by means of correlational analysis. 


\section{RESULTS}

Table 2-13 presents mean bias indices (i.e., pain-related, social threat, and positive) and scores on the questionnaires for both groups. The fear groups did not differ in the number of errors (1.3\%). Low fear individuals scored significantly lower on ASI $(p<0.001)$, PVAQ $(p=0.001)$, PCS $(p=0.001)$, but not on the Zung $(p=0.19)$. Repeated measures analysis of variance showed no main effect of Fear Group (Low Fear vs. High Fear $)(\mathrm{F}(1,86)=1.95, \mathrm{p}=0.17)$. No significant interaction between bias index and fear group $(\mathrm{F}(2,85)=0.63, \mathrm{p}=0.53)$ was found. Correlational analyses were also conducted between the questionnaire measures and bias indices (see table 2-14). None of the self-report measures were substantially associated with the bias indices.

Table 2-13: Descriptive statistics of the bias indices (ms.) and questionnaire scores for experiment one.

\begin{tabular}{lrrrr}
\hline & \multicolumn{2}{c}{ Low fear group $(\mathrm{n}=45)$} & \multicolumn{2}{c}{ High fear group $(\mathrm{n}=45)$} \\
\hline & \multicolumn{1}{c}{ Mean } & SD & \multicolumn{2}{c}{ Mean } \\
\cline { 2 - 5 } FPQ & 53.26 & 6.56 & 94.79 & 8.04 \\
ASI & 24.89 & 5.43 & 30.26 & 8.29 \\
PVAQ & 30.25 & 9.76 & 37.40 & 11.20 \\
PCS & 9.84 & 5.70 & 15.37 & 8.16 \\
Zung & 34.10 & 6.46 & 35.88 & 6.97 \\
Age (years) & 19.93 & 1.81 & 19.93 & 1.74 \\
Bias index pain & 8.75 & 28.39 & 2.38 & 23.22 \\
Bias index social threat & 6.72 & 26.44 & -2.23 & 37.59 \\
Bias index positive & -0.89 & 25.81 & -1.51 & 24.65 \\
\hline
\end{tabular}

Note: $F P Q=$ Fear of Pain Questionnaire; $A S I=$ Anxiety Sensitivity Index; PVAQ = Pain Vigilance and Awareness Questionnaire; PCS = Pain Catastrophizing Scale.

Table 2-14: Correlational analyses of questionnaires and bias indices for experiment one.

\begin{tabular}{lrrrc}
\hline & ASI & PVAQ & PCS & Zung \\
\hline Bias index pain & -0.08 & -0.11 & -0.15 & 0.16 \\
Bias index social & 0.02 & 0.07 & 0.15 & -0.16 \\
Bias index positive & 0.01 & 0.07 & 0.03 & -0.13 \\
\hline
\end{tabular}

Note: $A S I=$ Anxiety Sensitivity Index; PVAQ = Pain Vigilance and Awareness Questionnaire; $P C S=$ Pain Catastrophizing Scale.

\section{DISCUSSION}

The results from the first experiment did not support the hypothesis that high fearful individuals selectively pay attention towards pain-related words as compared to low fearful individuals. Two remarks with regard to the first experiment need further addressing. First, with respect to the presentation time of stimuli, a 'vigilance- 
avoidance' pattern has been proposed (Mathews, 1990; Mogg et al., 1987, Mogg \& Bradley, 1998), which states that only in individuals high on trait anxiety, attention is initially directed to threat but then detailed processing is avoided in an attempt to minimize discomfort. Such a pattern of selective attention might maintain anxiety states, whereas subsequent attentional avoidance would interfere with habituation or objective evaluation of them. This in turn would contribute to a failure of emotional processing (Foa \& Kozak, 1986; Rachman, 1980). Thus, the 'vigilance-avoidance' hypothesis predicts selective attention for threat-related stimuli at a short presentation time (500 ms.) whereas avoidance would take place at greater presentation times $(750 \mathrm{~ms}$. and $1000 \mathrm{~ms}$.) in individuals with high levels of trait anxiety. Experiment two further elaborated on selective attention to and avoidance of pain-related stimuli. More specifically, experiment two examined whether fear of pain scores in isolation or in interaction with presentation time, which was set at either $500 \mathrm{~ms} .750 \mathrm{~ms}$., or $1000 \mathrm{~ms}$. would be associated with selective attention to or avoidance of pain-related stimuli. We hypothesized that the interaction between fear of pain scores and presentation time would account for selective attention to or avoidance of pain-related stimuli. Especially in individuals high on pain-related fear, selective attention to pain-related stimuli would be present at short presentation times (500 ms.) whereas avoidance of pain-related stimuli would occur at greater presentation times (750 ms. and $1000 \mathrm{~ms}$.).

Second, the first experiment included only females. Previous studies have also predominantly relied on females (Keogh et al., 2001a; Keogh et al., 2001b; Keogh et al., 2002). Edwards and colleagues (2000) have shown that male chronic pain patients with high pain-related anxiety reported greater pain severity, greater interference of pain, and lower levels of daily activity than male patients with low anxiety. Moreover, this effect was not present among female chronic pain patients. On the basis of these results, one may predict that males high in pain-related fear may also selectively pay attention to pain-related words as measured with a dot-probe task. Experiment two included an equal number of males and females to examine the effects of gender on avoidance of pain-related stimuli.

\section{EXPERIMENT TWO}

\section{MATERIALS AND METHODS}

\section{Participants}

A total number of 120 healthy University students (60 males, 60 females; mean age = 20.1 years, $S D=2.1$ years, range $18-28$ years) voluntarily took part in experiment two. All participants verbally reported the absence of pain during the experiment and signed an informed consent in which part of the experimental protocol was described. Participants were unfamiliar with the visual dot-probe task. 


\section{Design}

In experiment two, the presentation time of words was varied (i.e., $500 \mathrm{~ms} ., 750 \mathrm{ms.}$., and $1000 \mathrm{~ms}$.). Accordingly, participants (males and females separately) were randomly allocated to one of the three conditions of word time presentation. This way, six equally sized groups $(n=20)$ were created (gender $x$ presentation time). In contrast to experiment one, participants were not further subdivided in fear groups based on their FPQ scores.

\section{Materials and procedure}

The visual dot-probe task was identical to the one used in the first experiment except for the presentation time of words, which was varied in the present experiment. Furthermore, after the dot-probe task, participants completed the same set of questionnaires as in the first experiment.

\section{Statistical analysis}

Similar to the first experiment, incorrect responses, outliers and reaction times deviating more than three standard deviations from the mean were removed from the analysis. A repeated measures analysis of variance was performed with bias indices (pain-related, social threat, and positive) as the within-subjects factor and presentation time (500 ms. vs. $750 \mathrm{~ms}$. vs. $1000 \mathrm{~ms}$.), gender (male vs. female) as between-subjects variables. FPQ scores were entered in the analysis as a continuous covariate. Furthermore, correlational analysis was used to examine the extent to which the bias index of pain was associated with trait variables as measured by questionnaires.

\section{RESULTS}

Table 2-15 presents mean bias indices (i.e. pain-related, social threat, and positive) for gender and presentation time. All groups (gender x presentation time) did not differ in the number of errors (1.6\%). Table 2-16 shows descriptive statistics of the questionnaire scores. Analysis of variance showed that females scored significantly higher on the FPQ $(p<0.001)$, ASI ( $p=0.024)$, PVAQ $(p=0.018)$, PCS $(p=0.044)$, but not on the Zung $(\mathrm{p}=0.412)$. Repeated measures analysis of variance showed no main effect of presentation time $(\mathrm{F}(2,108)=1.11, \mathrm{p}=0.33)$, gender $(\mathrm{F}(1,108)=.15, \mathrm{p}=0.70)$, and FPQ score $(\mathrm{F}(1,108)=0.60, \mathrm{p}=0.44)$. No significant two-way interactions between bias indices and presentation time $(\mathrm{F}(4,214)=1.81, \mathrm{p}=0.13)$, bias indices and gender $(\mathrm{F}(2,107)=.03, \mathrm{p}=0.97)$, and bias indices and FPQ score $(\mathrm{F}(2,107)=0.14, \mathrm{p}=0.87)$ were found. Further, no significant three-way interactions were found for bias indices, presentation time, gender $(\mathrm{F}(4,214)=1.49, \mathrm{p}=0.21)$, bias indices, gender, $\mathrm{FPQ}$ score $(\mathrm{F}(2,107)=0.008, \mathrm{p}=0.99)$, and bias indices, presentation time, FPQ score $(\mathrm{F}(4,214)=1.63, \mathrm{p}=0.17)$. The four-way interaction between bias indices, presentation time, gender, and FPQ score did not reach statistical significance $(F(4,214)=1.52$, 
$\mathrm{p}=0.20)$. Thus, the expected patterns of attention and avoidance in males and females high in pain-related fear as a function of presentation times was not found in experiment two. Table 2-17 depicts correlational analyses of the questionnaire scores and the bias indices. No significant correlation coefficients were found between selfreport measures and bias indices. Additionally, no significant correlation $(r=0.04$, $\mathrm{p}=0.68$ ) was found between medically related pain (a subscale of the FPQ) and the bias index for pain-related words in the present study (cf. Keogh et al., 2001b).

Table 2-15: Descriptive statistics of the bias indices for gender and presentation time (ms.) for experiment two.

\begin{tabular}{lcccccccc}
\hline Presentation time & \multicolumn{2}{c}{$500 \mathrm{~ms}}$. & \multicolumn{2}{c}{$750 \mathrm{~ms}}$. & \multicolumn{2}{c}{$1000 \mathrm{~ms}}$. & \multicolumn{2}{c}{ Total } \\
\hline & Mean & SD & Mean & SD & Mean & SD & Mean & SD \\
\cline { 2 - 9 } Males & & & & & & & & \\
Bias index (pain) & -3.14 & 31.12 & 4.66 & 23.92 & 3.23 & 24.56 & 1.58 & 26.50 \\
$\begin{array}{l}\text { Bias index (social } \\
\text { threat) }\end{array}$ & 9.59 & 17.92 & 8.92 & 15.17 & 4.76 & 23.59 & 7.76 & 19.01 \\
$\begin{array}{l}\text { Bias index (positive) } \\
\text { Females }\end{array}$ & -7.40 & 26.89 & -5.91 & 21.99 & 0.34 & 17.49 & -4.32 & 22.33 \\
$\begin{array}{l}\text { Bias index (pain) } \\
\text { Bias index (social }\end{array}$ & -2.20 & 27.95 & 2.54 & 25.98 & 0.85 & 28.59 & 0.40 & 27.13 \\
threat) & -6.78 & 34.49 & 3.83 & 26.42 & 2.90 & 20.58 & -0.02 & 27.71 \\
Bias index (positive) & 3.81 & 25.39 & 7.74 & 24.48 & 5.60 & 24.10 & 5.72 & 24.30 \\
\hline
\end{tabular}

Table 2-16: Descriptive statistics of the questionnaires for experiment two.

\begin{tabular}{lcccccc}
\hline & \multicolumn{2}{c}{ Females $(\mathrm{n}=60)$} & \multicolumn{2}{c}{ Males $(\mathrm{n}=60)$} & \multicolumn{2}{c}{ Total $(\mathrm{n}=120)$} \\
\hline Mean & SD & Mean & SD & Mean & SD \\
ASI & 84.33 & 12.01 & 70.94 & 14.87 & 77.63 & 15.05 \\
PVAQ & 29.67 & 8.28 & 27.02 & 5.85 & 28.34 & 7.26 \\
PCS & 39.48 & 11.70 & 34.50 & 11.06 & 36.99 & 11.61 \\
Zung & 16.67 & 8.85 & 13.58 & 7.74 & 15.13 & 8.42 \\
Age (years) & 37.60 & 6.80 & 35.73 & 6.63 & 36.67 & 6.75 \\
\hline
\end{tabular}

Note: $\mathrm{FPQ}=$ Fear of Pain Questionnaire; $\mathrm{ASI}=$ Anxiety Sensitivity Index; $\mathrm{PVAQ}=\mathrm{Pain}$ Vigilance and Awareness Questionnaire; PCS = Pain Catastrophizing Scale.

Table 2-17: Correlational analyses of questionnaires and bias indices for experiment two.

\begin{tabular}{lcccc}
\hline & ASI & PVAQ & PCS & Zung \\
\hline Bias index pain & -0.05 & -0.03 & 0.02 & -0.05 \\
Bias index social & 0.12 & -0.12 & -0.09 & 0.06 \\
Bias index positive & -0.02 & 0.04 & -0.04 & 0.04 \\
\hline
\end{tabular}

Note: $\mathrm{ASI}=$ Anxiety Sensitivity Index; PVAQ = Pain Vigilance and Awareness Questionnaire; PCS = Pain Catastrophizing Scale. 


\section{GENERAL DISCUSSION}

The present study consists of two successive experiments, in which a dot-probe paradigm was applied to investigate attentional bias for pain-related stimuli in healthy University students. The first experiment attempted to replicate a previous study (Keogh et al., 2001b) that found support for individuals scoring high on fear of pain to display attentional bias towards pain-related words as measured with a dotprobe task. In contrast to the results from the study by Keogh and colleagues (2001b), the first experiment failed to find evidence for attentional bias towards pain-related words in high fearful University students. It may be that the presentation time of the word stimuli (i.e., $500 \mathrm{~ms}$.) allows too much processing and does not capture initial attentional focus. A shorter presentation time could have produced selective attentional processing, especially in highly fearful individuals. However, a recent dot-probe study applied a presentation time of $300 \mathrm{~ms}$., but did not find evidence for selective attention towards pain-related stimuli but rather found orientation away from pain in pain-free individuals with low fear of pain (Keogh et al., 2003).

The second experiment was set up to examine whether selective attention to and avoidance of pain-related stimuli was influenced by presentation time of word pairs and to investigate the effects of gender on processing pain-related stimuli. The results from the second experiment did not demonstrate the expected patterns of attention and avoidance in males and females high in pain-related fear as a function of presentation times. Thus, no evidence for the proposed 'vigilance-avoidance' pattern of attentional bias was provided in experiment two.

An explanation for not finding selective attention for pain-related stimuli in highly fearful individuals might be due to the mean levels of pain-related fear in each of the fear groups. The Low Fear group and High Fear group in the Keogh et al. study (Keogh et al., 2001b) were defined as scores in the lower quartile $(<70)$ and upper quartile (>96) respectively. In experiment one of the present study, the Low Fear group and High Fear group were defined as scores in the lower quartile $(<62)$ and upper quartile $(>85)$. In the second experiment, fear of pain scores were analyzed as a continuous covariate but dividing these individuals in quartile scores showed that scores in the lower quartile were below 67 and the upper quartile above 89. Thus, in both experiments participants were generally less fearful with regard to pain when compared to the study by Keogh et al. (2001b). One may speculate that selective attention to pain-related words as measured with a dot-probe can only be found in individuals that show extreme levels of pain-related fear. The present study did not include these individuals.

An alternative explanation for the failure to reveal the hypothesized selective attentional processing in highly fearful individuals at a short presentation time (experiment one and two) and the postulated avoidance in especially individuals high in fear of pain at greater presentation times (experiment two), would be that relatively mild threat stimuli (i.e., word pairs) were used in the present study. These 
stimuli may not be salient enough to produce the expected attentional processing effects. Consequently, stimuli with a higher threat value should be included in future studies (Bradley et al., 1998). Further, one may argue that the use of pain-related measures (i.e., FPQ, PVAQ, PCS) in pain-free individuals may be limited simply because they are not in pain. It is clear that fear of pain in pain-free individuals is qualitatively different compared to fear experienced in pain patients. However, it should be noted that the validity of these pain measures in healthy groups has been well demonstrated (Crombez et al., 1998; McCracken, 1997; Roelofs et al., 2002b, Van Damme et al., 2002).

In conclusion, attentional bias for pain-related words as measured with the dot-probe is not a robust phenomenon in non-pain populations, which proves difficult to replicate. To date, only one study has investigated selective attention for pain-related words in chronic pain patients by means of a dot-probe task (Asmundson et al., 1997). In the anxiety literature, dot-probe studies have yielded more robust evidence for attentional bias (Asmundson \& Stein, 1994; Bryant \& Harvey, 1997; MacLeod et al., 1986; McNally, 1995). In this context, attentional bias is assumed to be related to personal significance of the words employed in the dotprobe task (Rachman, 1980). Future studies should apply the dot-probe paradigm with different stimuli categories such as words and photographs that are matched to an individual's concerns (Riemann \& McNally, 1995), to different (chronic) pain populations (e.g., chronic low back pain, fibromyalgia) so that its potential usefulness in these pain syndromes can be demonstrated.

\section{REFERENCES}

Asmundson, G. J. G., \& Stein, M. B. (1994). Selective processing of social threat in patients with generalized social phobia: Evaluation using a dot-probe paradigm. Journal of Anxiety Disorders, 8(2), 107-117.

Asmundson, G. J. G., Kuperos, J., \& Norton, G. (1997). Do patients with chronic pain selectively attend to pain-related information? Preliminary evidence for the mediating role of fear. Pain, 72, 27-32.

Beck, A. T. (1976). Cognitive therapy and the emotional disorders. New York, International University Press.

Beck, A. T., Emery, G., \& Greenberg, R. C. (1986). Anxiety disorders and phobias: a cognitive perspective. New York, Basic Books.

Beck, J. G, Freeman, J. B., Shipherd, J.C., Hamblen, J. L., \& Lackner, J. M. (2001). Specificity of Stroop interference in patients with pain and PTSD. Journal of Abnormal Psychology, 110(4), 536-543.

Boissevain, M. D. (1994). Information processing in chronic pain: the role of depression. Unpublished thesis. University of Western Ontario, Canada.

Bower, G. H. (1981). Mood and memory. American Psychologist, 36, 129-148. 
Bower, G. H. (1987). Commentary on mood and memory. Behaviour Research and Therapy, 25, 443-456.

Bradley, B. P., Mogg, K., \& Falle, S. J., \& Hamilton, L. R. (1998). Attentional bias for threatening facial expressions in anxiety: manipulation of stimulus duration. Cognition and Emotion, 12(6), 737-753.

Bryant, R. A., \& Harvey, A. G. (1997) Attentional bias in posttraumatic stress disorder. Journal of Traumatic Stress, 10(4), 635-644.

Crombez, G., \& Vlaeyen, J. W. S. (1998). The Pain Vigilance and Awareness Questionnaire: unpublished authorized Dutch translation.

Crombez, G., \& Vlaeyen, J. W. S. (1996). The Pain Catastrophizing Scale: unpublished authorized Dutch/Flemish translation.

Crombez, G., Eccleston, C., Baeyens, F., \& Eelen, P (1998). When somatic information threatens, catastrophic thinking enhances attentional interference. Pain, 75, 187-198.

Edwards, R., Auguston, E. M., \& Fillingim, R. (2000). Sex-specific effects of painrelated anxiety on adjustment to chronic pain. Clinical Journal of Pain, 16(1), 46-55.

Foa, E. G., \& Kozak, M. J. (1986). Emotional processing and fear: exposure to corrective information. Psychological Bulletin, 99, 20-35.

Keogh, E., Dillon, C., Georgiou, G., \& Hunt, C. (2001a). Selective attentional biases for physical-threat in physical anxiety sensitivity. Journal of Anxiety Disorders, 15, 299315.

Keogh, E., Ellery, D., Hunt, C., Hannent, I. (2001b). Selective attentional bias for painrelated stimuli amongst pain fearful individuals. Pain, 91, 91-100.

Keogh, E., \& Cochrane, M. (2002). Anxiety sensitivity, cognitive biases and the experience of pain. Journal of Pain, 3(4), 320-329.

Keogh, E., Thompson, T., \& Hannent, I. (2003). Selective attentional bias, conscious awareness and the fear of pain. Pain, 104, 85-91.

MacLeod, C., Mathews, A., \& Tata., P (1986). Attentional bias in emotional disorders. Journal of Abnormal Psychology, 95(1), 15-20.

Mathews, A. (1990). Why worry? The cognitive function of anxiety. Behaviour Research and Therapy, 30, 479-491.

McCracken, L. M. (1997). "Attention" to pain in persons with chronic pain: A behavioral approach. Behavior Therapy, 28(2), 271-284.

McNally, R. J. (1995). Automaticity and the anxiety disorders. Behaviour Research and Therapy, 33(7), 747-754.

McNeil, D. W., \& Rainwater, A. J. (1998). Development of the Fear of Pain Questionnaire-III. Journal of Behavior Medicine, 23, 389-410.

Melzack, R. (1975). The McGill Pain Questionnaire: Major properties and scoring methods. Pain, 1, 277-299.

Mogg, K., Bradley, B. P., \& Weinman, J. (1987). Memory bias in clinical anxiety. Journal of Abnormal Psychology, 96, 94-98.

Mogg, K., \& Bradley, B. P. (1998). A cognitive-motivational analysis of anxiety. Behaviour Research and Therapy, 36, 809-848. 
Pearce, J., \& Morley, S. (1989). An experimental investigation of the construct validity of the McGill Pain Questionnaire. Pain, 39, 115-121.

Pincus, T., Fraser, L., \& Pearce, S. (1998). Do chronic pain patients 'stroop' on pain stimuli? British Journal of Clinical Psychology, 37, 49-58.

Pincus, T., \& Morley, S. (2001). Cognitive-processing bias in chronic pain: A review and integration. Psychological Bulletin, 127, 599-617.

Rachman, S. Emotional processing. Behaviour Research and Therapy, 18, 51-60.

Reiss, S., Peterson, R. A., Gursky, D. M., \& McNally, R. J. (1986). Anxiety sensitivity, anxiety frequency and the prediction of fearfulness. Behaviour Research and Therapy, 24, 1-8.

Riemann, B. C., \& McNally, R. J. (1995). Cognitive processing of personally relevant information. Cognition and Emotion, 9, 325-340.

Roelofs, J., Peters, M. L., Zeegers, M. P. A., \& Vlaeyen, J. W. S. (2002a). The modified Stroop paradigm as a measure of selective attention towards pain-related stimuli amongst chronic pain patients: a meta-analysis. European Journal of Pain, 6, 273281.

Roelofs, J., Peters, M. L. , Muris, P., \& Vlaeyen J. W. S (2002b). Dutch version of the Pain Vigilance and Awareness Questionnaire: validity and reliability in a pain-free population. Behaviour Research and Therapy, 40, 1081-1090.

Snider, B. S., Asmundson, G. J., \& Wiese, K. C. (2000). Automatic and strategic processing of threat cues in patients with chronic pain: a modified stroop evaluation. Clinical Journal of Pain, 16(2), 144-154.

Sullivan, M. J. L., Bishop, S. R., \& Pivik, J. (1995). The pain catastrophizing scale: development and validation. Psychological Assessment, 7, 524-532.

Van Damme, S., Crombez, G., Bijtebier, P., Goubert, L., \& Van Houdenhove, B. A. (2002). Confirmatory factor analysis of the Pain Catastrophizing Scale: invariant factor structure across clinical and non-clinical populations. Pain, 96, 319-324.

Zung, W. W. K. A Self-rating depression scale. Archives of General Psychiatry, 12, 63-70. 


\title{
2.6 THE ROLE OF FEAR OF MOVEMENT AND (RE)INJURY IN SELECTIVE ATTENTIONAL PROCESSING IN CHRONIC LOW BACK PAIN PATIENTS*
}

\begin{abstract}
The present study investigated selective attentional processing by applying two dotprobe tasks (with words and pictures) to chronic low back pain patients and controls. Three outcome measures were used in this study: the conventional bias index, vigilance to threat, and difficulty to disengage from threat. The role of pain-related fear in selective attentional processing of pain stimuli was also examined. Results were analyzed with (repeated measures) analysis of variance. For the dot-probe task containing words, none of the outcome measures provided support for selective attentional processing. Pain-related fear as a trait measure (TSK) was not associated with selective attentional processing of word stimuli. For the dot-probe task containing pictorial stimuli, strong support for the difficulty to disengage from threat was found in both patients and controls. Scores on the TSK were positively associated with this difficulty to disengage from threat only in controls. Results from the dot-probe tasks are discussed and directions for future research are provided.
\end{abstract}

\footnotetext{
* Roelofs, J., Peters, M. L., Fassaert, T., \& Vlaeyen, J. W. S. The role of fear of movement and (re)injury in selective attentional processing in chronic low back pain patients (manuscript submitted).
} 


\section{INTRODUCTION}

The cognitive approach of psychopathology has mainly been inspired by the schema theory of Beck and Bower's network theory of the relation between cognition and emotion (Beck, 1976; Beck et al., 1986; Bower, 1981; Bower, 1987). Researchers adherent to the cognitive approach have begun studying biases in information processing, especially biases in attention, memory, and interpretation in emotional disorders (e.g., several anxiety disorders, depression, eating disorders). In the last decade, research in information processing has also been applied to the field of chronic pain. Although firm evidence for interpretation bias and memory bias has been reported, evidence for attentional bias appears to be less robust (see for an overview Pincus \& Morley, 2001).

A recent model of chronic (low back) pain has emphasized the importance of pain-related fear in attentional processing in chronic low back pain patients (Vlaeyen \& Linton, 2000). More specifically, higher levels of pain-related fear are associated with selective attentional processing of pain-related material. One influential paradigm for measuring selective attentional processing is the visual dot-probe paradigm. Generally, in a visual dot-probe paradigm, two words (an emotional word and a neutral word) appear on a computer screen above each other simultaneously. One of these two words is then replaced by a small dot of which the location has to be indicated (i.e., upper or lower). Compared to non-clinical subjects, patients with chronic pain are expected to respond faster to probes that replace pain words (e.g., congruent trials) than neutral words (e.g., incongruent trials). This speeding up of response times is considered indicative of selective attention towards pain-related words.

Only two published studies have used the dot-probe paradigm in patients with chronic pain (Asmundson et al., 1997; Dehghani et al., 2003). Asmundson et al. (1997) administered a dot-probe task containing both sensory and affective pain words selected from the McGill Pain Questionnaire (MPQ: Melzack, 1975) to 19 pain patients and 22 pain-free control subjects. No evidence was found for selective attentional processing in pain patients compared to pain-free controls. However, when pain patients were divided in two groups on the basis of their scores on a measure of anxiety sensitivity (i.e., the proneness to experience fear in response to anxiety-related sensations), those with low anxiety sensitivity shifted attention away from stimuli to pain, while those with high anxiety sensitivity responded similarly to dot probe regardless of the location of presentation. Dehghani et al. (2003) administered a dot-probe study containing sensory pain, affective pain, disability, and threat-related words, to a sample of 169 pain patients. Results provided support for selective attentional processing only on sensory pain words in all chronic pain patients, irrespective of the level of fear. However, this study did not include a control group so that it is unknown whether the observed bias might also have occurred within this group. 
Drawing on the findings of Asmundson et al. (1997), Keogh and colleagues conducted four dot-probe in undergraduates aimed to further investigate the role of anxiety sensitivity and fear of pain in selective attentional processing of pain-related stimuli. In the first study (Keogh et al., 2001a), a dot-probe task was applied to 51 participants who were selected on the basis as to whether they were high $(n=24)$ or low $(n=27)$ in their anxious concern for physical sensations, as tapped by a subscale of the Anxiety Sensitivity Index (ASI: Reiss et al., 1986). The results from this study indicated that those high in physical anxiety sensitivity selectively paid attention only to physical threat-related words, whereas those low in physical anxiety sensitivity were found to avoid such material. The second dot-probe study investigated whether individuals high in fear of pain would selectively attend to pain-related words compared to those who are low in fear of pain (Keogh et al., 2001b). Participants were allocated to a low, medium or high fear group, based on their scores on the Fear of Pain Questionnaire (FPQ: McNeil \& Rainwater, 1998). The results from this study showed that only the high fear of pain group selectively paid attention towards pain-related information, compared to those classified as medium and low in fear of pain. Importantly, no attentional effects were found for either social-threat words or positive words, indicating that the observed bias was specific to pain words. However, recent attempts to replicate these dot-probe effects have failed to find evidence for selective attention towards pain-related information as a function of anxiety sensitivity (Keogh et al., 2002) or fear of pain (Keogh et al., 2003; Roelofs et al., 2003). Taken together, the dot-probe paradigm as a measure of selective attention for pain-related stimuli has yielded inconsistent results in nonclinical populations and has been scarcely used in patients with chronic pain.

The dot-probe studies described so far have compared congruent trials with incongruent trials. Response times to congruent trials and incongruent trials can be summarized into a bias index. A positive score on this bias is interpreted as vigilance to threat and a negative score as avoidance from threat. An alternative way to analyze dot-probe effects is to compare threatening trials (i.e., congruent trials or incongruent trials) to neutral trials. More specifically, selective attentional processing can be examined by comparing response times on congruent trials to neutral trials (congruency effect) or by comparing incongruent trials to neutral trials (incongruency effect). A congruency effect can be interpreted as vigilance for threat, whereas an incongruency effect is indicative of a difficulty to disengage from threat (see Derryberry \& Reed, 2002; Koster et al., in press). It is important to note that vigilance to threat and difficulty to disengage are not mutually exclusive effects. It is possible that individuals both display vigilance to threat and experience difficulty to disengage from threat. Koster and co-workers examined both processes in a nonclinical sample of undergraduates by applying a pictorial dot-probe detection task (Koster et al., in press). Highly threatening, mildly threatening, and neutral pictures were selected from the International Affective Picture System (IAPS: Lang et al., 1988). Results supported the notion of difficulty to disengage from threat but could 
not provide evidence for vigilance to threat. Clearly, these results warrant replication in clinical samples.

The present study investigated selective attentional processing in chronic low back pain patients and pain-free controls by means of two dot-probe tasks containing words and pictures. The results from both dot-probe tasks were analyzed in three ways. First, consistent with previous research, a bias index was computed as a measure of vigilance to or avoidance from threat. Second, the presence of a congruency effect (faster response times on congruent trials compared to neutral trials) was examined as a measure of vigilance to threat. Third, the presence of a incongruency effect (retarded response times on incongruent trials compared to neutral trials) was examined as a measure of difficulty to disengage from threat. The dot-probe task containing word stimuli applied different categories of pain words (e.g., sensory pain, affective pain, movement-related words, and injury-related words). A category of social threat words was also included to examine whether a general negativity bias was present. For the dot-probe task with pictorial stimuli, idiosyncratically chosen stimuli were used as they may reflect patients' concerns (e.g., possible harmful consequences of movements) more precisely. In line with the study from Koster and colleagues, we examined the extent to which support for the vigilance to threat and difficulty to disengage from threat could be obtained in CLBP patients and pain-free controls. Furthermore, the extent to which self-reported fear of movement and (re)injury was associated with vigilance to threat (congruency effect) and an increased difficulty to disengage from threat stimuli (incongruency effect) was also examined. A positive association between fear of movement and (re)injury and vigilance to threat was hypothesized. Similarly, a positive association was expected between fear of movement and (re)injury and difficulty to disengage from threat. Both effects were expected to be most profoundly present in CLBP patients.

\section{METHODS AND MATERIALS}

\section{Participants}

Forty-nine CLBP patients (mean age $=51.1 \mathrm{SD}=9.8$; range: 29 to 64 ) and forty-four pain-free controls (mean age $=45.6$; $\mathrm{SD}=13.0$; range: 18 to 65 ) participated in the present study. CLBP patients were recruited from the pain unit of the Maastricht University Hospital and via a Dutch patients' association for back pain patients. Controls were recruited from local advertisements. As the effect of pain-related fear (TSK) was investigated, a sufficient spread of TSK scores in patients and controls was strived for during recruitment. The CLBP sample comprised 23 males and 26 females and the sample of controls consisted of 18 males and 26 females. Current pain intensity was rated on a $100-\mathrm{mm}$. visual analogue scale. Mean pain intensity of the CLBP sample was $60.1 \mathrm{~mm}$. $(\mathrm{SD}=26.3)$ and pain intensity of the controls was 3.6 $\mathrm{mm}$. ( $\mathrm{SD}=8.6 \mathrm{~mm}$.). With respect to the level of disability, mean total score of the CLBP sample on the Quebec Back Pain Disability Scale (Kopec et al., 1995) was 55.4 
$(\mathrm{SD}=17.5)$ indicating that this sample was substantially disabled. Further, mean pain duration in the CLBP sample was 144 months (SD = 121 months, range: 18 to 420 months). All participants signed a written informed consent in which part of the experimental design was explained. Participants were unfamiliar with the hypothesis and the dot-probe and body-scanning tasks. Full debriefing took place immediately after the end of the experiment, and results from the experiment were sent by mail after completion of the study. The experimental protocol was approved by the Ethics Committee of the Academic Hospital Maastricht/Maastricht University.

\section{Dot-probe task with words}

The first task was a dot-probe task in which words were used as stimuli. Three word categories were used: pain words (affective pain and sensory pain words), injury and movement related words, and social threat words. The last category was included to examine whether a general negativity bias was present rather than a specific painrelated bias. All words were closely matched with a neutral word for the number of syllabi, word length, and word-frequency. Each word category contained ten words. More specifically, five affective and five sensory pain words were used as well as five movement and five injury related words. Further, ten social threat words were used as well as ten filler word pairs. Thus, five word groups were created (i.e., affective pain, sensory pain, movement, injury, social threat) and each word pair was presented four times (target upper or lower, dot upper or lower) producing a total number of $40 \times 4=160$ trials. These five word groups were taken into analyses.

\section{Dot-probe task with pictures}

The second task was a dot-probe task that included pictorial stimuli. All participants were shown a series of 96 pictures from the PHODA (Photograph series of Daily Activities: Kugler et al., 1999), and were asked to rate how threatening performance of the activity depicted on the picture would be for their back. The five pictures evaluated with the highest level of back injury (target) and five with the lowest level of back injury (control) were selected for each individual. Thus, the pictorial stimuli were selected idiosyncratically. Each trial consisted of two pictures (target vs. control) that were randomly combined for each individual. Each picture pair was presented four times (target upper or lower, dot upper or lower). Ten fillers were selected from the International Affective Picture System (Lang et al., 1988) on the basis of low arousal and neutral affect and were also presented four times each. Thus, a total number of 40 trials were administered to each participant. All pictures were resized to the same dimensions, 3 inches high $\times 3$ inches wide.

\section{Self-report measure of fear of movement/(re)injury}

After completing the three tasks, all participants completed the Tampa Scale for Kinesiophobia (TSK: Miller et al., 1991; Dutch version: Goubert et al., 2004). The TSK is a self-report measure of fear of movement and fear of (re)injury and has 17 items to 
be rated on a 4-point Likert scale. Anchors are labeled 'strongly agree' and 'strongly disagree'.

\section{Procedures}

In both visual dot-probe tasks, participants were initially presented with a fixation cross in the centre of a 17-inch color monitor for 500 milliseconds. Two words/pictures were presented, one above and one below this fixation point. After an additional 500 milliseconds, a dot replaced either the upper or the lower word/picture. Participants were instructed to press the ' $q$ ' key on the keyboard if the dot appeared in the upper position and the ' $z$ ' key if it appeared in the lower position. The dot appeared as soon as a response has been made or after 3000 milliseconds. The next trial began after 500 milliseconds. The order of both dot-probe tasks was counterbalanced and both tasks were controlled by E-prime version 1.0 (Psychology Software Tools, Inc.).

\section{Data reduction and statistical analyses}

\section{Dot-probe task with words}

Incorrect responses and outliers (defined as a reaction time deviating more than 3 standard deviations from each individual mean reaction time) were excluded. Mean reaction times for the four different presentation conditions were computed for each word group (i.e., affective pain, sensory pain, movement, injury, social threat). In line with previous dot-probe studies, a bias index was computed according to the following formula: Bias index $=(($ eudl - eldl $)+($ eldu - eudu $)) / 2$, where e $=$ emotional word, $d=d o t, u=$ upper position, and $1=$ lower position (see Keogh et al., 2001b). A positive score on the bias-index is indicative of vigilance to threat, whereas a negative score on the bias-index reflects a bias away (e.g., avoidance) from such material. A repeated measures analysis of variance was performed with bias index (affective pain, sensory pain, movement, injury, and social threat) as the withingroups factor and group (patients vs. controls) as the between-groups factor.

Vigilance to threat was alternatively analyzed by comparing response times on congruent trials to response times on neutral trials (i.e., congruency effect). Before conducting the actual analyses, mean response times were computed for both congruent conditions (e.g., pain word and dot upper position, pain word and dot lower position). A repeated measures analysis of variance was conducted with word category (affective pain, sensory pain, movement, injury, social threat, and neutral) as the within-groups factor and group (patients vs. controls) as the between groups factor. In a similar way, difficulty to disengage from threat was examined by using incongruent trials instead of congruent trials (i.e., incongruency effect).

Following this, the effect of fear of movement and (re)injury (TSK) on the bias index, the congruency effect (vigilance to threat), and the incongruency effect (difficulty to disengage from threat) was examined. It should be noted that mean TSK scores of patients were substantially higher compared to controls and the 
normal distributions of TSK scores from patients and controls showed only a limited overlap. Therefore, effects of pain-related fear (TSK) were analyzed in patients and controls separately by means of analysis of variance. The expected effect of TSK was expected to be most profound in CLBP patients.

\section{Dot-probe task with pictures}

Similar to the dot-probe task with words, a bias index was computed after removing incorrect responses and outliers. A positive score on this index is indicative of vigilance to threat hypothesis whereas a negative score on the bias index is indicative of avoidance. A univariate analysis of variance was used to examine whether the magnitude of the bias index (dependent variable) differed between patients and controls. Vigilance to threat was alternatively analyzed by comparing response times on congruent trials to reaction times on neutral trials (i.e., congruency effect). Mean response times were computed for both congruent conditions (e.g., threatening picture and dot upper position, threatening picture and dot lower position) and compared by means of a repeated measures analysis of variance with picture type as the within-groups factor (congruent vs. neutral trials) and group (patients vs. controls) as the between groups factor. In a similar way, difficulty to disengage from threat was examined by using incongruent trials instead of congruent trials (i.e., incongruency effect).

The effect of fear of movement and (re)injury (TSK) on the bias index, the congruency effect (vigilance to threat), and the incongruency effect (difficulty to disengage from threat) was examined by means of analysis of variance for patients and controls separately. This effect of TSK was expected to be most profound in CLBP patients.

\section{RESULTS}

Before addressing the main results of the study, one remark has to be made. Due to technical problems with the dot-probe task with words, 31 CLBP patients and 40 controls actually completed this task. A total number of 49 CLBP patients and 42 controls participated in the dot-probe task with pictures. Table 2-18 depicts descriptive statistics of the TSK and mean response times for the bias indices on both words and pictures. After removing missing values and outliers, mean response times on congruent trials, incongruent trials, and neutral trials for all word categories and the pictorial dot-probe were computed and are presented in table 2-19. As can be seen in table 2-19, response times to pictorial stimuli were generally slower compared to response times of word stimuli in both CLBP patients and controls. 
Table 2-18: Descriptive statistics of the questionnaires and bias indices.

\begin{tabular}{lcccc}
\hline & \multicolumn{2}{c}{ CLBP patients } & \multicolumn{2}{c}{ Controls } \\
\hline & Mean & SD & Mean & SD \\
\hline TSK & 40.1 & 10.0 & 31.2 & 6.0 \\
Bias index sensory words & 13.1 & 68.8 & -8.2 & 45.8 \\
Bias index affective words & -2.0 & 57.0 & 5.3 & 40.6 \\
Bias index injury words & 4.6 & 50.3 & -7.7 & 55.8 \\
Bias index movement words & 4.4 & 69.1 & -0.3 & 56.7 \\
Bias index social words & 11.5 & 39.0 & 6.1 & 25.9 \\
Bias index pictures & 10.2 & 69.2 & 7.9 & 45.5 \\
\hline
\end{tabular}

Note: TSK = Tampa Scale for Kinesiophobia.

Table 2-19: Response times on congruent, incongruent, and neutral trials for CLBP patients and controls.

\begin{tabular}{lccc}
\hline & $\begin{array}{c}\text { Congruent trials } \\
\text { Mean (SD) }\end{array}$ & $\begin{array}{c}\text { Incongruent trials } \\
\text { Mean (SD) }\end{array}$ & $\begin{array}{c}\text { Neutral trials } \\
\text { Mean (SD) }\end{array}$ \\
\hline CLBP patients & $662(123)$ & $676(132)$ & - \\
\hline Sensory words & $659(126)$ & $660(124)$ & - \\
Affective words & $671(139)$ & $678(142)$ & - \\
Injury words & $647(124)$ & $653(125)$ & - \\
Movement words & $658(127)$ & $670(133)$ & - \\
Social words & $746(154)$ & $742(163)$ & $659(119)$ \\
Pictures & - & - & $705(146)$ \\
Neutral words & - & $577(113)$ & - \\
Neutral pictures & & $580(129)$ & - \\
\hline Controls & $573(125)$ & $570(130)$ & - \\
\hline Sensory words & $575(129)$ & $573(133)$ & - \\
Affective words & $578(135)$ & $582(127)$ & - \\
Injury words & $574(132)$ & $665(164)$ & - \\
Movement words & $576(126)$ & - & - \\
Social words & $705(146)$ & $(150)$ & - \\
Pictures & - & & - \\
Neutral words & - & & - \\
Neutral pictures & & & - \\
\hline Note: Response & & & - \\
\hline
\end{tabular}

Note: Response times in milliseconds.

Dot-probe task with words

For the analysis using the bias index, no main effect of group $(F(1,69)=2.19, p=0.14)$ or bias index $(\mathrm{F}(4,66)=0.66, \mathrm{p}=0.63)$ was found. Further, the expected interaction between bias index and group $(\mathrm{F}(4,66)=0.56, \mathrm{p}=0.69)$ was non-significant. Univariate analyses of variance showed no effect of group on each of the specific 
biases (all p-values above 0.05). The analysis of the congruency effect (vigilance to threat), by comparing reaction times on congruent trials to neutral trials yielded a significant main effect of group $(\mathrm{F}(1,70)=8.30, \mathrm{p}=0.005)$, patients responding generally slower than controls. No significant effect of congruency was found is isolation $(F(5,66)=0.97, p=0.44)$ or in interaction with group $(F(5,66)=0.63, p=0.63)$. For the analysis of the incongruency effect (difficulty to disengage from threat), a significant main effect of group was found $(\mathrm{F}(1,70)=9.80, \mathrm{p}=0.003)$, patients having slower response times than controls. No significant effect of incongruency was found in isolation $(\mathrm{F}(5,66)=1.79, \mathrm{p}=0.13)$ or in interaction with group $(\mathrm{F}(5,66)=1.12$, $\mathrm{p}=0.36)$.

In the CLBP sample, no main effect of TSK was found $(F(1,29)=2.94, p=0.10)$ and no interaction effect between TSK and bias index was found $(F(4,26)=1.34$, $p=0.28)$. In the control group, neither the main effect of $\operatorname{TSK}(F(1,38)=0.78, p=0.38)$ nor the interaction between TSK and bias index reached statistical significance $(\mathrm{F}(4,35)=1.23, \mathrm{p}=0.32)$. For the analysis of the congruency effect (vigilance to threat) in CLBP patients, no significant main effect of TSK was found $(F(1,29)=0.84$, $\mathrm{p}=0.37)$. The interaction between TSK and congruency was also non-significant $(\mathrm{F}(5,25)=1.59, \mathrm{p}=0.20)$. For controls, no main effect of TSK was found $(\mathrm{F}(1,38)=1.22, \mathrm{p}=0.28)$. Further, no significant interaction between TSK and congruency was found $(F(5,25)=2.46, p=0.053)$. For the analysis of the incongruency effect (difficulty to disengage from threat) in CLBP patients, no significant main effect of TSK was found $(\mathrm{F}(1,29)=1.41, \mathrm{p}=0.25)$. The interaction between TSK and incongruency was non-significant $(\mathrm{F}(5,25)=1.57, \mathrm{p}=0.21)$. For controls, no main effect of TSK was found $(\mathrm{F}(1,38)=1.16, \mathrm{p}=0.29)$. No statistically significant interaction between TSK and incongruency was found $(F(5,34)=1.11, p=0.37)$.

\section{Dot-probe task with pictures}

Mean ratings of PHODA pictures that were selected as the least threatening were rated $3.8(\mathrm{SD}=5.5)$ by controls and $9.1(\mathrm{SD}=14.2)$ by CLBP patients on a scale of $0-100$. Ratings of pictures that were selected as most threatening were $60.7(\mathrm{SD}=34.3)$ for controls and $77.5(\mathrm{SD}=26.3)$ for CLBP patients. A repeated measures analysis of variance with picture category (high vs. low threat) as within-subjects factor and group (patients vs. controls) as between-subjects factor showed a significant effect of picture category $(\mathrm{F}(1,91)=452.0, \mathrm{p}<0.001)$, and a significant main effect of group $(\mathrm{F}(1,91)=8.90, \mathrm{p}=0.004)$, indicating that low threat pictures were scored as significantly less threatening than high threat pictures and that CLBP patients scored all activities as more threatening to the back than control participants.

For the analysis using the bias index, no main effect of group was found $(F[1,89]=0.03, p=0.85)$. For the analysis of the congruency effect (vigilance to threat) comparing congruent trials with neutral trials in CLBP patients, a significant main effect of group was found $(\mathrm{F}(1,90)=6.59, \mathrm{p}=0.012)$, patients showing retarded response times compared to controls. Further, a significant effect of congruency was found $(\mathrm{F}(1,90)=15.65, \mathrm{p}<0.001)$. Response times on neutral trials were faster 
compared to congruent trials. A significant interaction between congruency and group was found $(\mathrm{F}(1,90)=4.22, \mathrm{p}=0.043)$. In clarifying this interaction, differences between response times on neutral trials and congruent trials were found to be greater in patients than in controls (see table 2-19). For the incongruency effect (difficulty to disengage from threat), a significant main effect of group was found $(\mathrm{F}(1,90)=6.59, \mathrm{p}=0.012)$, patients showing retarded response times compared to controls. Further, a significant effect of incongruency was found $(F(1,90)=47.65$, $\mathrm{p}<0.001)$. The interaction between incongruency and group was also significant $(\mathrm{F}(1,90)=8.05, \mathrm{p}=0.006)$. The difference between response times on neutral trials and congruent trials was greater in patients compared to controls.

With respect to the effect of pain-related fear (TSK), no main effect of TSK was found on the bias index in the CLBP sample $(F(1,47)=0.29, p=0.59)$ and the control group $(\mathrm{F}(1,40)=0.01, \mathrm{p}=0.92)$. For the analysis of the congruency effect (vigilance to threat) in CLBP patients, no significant main effect of TSK was found $(F(1,47)=0.07$, $\mathrm{p}=0.80)$. The interaction between congruency and TSK was also non-significant $(\mathrm{F}(1,47)=2.91, \mathrm{p}=0.10)$. In controls, a significant main effect of TSK was found $(\mathrm{F}(1,40)=10.02, \mathrm{p}=0.003)$, showing a positive association between TSK scores and response times. The interaction between congruency and TSK was non-significant $(\mathrm{F}(1,40)=0.65, \mathrm{p}=0.42)$. For the analysis of the incongruency effect (difficulty to disengage from threat) in CLBP patients, no main effect of TSK was found $(F(1,29)=$ 1.39, $\mathrm{p}=0.25)$. The interaction between incongruency and TSK was also nonsignificant $(F(1,29)=0.24, p=0.63)$. In controls, no main effect of TSK was found $(\mathrm{F}(1,36)=3.12, \mathrm{p}=0.08)$. A significant interaction between incongruency and TSK was found $(\mathrm{F}(1,36)=6.44, \mathrm{p}=0.016)$. The (positive) association between TSK and response times was greater for incongruent trials compared to neutral trials.

\section{DISCUSSION}

The present study was set up to investigate selective attentional processing in CLBP patients by means of two visual dot-probe tasks containing either words or pictures. Three outcome measures were used, the conventional bias index, vigilance to threat (expressed in terms of a congruency effect, which compares mean response times to congruent trials and neutral trials), and difficulty to disengage from threat (reflected by a incongruency effect, which compares mean response times to incongruent trials and neutral trials). The effect of fear of movement and (re)injury (TSK) on the bias index, the congruency effect (vigilance to threat), and the incongruency effect (difficulty to disengage from threat) was examined by means of analysis of variance for patients and controls separately.

For the dot-probe task with word stimuli, no overall effect of selective attentional processing was found on the bias index between CLBP patients and controls. Higher scores on the TSK were neither associated with selective attentional processing as reflected by the bias index in both groups. With respect to the 
congruency effect (vigilance to threat), differences in response times on congruent trials and neutral trials in interaction with group were not significant, providing no support for vigilance to threat. Pain-related fear (TSK) was not significantly associated with the congruency effect neither in CLBP patients nor in controls. For the incongruency effect (difficulty to disengage from threat), differences in response times on incongruent trials and neutral trials in interaction with group was not significant, providing no support for the notion of difficulty to disengage from threat. Pain-related fear (TSK) showed no significant association with the incongruency effect in either CLBP patients or controls. Thus, for word stimuli no evidence for selective attentional processing was found on the bias index, the congruency effect, and the incongruency effect. One explanation for not finding support for selective attentional processing on different categories of pain words may be that words are not salient enough for CLBP patients in our study to produce the expected effect. It is possible that selective attentional processing could have been demonstrated when pain words were chosen idiosyncratically as was the case in the pictorial dot-probe task.

The present study offered a first attempt to examine selective attentional processing in chronic low back pain patients by means of a dot-probe task containing pictorial stimuli. Although the pictorial stimuli were selected idiosyncratically, CLBP patients did not display more selective attentional processing than controls as measured on the bias index. Scores on the TSK were not associated with selective attentional processing as tapped by the bias index in both groups. It is important to note that there was sufficient contrast between pictures representing low and high levels of threat of back injury in patients and controls. With respect to the congruency effect (vigilance to threat), a significant interaction between congruency (i.e., differences between response times on congruent trials and neutral trials) and group was found. In contrast to our expectation, response times on neutral trials were faster compared to congruent trials. This pattern of results was most strongly present in CLBP patients. These results do not provide support for the vigilance to threat hypothesis. Instead, it appears that CLBP patients, and to a lesser extent controls, have difficulty to disengage from threat pictures in the case of congruent trials. The congruency effect was not influenced by scores on the TSK in either of the groups. For the incongruency effect (difficulty to disengage from threat), a significant interaction between incongruency (i.e., differences between response times on incongruent trials and neutral trials) and group was found. Response times on neutral trials were faster compared to incongruent trials. This pattern of results was most strongly present in chronic low back pain patients. These results provide support for the difficulty to disengage from threat hypothesis. The incongruency effect was not influenced by TSK scores in either of the groups.

The results from this study provide evidence that chronic low back pain patients have more difficulty to disengage from threat than controls as measured with a visual dot-probe task containing pictorial stimuli. These results are in line with, and extend, the results found in the study from Koster and colleagues (in 
press). In that study, pictorial stimuli were presented in a visual dot-probe task applied to undergraduates. Difficulty to disengage was only found when incongruent trials were compared to neutral trials. The present study provided support for the notion of difficulty to disengage from threat in CLBP patients and to a lesser extent in controls. Importantly, the difficulty to disengage from threat did not only occur on incongruent trials but also on congruent trials in comparison with neutral trials. Thus, difficulty to disengage from threat occurred on all threatening trials (i.e., congruent trials and incongruent trials). Furthermore, we expected that difficulty to disengage from threat would show a positive association with scores on the TSK but this relationship was only present in controls and not in CLBP patients.

A difficulty issue with the dot-probe task is the measurement of attentional engagement as the threat stimulus has already been presented when a response to the dot probe has to be made. According to the notion of vigilance for threat, faster response times on congruent trials are expected compared to neutral trials. This would indicate that individuals preferentially hold their attention at the threatening location. It does, however, not show facilitated engagement with the threat stimulus. An alternative paradigm for studying engagement with the threat stimulus and difficulty to disengage from the threat is a recently developed cueing paradigm (see Van Damme et al., 2002). In this study, pain targets and tone targets had to be detected as quickly and as accurately as possible. The target stimuli were preceded by pain cues, tone cues, or neutral cues. This paradigm allows for investigating engagement effects. That is, attention to pain may be determined by the threat value of the pain cue predicting faster detection times of on pain targets when preceded by a pain cue compared to a neutral cue. Results showed that when a cue correctly primed a target, attention was optimally engaged in the identification of the target irrespective of the threatening context of the cue or target. Thus, there was no specific facilitated engagement effect for pain cues predicting pain targets. However, when pain was cued and did not occur, there was retardation in disengagement from the pain cue. This retardation was particularly present in individuals high in catastrophic thinking (Van Damme et al., 2002). Thus, two different paradigms (dot-probe and cueing paradigms) have now provided evidence that selective attentional processing is accounted for by difficulty to disengage from threat rather than vigilance to threat. However, there is no consistent evidence of the effect of pain-related fear or catastrophizing on the difficulty to disengage from threat.

Taken together, the present study examined selective attentional processing by applying two dot-probe tasks (with words and pictures) to chronic low back pain patients and controls. Support for the difficulty to disengage from threat hypothesis was found only on the pictorial dot-probe task. Difficulty to disengage from threat in CLBP patients and to a lesser extent in controls may be clinically relevant as it may result in prolonged anxious states. In this context, Koster and colleagues (in press) pointed out that limited attention is given to fear-disconfirming information, active coping strategies, and that feelings of uncontrollability may develop from the experience of being unable to shift attention away from threat An important 
implication of this study is that pictures may be more sensitive for demonstrating difficulty to disengage from threat than word stimuli. Consequently, future research with the dot-probe task and other paradigms for examining selective attentional processing should not only rely on word stimuli but also on pictorial stimuli. Future research should not only analyze results from dot-probe studies in terms of the conventional bias index but also by unraveling dot-probe effects in different components such as vigilance for threat and difficulty to disengage from threat as they appear to be more sensitive and more robust indicators of selective attentional processing than the bias index.

\section{ACKNOWLEDGEMENTS}

We would like to thank Julia Townshend at University of Sussex for providing the pictorial dot-probe program written in E-Prime, that we used in adapted form in the present study.

\section{REFERENCES}

Asmundson, G. J. G., Kuperos, J., \& Norton, G. (1997). Do patients with chronic pain selectively pay attention to pain-related information? Preliminary evidence for the mediating role of fear. Pain, 72, 27-32.

Beck, A. T. (1976). Cognitive therapy and the emotional disorders. New York: International University Press.

Beck, A. T., Emery, G., \& Greenberg, R. C. (1986). Anxiety disorders and phobias: A cognitive perspective. New York: Basic Books.

Bower, G. H. (1981). Mood and memory. American Psychologist, 36, 129-148.

Bower, G. H. (1987). Commentary on mood and memory. Behavioural Research and Therapy, 25, 443-456.

Dehghani, M., Sharpe, L., \& Nicholas, M. K. (2003). Selective attention to pain-related information in chronic musculoskeletal pain patients. Pain, 105, 37-46.

Derryberry, D., \& Reed, M. A. (2002). Anxiety-related attentional biases and their regulation by attentional control. Journal of Abnormal Psychology, 111, 225-236.

Goubert, L., Crombez, G., Van Damme, S., Vlaeyen, J. W. S., Bijttebier, P., \& Roelofs, J. (2004). Confirmatory factor analysis of the Tampa Scale for Kinesiophobia: invariant two-factor model across low back pain patients and fibromyalgia patients. Clinical Journal of Pain, 20(2), 103-110.

Keogh, E., Dillon, C., Georgiou, G., \& Hunt, C. (2001a). Selective attentional biases for physical-threat in physical anxiety sensitivity. Journal of Anxiety Disorders, 15, 299315.

Keogh, E., Ellery, D., Hunt, C., \& Hannent, I. (2001b). Selective attentional bias for pain-related stimuli amongst pain fearful individuals. Pain, 91, 91-100. 
Keogh, E., \& Cochrane, M. (2002). Anxiety sensitivity, cognitive biases and the experience of pain. Journal of Pain, 3, 320-329.

Keogh, E., Thompson, T., \& Hannent, I. (2003). Selective attentional bias, conscious awareness and the fear of pain. Pain, 104, 85-91.

Kopec, J. A., Esdaile, J. M., Abrahamowicz, M., Abenhaim, L., Woodauphinee, S., Lamping, D. L., \& Williams, J. I. (1995). The Quebec Back Pain Disability Scale. Measurement properties. Spine, 20(3), 341-352.

Koster, E., Crombez, G., Verschuere, B., De Houwer, J. Selective attention to threat in the dot probe paradigm: differentiating vigilance and difficulty to disengage. Behaviour Research and Therapy (in press).

Kugler, K., Wijn, J., Geilen, M., De Jong, J., \& Vlaeyen, J. W. S. (1999). The Photograph series of Daily Activities (PHODA). CD-rom version 1.0. Institute for Rehabilitation Research and School for Physiotherapy Heerlen, The Netherlands.

Lang, P. J., Öhman, A., \& Vaitl, D. (1988). The international affective picture system. Center for Research in Psychophysiology, University of Florida, Gainesville, Fla.

McNeil, D. W., \& Rainwater, A. J. (1998). Development of the Fear of Pain Questionnaire-III. Journal of Behavioral Medicine, 23, 389-410.

Melzack, R. (1975). The McGill Pain Questionnaire: Major properties and scoring methods. Pain, 1, 277-299.

Miller, R. P., Kori, S. H., \& Todd, D. D. (1991). The Tampa Scale. Unpublished report. Tampa, FL.

Pincus, T., \& Morley, S. (2001). Cognitive-processing bias in chronic pain: a review and integration. Psychological Bulletin, 127, 599-617.

Reiss, S., Peterson, R. A., Gursky, D. M., McNally, R. J. (1986). Anxiety sensitivity, anxiety frequency and the prediction of fearfulness. Behaviour Research and Therapy, 24, 1-8.

Roelofs, J., Peters, M. L., Zijden van der M., Thielen, F. G. J. M., \& Vlaeyen, J. W. S. (2003). Selective attention and avoidance of pain-related stimuli: a dot-probe evaluation in a pain-free population. Journal of Pain, 4(6), 322-328.

Van Damme, S., Crombez, G., \& Eccleston, C. (2002). Retarded disengagement from pain cues: the effects of pain catastrophizing and pain expectancy. Pain, 100, 111118.

Vlaeyen, J. W. S., \& Linton S. J. (2000). Fear-avoidance and its consequences in chronic musculoskeletal pain: a state of the art. Pain, 85, 317-332. 


\section{CHAPTER 3}

The influence of a manipulation of attentional focus on the pain experience 



\title{
3.1 DOES FEAR OF PAIN MODERATE THE EFFECTS OF ATTENTIONAL FOCUSING AND DISTRACTION ON COLD PRESSOR PAIN IN PAIN FREE INDIVIDUALS?*
}

\begin{abstract}
The present study investigated the influence of attentional focusing and distraction on pain tolerance and self-reported pain intensity in healthy female University students high and low in pain-related fear. Pain was induced experimentally by means of a cold-pressor test. Results showed that individuals high in pain-related fear had greater pain intensity ratings than those low in pain-related fear. Only for self-reported pain intensity, a trend towards significance was found for the interaction between fear group, cold pressor administration, and condition. A post hoc analysis showed that distraction produced reduced pain ratings only in low fearful individuals while attentional focusing led to reduced pain ratings only in high fearful individuals. Self-report measures of anxiety sensitivity, pain vigilance, and pain catastrophizing were positively associated with pain intensity but, except for pain vigilance, no meaningful association was found between these measures and pain tolerance. Implications of the results and directions for future research are provided.
\end{abstract}

\footnotetext{
* Roelofs, J., Peters, M. L., Van der Zijden, M., \& Vlaeyen, J. W. S. Does fear of pain moderate the effects of attentional focusing and distraction on cold pressor pain in pain-free individuals. (manuscript accepted for publication in revised form, The Journal of Pain).
} 


\section{INTRODUCTION}

Anxiety and attentional focus are widely believed to be involved in the experience of pain (James \& Hardardottir, 2002; Janssen et al., 1998). Experimental studies have shown that the influence of anxiety on pain experience is equivocal. Anxiety may increase (Cornwall \& Donderi, 1988; Dougher et al., 1987) decrease (Malow, 1981), or have no specific effect on pain experience (Arntz et al., 1991; Weisenberg et al., 1984). In the light of these inconsistencies, it may be important to account for attentional focus (distraction from versus attention to pain) in the relation between anxiety and pain.

In accounting for the effects of distraction on pain, the limited-capacity model of attention has been proposed as a major theoretical framework (see McCaul \& Malott, 1984). According to this model, human information processing has a limited capacity, which means that allocation of attentional resources to one modality limits the resources available to other modalities (Kahneman, 1973). Thus, an attentiondemanding task limits the capacity to process pain, resulting in reduced sensitivity to pain (Farthing et al., 1984). A number of studies have shown that pain is perceived as less intense when individuals are distracted from pain (e.g., Arntz et al., 1994; James \& Hardardottir, 2002; Johnson \& Petrie, 1997; McCaul \& Malott, 1984; Miron et al., 1989; Rode et al., 2001; Williams \& Kinney, 1991), although contrary results have also been reported. For example, McCaul et al. (1992) conducted a series of experiments in which they administered the cold-pressor test while participants were engaged in cognitive tasks (distraction tasks). These tasks varied in the amount of attention required to successfully perform the task. Across all experiments, the distraction task did not affect participants' responses to the cold-pressor pain. McCaul and coworkers concluded that distraction does not always work, but emphasized that distraction is only effective when the task is emotionally relevant. Emotion-relevant stimuli automatically capture attention more strongly than neutral stimuli (Eccleston \& Crombez, 1999; Robinson, 1998). Taken together, empirical evidence generally suggests that pain is perceived as less intense when individuals are distracted from the pain. These effects of distraction on pain perception appear to be especially strong when emotionally charged.

With regard to the effects of focused attention on pain, studies have produced less clearly interpretable results (Villemure \& Bushnell, 2002). Levine et al. (1982) asked post-operative patients to rate their pain more or less often. Those patients who rated their pain more often also reported more pain, indicating that attentional focusing on pain enhances the pain perception. However, Keogh et al. (2000) showed that in an experimental situation healthy males reported lower cold-pressor sensations when they were instructed to attend to pain than when they were instructed to avoid it. Females did not show this effect. In a further study, Keogh and Herdenfeldt (2002) found that males exhibit less negative pain responses when instructed to focus on the sensory component of pain, whereas emotional focusing 
was found to increase the affective pain experience only of females. Thus, empirical evidence for the notion that attentional focusing is associated with an increased pain perception is equivocal. Directing attention to pain may even lead to a reduced pain experience.

Several factors may account for the effects of distraction on the pain experience, and particularly, for the inconsistent results reported in studies that have investigated the influence of attentional focusing on the pain experience. McCaul and Haugtvedt (1982) have suggested that attentional focusing on and distraction from painful sensations may be differentially effective depending on the duration of the painful stimulus. More specifically, during a four-minute cold-pressor trial, distraction reduced distress early in the trial but attention to sensations appeared to be a superior strategy for the last two minutes of the trial. Cioffi and Holloway (1993) found no influence of instructions to monitor pain, suppress pain or distraction from pain during the cold-pressor trial, but found that monitoring resulted in a faster recovery from pain, whereas suppression seemed to slow the recovery process.

Personality characteristics may also account for the influence of distraction and attentional focusing on the pain experience. Heyneman et al. (1990) found that catastrophizing individuals trained with self-instruction (monitoring and manipulating thoughts related to the painful stimulus) had greater pain tolerance times while distraction produced greater tolerance times only in non-catastrophizing individuals. Yet another important personality characteristic that may influence the perception of pain is anxiety sensitivity. Keogh and Mansoor (2001) found that high anxiety sensitive women reported greater pain when instructed to avoid (ignore the cold water sensations and to think about something else) rather than to focus on cold pressor pain. Finally, Hadjistavropoulos et al. (2000) found that distraction from pain was not effective in reducing pain in health anxious patients while undergoing active physical therapy. Health-anxious chronic pain patients reported less anxiety and pain when they focused on the physical sensations. Thus, the effects of distraction and attentional focus on pain may be dependent on catastrophizing and anxiety in relation to bodily sensations (i.e., anxiety sensitivity). It may be proposed that high pain fearful individuals are less easily distracted from pain because for them pain constitutes a highly relevant signal. They may profit more from coping techniques that enable them to monitor and re-evaluate the pain signal more closely.

The present study examines the role of pain-related fear as a possible moderator of the effects of attentional focusing and distraction on pain perception induced by means of the cold-pressor test. James and Hardardottir (2002) found that pain tolerance was greater when participants were distracted and in individuals scoring low on trait anxiety compared to those scoring high on trait anxiety. Further, attention and anxiety interacted such that low-anxiety participants were most pain tolerant, and high-anxiety participants were least pain tolerant, only in the control condition in which no attempts were made to influence attentional focus. With respect to the distraction manipulation, pain tolerance increased in low anxiety participants more than in high anxiety participants, but this difference did not reach 
statistical significance. However, it should be noted that a general trait anxiety measure was used rather than a measure of pain-related fear. In the present study, we investigated the effects of a manipulation of attention on pain tolerance and pain intensity in high and low pain fearful individuals. For this purpose, healthy female individuals were selected on the basis of their scores on the Fear of Pain Questionnaire (FPQ; McNeil \& Rainwater, 1998), resulting in a high-fear and a lowfear group. We hypothesized that the effects of an attention manipulation (attentional focusing versus distraction) depends on the level of fear of pain. More specifically, in line with previous studies (Hadjistavropoulos et al., 2000; Heyneman et al., 1990), we predicted that distraction increases pain tolerance and decreases pain intensity ratings only in low fearful individuals. Attentional focusing was predicted to increase pain tolerance and decrease pain intensity ratings in highly fearful individuals. We further analyzed to what extent self-report measures such as anxiety sensitivity and catastrophizing were associated with pain tolerance and pain intensity.

\section{MATERIALS AND METHODS}

\section{Participants}

Ninety female participants were drawn from a pool of 272 undergraduates from Maastricht University, who completed the Fear of Pain Questionnaire (FPQ; [25]). We selected females only as the pool of undergraduates was predominantly female $(83 \%$ was female). These individuals scored either in the top ('high fear') or the bottom ('low fear') fourth of the distribution of the FPQ scores. Mean age of the ninety participants was 19.9 years (SD = 1.7 years, range 18 - 26). All participants signed a written informed consent in which the experimental design was explained. The experimental protocol was in accordance with the requirements of the Maastricht University Ethics Committee. Participants were unfamiliar with the hypotheses and the cold-pressor test. Further, all participants verbally reported the absence of pain. Full debriefing took place immediately after the end of the experiment and results from the experiment were sent to participants by mail after completion of the study.

\section{Design}

On the basis of the scores on the Fear of Pain Questionnaire, participants were allocated to either the low fear group $(n=45)$ or the high fear group $(n=45)$. Within each fear group, all individuals were randomly (block-randomization) assigned to one of three conditions (attentional focusing, distraction, and undirected attention), leaving a total number of six equally sized conditions (Group [high fear vs. low fear] $x$ Condition [attentional focusing, distraction, and undirected attention]). The coldpressor test was administered twice. The first test served as a baseline measure. Between the first (CPT1) and the second (CPT2) cold pressor test administrations, the focus of attention was manipulated. 


\section{Manipulation}

In the attentional focusing condition, individuals were instructed to concentrate their attention on the sensations in their hand from the moment they immersed their hand in the cold water. To emphasize the importance of closely attending to the sensations in the hand, participants were requested afterwards to write down in detail what they had felt during the cold-pressor test. In the distraction condition, participants completed a tone-discriminating task in which high $(1000 \mathrm{~Hz})$ and low $(250 \mathrm{~Hz})$ tones were presented. Participants were instructed to respond to whether a high or low tone was presented with their remaining hand on a response-box. The importance of speed and accuracy was emphasized. In the undirected attention condition, no attempt was made to manipulate attentional focus.

\section{Measures and cold-pressor apparatus}

All participants completed a Dutch version of the Fear of Pain Questionnaire (FPQ; McNeil \& Rainwater, 1998), which is a 30-item self-report measure of pain-related fear. Individuals have to indicate the amount of fear associated with painful experiences (e.g., "Breaking your arm") on a 5-point scale anchored 'not at all' and 'extreme'. Total scores range from 30 to 150 . At the beginning of the experiment all participants completed a set of Dutch questionnaires. The Pain Vigilance and Awareness Questionnaire (PVAQ; McCracken, 1997; Roelofs et al., 2003) is a 16-item self-report measure of pain vigilance (e.g., "I focus on sensations of pain") rated on a 6-point scale anchored 'never' and 'always'. PVAQ total scores range from 0 to 80. The Anxiety Sensitivity Index (ASI; Reiss et al., 1986) is a 16-item questionnaire that measures an individual's fear of the symptoms of anxiety (e.g., "Unusual body sensations scare $\left.\mathrm{me}^{\prime \prime}\right)$, rated on a five-point scale anchored 'very little' to 'very much'. ASI total scores can range from 0 to 64. The Pain Catastrophizing Scale (PCS; (Sullivan et al., 1995; Van Damme et al., 2002) is a self-report measure of catastrophizing related to pain and contains 13 items rated on a 4-point scale (e.g., "I keep thinking how badly I want the pain to stop"). Anchors are labeled 'not at all' and 'all the time'. PCS total scores range between 0 and 52. The Zung (Zung, 1965) is a self-report measure of depression consisting of 20 items (e.g., "I feel downhearted, blue and sad") rated on a 4-point scale anchored 'none or little of the time' to 'most or all of the time'. Zung total scores range from 0 to 60 . For all self-report measures, higher scores reflect higher levels of the underlying characteristic that the questionnaire presumes to measure.

The cold-pressor test required participants to immerse their non-dominant hand to the wrist into a container filled with ice water, which was circulated by a fish-tank aerator. The ice water was maintained at a temperature of 0.5 degrees Celsius ( \pm 0.3 degrees) by placing ice into the water. At the start of the experiment, ice was scooped out the container to prevent contact with the participants' skin. The water temperature was recorded for each participant but could not be read by the participant. Participants kept their hand immersed in the water as long as possible and pain tolerance, defined as the time elapsed (in seconds) between immersion and 
withdrawal of the hand from the cold water, was assessed. For this purpose, one electrode was placed on the hand and was connected to a Picker-Schwartzer EDA48 skin conductance measurement device. Another electrode was in direct contact with the water. The time interval from immersion (begin conductance) to withdrawal (end of conductance) was recorded with an accuracy of one millisecond. Pain intensity during the cold pressor task was measured directly after CPT1 and CPT2 on a 100$\mathrm{mm}$. visual analogue scale with anchors labeled 'not painful at all' and 'the worse pain I ever experienced'.

\section{Procedure}

Participants were invited for a laboratory session during which they sat alone in a sound-attenuated room. A female assistant supervised the experiment from an adjoining room. Participants were told that the primary task was to examine how women would react on coldness in general and no reference was made to the words 'pain' and 'pain experience'. After screening for medical problems, participants completed a set of questionnaires (see measures). After this, participants immersed their non-dominant hand in a bucket of room-temperature water for one minute. This way, baseline temperature of the hand's skin was standardized for each individual. At the start of CPT1, participants were asked to keep their hand immersed in the water as long as possible. No specific instructions were given to participants. Pain tolerance time was assessed and pain intensity was measured. The maximum pain tolerance time was 15 minutes of which participants were unaware. The rationale for the ceiling time of 15 minutes was that participants had to be unaware of any ceiling time as the cold pressor test was administered twice. The experiment continued when the pain and other sensations in the hand fully disappeared, which took a few minutes. Consequently, the time interval between CPT1 and CPT2 was not the same for each individual. Before the administration of CPT2, participants were instructed to either focus on pain (attentional focus condition) or to complete a tone-discriminating task (distraction condition). One group did not receive any instructions. After manipulating the focus of attention, the second cold-pressor test was administered. Similar to the first administration, the non-dominant hand was immersed and tolerance time and pain intensity were measured.

\section{Statistical analysis}

Accuracy on the tone-discriminating task (distraction condition) was analyzed by comparing mean reaction times and degree of errors made between high and low fearful individuals.

With respect to the main analyses, tolerance times and pain intensity ratings for CPT1 and CPT2 were available as well as scores on the self-report measures for each individual. The effect of attentional focusing and distraction on pain tolerance and pain intensity was examined by means of repeated measures analysis of variance, which was performed separately for pain tolerance and pain intensity. Cold 
pressor test administration (CPT1 vs. CPT2), in which tolerance time and pain intensity were repeatedly measured, was the within-subject factor and fear group (high fear vs. low fear) and condition (attentional focusing, distraction, and undirected attention) were the between-subjects factors. Correlational analyses were conducted between the self-report measures and pain tolerance time and selfreported pain intensity. Alpha was set to 0.05 .

\section{RESULTS}

Before addressing the main results of the present study, two remarks are in order. First, a total number of eight females were excluded from the experiment and were replaced. One participant had used drugs prior to the experiment and seven reached the maximum pain tolerance time for either the first or the second cold pressor task. Second, no differences were found on mean reaction times $(F(1,29)=0.001, p=0.995)$ and degree of errors $(\mathrm{F}(1,29)=1.063, \mathrm{p}=0.311)$ of the tone-discriminating task between low and high fearful individuals, indicating that the level of pain-related fear did not influence the accuracy of the distraction task.

\section{Effects of manipulation of attention in high fear and low fear individuals}

Table 3-1 presents mean tolerance times and mean self-reported pain intensity for CPT1 and CPT2, fear group (high fear vs. low fear), and condition (attentional focusing, distraction, and undirected attention). With respect to pain tolerance time, repeated measures analysis of variance showed no main effect of fear group $(\mathrm{F}(1,84)$ $=0.707, \mathrm{p}=0.403)$. Tolerance time for CPT1 did not differ from tolerance time at CPT2 $(\mathrm{F}(1,84)=0.175, \mathrm{p}=0.677)$. No significant interaction between fear group $\mathrm{X}$ cold pressor administration $(\mathrm{F}(1,84)=0.256, \mathrm{p}=0.614)$ or cold pressor administration $\mathrm{x}$ condition $(\mathrm{F}(2,84)=0.874, \mathrm{p}=0.421)$ was found. The critical interaction between fear group $\mathrm{x}$ cold pressor administration $\mathrm{x}$ condition $(\mathrm{F}(2,84)=0.233, \mathrm{p}=0.793)$ was statistically non-significant.

For pain intensity, a significant main effect of fear group was found $(\mathrm{F}(1,84)=4.327, \mathrm{p}=0.041)$. Thus, highly fearful individuals experienced the cold pressor pain as more intense compared to those who are low in fear. In addition, the pain experience for CPT1 was experienced as more intense as compared to CPT2 in both fear groups $(\mathrm{F}(1,84)=5.224, \mathrm{p}=0.025)$. No significant interaction between fear group $\mathrm{x}$ cold pressor administration $(\mathrm{F}(1,84)=0.251, \mathrm{p}=0.618)$ or cold pressor administration $\mathrm{x}$ condition $(\mathrm{F}(2,84)=0.428, \mathrm{p}=0.653)$ was found. The critical interaction of fear group $x$ cold pressor administration $x$ condition $(F(2,84)=2.640$, $\mathrm{p}=0.077$ ) did not reach statistical significance but showed a trend. Figure 3-1 clarifies this trend. While distraction led to reduced pain ratings in low fearful individuals, high fearful individuals showed a slight increase in pain ratings when distracted from the pain. Conversely, attentional focusing increased pain ratings in low fearful and decreased pain ratings in high fearful individuals. In the control condition, when 
no specific instructions were given, both groups showed a similar decrease in pain ratings. When in a post hoc analysis only the two conditions for which we had formulated specific hypotheses are compared (i.e., distraction vs. attentional focusing), the interaction between fear group $x$ cold pressor administration $x$ condition in fact did reach statistical significance $(F(1,56)=4.462, p=0.039)$.

Table 3-1: Mean tolerance times and mean self-reported pain intensity for CPT1 and CPT2, fear group (high fear vs. low fear), and condition (attentional focusing, distraction, and undirected attention).

\begin{tabular}{|c|c|c|c|c|c|c|c|c|c|}
\hline & & \multicolumn{4}{|c|}{ Pain tolerance (seconds) } & \multicolumn{4}{|c|}{ Pain intensity (mm. on VAS) } \\
\hline & & \multicolumn{2}{|l|}{ CPT1 } & \multicolumn{2}{|l|}{ СРТ2 } & \multicolumn{2}{|l|}{ CPT1 } & \multicolumn{2}{|l|}{ CPT2 } \\
\hline & & Mean & SD & Mean & SD & Mean & SD & Mean & SD \\
\hline \multirow{4}{*}{$\begin{array}{l}\text { Low fear group } \\
(n=45)\end{array}$} & Attentional focus $(n=15)$ & 171 & 181 & 179 & 163 & 29 & 19 & 31 & 20 \\
\hline & Distraction $(n=15)$ & 208 & 224 & 233 & 245 & 28 & 12 & 21 & 19 \\
\hline & Undirected $(n=15)$ & 179 & 161 & 168 & 106 & 35 & 24 & 31 & 23 \\
\hline & Total $(n=45)$ & 185 & 187 & 193 & 178 & 31 & 19 & 27 & 21 \\
\hline \multirow{4}{*}{$\begin{array}{l}\text { High fear group } \\
(n=45)\end{array}$} & Attentional focus $(n=15)$ & 89 & 80 & 95 & 93 & 38 & 20 & 34 & 24 \\
\hline & Distraction $(n=15)$ & 195 & 244 & 197 & 192 & 43 & 19 & 44 & 22 \\
\hline & Undirected $(n=15)$ & 193 & 177 & 182 & 177 & 36 & 21 & 33 & 24 \\
\hline & Total $(n=45)$ & 159 & 183 & 158 & 163 & 39 & 20 & 37 & 23 \\
\hline
\end{tabular}

Consistent with previous findings with respect to the effects of catastrophizing and anxiety sensitivity on the pain experience, we analyzed whether pain catastrophizing and anxiety sensitivity influenced pain tolerance and pain intensity in interaction or in combination with the attention manipulation. Neither pain catastrophizing nor anxiety sensitivity in isolation, or in interaction with the attention manipulation influenced, cold pressor tolerance time or pain intensity (data not shown).

\section{Self-report measures}

Table 3-2 shows descriptive statistics for the self-report measures. Table 3-3 depicts Pearson correlation coefficients between the self-report measures and tolerance time and pain intensity. Anxiety sensitivity, pain catastrophizing, and self-reported pain vigilance were positively associated with pain intensity, but not with pain tolerance. No meaningful association was found between tolerance time and pain intensity (i.e., Pearson correlation coefficient was -0.04 and -0.12 for the first and second cold pressor test administration respectively). 
Figure 3-1: Visual representation of the effects of attentional focusing, distraction, and undirected attention on pain intensity for individuals low and high in pain-related fear

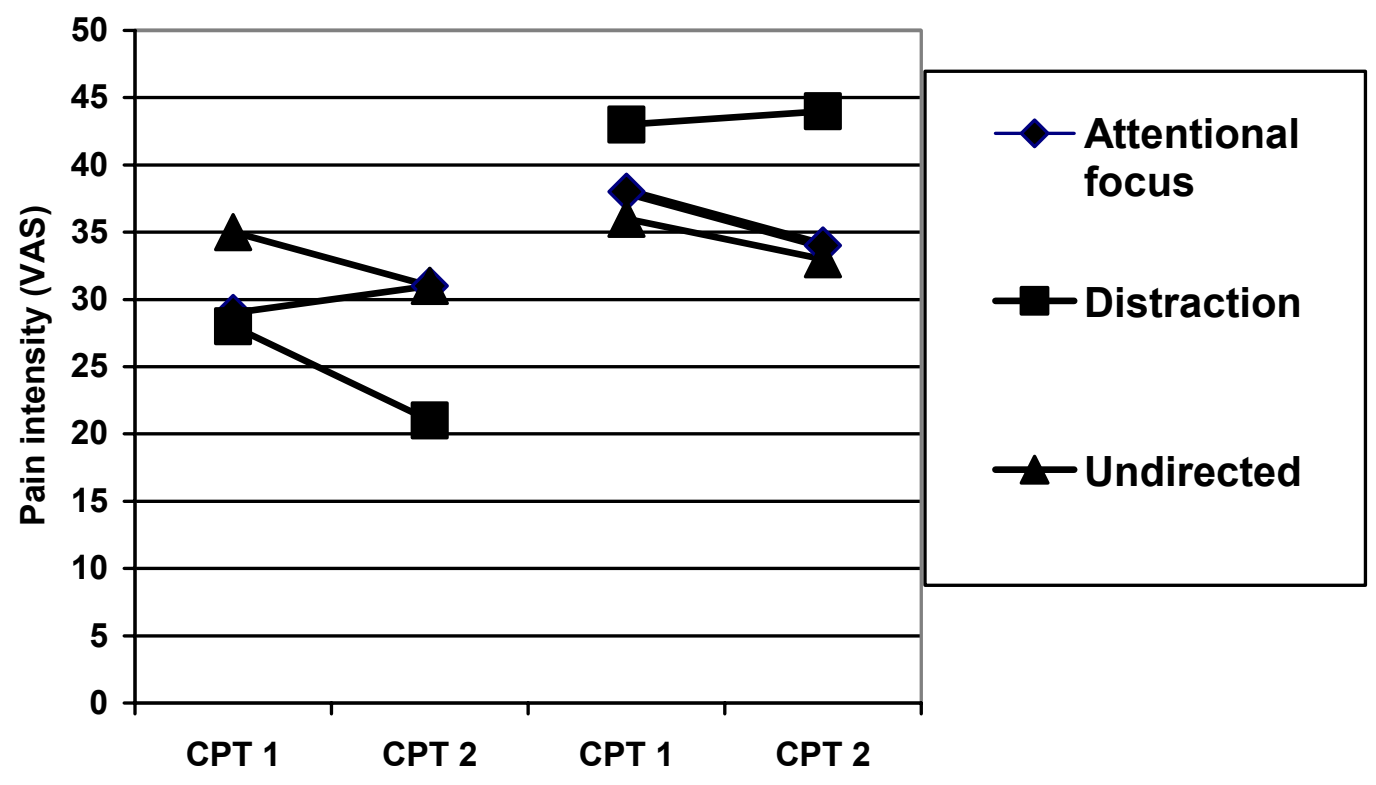

Low fear High fear

Table 3-2: Descriptive statistics of the questionnaire scores.

\begin{tabular}{lcccc}
\hline & \multicolumn{2}{c}{ Low fear group $(\mathrm{n}=45)$} & \multicolumn{2}{c}{ High fear group $(\mathrm{n}=45)$} \\
\hline FPQ & Mean & SD & Mean & SD \\
ASI & 53.3 & 6.6 & 94.8 & 8.0 \\
PVAQ & 24.9 & 5.4 & 30.3 & 8.3 \\
PCS & 30.3 & 9.8 & 37.4 & 11.2 \\
Zung & 9.8 & 5.7 & 15.4 & 8.2 \\
Age (in years) & 34.1 & 6.5 & 35.9 & 7.0 \\
\hline
\end{tabular}

Note: FPQ = Fear of Pain Questionnaire; $A S I=$ Anxiety Sensitivity Index; PVAQ = Pain Vigilance and Awareness Questionnaire; PCS = Pain Catastrophizing Scale.

Table 3-3: Pearson correlation coefficients between self-report measures and pain tolerance and pain intensity.

\begin{tabular}{lcccc}
\hline & \multicolumn{2}{c}{ Pain tolerance } & \multicolumn{2}{c}{ Pain intensity } \\
\hline ASI & CPT1 & CPT2 & CPT1 & CPT2 \\
PVAQ & 0.08 & -0.01 & $0.29^{* *}$ & $0.26^{*}$ \\
PCS & -0.13 & $-0.22^{*}$ & $0.30^{* *}$ & $0.32^{* *}$ \\
Zung & -0.003 & -0.08 & $0.30^{* *}$ & $0.32^{* *}$ \\
\hline
\end{tabular}

Note: $\mathrm{ASI}=$ Anxiety Sensitivity Index; PVAQ = Pain Vigilance and Awareness Questionnaire; PCS = Pain Catastrophizing Scale. CPT1 refers to the first cold-pressor test and CPT2 to the second cold-pressor test administration. ${ }^{*} p<0.05,{ }^{* *} p<0.01$. 


\section{DISCUSSION}

The present study investigated whether attentional focusing and distraction have differential effects on the pain tolerance and pain intensity for pain free individuals high and low in pain-related fear. Pain was induced experimentally by means of a cold-pressor test. More specifically, we hypothesized that distraction would increase pain tolerance and decrease pain intensity ratings only in low fearful individuals. Attentional focusing was predicted to increase pain tolerance and decrease pain intensity ratings in highly fearful individuals. In line with previous research, the results from the present study showed that highly fearful individuals rated their pain as more intense compared to those who are low in pain-related fear. For pain intensity, a trend towards a significant interaction was found between fear group, cold pressor administration, and condition. A post hoc analysis showed that distraction led to a significant decrease of pain ratings in low fearful individuals compared to high fearful individuals while attentional focusing led to a significant decrease in pain ratings in high fearful individuals compared to low fearful individuals. No effects of distraction and attentional focusing on pain tolerance were found. Thus, the hypotheses were confirmed only for self-reported pain intensity. One explanation for the failure to find the expected effects on pain tolerance is the relatively large spread of tolerance times (see table 3-1) across fear groups and conditions. Comparing our results with results form the study conducted by James and Hardardottir (2002) may be somewhat difficult. We found moderating effects of fear of pain on distraction and attentional focusing only with respect to self-reported pain intensity, but not for pain tolerance. Unfortunately, James and Hardardottir (2002) did not measure pain intensity. However, they found that individuals low in trait anxiety did show increased pain tolerance while those who were high in trait anxiety were least pain tolerant but only in the control condition, in which no manipulation of attention took place. Two important characteristics may account for the differences in results between both studies. First, James and Hardardottir applied an upper pain tolerance time limit of 2 minutes for inclusion. Our study applied an upper limit of 15 minutes for inclusion. Thus, it is possible that their sample was a selected group of merely pain-sensitive individuals. Second, we used the Fear of Pain Questionnaire to select individuals who are low and high in pain-related fear. This measure may be more specific and susceptible to manipulation of attention in cold pressor pain a measure of trait anxiety as used by James and Hardardottir (2002).

Distraction may be especially useful for low fearful individuals, as they are more capable of distracting from pain compared to high fearful individuals (Hadjistavropoulos et al., 2000). In contrast, high fearful individuals may profit from attentional focusing. The beneficial effects of attentional focusing on pain in high fearful individuals can be accounted for by Leventhal and Everhart's parallel processing model (Leventhal \& Everhart, 1979). According to this model, people who attend to physical sensations of the pain experience rather than to the aversiveness 
may find it less noxious as attentional focusing may prevent the activation of distress schemata. In other words, paying attention to the sensory aspects of pain may distract individuals from the experienced distress. In the present study, participants in the attentional focusing condition were indeed instructed to closely attend to sensory aspects of the pain experience. A clinical implication of these results may be that learning to focus on the sensory aspects of the pain experience rather than on aspects of distress may be beneficial for high fearful individuals. In attending to a threatening stimulus, high fearful individuals may initially shift attention to the fearful stimulus but then experience difficulty in disengaging from it (Eysenck, 1992; Mogg \& Bradley, 1998; Wells \& Matthews, 1994). If these processes also play a role in highly fearful chronic pain patients than this may implicate that in addition to reducing fear in these individuals, focusing on the sensory aspects of the pain stimulus can also be helpful in reducing the impact of the pain experience.

We also examined to what extent self-report measures such as anxiety sensitivity and catastrophizing were associated with pain tolerance and pain intensity. Self-report measures were modestly associated with pain intensity but, except for pain vigilance as measured with the PVAQ, none of the measures were meaningfully associated with pain tolerance. Most self-report measures directly refer to pain experiences themselves, but do not refer to behavioral responses to pain, which is reflected by tolerance time. Surprisingly, tolerance time was not meaningfully associated with self-reported pain intensity.

The present study has some limitations. First, gender differences in pain responding could not be assessed as the present study relied exclusively on females. Future research should also include males. Second, statistical power could be insufficient due to the small sample size. More specifically, when examining main effects such as fear of pain, there may be sufficient power to assess any differences. However, when assessing interactive effects ( 2 fear levels x 3 conditions), power may be insufficient to detect substantial differences. Third, self-report measures were completed before CPT1. It is possible that the content of these measures may have sensitized the participants toward reactivity to the cold pressor pain. Finally, no attempt was made to determine the menstrual cycle phase and the use of oral contraceptives. Although all women reported the absence of pain before the start of the experiment, it is possible that the hormonal status may have biased the pain experience (Hellstroem \& Anderberg, 2003). Second, the female experimenter was not blinded to the attention manipulation and experimenter effects and expectations cannot be ruled out. Despite these limitations, the results of the present study may have important implications for clinical interventions based on the use of distraction. Further, a simple paradigm has been used which is easy to replicate and provides a suitable degree of control. Future research should examine whether the effects of distraction and attentional focusing could be replicated in (chronic) pain populations. In chronic pain, pain-related fear may be a vulnerability factor for developing chronic pain problems (James \& Hardardottir, 2002; Vlaeyen \& Linton, 2000). 


\section{REFERENCES}

Arntz, A., Dreessen, L., \& Merckelbach, H. (1991). Attention, not anxiety, influences pain. Behaviour Research and Therapy, 29, 41-50.

Arntz, A., Dreessen, L., \& De Jong, P. (1994). The influence of anxiety on pain: attentional and attributional mediators. Pain, 56, 307-314.

Cioffi, D., \& Holloway, J. (1993). Delayed costs of suppressed pain. Journal of Personality and Social Psychology, 64, 274-282.

Cornwall, A., \& Donderi, D. C. (1988). The effect of experimentally induced anxiety of the experience of pressure pain. Pain, 35, 105-113.

Dougher, M. J., Goldstein, D., \& Leight, K. A. (1987). Induced anxiety and pain. Journal of Anxiety Disorders, 1, 259-264.

Eccleston, C., \& Crombez, G. (1999). Pain demands attention: a cognitive-affective model of the interruptive function of pain. Psychological Bulletin, 125, 356-366.

Eysenck, M. W. (1992). Anxiety: the cognitive perspective. Hillsdale: Lawrence Erlbaum Associates.

Farthing, G. W., Venturino, M., \& Brown, S. W. (1984). Suggestion and distraction in the control of pain: test of two hypothesis. Journal of Abnormal Psychology, 93, 266-276.

Hadjistavropoulos, H. D., Hadjistavropoulos, T., \& Quine, A. (2000). Health anxiety moderates the effects of distraction versus attention to pain. Behaviour Research and Therapy, 38, 425-438.

Hellstroem, B., \& Anderberg, U. M. (2003). Pain perception across the menstrual cycle phases in women with chronic pain. Perceptual and Motor Skills, 96(1), 201211.

Heyneman, N. E., Fremouw, W. J., Gano, D., Kirkland, F., \& Heiden, L. (1990). Individual differences and the effectiveness of different coping strategies for pain. Cognitive Therapy and Research, 14(1), 63-77.

James, J. E., \& Hardardottir, D. (2002). Influence of attention focus and trait anxiety on tolerance of acute pain. British Journal of Health Psychology, 7, 149-162.

Janssen, S. A., Arntz, A., \& Bouts, S. (1998). Anxiety and pain: epinephrine-induced hyperalgesia and attentional influences. Pain, 76, 309-16.

Johnson, M. H., \& Petrie, S. M. (1997). The effects of distraction on exercise and coldpressor tolerance for chronic low back pain sufferers. Pain, 69, 43-48.

Kahneman, D. (1973). Attention and effort. Prentice Hall, Englewood Cliffs NJ.

Keogh, E., Hatton, K., \& Ellery, D. (2000). Avoidance versus focused attention and the perception of pain: differential effects for men and women. Pain, 85, 225-230.

Keogh, E., \& Herdenfeldt, M. (2002). Gender, coping and the perception of pain. Pain, 97, 195-201.

Keogh, E., \& Mansoor, L. (2001). Investigating the effects of anxiety sensitivity and coping on the perception of cold pressor pain in healthy women. European Journal of Pain, 5(1), 11-22. 
Leventhal, H., \& Everhart, D. (1979). Emotion, pain, and physical illness. In Izard CE (Ed.), Emotions in personality and psychopathology. Plenum Press, New York, pp. 263-299.

Levine, J. D., Gordon, N. C., Smith, R., \& Fields, H. L. (1982). Post-operative pain: effect of extent of injury and attention. Brain Research, 234, 500-504.

McCaul, K. D., \& Haugtvedt, C. (1982). Attention, distraction, and cold-pressor pain. Journal of Personality and Social Psychology, 43(1), 154-162.

McCaul, K. D., \& Malott, J. M. (1984). Distraction and coping with pain. Psychological Bulletin, 95, 516-533.

McCaul, K. D., Monson, N., \& Maki, R. H. (1992). Does distraction reduce painproduced distress among college students? Health Psychology, 11, 210-217.

McCracken, L. M. (1997). "Attention" to pain in persons with chronic pain: a behavioral approach. Behavior Therapy, 28(2), 271-284.

McNeil, D. W., \& Rainwater, A. J. (1998). Development of the Fear of Pain Questionnaire-III. Journal of Behavioral Medicine, 23, 389-410.

Malow, R. W. (1981). The effects of induced anxiety on pain perception: a signal detection analysis. Pain, 11, 397-405.

Miron, D., Duncan, G. H., \& Bushnell, M. C. (1989). Effects of attention on the intensity and unpleasantness of thermal pain. Pain, 39, 345-352.

Mogg, K., \& Bradley, B. P. (1998). A cognitive-motivational analysis of anxiety. Behaviour Research and Therapy, 36, 809-848.

Reiss, S., Peterson, R. A., Gursky, D. M., \& McNally, R. J. (1986). Anxiety sensitivity, anxiety frequency and the prediction of fearfulness. Behaviour Research and Therapy, 24, 1-8.

Robinson, M. D. (1998). Running from William James' bear: a review of preattentive mechanisms and their contributions to emotional experience. Cognition and Emotion, 12, 697-713.

Rode, S., Salkovskis, P. M., \& Jack T. (2001). An experimental study of attention, labeling and memory in people suffering from chronic pain. Pain, 94, 193-203.

Roelofs, J., Peters, M. L., McCracken, L. M., \& Vlaeyen, J. W. S. (2003). The Pain Vigilance and Awareness Questionnaire (PVAQ): further psychometric evaluation in fibromyalgia and other chronic pain syndromes. Pain, 101, 299-306.

Sullivan, M. J. L., Bishop, S. R., \& Pivik, J. (1995). The Pain Catastrophizing Scale: development and validation. Psychological Assessment, 7, 524-532.

Van Damme, S., Crombez, G., Bijttebier, P., Goubert, L., \& Van Houdenhove, B. (2002). A confirmatory factor analysis of the Pain Catastrophizing Scale: Invariant factor structure across clinical and non-clinical populations. Pain, 96(3), 319-324.

Villemure, C., \& Bushnell, M. C. (2002). Cognitive modulation of pain: how do attention and emotion influence pain processing? Pain, 95, 195-199.

Vlaeyen, J. W. S., \& Linton, S. J. (2000). Fear-avoidance and its consequences in chronic musculoskeletal pain: a state of the art. Pain, 85, 195-199.

Weisenberg, M., Aviram, O., Wolf, Y., \& Raphaeli, N. (1984). Relevant and irrelevant anxiety in the reaction to pain. Pain, 20, 371-383. 
Wells, A., \& Matthews, G. (1994). Attention and emotion: a clinical perspective. Hove: Lawrence Erlbaum Associates.

Williams, S. L., \& Kinney, P. J. (1991). Performance and nonperformance strategies for coping with acute pain: the role of perceived self-efficacy, expected outcomes, and attention. Cognitive Research and Therapy, 15, 1-19.

Zung, W. W. K. (1965). A self-rating depression scale. Archives of General Psychiatry, 12, 63-70. 


\subsection{ELECTRONIC DIARY ASSESSMENT OF PAIN-RELATED FEAR, ATTENTION TO PAIN, AND PAIN INTENSITY IN CHRONIC LOW BACK PAIN PATIENTS*}

\section{ABSTRACT}

The present paper consists of two studies aimed at investigating the relationships between pain-related fear, attention to pain, and pain intensity in daily life in patients with chronic low back pain, applying an experience sampling method. Electronic diary data were collected from forty chronic low back pain patients, who carried a palmtop computer with them for three weeks. Multi-level analysis was used for all analyses. Study 1 examined whether attention to pain mediates the relation between pain-related fear and pain intensity. Although statistically significant mediation effects were found, the sizes of these effects were small and clinically irrelevant. Instead, results suggested that pain-related fear and attention to pain independently predicted pain intensity. Further, no evidence for moderation of the relation between attention to pain and pain intensity by pain-related fear was found. Study 2 examined the effects of a manipulation of attentional focusing (attention to pain versus distraction from pain) on pain intensity. No effects of manipulation were found in isolation or in interaction with scores on the TSK. Moreover, the manipulation check proved to be generally weak. Implications of the results from both studies are discussed and suggestions for future research are provided.

\footnotetext{
* Roelofs, J., Peters, M. L., Patijn, J., Vlaeyen, J. W. S., \& Erik G. W. Schouten. Electronic diary assessment of pain-related fear, attention to pain, and pain intensity in chronic low back pain patients. (manuscript submitted).
} 


\section{INTRODUCTION}

In attempting to explain how and why some individuals with an acute pain state develop a chronic pain syndrome, biopsychosocial models have emerged such as the 'fear-avoidance model of exaggerated pain perception' (Lethem et al., 1983). The central concept in this model is avoidance of movement or activities as a result of pain-related fear. Philips (1987) has stressed the importance of cognitions influencing avoidance behavior. Based on the work of Lethem et al. (1983) and Philips, the 'fearavoidance' model has lately been refined into a cognitively oriented model of painrelated fear in chronic musculoskeletal, which posits a behavioral mechanism whereby fear of movement and (re)injury might contribute to the maintenance of chronic pain (Vlaeyen et al., 1995a; Vlaeyen et al., 1995b; Vlaeyen \& Linton, 2000). According to this model, if individuals catastrophize about their pain, pain-related fear may evolve. This leads to increased attention (hypervigilance) to bodily sensations and pain, and avoidance behaviors. Subsequently, a chronic pattern of disability, depression, and disuse is maintained. Depression and disuse are known to be associated with decreasing pain tolerance and may promote the painful experience. The pain experiences fuel the cycle of increasing fear and avoidance, thus creating a vicious circle. In contrast, non-catastrophizing patients do not become fearful, and are more likely to confront daily activities, leading to (fast) recovery.

Particularly challenging for pain researchers is the unraveling of the relations between pain-related fear, hypervigilance, and the pain intensity. According to the cognitive theory of anxiety put forward by Eysenck (1992), the most important function of anxiety is facilitating the early detection of potentially dangerous stimuli. Anxiety represents a shift into a mode of hypervigilance, such that the person scans the environment for threatening stimuli. In the case of chronic pain, one may expect that high fearful individuals are hypervigilant towards somato-sensory signals and pain. As such, one may also predict that the pain experience is more intense in individuals having high levels of hypervigilance. Several experimental studies conducted in chronic low back pain patients and fibromyalgia patients have supported the association between pain-related fear and hypervigilance (attention to pain) and between hypervigilance and pain report as measured with various selfreport measures (Crombez et al., 1998; Ferguson \& Ahles, 1998; Peters et al., 2000a; Peters et al., 2002).

A potential drawback of experimental studies is that measurement of painrelated constructs such as pain-related fear or attention to pain is based on self-report measures that are completed by individuals at one moment in time. These measures rely on people's ability to accurately recall pain over a considerable number of days. There are two limitations of recall-based pain questionnaires. First, recall is an active reconstruction process likely to distort past experiences. Second, retrospective assessments do not provide information about the variability of the pain constructs. These two limitations are the major reasons for the growth in the popularity of pain 
diaries. Momentary sampling strategies such as Ecological Momentary Assessment (Stone \& Shiffman, 1994; Shiffman \& Stone, 1998; Hufford et al., 2001) and the Experience Sampling Method (Csikszentmihalyi \& Larsen, 1987; De Vries, 1992; Delespaul, 1995; Larson \& Csikszentmihalyi, 1983) have been developed. In these methods, chronic pain patients are asked to report on their immediate pain at several times throughout the day. Signal-contingent recording involves respondents to record their experiences whenever signaled by the researcher. Typically, the interest is with what the respondent is experiencing the precise moment they are signaled. ESM has important advantages over cross-sectional measures. First, the problem of retrospective recall can be avoided (cf. Eich et al., 1985; Jamison et al., 1989; Erskine et al., 1990; Stone et al., 2003). Second, daily fluctuations of different pain constructs can be examined. Third, an individual response bias such as exaggeration can be avoided since participants are used as their own controls (i.e., responses of the same person are compared and analyzed). Finally, temporal precedence to strengthen causal inferences can be established.

Compliance is particularly important for diary research. Non-compliance threatens the validity of diary research. The validity of paper diary records in particular may be questioned as concerns about compliance with paper diaries have been found to be justified (Stone et al., 2002). Non-compliers also tend to fabricate the data if they have not completed the requested information at the designated times (Litt et al., 1998). The advantages of using electronic diaries (e.g., palm-top computers) have been summarized by Stone and Shiffman (1994) and include both the encouragement of compliance with demanding reporting schedules and the ability to rule out "faked compliance". A higher reliability and ecological validity of such assessments (electronic diaries) can generally be assumed (Fahrenberg et al., 1999). A potential drawback of the use of pain diaries is that they cause patients to attend to their pain perhaps more than they otherwise would. Heightened attention to pain might consequently change a persons' experience of it. Such changes are referred to as reactive effects. However, little support for reactive effects in sampling patients with electronic diaries has been reported (Cruise et al., 1996; Stone et al., 2003). In a diary study by Peters and colleagues (Peters et al., 2000b) data on painrelated fear, attention to pain and pain intensity were collected in addition to several other pain characteristics. Although this study addressed a different research question and did not report the possible mediational effects of attention to pain in the relation between pain-related fear and pain intensity, preliminary analyses showed that pain-related fear was a predictor of hypervigilance and hypervigilance in turn was a predictor of pain intensity. When entered simultaneously in the multi-level regression analysis, pain-related fear and hypervigilance both predicted pain intensity. No evidence was found for hypervigilance as a mediator between painrelated fear and pain intensity. This is unexpected as laboratory studies with healthy individuals and experimentally induced pain stimuli have shown that there is evidence that the influence of anxiety on pain perception is mediated by attentional processes (Arntz et al., 1994). 
This paper describes two studies in which the influence of attention to pain and pain-related fear on pain intensity is examined. Study 1 elaborated on the study by Peters and colleagues $(2000 \mathrm{~b})$ and addressed two research questions. First, we investigated whether the relation between pain-related fear and pain intensity was mediated by attention to pain. We hypothesized that attention to pain (mediator) carried the influence of pain-related fear to pain intensity. Second, we investigated whether pain-related fear as a trait characteristic (reflected by scores on the Tampa Scale for Kinesiophobia [TSK; Miller et al., 1991]), moderated the relation between attention to pain and pain intensity. More specifically, we hypothesized that higher scores on the TSK would be associated with more attention to pain and subsequently with an increased pain intensity. In study 2, attentional focusing of patients was manipulated during daily life. Patients were instructed to either attend to or distract from the pain. So far, the effect of a manipulation of attentional focusing on pain intensity has mainly been restricted to the field of laboratory studies. This type of studies have shown that attending to pain may decrease pain tolerance and increase pain intensity in high fearful patients while distraction from pain may lead to increased pain tolerance and decreased pain intensity in low fearful individuals (e.g., Heyneman et al. 1990; Hadjistavropoulos et al., 2000). To date, only one study has examined the effects of a manipulation of attentional focusing on self-reported pain intensity in a diary study in fibromyalgia (Fors et al., 2002). Distraction from pain (patients were instructed to visualize beautiful, natural settings on nice summer days) administered daily on a videotape, reduced pain ratings of patients during the 28-day study period. Attentional focusing (patients were instructed to visualize their own pain-alleviating systems by showing how endorphins may reduce levels of pain on a videotape) did not differ from the control group in which no instructions were given. The manipulation used in the study by Fors et al. (2002) relied solely on imagination. Our study reported in this paper used a more active manipulation of attentional focus and is the first to examine the effect of a manipulation of attentional focusing in chronic low back pain patients. We investigated whether pain-related fear as a trait characteristic (measured with the TSK), moderated the effects of the attention and distraction manipulations. More specifically, we hypothesized that a manipulation of attention to pain would be associated with increased pain intensity especially in individuals with lower scores on the TSK. According to Leventhal and Everhart's parallel processing model, focusing on sensory aspects of the pain stimuli is beneficial as it prevents the distress schemata from activation. Therefore, a manipulation of attention to pain was expected to decrease pain intensity in individuals scoring high on the TSK. Further, we hypothesized that a distraction from pain manipulation would be associated with decreased pain intensity in individuals with lower scores on the TSK but that individuals scoring high on the TSK would not benefit from distraction. Duration of both studies together was three weeks. In the first week, research questions from study 1 were addressed while in the second and third week the effectiveness of the manipulation of attentional focusing was examined. 


\section{STUDY 1}

\section{METHODS}

\section{Patients}

Forty chronic low-back pain patients (57.1\% female), who were referred to the pain unit of the Maastricht University Hospital (The Netherlands) were recruited for participation in the present study. Inclusion criteria were (a) experiencing low back pain for at least six months; (b) age between 18 and 65; (c) having no hearing or sight problems; (d) being fluent in Dutch; and (e) having no difficulty holding a pen or writing. Exclusion criteria were (a) having serious psychiatric impairment or alcohol and/or drug problems; and (b) having participated in a previous ESM study. Mean age of the sample was 46.4 years ( $S D=9.9$, range 30-64) and mean pain duration was 148 months ( $\mathrm{SD}=118$, range 6-444). Interference with daily activities was measured with the Quebec Back Pain Disability Scale. Mean score on this measure was 55.6 $(\mathrm{SD}=15.7$, range 23-84), indicating that the sample was substantially disabled. Further, 100\% was Caucasian, $26.2 \%$ was working full time or part time, $85.7 \%$ was married or living with a partner, and $85.7 \%$ had one or more children. All patients were informed about the purpose of the study and signed a written consent. Patients were paid 25 Euro for participation. The study protocol was approved by the Ethics Committee of the Maastricht University Hospital.

\section{Electronic diary and assessment}

Each patient carried a palm-top computer (type m100) in a protective case. Diary questions were presented on-screen for completion via a touch screen (50 x $50 \mathrm{~mm})$ and entries were time- and date-stamped. PEAS software (see acknowledgements for more information about the software) was used on the palm top, which was programmed to 'beep' eight times a day between 8:00 h (weekend 9:00 h) and 22:00 h. over at least 7 consecutive days. In most cases, the experiment started on a Monday or Wednesday and lasted for a week. The beeps were presented in a random time schedule. Data captured from the palm was transferred to a PC where software turned data into SPSS. Before the start of the experiment, all participants were carefully trained in completing the diary.

Current pain intensity was assessed by means of the item "Right now, I am in pain". Two items measuring 'attention to pain' were drawn from the PVAQ (McCracken, 1997). Factor analysis of the PVAQ has identified two factors, which have been labeled 'attention to changes in pain' and 'attention to pain' (Roelofs et al., 2003). Consequently, two items were formulated: "Right now, I quickly notice changes in my pain" and "Right now, I am focusing on my pain". As this item reflects an active scanning process, we also added an item that captures attention to 
pain as a more passive process: "Right now, I find it easy to ignore my pain". Items reflecting pain-related fear were derived from the Tampa Scale for Kinesiophobia (TSK: Miller et al., 1991). As the TSK is a measure of fear of movement and (re)injury, two items were created reflecting both movement "Right now, I do not dare to move" and injury "Right now, moving is harmful for my body". As both TSK items were substantially intercorrelated, a composite TSK score was computed in which scores on both items were summed and divided by two. We also included an item directly reflecting pain-related fear: "Right now, I am afraid of my pain". All items were rated on a 7-point Likert scale labeled 'not at all' to 'very much'. Thirty additional questions were also included in each momentary assessment. However, since these data are not considered in the present study, a detailed presentation of these questions is omitted.

\section{Procedure}

Patients were seen in our research offices twice. During the first visit, informed consent was obtained and patients completed the TSK and the Quebec Back Pain Disability Scale. In addition, demographic details were also obtained. Patients were explained that the interest of the study was to investigate how pain was experienced during the day and what factors influence pain. They were told that an audible alarm would go off eight times a day at randomly selected moments during the morning, afternoon, and evening for at least seven consecutive days. Patients could delay answering a prompt for a maximum of 20 minutes when engaged in an activity that could not be interrupted. Patients were then trained to fill in questions on a palmtop demonstration version by choosing the fixed response options of each question and then pressing the 'next' button. Stand-by assistance during the experiment to handle (technical) problems was available.

\section{Data Analysis}

Data obtained in the present study requires a multilevel modeling strategy. In multilevel modeling, the repeated observations (replies to the "beeps") are called Level 1 units. These observations are organized within Level 2 units, which constitute days. Days are organized within level 3 units, which constitute persons. A critical feature of a multilevel model is that responses from the Level 1 observations are likely to be non-independent within each Level 2 unit and that Level 2 observations are non-independent within each Level 3 unit. The degree of dependency can be described by an intra-class correlation. The effect of daily observations on another (Level 1) is estimated while Level 2 variables (days) and Level 3 variables (persons) effects may "modify" the strength and direction of the relation that is modeled. In the present study, a random intercept model was used. The plan of analysis was as follows:

First, temporal fluctuations of pain intensity (dependent variable) within days as a linear and quadratic trend was examined, as pain intensity may show a gradual increase as the day goes on but decrease at the end of the day (cf. Peters et al., 2000b). 
The linear time trend was found to be different for each individual. Therefore, the linear time trend was analyzed as a random effect. The quadratic trend did not differ between patients and was analyzed as a fixed effect. Day-of-monitoring was entered as a continuous variable and a significant linear and borderline significant quadratic trend was found. Differences between pain intensity during the weekdays and the weekend was examined by means of a dummy variable (weekdays versus weekend). No effect on pain intensity was found. Thus, for analyses in which pain intensity was the dependent variable, time as a linear and quadratic trend was entered in the multi-level regression analyses.

Second, attention to pain as a mediator between pain-related fear and pain intensity was examined. One item reflecting attention to changes in pain (i.e., "Right now, I quickly notice changes in my pain") was not associated with items representing pain-related fear and pain intensity and subsequent results for this item will therefore not be presented here. Thus, as there are two items reflecting attention to pain, two items capturing pain-related fear, and one item measuring pain intensity, four mediation models were tested. Mediation was examined not only for measurements of pain-related fear, attention to pain, and pain intensity at the same 'beep' moment, but also in the case of temporal precedence of pain-related fear (and attention to pain in subsequent analyses), to the measurement of pain intensity. Thus, the same models were tested three times: (1) pain-related fear, attention to pain, and pain intensity at $\mathrm{t}=1$, (2) pain-related fear, attention to pain at $\mathrm{t}=1$, pain intensity at $\mathrm{t}=2$, and (3) pain-related fear at $\mathrm{t}=1$, and attention to pain and pain intensity at $\mathrm{t}=2$. Thus, a total number of $4 \times 3=12$ models were estimated. The Sobel's $t$ test was used to test whether the mediator (attention to pain) carried the influence of pain-related fear to pain intensity. To prevent spurious findings due to multiple testing, alpha was set to 0.005 .

Third, pain-related fear (measured with the TSK) as a potential moderator in the relation between attention to pain and pain intensity was examined. Moderation was examined not only for the measurement of attention to pain and at the same 'beep' moment but also in the case of temporal precedence of attention to pain to the measurement of pain intensity. As there are two items reflecting attention to pain and all items are measured both at $t=1$ and $t=2$, a total number of four models were estimated. In each model, a significant and substantial interaction between the attention to pain item and TSK scores was predicted. This model was compared to the model without the interaction term. As these analyses involve a maximum likelihood procedures, nested models can be compared by using the log likelihood ratio chi-square statistic (-2LL or 'deviance'). This statistic decreases as the model improves. Under the null-hypothesis that the two models are equivalent, this test statistic has a chi-square distribution with degrees of freedom equal to the number of constraints differentiating both models. Delayed responses (delay $>20$ minutes) were removed from analyses. All multi-level analyses were performed by MLWin version 1.1. 


\section{RESULTS}

Compliance with the monitoring procedure was good. Overall, participants answered $76.4 \%$ of the prompts. Inspection of the missing data revealed that $28 \%$ of the missing beeps accounted for days in which no response was given to any beep, and $61 \%$ of the beeps were missing for days in which no or only one beep was answered. Patients verbally reported that missing beeps were caused by performing activities in which they were not able to complete the beeps, such as going to family or going out for a day. Importantly, none of the patients reported that they could not complete the beeps due to their back pain.

\section{Mediation of attention to pain}

For examining mediation of attention to pain in the relation between pain-related fear and pain intensity, three successive multi-level regression analyses were conducted in line with the guidelines provided by Baron and Kenny (1986). Figure 32 presents a visual representation of the mediation process.

Figure 3-2: General mediation model

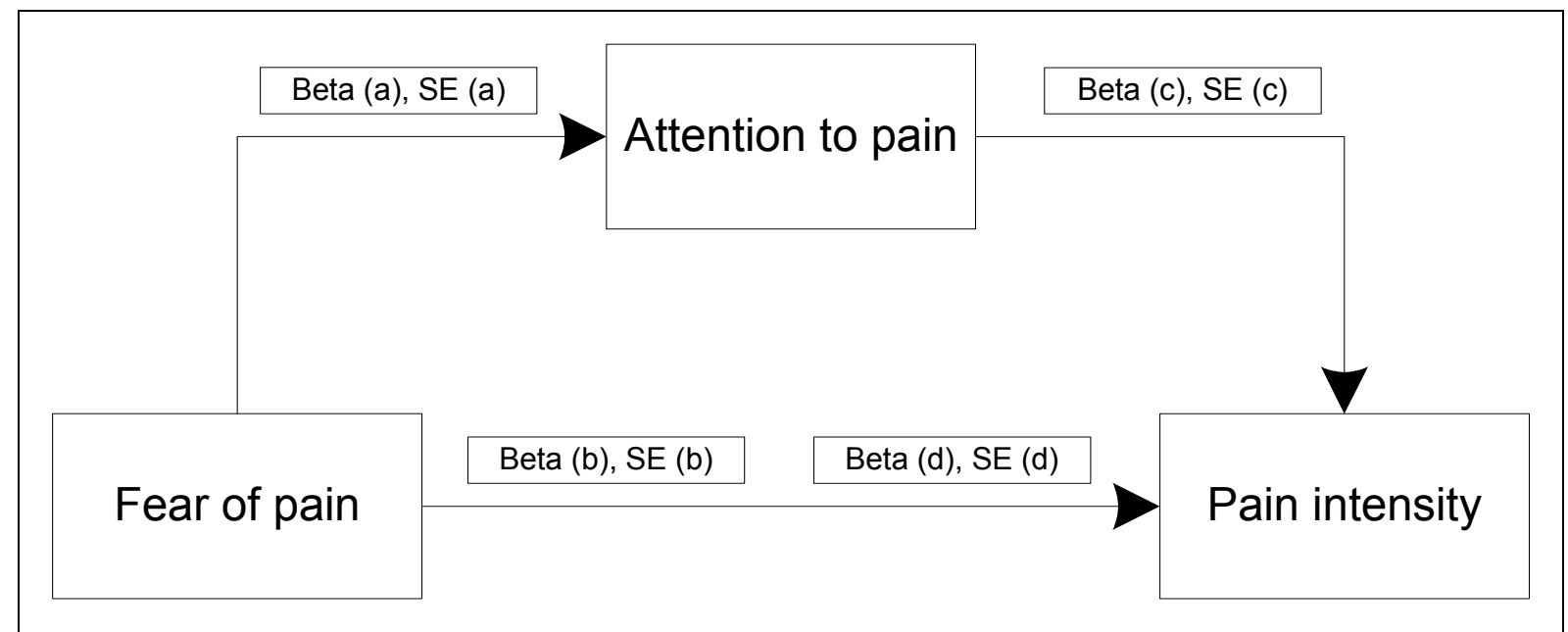

The first regression analysis was conducted in which the independent variable (painrelated fear) predicted the mediator. This analysis provided beta (a) and its standard error, SE (a). In the second regression analysis, the independent variable (painrelated fear) was regressed on the dependent variable (pain intensity). This analysis yielded beta (b) and SE (b). A final regression analysis in which the independent variable (pain-related fear) and the mediator (attention to pain) predicted the dependent variable (pain intensity), provided beta (c) and beta (d) and their corresponding standard errors, SE (c) and SE (d) (see figure 3-2 for betas and standard errors). Mediation is established when the relation between pain-related fear and pain intensity (beta b) drops substantially (beta d) when the mediator (attention to pain) is taken into analyses. 
Table 3-4: Standardized beta weights for the mediating effect of attention to pain in the relation between fear of pain and pain intensity.

\begin{tabular}{|c|c|c|c|c|c|c|c|c|c|c|}
\hline \multirow{3}{*}{$\begin{array}{l}\text { Pain-related } \\
\text { fear: } \\
\text { Attention to } \\
\text { pain: }\end{array}$} & \multicolumn{10}{|c|}{$\begin{array}{l}\text { Combination: "Right now, I do not dare to move" and "Right now, moving is harmful for my } \\
\text { body" }\end{array}$} \\
\hline & \multicolumn{10}{|c|}{ Item: " Right now, I am focusing on my pain" } \\
\hline & Beta (a) & SE (a) & Beta (b) & SE (b) & Beta (c) & SE (c) & Beta (d) & SE (d) & Sobel's t & P-value \\
\hline Model 1: & 0.393 & 0.025 & 0.259 & 0.028 & 0.106 & 0.026 & 0.229 & 0.029 & 3.99 & $<0.001$ \\
\hline Model 2: & 0.360 & 0.031 & 0.069 & 0.033 & 0.068 & 0.032 & 0.046 & 0.035 & 2.11 & 0.03 \\
\hline Model 3: & 0.092 & 0.032 & 0.069 & 0.033 & 0.161 & 0.030 & 0.056 & 0.033 & 2.47 & 0.01 \\
\hline $\begin{array}{l}\text { Pain-related } \\
\text { fear: }\end{array}$ & \multicolumn{10}{|c|}{ Item: "Right now, I am afraid of my pain" } \\
\hline \multirow{2}{*}{$\begin{array}{l}\text { Attention to } \\
\text { pain: }\end{array}$} & \multicolumn{10}{|c|}{ Item: "Right now, I am focusing on my pain" } \\
\hline & Beta (a) & SE (a) & Beta (b) & SE (b) & Beta (c) & SE (c) & Beta (d) & SE (d) & Sobel's t & P-value \\
\hline Model 1: & 0.290 & 0.024 & 0.156 & 0.026 & 0.154 & 0.026 & 0.117 & 0.027 & 5.34 & $<0.001$ \\
\hline Model 2: & 0.253 & 0.031 & 0.031 & 0.031 & 0.067 & 0.031 & 0.017 & 0.032 & 2.12 & 0.03 \\
\hline Model 3: & 0.073 & 0.032 & 0.031 & 0.031 & 0.167 & 0.030 & 0.020 & 0.031 & 2.12 & 0.03 \\
\hline $\begin{array}{l}\text { Pain-related } \\
\text { fear: }\end{array}$ & \multicolumn{10}{|c|}{$\begin{array}{l}\text { Combination: "Right now, I do not dare to move" and "Right now, moving is harmful for my } \\
\text { body" }\end{array}$} \\
\hline Attention to & \multicolumn{10}{|c|}{ Item: "Right now, I find it easy to ignore my pain" } \\
\hline & Beta $(a)$ & SE (a) & Beta (b) & SE (b) & Beta (c) & SE (c) & Beta $(d)$ & $\mathrm{SE}(\mathrm{d})$ & Sobel's t & P-value \\
\hline Model 1: & -0.211 & 0.031 & 0.259 & 0.028 & -0.257 & 0.020 & 0.214 & 0.026 & 5.95 & $<0.001$ \\
\hline Model 2: & -0.217 & 0.037 & 0.069 & 0.033 & -0.120 & 0.027 & 0.053 & 0.033 & 3.53 & $<0.001$ \\
\hline Model 3: & -0.011 & 0.038 & 0.069 & 0.033 & -0.244 & 0.026 & 0.061 & 0.032 & 0.27 & 0.79 \\
\hline $\begin{array}{l}\text { Pain-related } \\
\text { fear: }\end{array}$ & \multicolumn{10}{|c|}{ Item: "Right now, I am afraid of my pain" } \\
\hline Attention to & \multicolumn{10}{|c|}{ Item: "Right now, I find it easy to ignore my pain" } \\
\hline & Beta $(a)$ & SE (a) & Beta (b) & SE (b) & Beta (c) & $\mathrm{SE}(\mathrm{c})$ & Beta $(d)$ & $\mathrm{SE}(\mathrm{d})$ & Sobel's t & P-value \\
\hline Model 1: & -0.054 & 0.030 & 0.156 & 0.026 & -0.271 & 0.021 & 0.138 & 0.024 & 1.81 & 0.07 \\
\hline Model 2: & -0.100 & 0.037 & 0.031 & 0.031 & -0.121 & 0.027 & 0.027 & 0.031 & 2.34 & 0.02 \\
\hline Model 3: & -0.031 & 0.036 & 0.031 & 0.031 & -0.245 & 0.024 & 0.011 & 0.030 & 0.86 & 0.39 \\
\hline
\end{tabular}

Note: Model $1=$ measurement of pain-related fear, attention to pain, and pain intensity at the same beep moment

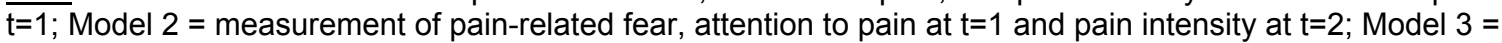
measurement of pain-related fear at $t=1$ and attention to pain and pain intensity $a t=2$.

Table 3-4 presents the results of the multi-level regression analyses for each possible combination of item pairs measuring pain-related fear and attention to pain. For each item pair, three models were assessed. In model 1, pain-related fear, attention to pain, and pain intensity were assessed at $t=1$. Model 2 assessed pain-related fear, attention to pain at $t=1$ but pain intensity at $t=2$. In model 3 , pain related fear was assessed at $t=1$ while attention to pain and pain intensity were assessed at $t=2$. The results presented in table 3-4 clearly suggest that the strongest associations between pain-related fear, attention to pain, and pain intensity were observed when measured 
at $\mathrm{t}=1$. Attention to pain as a mediator in the relation between pain-related fear and pain intensity was most profound in model 1. It should be noted that although mediation was statistically significant, the decline of the beta representing the association between the independent variable and the dependent variable was very small when the mediator was taken into account (see table 3-4).

\section{Moderation of pain-related fear (TSK)}

Table 3-5 depicts the results of the four successive multi-level regression analyses, in which the moderating effects of pain-related fear, measured with the TSK, were tested.

Table 3-5: Standardized beta weights for the moderating effects of pain-related fear (TSK) on the relation between attention to pain and pain intensity.

\begin{tabular}{|c|c|c|c|c|c|c|}
\hline \multirow[t]{2}{*}{ Attention to pain: } & \multicolumn{6}{|c|}{ Item: "Right now, I am focusing on my pain" } \\
\hline & Beta (att.) & SE (att.) & Beta (TSK) & SE (TSK) & Beta (inter) & SE (inter) \\
\hline \multicolumn{7}{|l|}{ Model 1: } \\
\hline Main-effects model & 0.183 & 0.025 & -0.077 & 0.146 & - & - \\
\hline Interaction-effect model & 0.089 & 0.132 & -0.078 & 0.109 & 0.118 & 0.177 \\
\hline \multicolumn{7}{|l|}{ Model 2: } \\
\hline Main-effects model & 0.072 & 0.030 & -0.023 & 0.107 & - & - \\
\hline Interaction-effect model & -0.221 & 0.161 & -0.095 & 0.119 & 0.293 & 0.176 \\
\hline \multirow[t]{2}{*}{ Attention to pain: } & \multicolumn{6}{|c|}{ Item: "Right now, I find it easy to ignore my pain" } \\
\hline & Beta (att.) & SE (att.) & Beta (TSK) & SE (TSK) & Beta (inter) & SE (inter) \\
\hline \multicolumn{7}{|l|}{ Model 1: } \\
\hline Main-effects model & -0.271 & 0.020 & -0.060 & 0.096 & - & - \\
\hline Interaction-effect model & -0.351 & 0.104 & -0.090 & 0.102 & 0.105 & 0.105 \\
\hline \multicolumn{7}{|l|}{ Model 2: } \\
\hline Main-effects model & -0.124 & 0.027 & -0.023 & 0.107 & - & - \\
\hline Interaction-effect model & -0.023 & 0.137 & 0.018 & 0.118 & -0.104 & 0.156 \\
\hline
\end{tabular}

Note: Model 1 = measurement of pain-related fear, attention to pain, and pain intensity at the same beep moment $\mathrm{t}=1$; Model 2 = measurement of pain-related fear, attention to pain at $t=1$ and pain intensity at $t=2$; Att. refers to attention to pain item.

In testing moderation, the difference in chi-square between the main-effect model (main effects consist of items reflecting attention to pain and TSK scores) and the interaction-effect model (including the main effects and the interaction between them) has a chi-square distribution with degrees of freedom equal to the number of constraints differentiating both models $(\mathrm{df}=1$ as the interaction term is the only term which differentiates both models). No moderating effect of TSK scores for the item: "I am focusing on my pain now" was found for model 1 (attention to pain and pain measured at $\mathrm{t}=1 ; \Delta-2 \mathrm{LL}=0.54, \mathrm{df}=1, \mathrm{p}=0.462$ ) and model 2 (attention to pain measured at $\mathrm{t}=1$, pain at $\mathrm{t}=2 ; \Delta-2 \mathrm{LL}=2.92, \mathrm{df}=1, \mathrm{p}=0.087$ ). Similarly, for the item "I 
find it easy to ignore my pain now", no moderating effects of TSK scores were found for model $1(\Delta-2 \mathrm{LL}=0.61, \mathrm{df}=1, \mathrm{p}=0.435)$ and $\operatorname{model} 2(\Delta-2 \mathrm{LL}=0.55, \mathrm{df}=1, \mathrm{p}=$ $0.458)$.

\section{DISCUSSION}

The purpose of study 1 was to examine the relations among pain-related fear, attention to pain, and pain intensity in individuals with chronic low back pain. Painrelated fear and attention to pain were each substantially and significantly associated with pain intensity, particularly when measured at the same 'beep' moment. Only one combination of pain-related fear and attention to pain items, in which both preceded the moment pain was measured, produced a significant mediation effect. Thus, mediation effects appear to be more consistent when measured at the same beep time. However, it should be noted that the largest decline of a beta that reflects the association between pain-related fear and the independent variable was 0.05 when the mediator was taken into account. With respect to the moderating effects of pain-related fear (TSK), higher scores on the TSK were not associated with more attention to pain and subsequently with increased pain intensity, providing no support for the moderating role of pain-related fear (TSK). The influence of a manipulation of attention to pain on pain intensity was examined in study 2 , which is described below.

\section{STUDY 2}

\section{METHODS}

\section{Patients}

Four out of forty patients dropped out at the start of week two leaving a total number of thirty-six patients in study 2. These four patients reported that the reason for quitting was that participation was difficult to combine with their work or home situation.

\section{Electronic diary, assessment, and manipulation}

Participants carried the same palm-top computer as they did in the first week. The same items were used to measure attention to pain, pain-related fear, and pain intensity. As in the first week, the palm-top computer was programmed to 'beep' eight times a day between 8:00 $\mathrm{h}$ (weekend 9:00) and 22:00 $\mathrm{h}$. The manipulation of attention to pain or distraction from pain occurred both during the second and third week. Each manipulation (attention vs. distraction) occurred two times in two weeks time with the constraint that within a week, a distraction manipulation was always 
followed by an attention to pain manipulation and vice versa. Further, time between two manipulations was at least two days and two manipulations could not occur during one day. Instructions for both manipulations were generated by the palm-top computer.

For the attention to pain manipulation, a brief message was displayed on the palm-top computer (i.e., "Pay close attention to your pain and other sensations today") at 9:00 h, 10:00 h, 13.30 h, and 18.30 h. Moreover, patients were instructed to complete the 'pain booklet' three times that day at random times. In this booklet, patients were instructed to write down all pain sensations and other somato-sensory sensations they had experienced since waking up or since the previous time they completed the booklet. The pain booklet also included an illustration of the human body surrounded by sensory and affective words derived from the McGill Pain Questionnaire (MPQ: Melzack, 1975). Patients were instructed to encircle the words that represented their pain most accurately and had to indicate by means of an arrow from the word to the place on the body for which that word was representative of the pain felt. It took approximately 5 to 10 minutes to complete each this assignment.

For the distraction from pain manipulation, a brief message was displayed on the palm-top computer (i.e., "Pay close attention to positive things in your environment") at 9:00 h, 10:00 h, 13.30 h, and 18.30 h. Moreover, patients were given a camera and were instructed to take pictures that day of positive things that they experienced in their environment. Patients were instructed to complete a 'photo booklet' three times a day at random times in which they were requested to write down the objects or persons from which they made pictures. They also had to indicate why this picture was positive for them. Patients also had to scan six pictures and indicate what picture they liked most and why they liked that picture most.

The attention to pain manipulation and the distraction from pain manipulation are similar with respect to form. That is, both manipulations were initiated by the palm-top computer and a booklet was used to write down pain sensations (attention to pain manipulation) or positively charged pictures (distraction condition). In addition, a scanning task was performed in both manipulations, viz. scanning the body in attention to pain manipulation and scanning the environment in the distraction manipulation. The effectiveness of the each manipulation was measured when patients completed their participation. Patients were requested to provide a percentage reflecting the extent to which they were able to either pay attention to or to distract from pain and bodily sensations and to complete the assignments that was part of the manipulation. This percentage was anchored zero (not effective at all) to hundred (most effective).

\section{Procedure}

Patients visited an office at Maastricht University after a week when two manipulations had occurred. Data was transferred from the palm-top computer into the researchers' computer and a new protocol was implemented on the palm-top 
computer. This was necessary as patients had to be unaware of the days at which manipulations occurred. Stand-by assistance during the experiment was available.

\section{Statistical analyses}

Data were analyzed with a multilevel modeling strategy. As in study 1, temporal fluctuations of pain intensity (dependent variable) within days were entered as a linear (random) and quadratic trend (fixed) in all analyses. No differences between pain intensity during the weekdays and the weekend was found. Analyses were conducted according to the top-down procedure, which involved starting with a full model including all interaction terms and main effects. We started the model with pain intensity as the dependent variable and the three-way interaction between all predictors (i.e., manipulation, TSK scores, and sequence of the manipulation). It might be important to examine the effect of sequence as the second distraction manipulation could work differently when the first distraction manipulation has occurred. Similarly, the second attention to pain manipulation could have different effects on the pain intensity when the first manipulation has taken place. In the absence of a statistically significant three-way interaction between all predictors, the two-way interaction between sequence and manipulation was examined. Further, the critical interaction between manipulation and TSK on pain intensity was examined. Manipulation was coded as two dummies representing the attention to pain manipulation and distraction from pain manipulation. The first week (study 1) served as the baseline reference. Statistical significance of an interaction term or main effect in a model was estimated by comparing the log likelihood ratio chi-square statistics (-2LL) between the model with and the model without this term. The -2LL is itself chi-square distributed with degrees of freedom equal to the number of constraints (terms) differentiating both models. In the initial analyses, the effect of manipulation in interaction with TSK on pain intensity was examined at the level of the day (model 1). However, when no substantial and statistically significant effects could be found, in a post-hoc fashion, analyses were repeated for manipulations of which the self-reported effectiveness is above $50 \%$ (model 2). Finally, in the absence of substantial and significant effects the analyses were repeated but the effects of the manipulations (effectiveness $>50 \%$ ) are only examined on the first beep immediately following the moment patients completed either the pain booklet (attention to pain manipulation) or the photo booklet (distraction from pain manipulation) (model 3). For all analyses, models including the interaction between manipulation and TSK are compared with the model without this interaction by means of the -2LL.

Multi-level analysis was also used for the manipulation check. The effectiveness of the attention to pain manipulation was examined by regressing the manipulation (dummy) on the attention to pain item "I am focusing on my pain now". The distraction manipulation (dummy) was regressed on the item "I find it easy to ignore my pain now". The model with the manipulation is compared to the model without manipulation and the -2LL can be used to test whether the 
manipulation check actually was successful. All analyses were conducted with MLWin version 1.1.

\section{RESULTS}

Comparable to study 1 , compliance with the monitoring procedure was reasonable in study 2. Participants answered $72.7 \%$ of the prompts, of which $13.2 \%$ accounted for missing data on days in which no response was given to any beep and $19.4 \%$ for missing data on days in which no or only one beep was answered. Patients verbally reported that missing beeps were not caused by the severity of their back pain but by performing activities in which they were not able to complete the beeps, such as going to family or going out for a day.

\section{Effect of manipulation on pain intensity}

To examine the effect of the attention to pain and distraction from pain manipulations in interaction with the TSK on pain intensity, a model with two threeway interactions (both manipulations coded as dummies in interaction with sequence and TSK) was estimated first. Compared to the model without the threeway interactions, the three-way interactions were not significant $(\Delta-2 L L=1.22$, $\mathrm{df}=2, \mathrm{p}=0.543)$. The two-way interaction between sequence and TSK was not significant $(\Delta-2 \mathrm{LL}=1.08, \mathrm{df}=1, \mathrm{p}=0.299)$. Two-way interactions between sequence and attention to pain manipulation and between sequence and distraction from pain were not significant $(\Delta-2 \mathrm{LL}=3.06, \mathrm{df}=2, \mathrm{p}=0.217)$. Thus, no sequence effect was found indicating that the second manipulation was not affected by the precedence of a similar manipulation. The critical interactions between manipulation and TSK did not reach statistical significance $(\Delta-2 \mathrm{LL}=3.58 \mathrm{df}=2, \mathrm{p}=0.167)$. Standardized beta weights of these interaction terms are presented in the upper part of table 3-6 (model 1 ). TSK in isolation did not predict pain intensity $(\Delta-2 L L=0.39, \mathrm{df}=1, \mathrm{p}=0.532)$. Both manipulations in isolation did not significantly influence pain intensity $(\Delta-2 \mathrm{LL}=0.98, \mathrm{df}=2, \mathrm{p}=0.613)$. Standardized beta weights of main effects of manipulation are also presented in the upper part of table 3-6 (model 1). Pain intensity ratings during baseline were normally distributed (Mean $=4.54$ and $\mathrm{SD}=$ 1.43). During the attention to pain manipulation (day level), mean pain intensity ratings were $4.61(\mathrm{SD}=1.56)$ and during distraction from pain manipulation mean pain intensity ratings were $4.50(\mathrm{SD}=1.49)$. Thus, there appears to be sufficient spread in the dependent variable.

To further examine the influence of a manipulation of attention to pain on pain intensity, the sequence of analyses was repeated twice as post-hoc analyses. In the first series of analyses only manipulations of which the self-reported effectiveness was above $50 \%$ were analyzed (model 2 ). The same pattern of results was obtained. The critical interactions between manipulation and TSK did not reach statistical significance $(\Delta-2 \mathrm{LL}=2.88, \mathrm{df}=2, \mathrm{p}=0.237)$. In addition, no significant main effects 
for the manipulations were found $(\Delta-2 \mathrm{LL}=1.87, \mathrm{df}=2, \mathrm{p}=0.393)$. In the next series of analyses, only the 'beep' immediately following the manipulation (i.e., completing either the pain booklet or the photo booklet) was analyzed (model 3). Also for these analyses, the same pattern of results was found. The critical interactions between manipulation and TSK did not reach statistical significance $(\Delta-2 \mathrm{LL}=4.76$, $\mathrm{df}=2$, $\mathrm{p}=0.093)$. Also, no significant main effects for the manipulations were found $(\Delta-2 \mathrm{LL}=4.00, \mathrm{df}=2, \mathrm{p}=0.135)$. The standardized beta weights of the critical interactions between manipulation and TSK as well as the main effects of both manipulations for both series of analyses are depicted in table 3-6 (upper part).

\section{Manipulation check}

The effectiveness of the manipulation was examined by regressing the manipulation (coded as two dummies) on two attention to pain items. The lower part of table 3-6 presents the standardized beta weights for the manipulations.

Table 3-6: Standardized beta weights of the manipulation in isolation and in interaction with TSK and manipulation check.

\begin{tabular}{|c|c|c|c|c|c|c|c|c|}
\hline \multirow[t]{2}{*}{ Manipulation } & \multicolumn{2}{|c|}{$\begin{array}{l}\text { Attention to pain } x \\
\text { TSK }\end{array}$} & \multicolumn{2}{|c|}{ Distraction x TSK } & \multicolumn{2}{|c|}{ Attention to pain } & \multicolumn{2}{|c|}{ Distraction } \\
\hline & Beta & SE (Beta) & Beta & SE (Beta) & Beta & SE (Beta) & Beta & SE (Beta) \\
\hline Model 1 & 0.18 & 0.10 & 0.01 & 0.10 & 0.02 & 0.02 & 0.01 & 0.02 \\
\hline Model 2 & 0.18 & 0.11 & 0.03 & 0.09 & 0.02 & 0.02 & -0.01 & 0.02 \\
\hline Model 3 & 0.19 & 0.09 & 0.01 & 0.08 & 0.03 & 0.02 & 0.01 & 0.02 \\
\hline Manipulation check & & & & & Beta & SE (Beta) & Beta & SE (Beta) \\
\hline \multirow[t]{2}{*}{ Model 1} & \multicolumn{4}{|c|}{ Item: "Right now, I am focusing on my pain" } & 0.02 & 0.02 & 0.01 & 0.02 \\
\hline & \multicolumn{4}{|c|}{$\begin{array}{l}\text { Item: "Right now, I find it easy to ignore my } \\
\text { pain" }\end{array}$} & -0.03 & 0.02 & 0.01 & 0.02 \\
\hline \multirow[t]{2}{*}{ Model 2} & \multicolumn{4}{|c|}{ Item: "Right now, I am focusing on my pain" } & 0.02 & 0.02 & 0.02 & 0.02 \\
\hline & \multicolumn{4}{|c|}{$\begin{array}{l}\text { Item: "Right now, I find it easy to ignore my } \\
\text { pain" }\end{array}$} & -0.03 & 0.02 & 0.03 & 0.02 \\
\hline \multirow[t]{2}{*}{ Model 3} & \multicolumn{4}{|c|}{ Item: "Right now, I am focusing on my pain" } & 0.02 & 0.02 & 0.02 & 0.02 \\
\hline & \multicolumn{4}{|c|}{$\begin{array}{l}\text { Item: "Right now, I find it easy to ignore my } \\
\text { pain" }\end{array}$} & -0.04 & 0.02 & 0.03 & 0.02 \\
\hline
\end{tabular}

Note: Model 1 = effect of manipulation examined at level of day of manipulation; Model 2: effect of manipulation examined at the level of day of manipulation and self-reported effectiveness above $50 \%$; Model 3: effect of manipulation on following 'beep' moment and with self-reported effectiveness above $50 \%$.

For all models, the manipulation was unsuccessful. Substantial and significant beta weights were expected. Unfortunately, the manipulation check proved unsuccessful with respect to the item "I am focusing on my pain now" for model $1(\Delta-2 L L=1.10$, $\mathrm{df}=2, \mathrm{p}=0.577)$, model $2(\Delta-2 \mathrm{LL}=1.83, \mathrm{df}=2, \mathrm{p}=0.401)$, and model $3(\Delta-2 \mathrm{LL}=2.11$, $\mathrm{df}=2, \mathrm{p}=0.348)$ and for the item "I find it easy to ignore my pain now" the manipulation check proved successful only for model $3(\Delta-2 \mathrm{LL}=7.15, \mathrm{df}=2, \mathrm{p}=$ 
0.028), but not for model $1(\Delta-2 L L=2.08, d f=2, p=0.353)$ and model $2(\Delta-2 L L=4.19$, $\mathrm{df}=2, \mathrm{p}=0.123)$.

\section{GENERAL DISCUSSION}

This paper presents two studies on the relation between pain-related fear, attention to pain, and pain intensity in chronic low back pain patients measured in daily life using the experience sampling method. The first study addressed whether attention to pain mediates the relation between pain-related fear and pain intensity and whether pain-related fear as a trait characteristic moderated the relation between attention to pain and pain intensity. The second study examined whether a manipulation of attentional focusing influenced pain intensity.

With respect to the mediating effects of attention to pain on the relation between pain-related fear and pain intensity, support for mediation was found in a statistical sense, but this has little to do with the clinical significance of the mediation effect (cf. Jacobson \& Truax, 1991). Statistical significance refers to the extent that we can be confident that the obtained mediation effect is not simply chance findings. However, the existence of a mediation effect has no bearing on its size, importance, or clinical significance. Thus, although mediation has been demonstrated in a statistical sense, the size of the mediation effect is extremely small and therefore to our opinion not clinically significant. The best conclusion that can be drawn is that both pain-related fear and attention to pain substantially, and independently, predict pain intensity. The influence of attention to pain and pain-related fear on pain intensity was particularly prominent when all constructs were measured the same beep time. An important implication is that there is no indication for causality. In other words, it is still unknown whether increases in pain-related fear or attention to pain precede or are the consequence of increased pain intensity. These results are in line with results from a previous diary study, in which pain-related fear and attention to pain were both found to predict pain intensity substantially (Peters et al., $2000 \mathrm{~b}$ ). Another diary study has also found support for attention to pain as a predictor of pain intensity in fibromyalgia patients (Affleck et al., 1996). In this study, across-persons analyses showed that individuals in more pain paid more attention to pain. Within-persons analyses showed that they did so especially on more painful days. Further, study 1 provided no evidence for the moderating effects of painrelated fear (reflected by scores on the TSK) on the relation between attention to pain and the pain intensity was found. Thus, the effect of attention to pain on pain intensity was not dependent on the level of pain-related fear.

Study 2 attempted to manipulate attentional focusing in daily life. It was expected that the manipulation of attention to pain would lead to increased pain intensity in low trait fearful (measured with TSK) individuals, while decreased pain intensity is expected in high trait fearful individuals. Distraction from pain would be associated with decreased pain intensity in low trait fearful individuals. However, no 
substantial and statistically significant effects of the manipulations in isolation or in interaction with scores on the TSK were found. One could argue that the seven-point scale on which pain intensity is measured may not be sensitive to detect effects of a manipulation of attentional focusing. However, responses to the pain intensity item were normally distributed and showed sufficient spread during days of manipulation as well as during baseline. Importantly, the manipulation check proved to be unsuccessful in general. Only the manipulation check one beep after the manipulation itself proved to be successful on one item. Although major efforts were undertaken in the present study to manipulate attentional focus (e.g., assignments by means of booklets, repeated recalls to either pay attention to or distract from pain, the use of positive stimuli for the distraction manipulation), it still appears difficult to accomplish a manipulation of attentional focusing in daily life in patients with chronic low back pain.

A potential drawback in both studies is the relatively high percentage of missing data. We used a signal-contingent method, which is more intrusive than other methods since respondents have no control over when they will complete the records. As such they may be signaled at times when it is inconvenient to fill out the data form. The percentage of missing data is comparable to other studies. For example, Larson (1979) reported that one-third of the signals were missed. Other studies have reported a rate of missed signals between 15 and 20 percent (e.g., Csikszentmihalyi \& Graef, 1980: Larson \& Lampman-Petraitis, 1989). We did not give incentives when individuals did not have any missing data on a day or the complete week of sampling. Incentives could have improved compliance in the present study. One may further argue that the ability of respondents to tolerate the intrusiveness of these methods would decrease as the level of disorganization and stress in their lives increased. However, there are some indications that seriously ill patients are able to complete their pain diary for a long period of time (De Wit et al., 1999).

Future research could investigate attentional mechanisms in chronic pain patients by manipulating attention to pain by either instructing patients to focus on pain or to distract from pain by means of experimental studies. It is a well-known fact that attention (Arntz et al., 1991) and (emotional positive) distraction (McCaul et al., 1992) regulate the experience of pain (Vendrig \& Lousberg, 1997). With respect to the manipulation of attention to pain, the influence of this manipulation on pain intensity may be limited as the threat value of this manipulation was too low (see Eccleston \& Crombez, 1999). Alternatively, future research should examine the influence of attention to pain on pain intensity in situations with a higher threat value such as in the process of rehabilitation when patients return to work. Returning to work may be accompanied by increased attention to pain and subsequently increased pain intensity. Future research could also apply electronic diary studies to chronic low back pain patients while under treatment. For example, the mechanism behind the effectiveness of in vivo exposure could be further elucidated by analyzing how pain-related fear, attention to pain, and pain intensity change over time. 


\section{ACKNOWLEDGEMENTS}

We would like to express our greatest gratitude to Rosanne Janssen for her assistance in the data management. For more information about PEAS software, please contact Ph. Delespaul (ph.delespaul@sp.unimaas.nl) (C) 2003 UM/H\&G PEAS - PsychoEcological Assessment Systems (v1.6).

\section{REFERENCES}

Affleck, G., Urrows, S., Tennen, H., Higgens, P., \& Abeles, M. (1996). Sequential daily relations of sleep, pain intensity, and attention to pain among women with fibromyalgia. Pain, 68, 363-368.

Arntz, A., Dreessen, L., \& Merckelbach, H. (1991). Attention, not anxiety influence pain. Behaviour Research and Therapy, 29, 41-50.

Arntz, A., Dreessen, L., \& De Jong, P. (1994). The influence of anxiety on pain: attentional and attributional mediators. Pain, 56, 307-314.

Baron, R. M., \& Kenny, D. A. (1986). The moderator-mediator variable distinction in social psychological research: conceptual, strategic, and statistical considerations, Journal of Personality and Social Psychology, 51, 1173-1182.

Csikszentmihalyi, M., \& Graef, R. (1980). The experience of freedom in daily life. American Journal of Community Psychology, 8, 401-414.

Csikszentmihalyi, M., \& Larsen, R. E. (1987). Validity and reliability of the experience sampling method. Journal of Nervous and Mental Disease, 175, 526-536.

Crombez, G., Vervaet, L., Lysens, R., Baeyens, F., \& Eelen, P. (1998). Avoidance and confrontation of painful, back-straining movements in chronic back pain patients. Behavior Modification, 22, 62-77.

Cruise, C. E., Broderick, J. E., Porter, L., Kaell, A., \& Stone, A. A. (1996). Reactive effects of diary self-assessment in chronic pain patients. Pain, 67, 253-258.

Delespaul, P. (1995). Assessing schizophrenia in daily life - the experience sampling method. Maastricht: Maastricht University Press.

De Vries, M. The experience of psychopathology. (1992). Cambridge, UK: Cambridge University Press.

De Wit, R., Van Dam, F., Hannman, M., Zandbelt, L., Van Buuren, A., Van der Heijden, K., Leenhouts, G., Loonstra, S., \& Huijer Abu-Saad, H. (1999). Evaluation of the use of a pain diary in chronic cancer pain patients at home. Pain, 79, 89-99.

Eccleston, C., \& Crombez, G. (1999). Pain demands attention: a cognitive-affective model o the interruptive function of pain. Psychological Bulletin, 125, 356-366.

Eich, E., Reeves, J. L., Jaeger, B., \& Graff-Radford, S. B. (1985). Memory for pain: relation between past and present pain intensity. Pain, 23, 375-379.

Erskine, A., Morley, S., \& Pearce, S. (1990). Memory for pain: a review. Pain, 41, 255265. 
Eysenck, M. W. (1992). Anxiety: the cognitive perspective. Hillsdale: Lawrence Erlbaum Associates.

Fahrenberg, J., Brügner, G., Foerster, F., \& Käppler, C. (1999). Ambulatory assessment of diurnal changes with a handheld computer: Mood, attention and morningness-eveningness. Personality and Individual Differences, 26, 641-656.

Ferguson, R. J., \& Ahles, T. A. (1998). Private body consciousness, anxiety and pain symptom reports of chronic pain patients. Behaviour Research and Therapy, 36, 527-535.

Fors, E. A., Sexton, H., \& Götestam, K. G. (2002). The effect of guided imagery and amitriptyline on daily fibromyalgia pain: a prospective, randomized, controlled trial. Journal of Psychiatric Research, 36, 179-187.

Hadjistavropoulos, H. D., Hadjistavropoulos, T., \& Quine, A. (2000). Health anxiety moderates the effects of distraction versus attention to pain. Behaviour Research and Therapy, 38, 425-438.

Heyneman, N. E., Fremouw, W. J.., Gano, D., Kirkland, F., \& Heiden, L. (1990). Individual differences and the effectiveness of different coping strategies for pain. Cognitive Therapy and Research, 14(1), 63-77.

Hufford, M., Shiffman, S., Paty, J., \& Stone, A. A. (2001). Ecological momentary assessment: real-world, real-time measurement of patient experience. In Fahrenberg, J., \& Myrtek, M. (Ed.), Progress in ambulatory assessment. Seattle, WA: Hogrefe and Huber, pp. 69-92.

Jacobson, N. S. \& Truax, P. Clinical significance: A statistical approach to defining meaningful change in psychotherapy research. Journal of Consulting and Clinical Psychology, 1, 12-19.

Jamison, R. N., Sbrocco, T., \& Parris, W. C. V. (1989). The influence of physical and psychosocial factors on accuracy of memory for pain in chronic pain patients. Pain, 37, 289-294.

Larson, R. (1979). The significance of solitude in adolescent lives. Unpublished doctoral dissertation, University of Chicago.

Larson, R., \& Csikszentmihalyi, M. (1983). The experience sampling method. In H. T. Reis (Ed.). Naturalistic approaches to studying social interaction. San Francisco: Jossey-Bass.

Larson, R., \& Lampman-Petraitis, C. (1989). Daily emotional stress as reported by children and adolescents. Child Development, 60, 1250-1260.

Lethem, J., Slade, P. D., Troup, J. D. G., \& Bentley, G. (1983). Outline of a fearavoidance model of exaggerated pain perceptions. Behaviour Research and Therapy, 21, 401-408.

Leventhal, H., \& Everhart, D. (1979). Emotion, pain, and physical illness. In Izard CE (Ed.), Emotions in personality and psychopathology. Plenum Press, New York, pp. 263-299.

Litt, M. D., Cooney, N. L., \& Morse, P. Ecological momentary assessment (EMA) with treated alcoholics: methodological problems and potential solutions. Health Psychology, 17, 48-52. 
McCaul, K. D., Monson., \& Maki, R. H. (1992). Does distraction reduce pain produced distress among college students? Health Psychology, 11, 210-217.

McCracken, L. M. (1997). Attention to pain in persons with chronic pain: a behavioral approach. Behavior Therapy, 28, 271-284.

Melzack, R. (1975). The McGill Pain Questionnaire: major properties and scoring methods. Pain, 1, 277-299.

Miller, R. P., Kori, S., \& Todd, D. D. (1991). The Tampa Scale. Unpublished report, Tampa, FL.

Peters, M. L., Vlaeyen, J. W. S., \& Van Drunen, C. (2000a). Do fibromyalgia patients display hypervigilance for innocuous somatosensory stimuli? Application of a body scanning reaction time paradigm. Pain, 86, 283-292.

Peters, M. L., Sorbi, M. J., Kruise, D. A., Kerssens, J. J., Verhaak, P. F. M., \& Bensing, J. M. (2000b). Electronic diary assessment of pain, disability and psychological adaptation in patients differing in duration of pain. Pain, 84, 181-192.

Peters, M. L., Vlaeyen, J. W. S., \& Kunnen, A. M. W. (2002). Is pain-related fear a predictor of somatosensory hypervigilance in chronic low back pain patients? Behaviour Research and Therapy, 40, 85-103.

Philips, H. C. (1987). Avoidance behaviour and its role in sustaining chronic pain. Behaviour Research and Therapy, 25, 273-279.

Roelofs, J., Peters, M. L., McCracken, L. M., \& Vlaeyen, J. W. S. (2003). The Pain Vigilance and Awareness Questionnaire (PVAQ): further psychometric evaluation in fibromyalgia and other chronic pain syndromes. Pain, 101, 299-306.

Shiffman, S., \& Stone, A. A. (1998). Ecological Momentary assessment: a new tool for behavioral medicine research. In: Krantz D, Baum A, editors. Technology and methods in behavioral medicine. Mahwah, NJ: Erlbaum, p. 117-131.

Stone, A. A., \& Shiffman, S. Ecological Momentary Assessment (EMA) in behavioral medicine. (1994). Annual Behavioral Medicine, 16, 199-202.

Stone, A. A., Shiffman, S. Schwartz, J. E., Broderick, J. E., Hufford, M. R. (2002). Patient non-compliance with paper diaries. British Medical Journal, 324, 1193-1194.

Stone, A. A., Broderick, J. E., Schwartz, J. E., Shiffman, S., Litcher-Kelly, L., \& Calvanese, P. (2003). Intensive momentary reporting of pain with an electronic diary: reactivity compliance and patient satisfaction. Pain, 104(1/2), 343-351.

Vendrig, A. A., \& Lousberg, R. (1997). Within-person relationships among pain intensity, mood and physical activity in chronic pain: a naturalistic approach. Pain, 73, 71-76.

Vlaeyen, J. W. S., Kole-Snijders, A. M. J., Boeren, R. G. B., \& Van Eek, H. (1995a). Fear of movement/(re)injury in chronic low back pain and its relation to behavioral performance. Pain, 62, 363-372.

Vlaeyen, J. W. S., Kole-Snijders, A. M. J., Rotteveel, A., Ruesink, R., \& Heuts, P. H. T. G. (1995b). The role of fear of movement/(re)injury in pain disability. Journal of Occupational Rehabilitation, 5, 235-252.

Vlaeyen, J. W. S., \& Linton, S. J. (2000). Fear-avoidance and its consequences in chronic musculoskeletal pain: a state of the art. Pain, 85, 317-332. 


\section{CHAPTER 4}

Psychometric properties of selfreport measures of pain vigilance and fear of pain 



\subsection{DUTCH VERSION OF THE PAIN VIGILANCE AND AWARENESS QUESTIONNAIRE: VALIDITY AND RELIABILITY IN A PAIN- FREE POPULATION*}

\section{ABSTRACT}

The current study examined validity and reliability of the Pain Vigilance and Awareness Questionnaire (PVAQ) in two samples of healthy college students. Exploratory and confirmatory factor analysis showed that a two-factor model of the PVAQ was most suitable in the present study. The first factor could be referred to as attention to pain whereas the second factor could be specified as attention to changes in pain. With regard to the convergent and divergent validity, the PVAQ was found to correlate highly with related constructs like catastrophizing (PCS) and general body vigilance (BVQ). The correlation between PVAQ and pain-related fear (FPQ) was moderate, whereas correlations with unrelated constructs like trait anxiety (STAI-T) and fear of spiders (FSQ) were low. Furthermore, the PVAQ showed good internal consistency and fair test-retest reliability. Altogether, these findings suggest that the PVAQ is a valid and reliable measure of pain vigilance in healthy individuals. The results of this study can be regarded as a starting point for further validation of the PVAQ in clinical pain populations. Implications for future research and treatment interventions are discussed.

\footnotetext{
* Roelofs, J., Peters, M. L., Muris, P., \& Vlaeyen, J. W. S. (2002). Dutch version of the Pain Vigilance and Awareness Questionnaire: validity and reliability in a pain-free population. Behaviour Research and Therapy, 40, 1081-1090.
} 


\section{INTRODUCTION}

Preoccupation with or attention to pain is associated with fear of pain and perceived pain severity in chronic pain patients. According to the cognitive theory of anxiety put forward by Eysenck (1992), the most important function of anxiety is facilitating the early detection of potentially dangerous stimuli. Anxiety may therefore represent a shift into a mode of hypervigilance (i.e., increased attention for pain and other somato-sensory signals), such that the person scans the environment for threatening stimuli. This is defined as specific hypervigilance. Highly anxious individuals may also tend to pay attention to other irrelevant (neutral) stimuli, which is referred to as general hypervigilance. In the case of chronic pain, if pain is interpreted as threatening, possibly through the cognitive process of catastrophizing, pain-related fear evolves. Pain-related fear may induce a state of hypervigilance, which may in turn influence the perceived pain severity (McCracken, 1997) and lead to avoidance behaviors, which maintain a chronic pattern of disability, disuse and depression (see Vlaeyen \& Linton, 2000 for a review).

The measurement of pain vigilance was advanced by the development of the Pain Vigilance and Awareness Questionnaire, PVAQ (McCracken, 1997). The PVAQ, originally constructed to investigate attention to pain in persons with chronic pain, is a 16-item measure of attention to pain that assesses awareness, consciousness, vigilance, and observation of pain, all of which are expected to be functionally similar. The items were partly based on the Body Vigilance Questionnaire (BVQ; Mueller et al., 1992), a measure of preoccupation and sensitivity to bodily sensations for persons with panic disorder. Six of the 19 items of the BVQ were adopted directly by maintaining the form of the item but inserting pain in place of the other body sensations included in the BVQ. Ten additional items were created on a rational basis to capture other attentional responses appropriate to pain. Respondents are asked to consider their behavior over the last 2 weeks and to indicate how frequently, on a scale from 0 (never) to 5 (always), each item was a true description of them. The items have demonstrated good internal consistency reliability (Cronbach's alpha = 0.86) in a population of chronic low back pain patients (McCracken, 1997).

Recently, McWilliams and Asmundson (2001) conducted a principal components analysis with oblique rotation on PVAQ scores derived from 256 University students. A three-factor solution was found accounting for $63 \%$ of the variance, viz. Awareness of Change (six items), Intrusion (four items), and Monitoring (six items). Cronbach's alphas for the total PVAQ scale (0.92) and the three subscales identified (ranged from 0.65 to 0.88 ) indicated excellent to adequate internal consistency. The present study aims to further assess the validity and reliability of a Dutch version of the PVAQ in two populations of healthy university students. Therefore, an exploratory factor analysis was carried out to derive the factors and scales in the derivation sample that consisted of college students. The stability of both the factor structure from the derivation sample in the present study 
and the factor structure found by McWilliams and Asmundson (2001) were further tested in a comparable independent sample of college students (replication sample), using confirmatory factor analysis. Additionally, to assess convergent and divergent validity of the PVAQ, its relationship with related and unrelated constructs (reflected by questionnaire measures) was investigated. Subsequently, to further investigate the validity of the PVAQ, an exploratory factor analysis was performed in which all items of the PVAQ and other pain-related measures such as the Pain Catastrophizing Scale (PCS) and the Fear of Pain Questionnaire (FPQ) were included. It was expected that a model consisting of three factors (i.e. PVAQ, PCS and FPQ) would be most suitable. Reliability of the PVAQ was assessed by determining its internal consistency reliability (Cronbach's alpha) and test-retest reliability. In addition, deciles scores were computed and standardization of the questionnaire scores was performed.

\section{METHODS}

\section{Participants}

Two groups of participants were used in the present study. The first group (the derivation sample) consisted of 271 first-year college students (226 females, 54 males) who completed a battery of questionnaires. The second group (the replication sample) consisted of 207 first-year college students (175 females, 32 males) who also filled in a set of questionnaires a year before. As such, none of the participants took part in both groups. There were no differences in age between both groups $(M=19.4$, $S D=1.4$ versus $M=19.5, S D=1.9, \mathrm{t}(469)=1.3, \mathrm{p}=0.18)$. The replication sample was only used for confirmatory factor analysis and for the estimation of deciles scores and to perform standardization.

\section{Questionnaires}

Participants in both groups completed the Pain Vigilance and Awareness Questionnaire (McCracken, 1997), which contains 16 items rated on a 6-point scale. PVAQ scores range between 0 and 80 . Participants in the derivation sample only, further filled out a set of questionnaires. The trait version of the State-Trait Anxiety Inventory (STAI-T; Spielberger et al., 1970) is a self-report measure of trait anxiety and contains 20 items rated on a 4-point scale. STAI-T scores range between 20 and 80. The Pain Catastrophizing Scale (PCS; Sullivan et al., 1995) is a self-report measure of catastrophizing related to pain and contains 13 items rated on a 4-point scale. The PCS consists of three scales (magnification, rumination and helplessness). The Body Vigilance Questionnaire (BVQ; Mueller et al., 1992) is a self-report questionnaire measuring more general vigilance to bodily sensations. The scale consists of 18 items that are scored on a 10-point scale. The Fear of Pain Questionnaire (FPQ; McNeil \& Rainwater, 1998) is a general measure of pain-related fear containing 30 items rated on a 5-point scale. Finally, the Fear of Spiders Questionnaire (FSQ; Szymanski \& 
O'Donohue, 1995), which measures specific anxiety related to spiders, consists of 18 items scored on a 8-point scale. For all questionnaires, higher scores reflect higher levels of the underlying person characteristic that the questionnaire presumes to measure.

\section{Statistical analyses}

The Statistical Package for Social Sciences (SPSS) was used for computing descriptive statistics, correlations, estimates of reliability, exploratory factor analysis and t-test comparisons. To further examine the structure of the PVAQ, confirmatory factor analysis was conducted, employing the structural equations models LISREL software (Du Toit et al., 1999). With regard to missing data in the questionnaire scores, an estimation of missing values was derived from a regression algorithm. That is, missing values were estimated by means of multiple linear regression, which takes into account both how a particular person who has a missing value is scoring on the other items and how others are scoring on the item, which has a missing value for that particular person.

Validity refers to the ability of an instrument to measure the theoretical construct for which it is developed. Factor analysis is a technique, which may be used to assess psychometric validity. Items relating to a particular scale can be grouped within one or more factors. Items that are grouped within factors relating to more than one scale should be considered for rejection. In order to carry out an exploratory factor analysis, data from the derivation sample were subjected to principal component analysis. The scree test (Cattell, 1978) and the magnitude of the eigenvalues were used to determine the most suitable number of factors. An oblique rotation was performed to obtain the factor loadings. An oblique rotation allows factors obtained to be mutually correlated. Applying the criteria by Comree and Lee (1992), only loadings of 0.32 and above are interpreted. With regard to the confirmatory factor analysis, the stability of the factor loadings and structure from the derivation sample were tested in the replication sample using polychoric correlations. The goodness-of-fit was evaluated using multiple criteria: (a) Root Mean Square Error of Approximation (RMSEA); (b) the comparative fit index (CFI); (c) the non-normed fit index (NNFI); (d) the goodness of fit index (GFI). With regard to the RMSEA, values below 0.08 are considered to indicate adequate fit whereas for CFI, NNFI and the GFI, values above 0.90 are considered as indicative of an adequate fit. In order to assess the convergent and divergent validity of the PVAQ, Pearson correlation coefficients were computed between the various questionnaires. It was expected that related constructs like PCS, BVQ and FPQ would correlate highly with PVAQ, whereas relatively lower correlations were expected for STAI-T and FSQ with PVAQ. In addition, it was tested whether differences in the magnitude of some of the correlations were statistically significant. To further test the validity of the PVAQ, an exploratory factor analysis was conducted in which all items of the PVAQ, PCS and FPQ were analyzed. As the PVAQ, PCS, and FPQ are assumed to measure different 
pain-related constructs, it was expected that each questionnaire would load on a different factor, thereby representing a three-factor solution.

Reliability refers to the reproducibility of a measure on one individual across different settings and in different individuals in the same setting. Internal consistency reliabilities (Cronbach's alpha) were estimated. The test-retest reliability was estimated for only ninety-three participants from the derivation sample as they also participated in a further experiment. To compute deciles scores and to perform standardization, both samples were taken together. Before computing deciles scores and standardizing, it was investigated whether gender and age influenced scores on the PVAQ using t-tests.

\section{RESULTS}

\section{Descriptive statistics of the questionnaires}

Before addressing the main results, three remarks about the descriptive statistics of the various questionnaires are in order (see table 4-1). First, scores on the PVAQ were normally distributed with scores ranging from 6 to 73, indicating sufficient spread. Second, the questionnaires generally had satisfactory internal consistency. The lowest Cronbach's alpha (0.70) was observed for the BVQ. Third, significant gender differences were found for the FPQ $(t=2.71, p=0.007)$ and for the FSQ $(t=3.57$, $\mathrm{p}<0.001)$.

Table 4-1: Descriptive statistics of the questionnaires. Standard deviations in parenthesis. ( $n=271)$.

\begin{tabular}{lllll}
\hline & Mean & Males & Females & Alpha \\
\hline PVAQ & $34.4(11.8)$ & $33.8(10.8)$ & $34.5(12.0)$ & 0.88 \\
BVQ & $16.3(5.5)$ & $16.3(5.5)$ & $16.3(5.6)$ & 0.70 \\
PCS & $14.3(7.9)$ & $13.1(9.2)$ & $14.5(7.6)$ & 0.90 \\
FPQ & $74.0(16.3)$ & $68.0(13.5)$ & $75.1(16.5)$ & 0.93 \\
STAI-T & $37.8(9.3)$ & $36.8(9.7)$ & $37.9(9.2)$ & 0.92 \\
FSQ & $15.6(21.1)$ & $5.5(10.7)$ & $17.6(22.2)$ & 0.96 \\
\hline
\end{tabular}

Note: $P V A Q=$ Pain Vigilance and Awareness Questionnaire; BVQ = Body Vigilance Questionnaire; PCS = Pain Catastrophizing Scale; FPQ = Fear of Pain Questionnaire; STAI-T= Trait version of the State-Trait Anxiety Inventory; FSQ = Fear of Spiders Questionnaire.

The scree test and eigenvalues $>1.0$ indicated the relative suitability of two or three factors for the PVAQ. However, with regard to the third factor, two items that were reversed keyed (item 8 and 16) loaded highly on this factor, indicating that the third factor might be a statistical artifact, leaving two factors. On the basis of these results, the entire derivation sample was factor analyzed, and two factors were rotated to an oblique solution. The two rotated factors accounted for $52.1 \%$ of the total variance. Table 4-2 presents the items, the factor loadings and eigenvalues for each factor. 
Table 4-2: Factor loadings and eigenvalues of PVAQ items as obtained by exploratory factor analysis.

\begin{tabular}{llll}
\hline Item & Description & Factor 1 & Factor 2 \\
\hline 13 & I pay close attention to my pain & 0.83 & \\
12 & I seem to be more conscious of pain than others & 0.79 & \\
15 & I become preoccupied with pain & 0.76 & \\
6 & I focus on sensations of pain & 0.70 & \\
1 & I am very sensitive to pain & 0.66 & \\
7 & I notice pain even if I am busy with another activity & 0.65 & 0.36 \\
14 & I keep track of my pain level & 0.58 & \\
16 & I do not dwell on pain & 0.57 & \\
8 & I find it easy to ignore pain & 0.51 & \\
10 & When I do something that increases pain, the first thing I & 0.40 & 0.84 \\
& do is check to see how much pain was increased & & 0.82 \\
3 & I know immediately when pain decreases & & 0.81 \\
9 & I am quick to notice changes in pain intensity & & 0.78 \\
5 & I know immediately when pain starts or increases & & 0.74 \\
2 & I am quick to notice changes in location or extent of pain & & 0.49 \\
4 & I am aware of sudden or temporary changes in pain & & 2.3 \\
\hline Eigenvalues & I am quick to notice effects of medication on pain & & \\
\hline
\end{tabular}

Note: Only factor loadings $\geq 0.32$ are shown.

The ten items that loaded on the first factor appeared to represent attention to pain ("I pay close attention to pain", "I seem to be more conscious of pain than others"). The second factor consisted of six items that appeared to represent attention to changes in pain ("I know immediately when pain decreases", "I am quick to notice changes in pain intensity"). As can be seen in table 4-2, the vast majority of the PVAQ items loaded uniquely on one of both factors. Only item 14 "I keep track of my pain level" showed a secondary loading (0.36) on the "Changes in pain" factor. However, it should be noted that this item loaded most substantially $(0.58)$ on the "Attention to pain" factor.

\section{Confirmatory factor analysis}

The goodness-of-fit of the two-factor model derived from the derivation sample in the present study and the three-factor solution provided by McWilliams and Asmundson (2001) were applied to the replication sample. Table 4-3 provides the goodness-of-fit indicators for both models. 
Table 4-3: Goodness-of-fit indices statistics for both the two and three factor PVAQ solution as obtained by means of confirmatory factor analysis

\begin{tabular}{lcccc}
\hline & RMSEA & CFI & NNFI & GFI \\
\hline Roelofs & 0.075 & 0.96 & 0.95 & 0.97 \\
McWilliams & 0.075 & 0.96 & 0.95 & 0.96 \\
\hline
\end{tabular}

Note: RMSEA = Root Mean Square Error of Approximation, CFI = Comparative Fit Index, NNFI = Non-Normed Fit Index, GFI = Goodness of Fit Index.

For both models, the RMSEA is below 0.08 indicating an adequate fit. Furthermore, the CFI, NNFI, and GFI are all well above 0.90 indicating good fit. Taken together, the goodness-of-fit indicators show a good fit of both the two-factor model proposed in the present study and the three-factor model proposed by McWilliams and Asmundson (2001).

\section{Convergent and divergent validity}

Table 4-4 shows a correlation matrix (Pearson-correlation) of the various questionnaire scores. As expected, the PVAQ total score and the scores on both subscales correlated highly with theoretically related constructs as general body vigilance (BVQ) and catastrophizing (PCS). With regard to the PCS, the magnification scale and the rumination scale correlated highly with the PVAQ whereas a relatively lower correlation was observed between the PCS helplessness scale and PVAQ. The PVAQ correlated significantly higher with both the PCS and the BVQ than with the STAI-T. The differences in the magnitude of the correlations were statistically significant $(z=5.92, p<0.001$ and $z=4.94, p<0.001$ respectively). Furthermore, the PVAQ correlated stronger with FPQ than with the STAI-T and the FSQ. However, the difference in the magnitude of the correlation between PVAQ and FPQ and the magnitude of the correlation between PVAQ and STAI-T, and PVAQ and FSQ, did not reach statistical significance $(z=1.28, p=0.20$ and $z=1.48, p=0.14$ respectively). Partial correlation coefficients between the various questionnaire measures, controlling for gender and general anxiety (STAI-T) yielded correlations comparable to those in table 4-4. 
Table 4-4: Pearson correlation coefficients of various questionnaires

\begin{tabular}{|c|c|c|c|c|c|}
\hline & PVAQ & PCS & STAI-T & $B \vee Q$ & $\mathrm{FPQ}$ \\
\hline PCS & $0.58^{* \star}$ & & & & \\
\hline PCS rumination & $0.82^{* *}$ & & & & \\
\hline $\mathrm{PCS}_{\text {magnification }}$ & $0.83^{* *}$ & & & & \\
\hline PCS helplessness & $0.52^{* *}$ & & & & \\
\hline STAI-T & $0.23^{* \star}$ & $0.39^{* *}$ & & & \\
\hline$B \vee Q$ & $0.56^{* *}$ & $0.38^{* *}$ & $0.22^{* *}$ & & \\
\hline $\mathrm{FPQ}$ & $0.32^{* *}$ & $0.38^{* *}$ & $0.26^{\star *}$ & $0.29^{* *}$ & \\
\hline FSQ & $0.21^{* \star}$ & $0.13^{*}$ & 0.08 & 0.10 & $0.18^{* *}$ \\
\hline$P V A Q_{\text {attention to pain }}$ & $0.91^{* *}$ & $0.68^{* *}$ & $0.36^{\star *}$ & $0.52^{* *}$ & $0.36^{* *}$ \\
\hline 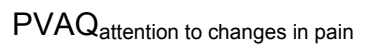 & $0.79^{* *}$ & $0.23^{* *}$ & -0.06 & $0.40^{* *}$ & $0.15^{*}$ \\
\hline
\end{tabular}

Note: $P V A Q=$ Pain Vigilance and Awareness Questionnaire including both subscales; PCS = Pain Catastrophizing Scale including subscales; STAI-T= Trait version of the State-Trait Anxiety Inventory; BVQ = Body Vigilance Questionnaire, FPQ = Fear of Pain Questionnaire; FSQ = Fear of Spiders Questionnaire. ${ }^{*} p=0.05$ and ${ }^{* *} p<0.01$

\section{Exploratory factor analysis with PVAQ, PCS and FPQ}

The complete derivation sample was factor analyzed to examine whether painrelated measures like the PVAQ, PCS and FPQ were distinct concepts. For this reason, three factors were rotated to an oblique solution (data not shown). The three rotated factors accounted for $39.8 \%$ of the total variance. The first factor consisted of all FPQ items. The second factor consisted of all PCS items, in addition to the items from the first scale of the PVAQ (attention to pain). The third scale consisted of the remaining items from the second PVAQ scale (attention to changes in pain).

\section{Reliability}

Internal consistency reliabilities of the total questionnaire in the derivation sample was 0.88 (see table 4-1) and for the first scale (attention to pain) 0.86 and for the second scale (attention to changes in pain) 0.85 . Both scales were moderately intercorrelated $(\mathrm{r}=0.36)$. Test-retest reliability of the PVAQ for ninety-three participants was 0.77 (mean $=34.4, \mathrm{SD}=12.7$ for the first administration (adm1) and mean $=33.9, \mathrm{SD}=11.1$ for the second administration $(\operatorname{adm} 2))$. With regard to the 'attention to pain' scale, a test-retest reliability of 0.82 was estimated $(\mathrm{adm} 1$ : mean $=$ 17.9, $\mathrm{SD}=9.4 ;$ adm2: mean $=17.4, \mathrm{SD}=8.2$ ), whereas a test-retest reliability of 0.71 was observed for the 'attention to changes in pain' scale ( $\operatorname{adm1} 1$ : mean $=16.5, \mathrm{SD}=5.3$; adm2: mean $=16.5, S D=5.1$ ). The time between completing the questionnaires was about three months. No differences in scores were found for gender nor age. This may be a function of little variability in age and the fact that the sample was predominantly female. In order to compute deciles scores, data from both samples were used. Table 4-5 displays the deciles scores and standardization. 
Table 4-5: Deciles scores of the PVAQ $(n=478)$.

\begin{tabular}{lll}
\hline Decile & Questionnaire score & Standardization \\
\hline 1 & 21.0 & Low \\
2 & 26.0 & Below average \\
3 & 29.0 & Below average \\
4 & 32.0 & Average \\
5 & 34.0 & Average \\
6 & 37.0 & Above average \\
7 & 40.0 & Above average \\
8 & 43.0 & High \\
9 & 49.0 & \\
\hline
\end{tabular}

\section{DISCUSSION}

According to cognitive models of chronic pain, vigilance (or attention) to pain is considered to be an important feature in people suffering from chronic pain. A reliable and valid instrument to measure pain vigilance is therefore required. The current study examined the validity and reliability of the Pain Vigilance and Awareness Questionnaire in two samples of healthy Dutch college students. Validity was assessed by exploratory factor analysis that was used to investigate the factor structure of the 16-item PVAQ. A two-scale model was found to be most suitable. Interpreting both factors, the first factor could be referred to as attention to pain whereas the second factor could be specified as attention to changes in pain. In order to test the two-factor solution found in the present study and the three factor solution provided by McWilliams and Asmundson (2001), a confirmatory factor analysis was conducted in an independent sample of University students. The goodness-of-fit indices for both models indicated a good fit. However, one important remark about both factor solutions is in order. The "Intrusion" factor and "Monitoring" factor proposed by McWilliams and Asmundson (2001) merged into one factor viz. "Attention to pain" in the present study. The "Intrusion" factor consists of only four items of which the two most salient items were are also the reversed keyed items. The Cronbach's alpha for the "Intrusion" factor was relatively low (0.58) in the present population. One may question the clinical use of this factor and consider the 
use of more thorough and unequivocal measures of (pain-related) intrusion (see Kerns et al., 1993). In order to investigate the uniqueness of the PVAQ in relation to the PCS and the FPQ an exploratory factor analysis was carried out in which all items of the PVAQ, PCS and FPQ were analyzed. A three-factor structure revealed that the PVAQ items from the 'attention to pain' scale loaded on the same factor as all PCS items and the remaining PVAQ items ('attention to changes in pain') loaded on a separate factor. This may explain the higher correlation between PVAQ and PCS compared to PVAQ and FPQ in this study and an earlier study (Roelofs et al., 2002). This may also account for the finding that no statistically significant differences were found in the magnitude of the correlations between PVAQ and the various measures of fear (FPQ, STAI-T, FSQ). The FPQ does not have any items that load on a latent factor together with items from the PVAQ. This suggests that PVAQ and FPQ should be considered as different constructs, in contrast to PVAQ and PCS, which appear to have some overlap. With regard to the PVAQ and PCS, higher correlations were found between PVAQ and the PCS rumination and magnification scale compared to the PCS helplessness scale. This can be explained in terms of coping to stress. That is, the magnification scale and the rumination scale from the PCS may be related to primary appraisal processes where individuals focus on and exaggerate the threat value of a painful stimulus. The PCS helplessness scale may be related to secondary appraisal processes where individuals negatively evaluate their ability to deal effectively with painful stimuli (Sullivan et. al., 1995).

Reliability analyses showed good internal consistency (Cronbach's alpha) for both the complete questionnaire (0.88) and the scales (0.86 and 0.85$)$ and a fair testretest reliability (0.77). This is in line with the findings of McCracken, who reported a Cronbach's alpha of 0.86 (McCracken, 1997). However, with regard to the test-retest reliability coefficient, it should be remarked that the time between both measures was about three months. Although pain vigilance is considered to be a trait variable, changes in pain vigilance could occur due to the relative large period between both questionnaire administrations.

In conclusion, the present data provide evidence that the PVAQ is a reliable and valid measure of pain vigilance in a population of healthy University college students. The factor structure found in the current study should be further tested in samples with greater variability in age and sex and in different pain populations, like chronic low-back pain and fibromyalgia. Unlike chronic pain patients, the pain free individuals in the current study may have experienced some difficulty in filling in questions with regard to attention to changes in pain, simply because they do not experience pain on a regular basis. Chronic pain patients seek for solutions to their pain and attend to possible changes in pain. Thus, 'attention to pain' and 'attention to changes in pain' might be more closely related to each other in chronic pain patients than in healthy individuals. Future research should examine to what extent 'attention to pain' and 'attention to changes in pain' may change in the development of pain chronicity. More specifically, the relationship of the PVAQ and its subscales to pain 
severity, somatic symptoms, disability, reassurance seeking and healthy care utilization should be investigated.

The responsiveness of the PVAQ and its subscales to treatment interventions should be explored. It is possible that chronic pain patients who display high levels of pain-related fear may have developed inadequate strategies to attend to changes in pain. This may explain the observation that distraction from pain (a coping strategy) does not seem to work in highly fearful patients (Hadjistavropoulos, Hadjistavropoulos \& Quine, 2000). In addition, the effects of fear-reducing techniques, like exposure in vivo (see Vlaeyen et al., 2001), may lead to reductions in pain vigilance and hence possibly to reductions in pain intensity.

\section{REFERENCES}

Cattell, R. B. (1978). The scientific use of factor analysis in behavioural and life sciences. New York: Plenum Press.

Comrey, A. L. \& Lee, H. B. (1992). A first course in factor analysis. (2 ${ }^{\text {nd }}$. Ed.) Hillsdale, NJ: Erlbaum.

Du Toit, S., Du Toit, M., Jöreskog, K. G., \& Sörbom, D. (1999). Interactive LISREL: User's guide. Chicago, IL: Scientific Software International Inc.

Eysenck, M. W. (1992). Anxiety: The cognitive perspective. Hove: Erlbaum.

Hadjistavropoulos, H. D., Hadjistavropoulos, T., \& Quine, A. (2000). Health anxiety moderates the effects of distraction versus attention to pain. Behaviour Research and Therapy, 38, 425-438.

Kerns, J. M. C., Rosenberg, R., \& Haythronthwaite, J. (1993). Chronic pain: intrusion and accommodation. Behaviour Research and Therapy, 31(5), 519-527.

McCracken, L. M. (1997). "Attention" to pain in persons with chronic pain: A behavioural approach. Behaviour Therapy, 28, 271-284.

McNeil, D. W., \& Rainwater, A. J. (1998). Development of the Fear of Pain Questionnaire-III. Journal of Behavioural Medicine, 21, 389-410.

McWilliams, L. A., \& Asmundson, G. J. G. (2001). Assessing individual differences in attention to pain: Psychometric properties of the Pain Vigilance and Awareness Questionnaire modified for a non-clinical pain sample. Personality and Individual Differences, 31, 239-246.

Mueller, G. P., Telch, M. J., \& Curry, J. (1992). Validation of the Body Vigilance Questionnaire. Paper presented at the annual meeting of the Association for Advancement of Behaviour Therapy. Boston.

Roelofs, J. Peters, M. L., \& Vlaeyen, J. W. S. (2002). Selective attention for pain-related information in healthy individuals: the role of pain and fear. European Journal of Pain, 6, 331-339.

Spielberger, C. D., Gorsuch, R. L., \& Lushene, R. E. (1970). State-Trait Anxiety Inventory. Palo Alto: Consulting Psychologists Press. 
Sullivan, M. J. L., Bishop, S. R., \& Pivik, J. (1995). The pain catastrophizing scale: development and validation. Psychological Assessment, 7, 524-532.

Szymanski, J., \& O'Donohue, W. (1996). Fear of Spiders Questionnaire. Journal of Behaviour Therapy and Experimental Psychiatry, 26, 31-34.

Vlaeyen, J. W. S., De Jong, J., Geilen, M., Heuts, P. H. T. G. (2001). Graded exposure in vivo in the treatment of pain-related fear: a replicated single-case experimental design in four patients with chronic low back pain. Behavioural Research and Therapy, 39, 151-166.

Vlaeyen, J. W. S., \& Linton, S. J. (2000). Fear-avoidance and its consequences in chronic musculoskeletal pain: a state of the art. Pain, 85, 317-332. 


\subsection{The Pain Vigilance AND AWARENESS QueStionNAIRE (PVAQ): FURTHER PSYCHOMETRIC EVALUATION IN FIBROMYALGIA AND OTHER CHRONIC PAIN SYNDROMES*}

\section{ABSTRACT}

In chronic pain patients, preoccupation with or attention to pain is associated with pain-related fear and perceived pain severity. The current study investigated psychometric properties of the Pain Vigilance and Awareness Questionnaire (PVAQ). An exploratory factor analysis on Dutch fibromyalgia patients indicated that a two-factor solution was most suitable. The first factor could be referred to as Attention to Pain and the second factor was interpreted as Attention to Changes in Pain. A confirmatory factor analysis, testing three different factor structures in two independent samples (Dutch fibromyalgia patients and American pain patients with various diagnoses) showed that the goodness-of-fit indicators for all models were satisfactory. The existence of the previously reported Intrusion subscale of the PVAQ as a unique construct within the PVAQ was discussed. This subscale should be further extended by non-reverse-keyed items. With regard to the convergent validity, the PVAQ was highly correlated with related constructs such as the pain catastrophizing (PCS), pain-related fear (PASS), and fear of movement/(re)injury (TSK). The Attention to Pain subscale was significantly stronger associated with these pain related measures than the Attention to Changes in Pain subscale, indicating that Attention to Changes in Pain is a distinctive construct. The uniqueness of the Attention to Changes in Pain subscale was also supported by an exploratory factor analysis on all items of the PVAQ, PCS, PASS, and TSK, which showed that all items from that scale loaded on one separate factor. Overall, the PVAQ showed good internal consistency. Implications for future research and treatment interventions are discussed.

\footnotetext{
* Roelofs, J., Peters, M. L., McCracken, L. M., \& Vlaeyen, J. W. S. (2003). The Pain Vigilance and Awareness Questionnaire (PVAQ): further psychometric evaluation in fibromyalgia and other chronic pain syndromes. Pain, 101, 299-306.
} 


\section{INTRODUCTION}

In chronic pain patients, preoccupation with or attention to pain is assumed to be associated with perceived pain severity (Melzack \& Wall, 1982). In theorizing on the relation between attention to pain and the pain experience, Eccleston and Crombez (1999) introduced a cognitive-affective model of the interruptive function of pain. From an evolutionary view, attention is defined as selection for action, which serves the intrinsic purpose of escape. The experience of pain is assumed to interrupt attention automatically. The degree of disruption of attention by pain may depend on factors related to pain such as intensity, novelty, predictability, threat, and factors related to the environment of pain, such as emotional arousal. This cognitive model of the interruptive function of pain clearly assumes that, as a consequence of pain, attention is automatically directed to the pain. Alternatively, several experimental studies have shown that (excessive) attention to pain may exacerbate the pain experienced in acute pain (Janssen \& Arntz, 1996; Arntz et al., 1994; Arntz \& De Jong, 1993; Arntz et al., 1991). This excessive attention to pain is called hypervigilance.

The concept of hypervigilance was first introduced in the pain literature by Chapman (1978). Chapman defined hypervigilance as constant scanning of the body for somatic and, particularly, pain sensations. Increased attention to pain and other somato-sensory signals is defined as specific hypervigilance, while increased attention directed towards irrelevant (neutral) stimuli, is referred to as general hypervigilance. Recently, a cognitive-behavioral model of chronic low back pain, also referred to as a 'fear-avoidance model', has been proposed. According to his model, when pain sensations are interpreted as threatening, pain-related fear may evolve. In line with the cognitive theory of anxiety put forward by Eysenck (1992), which states that the most important function of anxiety is facilitating the early detection of potentially dangerous stimuli, pain-related fear may lead to a state of hypervigilance. Hypervigilance may in turn influence (i.e., increase) the perceived pain severity and lead to avoidance behavior. Subsequently, avoiding activities may result in a chronic pattern of disability, disuse and depression (see Vlaeyen and Linton, 2000 for a review). According to this 'fear-avoidance model', one may hypothesize that especially highly fearful pain patients may display hypervigilance towards their pain. Although experimental paradigms exist to indirectly assess attentional redirection, for clinical purposes it is much more convenient to have a sensitive selfreport measure of the propensity of patients to attend to their pain.

The Pain Vigilance and Awareness Questionnaire (PVAQ; McCracken, 1997) was developed as a broad measure of attention to pain, which can be applied to various pain populations. The PVAQ consists of 16 items and respondents are asked to consider their behavior over the last 2 weeks and to indicate how frequently, on a six-point scale from zero (never) to five (always), each item is a true description of them. McCracken (1997) evaluated psychometric properties of the PVAQ in eighty chronic low back pain patients and found good internal consistency (Cronbach's 
alpha $=0.86)$ and adequate test-retest reliability $(r=0.80)$. Furthermore, PVAQ scores correlated positively with private body consciousness (BCQ; Miller et al., 1981) and negatively with ignoring pain (CSQ; Rosenstiel \& Keefe, 1983), providing support for construct validity of the PVAQ. Moreover, the criterion validity of the PVAQ was supported as patients reporting more pain vigilance were also found to report higher levels of pain intensity, emotional distress, psychosocial disability, and more physician visits due to pain (even when controlling for pain severity and demographic variables).

McWilliams and Asmundson (2001) investigated the incidence of attention to pain in a non-clinical pain sample. With regard to the factorial validity of the PVAQ, they conducted a principal components analysis with oblique rotation on PVAQ scores derived from 256 University students. A three-factor solution was obtained accounting for $63 \%$ of the variance. The factors were labeled Awareness of Change $(6$ items), Intrusion (4 items), and Monitoring (6 items). Cronbach's alphas for the total PVAQ scale (0.92) and the three subscales identified (ranged from 0.65 to 0.88 ) indicated adequate to excellent internal consistency. Recently, we investigated the factorial validity of the PVAQ in a sample of University students by means of exploratory factor analysis and confirmatory factor analysis (Roelofs et al., 2002). With regard to the exploratory factor analysis, a principal components analysis with oblique rotation was conducted on PVAQ scores from 271 University students. A two-factor solution was retained accounting for $52 \%$ of the variance. The first factor was referred to as Attention to Pain (10 items) whereas the second factor was labeled Attention to Changes in Pain (6 items). Internal consistency reliability of the total questionnaire was good (Cronbach's alpha $=0.88$ ). With regard to the Attention to Pain and Attention to Changes in Pain subscales, Cronbach's alphas were 0.86 and 0.85 respectively indicating good internal consistency. Furthermore, test-retest reliability was 0.77 for the total PVAQ and 0.82 and 0.71 for the Attention to Pain subscale and the Attention to Changes in Pain subscale respectively, indicating adequate test-retest reliability. The Attention to Changes in Pain factor obtained in our study was identical to the Awareness of change factor as obtained by McWilliams and Asmundson. Unlike the single Attention to Pain factor obtained in our study, they showed an Intrusion factor and a Monitoring factor. In a confirmatory factor analysis, we further tested our two-factor solution and the threefactor solution as obtained by McWilliams and Asmundson. The goodness-of-fit indicators showed a good fit for both the two-factor and three-factor model.

In sum, the preliminary data on psychometric properties of the Pain Vigilance and Awareness Questionnaire support the construct validity and criterion validity as well as its reliability (internal consistency and test-retest reliability). The factorial validity has been documented in (healthy) University students and yielded inconsistent results with regard to the number of factors to retain (McWilliams \& Asmundson, 2001; Roelofs et al., 2002). The present study aims to further evaluate the psychometric properties of the PVAQ in chronic pain patients. Therefore, an exploratory factor analysis was conducted in a sample of Dutch fibromyalgia 
patients (objective 1). The stability and generality of the factor structure obtained by exploratory factor analysis as well as the two-factor solution obtained in our previous study (Roelofs et al., 2002) and the three-factor solution provided by McWilliams and Asmundson (2001) were further tested in a second independent sample of Dutch fibromyalgia patients and a third sample of American pain patients with various diagnoses by means of confirmatory factor analysis (objective 2). Furthermore, to assess convergent validity of the PVAQ, its relationship with other pain-related selfreport measures such as the Pain Catastrophizing Scale (PCS), the Pain Anxiety Symptoms Scale (PASS), and the Tampa Scale for Kinesiophobia (TSK) was investigated (objective 3). Subsequently, to investigate the cohesiveness and relative independence of the domains assessed by the PVAQ relative to the content of related inventories, an exploratory factor analysis was conducted in which all items of the PVAQ, PCS, PASS, and TSK were included (objective 4). It was expected that a model with four factors (i.e., PVAQ, PCS, PASS, and TSK) was most suitable. Reliability of the PVAQ was assessed by determining the internal consistency reliability (Cronbach's alpha) (objective 5).

\section{METHODS}

\section{Participants}

Three independent samples were used in the present study. Sample one and two were formed out of a larger sample of fibromyalgia patients. Approximately one thousand fibromyalgia patients who were all member of a patients' association were initially approached and asked to fill in a set of questionnaires of which 404 patients actually responded. For the PVAQ, only three patients had more than 10 percent missing values. These patients were omitted, leaving a total number of 401 patients. Two separate consecutive samples were derived from these patients. Sample 1 consisted of 200 Dutch fibromyalgia patients and was used for exploratory factor analysis whereas sample 2 consisting of the remaining 201 Dutch fibromyalgia patients, was used for confirmatory factor analysis. As ten patients had more than 10 percent missing values on the other questionnaires, only 391 patients (also for the PVAQ) were taken into account for further analyses (i.e., convergent validity, exploratory factor analysis with PVAQ, PCS, PASS, and TSK, and reliability analysis). Sample 3 consisted of 276 pain patients with various diagnoses (e.g., fibromyalgia, arthritis, neck pain) who attended a pain clinic in Chicago (USA). Sample 3 was used for confirmatory factor analysis. Samples 1 and 2 were taken together in order to assess the convergent validity, exploratory factor analysis with PVAQ, PCS, PASS, and TSK, and the internal consistency reliability. Table 4-6 presents descriptive information for the three samples used in the present study. 
Table 4-6: Descriptive information for the three samples.

\begin{tabular}{|c|c|c|c|c|c|c|c|}
\hline & \multirow[t]{2}{*}{$\mathrm{n}$} & \multicolumn{2}{|c|}{ Age } & \multirow[t]{2}{*}{$\%$ Female } & \multicolumn{2}{|c|}{ Pain duration } & \multirow[t]{2}{*}{$\%$ Working } \\
\hline & & Mean & $\mathrm{SD}$ & & Mean & $\mathrm{SD}$ & \\
\hline Sample 1 & 200 & 46.7 & 9.8 & 96 & 148 & 105 & 39 \\
\hline Sample 2 & 201 & 48.1 & 10.4 & 93 & 171 & 125 & 31 \\
\hline Sample 3 & 276 & 46.7 & 13.8 & 66 & 63 & 80 & 26 \\
\hline
\end{tabular}

Note: Sample 1 and 2 refer to Dutch fibromyalgia patients, Sample 3 refers to American pain patients. Age is expressed in years and pain duration in months.

\section{Questionnaires}

Participants in samples 1 and 2 completed the Dutch version of the Pain Vigilance and Awareness Questionnaire (PVAQ; McCracken, 1997) and participants in sample 3 completed the English version of the PVAQ. No substantial differences between both versions exist. The PVAQ consists of 16 items rated on a 6-point scale. Participants in samples 1 and 2 completed an additional set of questionnaires. The Pain Catastrophizing Scale (PCS; Sullivan et al., 1995) is a self-report measure of catastrophizing related to pain and contains 13 items rated on a 4-point scale. The PCS consists of three subscales (i.e., rumination, magnification, helplessness). The Pain Anxiety Symptoms Scale (PASS; McCracken et al., 1992) is a 40-item self-report instrument rated on a 6-point scale, intended to assess four components of painrelated anxiety (i.e., fearful appraisal of pain, cognitive anxiety, physiological anxiety, escape and avoidance behavior). The Tampa Scale for Kinesiophobia (TSK; Miller et al., 1991) is a self-report questionnaire measuring fear of movement and (re)injury. The scale consists of 17 items that are scored on 4-point scale. The TSK comprises four subscales (harm, fear of (re)-injury, importance of movements, and escape and avoidance behavior). The psychometric properties (i.e., validity and reliability) of the PCS (Sullivan et al., 1995; Osman et al., 1997; Osman et al., 2000; Van Damme et al., 2002), the PASS (McCracken et al., 1992; Osman et al., 1994; Larsen et al., 1997; Burns et al., 2000), and the TSK (Vlaeyen et al., 1995; Goubert et al., 2000) are well documented and supported. For all questionnaires, higher scores reflect higher levels of each of the variables assessed.

\section{Data analysis}

With regard to the factorial validity of the PVAQ, an exploratory factor analysis was conducted (using SPSS version 10 for Windows), in which PVAQ data from the first sample was subjected to a principal components analysis with oblique rotation (objective 1). Oblique rotation allows factors obtained to be mutually correlated. The scree test (Cattell, 1978) and the eigenvalue $>1$ criterion were used to determine the most suitable number of factors. Applying the criteria provided by Comrey and Lee (1992), only factor loadings of 0.32 and above are interpreted.

To further test the stability of the factor loadings and factor structure obtained by exploratory factor analysis, a confirmatory factor analysis was conducted (objective 2), in which three factor structures were tested (i.e., the factor structure as 
obtained by exploratory factor analysis in the present investigation, the factor structure as previously found by Roelofs and colleagues, and the factor structure as proposed by McWilliams and Asmundson). The goodness-of-fit was evaluated employing the structural equations models LISREL software (Du Toit et al., 1999) which offers multiple criteria: (a) Root Mean Square Error of Approximation (RMSEA); (b) the Comparative Fit Index (CFI); the Non-Normed Fit Index (NNFI); (d) the Goodness of Fit Index (GFI). With regard to the RMSEA, values below 0.08 are considered to indicate adequate fit whereas for CFI, NNFI, and the GFI, values above 0.90 indicate an adequate fit.

In order to assess the convergent validity of the PVAQ (objective 3), Pearson correlation coefficients were computed between the PVAQ and the measures of catastrophizing, pain-related anxiety, and fear of movement/(re)injury (PCS, PASS, and TSK). Furthermore, an exploratory factor analysis with oblique rotation was conducted including all items of the PVAQ, PCS, PASS, and TSK (objective 4). It was expected that each questionnaire would uniquely load on a different factor, thus representing a four-factor solution. Reliability was examined by means of internal consistency (Cronbach's alpha) for the total PVAQ scale as well as for its subscales (objective 5). With regard to the last three objectives, data from the first and second sample were pooled.

\section{RESULTS}

\section{Descriptive statistics of the questionnaires}

Table 4-7 presents descriptive information on the questionnaires for sample 1 and 2 together. Before addressing the main results, two remarks about the descriptive statistics of the various questionnaires are in order (see table 4-6). First, scores on the PVAQ were normally distributed and total scores ranged from 2 to 78, indicating sufficient spread. Second, the internal consistency reliability (Cronbach's alphas) for each questionnaire was good to excellent.

Table 4-7: Descriptive statistics for the various questionnaires for sample 1 and 2 together (fibromyalgia samples; $n=391$ ).

\begin{tabular}{lll}
\hline & Mean (SD) & Alpha \\
\hline PVAQ & $40.0(12.1)$ & 0.87 \\
PCS & $20.3(11.5)$ & 0.92 \\
PASS & $68.4(32.9)$ & 0.94 \\
TSK & $34.2(8.1)$ & 0.80 \\
\hline
\end{tabular}

Note: PVAQ = Pain Vigilance and Awareness Questionnaire, PCS = Pain Catastrophizing Scale, PASS = Pain Anxiety Symptoms Scale, TSK = Tampa Scale for Kinesiophobia. 


\section{Exploratory factor analysis}

The scree test and eigenvalues $>1$ indicated the relative suitability of two or three factors for the PVAQ (eigenvalues: 5.2; 2.6; 1.2). Similar to our previous study (Roelofs et al., 2002), the third factor comprising two items that were reversed-keyed (items 8 and 16), loaded substantially on this factor, indicating that this factor might be a statistical artifact. Thus, a two-factor solution was found most suitable accounting for $49 \%$ of the variance. The two-factor solution indicated that eight items loaded substantially on the first factor, which appeared to represent "Attention to Pain" (e.g., "I pay close attention to pain"). The second factor consisted of six items, which appeared to represent "Attention to Changes in Pain" (e.g., "I know immediately when pain decreases"). All items loaded substantially on one of the two factors except for item 8 and 16 (the reverse-keyed items), though they tend to load on the Attention to Pain subscale. Table 4-8 presents the items and the factor loadings.

Table 4-8: Factor loadings of PVAQ items as obtained by exploratory factor analysis.

\begin{tabular}{llcc}
\hline Item & Description & Factor 1 & Factor 2 \\
\hline 13 & I pay close attention to my pain & $\mathbf{0 . 8 4}$ & -0.02 \\
15 & I become preoccupied with pain & $\mathbf{0 . 8 1}$ & -0.16 \\
6 & I focus on sensations of pain & $\mathbf{0 . 7 9}$ & -0.11 \\
14 & I keep track of my pain level & $\mathbf{0 . 7 4}$ & 0.07 \\
1 & I am very sensitive to pain & $\mathbf{0 . 7 0}$ & -0.01 \\
12 & I seem to be more conscious of pain than others & $\mathbf{0 . 6 3}$ & 0.19 \\
10 & When I do something that increases the pain, the first thing I do is & $\mathbf{0 . 5 8}$ & 0.23 \\
& check to see how much pain was increased & & \\
7 & I notice pain even if I am busy with another activity & $\mathbf{0 . 5 5}$ & 0.02 \\
8 & I find it easy to ignore pain & 0.29 & 0.03 \\
16 & I do not dwell on pain & -0.24 & 0.02 \\
3 & I am quickly to notice changes in pain intensity & 0.07 & $\mathbf{0 . 8 2}$ \\
5 & I am quick to notice changes in location or extent of pain & 0.15 & $\mathbf{0 . 7 8}$ \\
2 & I am aware of sudden or temporary changes in pain & 0.13 & $\mathbf{0 . 7 7}$ \\
11 & I know immediately when pain decreases & -0.05 & $\mathbf{0 . 7 3}$ \\
9 & I know immediately when pain starts or increases & 0.24 & $\mathbf{0 . 6 6}$ \\
4 & I am quick to notice effects of medication on pain & -0.24 & $\mathbf{0 . 5 9}$ \\
\hline
\end{tabular}

\section{Confirmatory factor analysis}

The factor structure obtained by exploratory factor analysis in the present study was further tested by means of confirmatory factor analysis in two independent samples (sample 2 refers to Dutch fibromyalgia patients, sample 3 refers to American pain patients). Only 14 items were taken into account as item 8 and 16 loaded below 0.32 (see Comrey \& Lee, 1992). The factor structure previously obtained by Roelofs and colleagues and McWilliams and Asmundson were also tested (both included item 8 
and 16). Table 4-9 displays the goodness-of-fit indicators for all three models. Generally, the goodness-of-fit indices indicated a good fit for all three models.

Table 4-9: Goodness-of-fit indices for three PVAQ factor solutions as obtained by means of confirmatory factor analysis.

\begin{tabular}{lllll}
\hline & RMSEA & CFI & NNFI & GFI \\
\hline Sample 2* $^{*}$ & & & & \\
Roelofs (present study) & 0.069 & 0.95 & 0.93 & 0.96 \\
Roelofs (previous study) & 0.080 & 0.92 & 0.91 & 0.95 \\
McWilliams & 0.077 & 0.93 & 0.92 & 0.96 \\
\hline Sample 3 & & & & \\
Roelofs (present study) & 0.075 & 0.94 & 0.93 & 0.97 \\
Roelofs (previous study) & 0.078 & 0.93 & 0.91 & 0.96 \\
McWilliams & 0.074 & 0.94 & 0.92 & 0.96 \\
\hline
\end{tabular}

Note: RMSEA = Root Mean Square Error of Approximation, CFI = Comparative Fit Index, NNFI = Non-Normed Fit Index, GFI = Goodness of Fit Index. * Sample 2 refers to Dutch fibromyalgia patients, Sample 3 refers to American pain patients.

One remark with regard to the confirmatory factor analyses is in order. In factor analysis, a second order analysis refers to the extent that subscales represent one latent construct. With regard to the factor structure proposed by McWilliams and Asmundson (2001), a second order analysis could not be confirmed for sample 2 (Dutch fibromyalgia patients, data not shown). An inability to confirm a second order analysis may be the result of too highly intercorrelated subscales.

\section{Convergent validity}

Convergent validity was assessed by computing Pearson-correlations of the various questionnaires and their subscales (see table 4-10). As expected, the PVAQ total score and the scores on both subscales, as obtained in the present study, correlated highly with theoretically related constructs such as catastrophizing (PCS), pain-related fear (PASS), and fear of movement and (re)injury (TSK). Notably, the Attention to Pain subscale is stronger correlated with related constructs (i.e., PCS, PASS, TSK) than the Attention to Changes in Pain subscale. The difference in the magnitude of these correlations of both subscales with the total scores on the PCS, PASS, and TSK was statistically significant (PCS; $\mathrm{z}=8.88, \mathrm{p}<0.001$; PASS; $\mathrm{z}=8.87, \mathrm{p}<0.001 ; \mathrm{TSK} ; \mathrm{z}=3.55$, $\mathrm{p}<0.001)$. 
Table 4-10: Correlation matrix of pain-related measures and its subscales.

\begin{tabular}{|c|c|c|c|}
\hline & PVAQ & PVAQ (ap) & PVAQ (acp) \\
\hline PVAQ (ap) & $0.90^{* *}$ & & \\
\hline PVAQ (acp) & $0.75^{\star *}$ & $0.38^{* *}$ & \\
\hline PCS & $0.61^{* *}$ & $0.68^{* *}$ & $0.27^{* *}$ \\
\hline PCS (rum) & $0.61^{\star \star}$ & $0.65^{* *}$ & $0.30^{* *}$ \\
\hline PCS (mag) & $0.52^{* *}$ & $0.63^{* *}$ & $0.15^{*}$ \\
\hline PCS (help) & $0.53^{* *}$ & $0.59^{* *}$ & $0.24^{* *}$ \\
\hline PASS & $0.59^{* *}$ & $0.66^{* *}$ & $0.24^{\star *}$ \\
\hline PASS (fear) & $0.51^{* *}$ & $0.63^{* *}$ & 0.13 \\
\hline PASS (cogn) & $0.52^{\star *}$ & $0.59^{* *}$ & $0.20^{* *}$ \\
\hline PASS (phy) & $0.42^{* *}$ & $0.46^{* *}$ & $0.20^{\star \star}$ \\
\hline PASS (esc) & $0.55^{\star *}$ & $0.55^{* *}$ & $0.32^{* *}$ \\
\hline TSK & $0.48^{* *}$ & $0.47^{*}$ & $0.29^{* *}$ \\
\hline TSK (harm) & $0.32^{* *}$ & $0.33^{* *}$ & $0.17^{*}$ \\
\hline TSK (fear) & $0.40^{* *}$ & $0.41^{* *}$ & $0.22^{* \star}$ \\
\hline TSK (exercise) & $0.16^{*}$ & 0.12 & $0.16^{*}$ \\
\hline TSK (avoid) & $0.45^{\star *}$ & $0.40^{\star \star}$ & $0.34^{\star *}$ \\
\hline
\end{tabular}

Note: $P V A Q=$ Pain Vigilance and Awareness Questionnaire including both subscales, $P$ VAQ (ap) = Attention to pain subscale, $\mathrm{PVAQ}(\mathrm{acp})=$ Attention to changes in pain subscale, PCS = Pain Catastrophizing Scale, PCS (rum) = rumination subscale, PCS $(\mathrm{mag})=$ magnification subscale, $\mathrm{PCS}($ help) $=$ helplessness subscale, PASS = Pain Anxiety Symptoms Scale, PASS (fear) = fearful appraisal of pain subscale, PASS (cogn) = cognitive anxiety subscale, PASS (phy) = physiological anxiety subscale, PASS (esc) = escape and avoidance behavior subscale, TSK = Tampa Scale for Kinesiophobia, TSK (harm) = harm subscale, TSK (fear) $=$ fear of (re)/injury subscale, TSK (exercise) $=$ importance of exercise subscale, TSK (avoid) $=$ Avoidance of activity subscale.

${ }^{*} p<0.01,{ }^{* *} p<0.001$.

\section{Exploratory factor analysis with PVAQ, PCS, PASS, and TSK}

Data from sample 1 and 2 were combined and factor analyzed in order to examine whether pain-related measures such as the PVAQ, PCS, PASS, and TSK are unique concepts. Four factors were rotated to an oblique rotation (see table 4-11). Items with a loading below 0.32 (see Comrey \& Lee, 1992) were removed from the analysis, as were items with a secondary loading above 0.32 . The four factors accounted for $42 \%$ of the total variance. The first factor consisted of most of the PCS items and items from the Attention to Pain subscale of the PVAQ. In addition, ten items from the PASS loaded on the first factor. In general, all items that loaded on the first factor appeared to represent Preoccupation with Pain. The second factor consisted of the Attention to Changes in Pain subscale from the PVAQ. The third factor consisted of the remaining PASS items, which represents escape and avoidance behavior as well as physiological anxiety. The last factor consisted of all TSK items thus indicating fear of movement and (re)injury. Pearson correlations between the factors ranged from 0.18 to 0.38 . 
Table 4-11: Factor loadings of PVAQ, PCS, PASS, and TSK items as obtained by exploratory factor analysis.

\begin{tabular}{|c|c|c|c|c|c|}
\hline Item No. & Item description & Factor 1 & Factor 2 & Factor 3 & Factor 4 \\
\hline PCS 10 & I keep thinking about how much it hurts & 0.82 & 0.05 & 0.04 & -0.06 \\
\hline PVAQ 6 & I focus on sensations of pain & 0.77 & 0.09 & -0.02 & -0.11 \\
\hline PCS 9 & I can't seem to keep it out of my mind & 0.76 & 0.06 & 0.04 & -0.02 \\
\hline PVAQ 15 & I become preoccupied with pain & 0.75 & 0.05 & -0.01 & -0.03 \\
\hline PVAQ 13 & I pay close attention to pain & 0.70 & 0.14 & 0.06 & -0.07 \\
\hline PASS 26 & When I hurt, I think about the pain constantly & 0.70 & 0.005 & 0.17 & -0.05 \\
\hline PCS 6 & I become afraid that the pain may get worse & 0.69 & 0.06 & 0.12 & 0.10 \\
\hline PASS 22 & $\begin{array}{l}\text { During painful episodes it is difficult for me to think } \\
\text { of anything besides the pain }\end{array}$ & 0.62 & 0.06 & 0.26 & -0.09 \\
\hline PVAQ 1 & I am very sensitive to pain & 0.60 & 0.06 & -0.005 & 0.007 \\
\hline PCS 11 & $\begin{array}{l}\text { I keep thinking about how badly I want the pain to } \\
\text { stop }\end{array}$ & 0.58 & 0.17 & 0.14 & 0.04 \\
\hline PVAQ 14 & I keep track of my pain level & 0.58 & 0.21 & 0.03 & 0.002 \\
\hline PCS 1 & I worry all the time about whether the pain will end & 0.58 & -0.009 & 0.08 & 0.19 \\
\hline PCS 3 & $\begin{array}{l}\text { It's terrible and I think it's never going to get any } \\
\text { better }\end{array}$ & 0.58 & -0.07 & 0.09 & 0.21 \\
\hline PCS 5 & I feel I can't stand it any more & 0.56 & 0.02 & 0.26 & 0.03 \\
\hline PASS 29 & I dread feeling pain & 0.53 & -0.09 & 0.15 & 0.15 \\
\hline PASS 37 & I worry when I am in pain & 0.52 & -0.06 & 0.23 & 0.17 \\
\hline PCS 2 & I feel I can't go on & 0.52 & -0.04 & 0.18 & 0.11 \\
\hline PVAQ 12 & I seem to be more conscious of pain than others & 0.50 & 0.23 & 0.06 & 0.01 \\
\hline PASS 1 & $\begin{array}{l}\text { I think that if my pain gets too severe, it will never } \\
\text { decrease }\end{array}$ & 0.50 & -0.07 & 0.22 & 0.18 \\
\hline PCS 7 & I think of other painful experiences & 0.49 & -0.15 & 0.13 & 0.13 \\
\hline PCS 8 & I anxiously want the pain to go away & 0.48 & 0.20 & 0.13 & 0.006 \\
\hline PASS 5 & When I feel pain, I try to stay as still as possible & 0.48 & -0.24 & 0.25 & 0.18 \\
\hline PVAQ 10 & $\begin{array}{l}\text { When I do something that increases pain, the first } \\
\text { thing I do is check to see how much pain was } \\
\text { increased }\end{array}$ & 0.44 & 0.28 & 0.04 & 0.06 \\
\hline PASS 30 & $\begin{array}{l}\text { I am bothered by unwanted thoughts when I'm in } \\
\text { pain }\end{array}$ & 0.43 & -0.14 & 0.26 & 0.07 \\
\hline PVAQ 7 & I notice pain even if I am busy with another activity & 0.40 & 0.28 & 0.07 & 0.02 \\
\hline PVAQ 8 & I find it easy to ignore pain & 0.39 & 0.05 & -0.17 & 0.02 \\
\hline PASS 31 & $\begin{array}{l}\text { If a chance comes to do something I enjoy, I do it } \\
\text { even if it causes pain }\end{array}$ & 0.39 & -0.16 & -0.18 & 0.07 \\
\hline PASS 18 & $\begin{array}{l}\text { I think I have a serious medical problem that my } \\
\text { physician has failed to uncover }\end{array}$ & 0.39 & -0.21 & 0.14 & 0.26 \\
\hline PASS 13 & When I feel pain, I become afraid of dying & 0.36 & -0.26 & 0.17 & 0.22 \\
\hline PVAQ 3 & I am quick to notice changes in pain intensity & 0.05 & 0.79 & 0.002 & 0.14 \\
\hline PVAQ 2 & $\begin{array}{l}\text { I am aware of sudden or temporary changes in } \\
\text { pain }\end{array}$ & 0.09 & 0.77 & -0.01 & 0.13 \\
\hline PVAQ 5 & $\begin{array}{l}\text { I am quick to notice changes in location or extent } \\
\text { of pain }\end{array}$ & 0.10 & 0.73 & 0.02 & 0.07 \\
\hline PVAQ 11 & I know immediately when pain decreases & 0.12 & 0.67 & -0.03 & -0.04 \\
\hline
\end{tabular}




\begin{tabular}{|c|c|c|c|c|c|}
\hline PVAQ 9 & I know immediately when pain starts or increases & 0.11 & 0.59 & 0.13 & 0.13 \\
\hline PASS 12 & $\begin{array}{l}\text { I begin trembling when engaged in an activity that } \\
\text { increases pain }\end{array}$ & -0.19 & 0.05 & 0.80 & 0.01 \\
\hline PASS 9 & My body gets shaky when I hurt & -0.18 & 0.01 & 0.75 & 0.004 \\
\hline PASS 24 & When I sense pain, I feel dizzy or faint & 0.12 & -0.05 & 0.65 & 0.03 \\
\hline PASS 17 & Pain seems to cause my heart to pound or race & 0.03 & 0.05 & 0.64 & 0.07 \\
\hline PASS 32 & Pain makes me nauseous & 0.06 & -0.03 & 0.61 & -0.12 \\
\hline PASS 4 & I become sweaty when in pain & -0.20 & 0.16 & 0.61 & 0.10 \\
\hline PASS 28 & $\begin{array}{l}\text { I have trouble catching my breath when I have } \\
\text { pain sensations }\end{array}$ & 0.14 & -0.04 & 0.60 & -0.09 \\
\hline PASS 10 & I feel disoriented and confused when I hurt & 0.05 & -0.01 & 0.59 & 0.12 \\
\hline PASS 14 & I can't think straight when in pain & 0.16 & -0.07 & 0.59 & -0.04 \\
\hline PASS 20 & $\begin{array}{l}\text { I have pressure or tightness in my chest when in } \\
\text { pain }\end{array}$ & 0.08 & -0.02 & 0.59 & 0.09 \\
\hline PASS 34 & I find it hard to concentrate when I hurt & 0.18 & 0.13 & 0.57 & -0.07 \\
\hline PASS 38 & My stomach bothers me when I experience pain & 0.18 & -0.16 & 0.53 & 0.06 \\
\hline PASS 36 & $\begin{array}{l}\text { I find it difficult to calm my body down after } \\
\text { periods of pain }\end{array}$ & 0.22 & 0.03 & 0.41 & -0.09 \\
\hline PASS 15 & $\begin{array}{l}\text { I will stop any activity as soon as I sense pain } \\
\text { coming on }\end{array}$ & 0.16 & 0.06 & 0.37 & 0.10 \\
\hline PASS 7 & I go immediately to bed when I feel severe pain & 0.21 & -0.07 & 0.36 & 0.03 \\
\hline PASS 3 & When I feel pain, I try to stay as still as possible & 0.16 & 0.09 & 0.35 & 0.09 \\
\hline PASS 23 & I avoid important activities when I hurt & 0.25 & 0.06 & 0.33 & 0.14 \\
\hline TSK 3 & $\begin{array}{l}\text { My body is telling me I have something } \\
\text { dangerously wrong }\end{array}$ & -0.05 & -0.002 & 0.12 & 0.68 \\
\hline TSK 11 & $\begin{array}{l}\text { I wouldn't have this much pain if there weren't } \\
\text { something potentially dangerous going on in my } \\
\text { body }\end{array}$ & 0.03 & -0.10 & -0.02 & 0.62 \\
\hline TSK 7 & Pain always mean I have injured my body & -0.06 & 0.02 & 0.07 & 0.58 \\
\hline TSK 6 & $\begin{array}{l}\text { My accident has put my body at risk for the rest of } \\
\text { my life }\end{array}$ & 0.09 & -0.09 & 0.13 & 0.57 \\
\hline TSK 1 & I'm afraid that I might injury myself if I exercise & 0.14 & 0.14 & -0.02 & 0.54 \\
\hline TSK 12 & $\begin{array}{l}\text { Although my condition is painful, I would be better } \\
\text { off if I were physically active }\end{array}$ & -0.06 & 0.13 & -0.11 & 0.51 \\
\hline TSK 9 & I am afraid that I might injure myself accidentally & 0.12 & -0.06 & 0.03 & 0.50 \\
\hline TSK 8 & $\begin{array}{l}\text { Just because something aggravates my pain does } \\
\text { not mean it is dangerous }\end{array}$ & 0.06 & -0.10 & -0.008 & 0.48 \\
\hline TSK 16 & $\begin{array}{l}\text { Even though something is causing me a lot of } \\
\text { pain, I don't think it's actually dangerous }\end{array}$ & 0.07 & -0.14 & -0.08 & 0.48 \\
\hline TSK 14 & $\begin{array}{l}\text { It's really not safe for a person with a condition } \\
\text { like mine to be physically active }\end{array}$ & -0.10 & 0.10 & 0.10 & 0.47 \\
\hline TSK 4 & $\begin{array}{l}\text { My pain would probably be relieved if I were to } \\
\text { exercise }\end{array}$ & -0.11 & 0.06 & -0.03 & 0.40 \\
\hline TSK 15 & $\begin{array}{l}\text { I can't do all the things normal people do because } \\
\text { it's too easy for me to get injured }\end{array}$ & 0.10 & 0.20 & 0.10 & 0.40 \\
\hline TSK 17 & $\begin{array}{l}\text { No one should have to exercise when he/she is in } \\
\text { pain }\end{array}$ & 0.12 & 0.09 & -0.04 & 0.36 \\
\hline
\end{tabular}




\section{Reliability}

Internal consistency reliability analyses of the total PVAQ questionnaire for sample one and two together was good (Cronbach's alpha $=0.83$ ). Internal consistency reliability (Cronbach's alpha) for the Attention to Pain subscale was 0.85 and for the Attention to Changes in Pain subscale 0.80, indicating good internal consistency. Items 4,8 , and 16 had low corrected item-total correlations (below 0.25). Both subscales were moderately intercorrelated $(\mathrm{r}=0.38)$.

\section{DISCUSSION}

The present study investigated psychometric properties of the Pain Vigilance and Awareness Questionnaire in three independent clinical samples. With regard to the factorial validity of the PVAQ, an exploratory factor analysis on PVAQ data derived from 200 fibromyalgia patients (objective 1) indicated that a two-factor solution is most suitable. In interpreting these subscales, the first factor can be referred to as Attention to Pain whereas the second subscale can be interpreted as Attention to Changes in Pain. A similar factor structure was previously obtained in healthy individuals by Roelofs et al. (2002).

The stability of the factor loadings and structure of the PVAQ obtained by exploratory factor analysis in the current investigation and the previously reported factor structure by Roelofs et al., (2002) and McWilliams and Asmundson (2001) was tested by means of confirmatory factor analysis (objective 2). Two independent samples (Dutch fibromyalgia patients and American pain patients with various diagnoses) were used for this purpose. The goodness-of-fit indices indicated a good fit for all three models. However, an attempt to confirm a second order analysis of the factor structure of McWilliams and Asmundson on the sample of Dutch fibromyalgia patients failed. This was, however, not the case for the sample of American pain patients. A possible explanation for failure to confirm a second order factor structure is multi-collinearity (i.e., the Intrusion subscale was too highly correlated with the Monitoring scale). The Intrusion subscale and the Monitoring subscale are highly intercorrelated suggesting they may represent the same underlying construct. Intrusion can be defined as repetitive thoughts, images or impulses that are unacceptable and/or unwanted (Rachman, 1978). In the present form, the Intrusion subscale of the PVAQ can be modified and extended with appropriate items based for example on the Impact of Event Scale (Horovitz et al., 1978), which is a measure of intrusion in PTSD. Items from this scale should be reformulated so that they can be used in chronic pain samples. Appropriate items should reflect the repetitive character of the thought (i.e., "I am frequently tormented by thoughts about my pain)" and the intrusive nature (i.e., "Sometimes I can't help thinking about my pain"). In addition, items measuring coping with intrusion can also be constructed. The use of reverse-keyed items herein should be carefully considered. 
With regard to the convergent validity (objective 3), PVAQ scores were strongly associated with related constructs such as catastrophizing (PCS), painrelated fear (PASS), and fear of movement and (re)injury (TSK), supporting the construct validity of the PVAQ. However, the association of these measures with the Attention to Pain subscale was significantly stronger compared to the association with the Attention to Changes in Pain subscale. This may indicate that the Attention to Changes in Pain subscale is a unique construct among the other pain-related measures.

The uniqueness of the PVAQ in relation to the PCS, PASS, and TSK was further investigated by means of an exploratory factor analysis in which all scores on these measures were subjected to principal components analysis with an oblique rotation (objective 4). The results supported a four-factor solution in which the first factor appeared to represent Preoccupation with Pain. The Attention to Changes in Pain items of the PVAQ loaded uniquely on the second factor indicating that these items represent a latent construct that is not included in any other measure. It may be speculated that attending to changes in pain may reflect an adaptive strategy that some patients use to get or retain control of their pain. That is, these patients may adapt activities in daily life according to the changes in pain intensity they experience. In contrast, patients who constantly attend to pain and who are unable to disengage from pain may see pain as threatening and may be more vulnerable for developing chronic manifestations of pain. The third factor comprised mainly the PASS items that referred to escape and avoidance behavior and physiological anxiety. The fourth factor consisted of all TSK items, representing fear of movement and (re)injury. Thus, the uniqueness of the PVAQ, in particular the Attention to Changes in Pain subscale, is supported. Reliability analyses (objective 5) showed good internal consistency (Cronbach's alpha) for the complete questionnaire and the subscales.

Treatment programs should take the role of attentional processes into account. Distraction is a coping strategy in which patients have to focus on a non-painful stimulus in the immediate environment in order to divert attention from discomfort (Fernandez, 1986). However, research has shown that the use of distraction may be limited as it appears to be ineffective in highly fearful pain patients (Hadjistavropoulos et al., 2000). Evidence from a series of experiments using the cold-pressor procedure and different distraction task has indicated that these distraction tasks did not affect physiological, self-report, and behavioral responses to cold-pressor pain (McCaul et al., 1992). McCaul and colleagues have suggested that emotional components rather than attention mediate the pain reducing effects of distraction per se. Evidence that distraction is a useful coping strategy is equivocal. The assessment of the effectiveness of distraction in reducing pain is paradoxical, as patients have to inquire about the subjective experience of pain. Thus, patients attend to pain in order to report, which may potentially counteract the analgesic impact of the distraction. Consequently, it may be important to first reduce pain-related fear. A fear-reducing technique in the treatment of chronic pain is cognitive-behavioral in 
vivo exposure, which consists of graded exposure to situations the patient has identified as 'dangerous' or 'threatening'. Subsequently, individually tailored practice tasks are developed based on the graded hierarchy of fear-eliciting situations. In vivo exposure has preliminary been shown to be effective in reducing levels of pain-related fear. Importantly, this was accompanied by decreases in pain vigilance (Vlaeyen et al., 2002).

In conclusion, the present data provide support that the PVAQ is a reliable and valid measure of pain vigilance in fibromyalgia patients. For use in research and clinical practice, we suggest to use either a total PVAQ score or the two subscales, including all 16 items, obtained in the present study. The support for an Intrusion subscale is inconsistent. The PVAQ could be further modified and extended by intrusion-related items that are preferably non-reverse-keyed. Furthermore, testretest reliability should be examined and the factor structure found in the present study should be further cross-validated among different pain populations and cultures. The responsiveness of the PVAQ and its subscales to treatment interventions should also be further examined.

\section{REFERENCES}

Arntz, A., Dreessen, L., \& De Jong, P. (1994). The influences of anxiety on pain: attentional and attributional mediators. Pain, 56, 307-314.

Arntz, A., \& De Jong, P. Anxiety, attention and pain. Journal of Psychosomatic Research, 37, 423-431.

Arntz, A., Dreessen, L., \& Merckelbach, H. (1991). Attention, not anxiety, influences pain. Behaviour Research and Therapy, 29, 41-50.

Burns, J. W., Mullen, J. T., Higdon, L. J., Mei Wei, J., \& Lansky, D. (2000). Validity of the Pain Anxiety Symptoms Scale (PASS): Prediction of physical capacity variables. Pain, 84, 247-252.

Cattell, R. B. (1978). The scientific use of factor analysis in behavioural and life sciences. New York: Plenum Press.

Chapman, C. R. (1978). Pain: The perception of noxious events. In RA Sternbach (Ed.), The psychology of pain (pp. 169-202). New York: Raven Press.

Comrey, A. L., \& Lee, H. B. (1992). A first course in factor analysis (2 ${ }^{\text {nd }}$ Ed.) Hillsdale, NJ: Erlbaum.

Du Toit, S., Du Toit, M., Jöreskog, K. G., \& Sörbom, D. (1999). Interactive LISREL: User's guide. Chicago, IL: Scientific Software International Inc.

Eccleston, C., \& Crombez, G. (1999). Pain demands attention: a cognitive-affective model o the interruptive function of pain. Psychological Bulletin, 125, 356-366.

Eysenck MW. Anxiety: The cognitive perspective. Hove: Erlbaum, 1992.

Fernandez E. A classification system of cognitive coping strategies for pain. Pain 1986;26:141-151. 
Goubert L, Crombez, G., Vlaeyen, J. W. S., Van Damme, S., Van den Broeck, A., \& Van Houdenhove, B. (2000). De Tampa Schaal voor Kinesiofobie: psychometrische karakteristieken en normering. Gedrag \& Gezondheid, 28(2), 54-62.

Hadjistavropoulos, H. D., Hadjistavropoulos, T., \& Quine, A. (2000). Health anxiety moderates the effects of distraction versus attention to pain. Behaviour Research and Therapy, 38, 425-438.

Horovitz, M. J., Wilner, N., \& Alvarez, W. (1979). Impact of event scale: A measure of subjective stress. Psychosomatic Medicine, 41, 209-218.

Janssen, S. A., \& Arntz, A. (1996). Anxiety and pain: Attentional and endorphinergic influences. Pain, 66, 145-150.

Larsen, D. K., Taylor, S., \& Asmundson, G. J. G. (1997). Exploratory factor analysis of the Pain Anxiety Symptoms Scale in patients with chronic pain complaints. Pain, 69, 27-34.

McCaul, K. D., Monson, N., \& Maki, R. H. (1992). Does distraction reduce painproduced distress among college students? Health Psychology, 11(4), 210-217.

McCracken, L. M., Zayfert, C., \& Gross, R. T. (1992). The Pain Anxiety Symptoms Scale: development and validation of a scale to measure fear of pain. Pain, 50, 67-73. McCracken, L. M. (1997). "Attention" to pain in persons with chronic pain: A behavioural approach. Behavior Therapy, 28, 271-284.

McWilliams, L. A., \& Asmundson, G. J. G. (2001). Assessing individual differences in attention to pain: Psychometric properties of the Pain Vigilance and Awareness Questionnaire modified for a non-clinical pain sample. Personality and Individual Differences, 31, 239-246.

Melzack, R, \& Wall, P. D. (1982). The challenge of pain. New York: Penguin.

Miller, R. P., Kori, S. H., \& Todd, D. D. (1991). The Tampa Scale. Unpublished Report, Tampa, FL.

Miller, L. C., Murphy, R., \& Buss, A. H. (1981). Consciousness of body: Private and public. Journal of Personality and Social Psychology, 41, 397-406.

Osman, A., Barrios, F. X., Osman, J. R., Schneekloth, R., \& Troutman, J. A. (1994). The Pain Anxiety Symptoms Scale: Psychometric properties in a community sample. Journal of Behavior Medicine, 17, 511-522.

Osman, A., Barrios, F. X., Kopper, B. A., Hauptmann, W., Jones, J., \& O’Neill, E. (1997). Factor structure, reliability, and validity of the Pain Catastrophizing Scale. Journal of Behavioral Medicine, 20(6), 589-605.

Osman, A., Barrios, F. X., Gutierrez, P. M., Kopper, B. A., Merrifield, T., \& Grittmann, L. (2000). The Pain Catastrophizing Scale: Further psychometric evaluation with adult samples. Journal of Behavioral Medicine, 23(4), 351-365.

Rachman, S. (1978). An anatomy of obsessions. Behavioral Analysis and Modification, 2, 235-278.

Roelofs, J., Peters, M. L., Muris, P., \& Vlaeyen, J. W. S. (2002). Dutch version of the Pain Vigilance and Awareness Questionnaire: validity and reliability in a pain-free population. Behaviour Research and Therapy, 40, 1081-1090. 
Rosenstiel, A. K., \& Keefe, F. J. (1983). The use of coping strategies in chronic low back pain patients: Relationship to patient characteristics and current adjustment. Pain, 17, 33-44.

Sullivan, M. J. L., Bishop, S. R., \& Pivik, J. (1995). The Pain Catastrophizing Scale: development and validation. Psychological Assessment, 7, 524-532.

Van Damme, S., Crombez, G., Bijtebier, P., Goubert, L., \& Van Houdenhove, B. (2002). A confirmatory factor analysis of the Pain Catastrophizing Scale: Invariant factor structure across clinical and non-clinical populations. Pain, 96, 319-324.

Vlaeyen, J. W. S., Kole-Snijders, A. M. J., Rotteveel, A. M., Ruesink, R., \& Heuts, P. H. T. G. (1995). The role of fear of movement/(re)injury in pain disability. Journal of Occupation and Rehabilitation, 5, 235-251.

Vlaeyen, J. W. S., \& Linton, S. J. (2000). Fear-avoidance and its consequences in chronic musculoskeletal pain: a state of the art. Pain, 85, 317-332.

Vlaeyen, J. W. S., De Jong, J., Geilen, M., Heuts, P. H. T. G., Van Breukelen, G. (2002). The treatment of fear of movement/(re)injury in chronic low back pain - Further evidence on the effectiveness of exposure in vivo. Clinical Journal of Pain, 18(4), 251-261. 


\title{
4.3 Psychometric eVAluation of the Pain AnXIETy SYMPTOMS SCALE (PASS) IN CHRONIC PAIN PATIENTS*
}

\begin{abstract}
The present study examined psychometric properties of the Pain Anxiety Symptoms Scale (PASS), a measure of pain-related fear. A recently developed shortened version of the PASS, the PASS-20, was also investigated. Previously reported factor structures of the PASS were tested by means of confirmatory factor analysis. Results indicated that all models fitted adequately but that a five-factor solution fitted slightly better compared to the other models tested. The four-factor solution of the PASS-20 was tested by means of confirmatory factor analysis and results indicated adequate fit. Moreover, the four-factor solution of the PASS-20 was invariant amongst fibromyalgia and low-back pain patients. Convergent validity of the original PASS and the PASS-20 was good and internal consistency reliability adequate to excellent. The suitability of the original PASS and the PASS-20 are discussed and directions for future research are provided.
\end{abstract}

\footnotetext{
* Roelofs, J., McCracken, L. M., Peters, M. L., Crombez, G., Van Breukelen, G., \& Vlaeyen, J. W. S. (2004). Psychometric evaluation of the Pain Anxiety Symptoms Scale (PASS) in chronic pain patients. Journal of Behavioral Medicine, 27(2), 167-183.
} 


\section{INTRODUCTION}

Research in many anxiety disorders has demonstrated that the avoidance of feareliciting stimuli may lead to the maintenance of anxiety itself. With regard to avoidance behavior in chronic pain, Philips (1987) has suggested that chronic pain sufferers may learn to avoid stimuli that are associated with the initiation or exacerbation of their pain symptoms. The concept of avoidance behavior is also incorporated in the so-called "fear-avoidance" models of chronic pain. These models postulate that fear-related avoidance of movement or activity plays a crucial role in the maintenance of pain (Lethem et al., 1983). Based on the work of Lethem and colleagues, a cognitive behavioral model has been proposed which posits a behavioral mechanism in which fear of movement/(re)injury might contribute to the maintenance of chronic pain (Vlaeyen et al., 1995a; Vlaeyen et al., 1995b; Vlaeyen \& Linton, 2000). The model starts with the acute phase of the injury. If pain is interpreted as threatening, possibly through the cognitive process of catastrophizing, pain-related fear may evolve. This leads to avoidance behavior and hypervigilance to bodily sensations and pain, which maintains a chronic pattern of disability, disuse and depression. Both depression and disuse are assumed to be associated with decreasing pain tolerance and hence promoting the painful experience, which fuel the cycle of increasing fear and avoidance.

Self-report measures (questionnaires) are an important tool in obtaining information about pain-related fear in chronic pain patients. Several questionnaires of pain-related fear have been developed aimed to capture specific aspects of pain related fear (see for a comparison of instruments McCracken et al., 1996). For example, the Pain and Impairment Relationship Scale (PAIRS) is a self-report measure of chronic pain patients' attitudes concerning activities and pain (Riley et al., 1988). The Fear-Avoidance Beliefs Questionnaire (FABQ) is a measure of patients' beliefs about how work and physical activity affect their low-back pain (Waddell et al., 1993). The Tampa Scale for Kinesiophobia (TSK) is a measure of fear movement and (re)injury (Miller et al., 1991). In contrast to these measures that tap specific aspects of pain-related fear, the Pain Anxiety Symptoms Scale (PASS) has been developed as a general measure of anxiety and fear in individuals with various chronic pain disorders (McCracken et al., 1992). The PASS consists of 40 rationally derived items intended to assess four components of pain-related anxiety: (a) fearful appraisal of pain (e.g., 'When I feel pain I am afraid something terrible will happen'), (b) cognitive anxiety (e.g., 'During painful episodes it is difficult for me to think of anything besides the pain'), (c) physiological anxiety (e.g., 'Pain seems to cause my heart of pound or race'), (d) escape and avoidance behavior (e.g., 'I avoid important activities when I hurt'). Respondents are asked to indicate to what extent the items are a true description of them on a 6-point scale, ranging from never (0) to always (5). Five items are reverse-scored. 
The investigation of the psychometric properties (i.e., reliability and validity) of the PASS has been the subject of an increasing number of studies. Although the PASS is in many aspects psychometrically sound (McCracken \& Dhingra, 2002), the factor structure appears to be less clear. To date, McCracken et al. (McCracken et al., 1993) conducted a principal components analysis with oblique rotation on PASS scores derived from 180 patients with chronic pain referred to a university pain management clinic. McCracken and colleagues did not mention the method used for determining the appropriate number of factors to be rotated (e.g., eigenvalue $>1$, Cattell's Scree, parallel analysis; see for an overview Zwick \& Velicer, 1986) but obtained a four-factor solution accounting for $49 \%$ of the variance. The identified factors corresponded to the previously proposed subscales by McCracken et al. (McCracken et al., 1992).

Osman et al. (1994) conducted a confirmatory factor analysis on PASS scores obtained from a community sample of 224 adults. Results indicated that the fourfactor structure of the PASS, as suggested by McCracken et al. (1993) for clinical samples, provided a reasonably good fit to the data. In their analyses, however, Osman and colleagues relied on the use of polychoric correlation matrices. The use of these correlation matrices is limited as it requires more participants than their 224 . Furthermore, the study relied on non-pain patient samples and it is unsure whether all participants may have experienced one or more painful experiences of moderate intensity.

Larsen et al. (1997) conducted an exploratory factor analysis using principal components analysis with oblique rotation on PASS scores obtained from 259 chronic pain patients. Parallel analysis was used to identify the appropriate number of factors to rotate. Results from a four-factor solution and a five-factor solution were presented but parallel analysis showed that the five-factor solution, accounting for $44 \%$ of the variance was most appropriate. Parallel analysis has been recommended as one of the most accurate methods for determining the number of factors (Zwick \& Velicer, 1986). However, parallel analysis assumes that all items are normally distributed, which is often not the case. Non-normality of items may affect the estimation of eigenvalues thereby biasing the identification of the appropriate number of factors to retain. Therefore, the use of parallel analysis should be carefully considered. The factors retained were labeled Catastrophic Thought, Physiological Anxiety, Escape/Avoidance, Cognitive Interference, and Coping Strategies. The major difference between the four- and five-factor structure solution was that in the four-factor solution, the factor labeled Coping Strategies merged with the Escape/Avoidance factor.

Recently, McCracken attempted to develop and validate the PASS-20, a short form version of the original PASS (McCracken \& Dhingra, 2002) consisting of 20 items. The PASS-20 can be especially useful when there is concern about the time and amount of effort asked of individuals. In addition, previous studies that have investigated the factor structure of the original 40-item PASS have resulted in slightly different structures depending on the sample and method used for factor analysis 
(i.e., McCracken et al., 1992; Osman et al., 1994; Larsen et al., 1997). Alternatively, the PASS-20 may provide an unequivocal factor structure. In the construction of the PASS-20, items were selected based on the magnitude of their corrected item-total correlation. The PASS-20 showed strong internal consistency, reliability, and good predictive and construct validity. However, these results require cross-validation to examine the strengths and limits of the PASS-20.

Taken together, the factor analytic studies on the PASS have predominantly relied on exploratory factor analysis. In exploratory factor analysis, one wants to explore the empirical data to discover and detect characteristic features and interesting relationships without imposing any definite model on the data. At this point, there is a need to test the goodness-of-fit of the factor solutions that have been proposed by means of confirmatory factor analysis. In confirmatory factor analysis, one builds a model based on a priori information about the data structure derived from previous studies, assumed to describe, explain, or account for the empirical data. The aim of the present study is twofold. First, the goodness-of-fit of the fourfactor structure found by McCracken et al. (1993) and the four- and five-factor structures proposed by Larsen et al. (1997) were tested by means of confirmatory factor analysis. A one-factor solution, in which all items load on one factor, was also tested because researchers sometimes report total scores on the PASS as a general indication of the level of pain-related fear. Similarly, clinicians working in the field of pain management may also be interested in the level of pain-related fear reflected by a single measure. Second, the current study attempted to examine the psychometric properties of the PASS-20. The stability of the factor structure of the PASS-20 and its subscales was examined by means of confirmatory factor analysis. Further, it is unknown to what extent the PASS measures the same processes in different pain syndromes. It is possible that the factor structure of the PASS varies as a function of differences in the experience and the localization of pain. Therefore, confirmatory factor analysis was used to test the invariance of the factor structure of the PASS-20 among fibromyalgia patients and chronic low-back pain patients. Next, we examined whether the PASS-20 is a good reflection of the original PASS, by comparing their scores. Convergent validity of the PASS-20 was assessed by comparing the magnitude of the correlations for both the PASS-20 and the original PASS with other pain-related measures. Finally, the internal consistency reliability (Cronbach's alpha) of the PASS-20 and its subscales was determined.

\section{METHODS AND MATERIALS}

\section{Participants}

Three samples were used in the current study. The first sample consisted of 398 predominantly Dutch female fibromyalgia patients $(94.5 \%$ female). Mean age was 47.6 years $(S D=10.1)$ and mean pain duration was 159 months $(S D=115)$. No data on actual pain ratings was available. With respect to interference with daily activities, 
mean scores on the Disability Rating Index (Salén et al., 1994) were 59.7 (SD = 14.8). Further, 34\% were working (part-time or full-time) and 37\% were recipient of disablement insurance benefits. Patients were diagnosed as having fibromyalgia by either the rheumatologist or the general practitioner.

The second sample included 228 Dutch chronic low-back pain patients $(60.7 \%$ female) who were referred to the pain unit of the Maastricht University Hospital (The Netherlands). Mean age was 50.0 (SD = 13.5). Mean pain duration was 74 months $(S D=92)$. Mean VAS pain ratings were $63.9 \mathrm{~mm}$. $(S D=15.6)$. For interference with daily activities, mean scores on the Quebec Back Pain Disability Scale (Kopec et al., 1995) were 61.2 (SD = 17.4).

The third sample comprised a heterogeneous sample of 284 North-American pain patients (e.g., lower and upper limbs, cervical, thoracic) (65.8\% female) referred to a pain unit in Chicago (USA). Mean age was $46.6(\mathrm{SD}=13.8)$. Mean pain duration was 63 months $(\mathrm{SD}=79.7)$, with a minimum duration of three months. Mean pain ratings on a 10-point scale were $7.2(\mathrm{SD}=1.9)$. Disability was measured with the Sickness Impact Profile (Bergner et al., 1981). Mean total scores on the SIP were $18 \%$ $(\mathrm{SD}=12 \%)$, indicating that the sample was moderately to severely disabled. In addition, only $26 \%$ of the patients were working (part-time or full-time).

\section{Procedure}

Fibromyalgia patients (first sample) were identified by approaching approximately 1000 patients via a Dutch patients' association. They were asked to complete a set of questionnaires (see below) at home, of which 404 actually responded. For the PASS, six patients had more than $10 \%$ missing values and were omitted from analyses, leaving a total number of 398 fibromyalgia patients. Chronic low-back pain patients (second sample) and the North-American pain patients (third sample) were contacted in the normal course of an initial clinical assessment and completed the measures in a waiting area. For patients in all samples, patients were free to refuse and there were no incentives for completion of the questionnaires.

\section{Measures}

Participants in all three samples completed the Pain Anxiety Symptoms Scale (McCracken et al., 1992), which consists of 40 items rated on a 6-point scale. Participants in samples one and two completed a Dutch version of the PASS, while participants in sample three completed an English version of the PASS. The translation of the English version of the PASS into the Dutch version was done in a state-of-the-art manner that involved back translation and re-translation. PASS total scores range between 0 and 200. Anchors are labeled 'never' and 'always'. To assess convergent validity, patients in the first sample (fibromyalgia patients) completed a further set of questionnaires.

The Pain Vigilance and Awareness Questionnaire (McCracken, 1997; Dutch version: Crombez \& Vlaeyen, 1996a) is a measure of pain vigilance (e.g., "I focus on sensations of pain") containing 16 items rated on a 6-point scale anchored 'never' and 
'always'. PVAQ total scores range between 0 and 80. The PVAQ has shown good reliability and validity in fibromyalgia patients (see Roelofs et al., 2003).

The Tampa Scale for Kinesiophobia (Miller et al., 1991; Dutch version: Vlaeyen et al., 1995a) is a self-report questionnaire measuring fear of movement (e.g., "It is really not safe for a person with a condition like mine to be physically active") and injury (e.g., "Pain always means I have injured my body"). The scale consists of 17 items that are scored on a 4-point scale. Anchors are labeled 'strongly agree' and 'strongly disagree'. TSK total scores range between 17 and 68. The TSK is a reliable and valid self-report measure of fear of movement and (re)injury in fibromyalgia patients (see Goubert et al., 2004).

The Pain Catastrophizing Scale (Sullivan et al., 1995; Dutch version: Crombez \& Vlaeyen, 1996b) is a self-report measure of catastrophizing related to pain and contains 13 items rated on a 4-point scale (e.g., "I keep thinking how badly I want the pain to stop"). PCS total scores range between 0 and 52 and anchors are labeled 'not at all' and 'all the time'. The PCS has shown good reliability and validity in fibromyalgia patients (Van Damme et al., 2002). For all questionnaires, higher scores reflect higher levels of the underlying person characteristic that the questionnaire presumes to measure.

\section{Data Analysis}

The stability of the previously reported factor structures of the PASS (McCracken et al., 1993; Larsen et al., 1997), as well as a one-factor solution was examined with confirmatory factor analysis by means of LISREL (Jöreskog \& Sörbom, 1999). For this purpose, PASS data from the three samples were pooled. Pooling data from these three samples seems legitimate since the PASS has originally been designed to assess pain-related fear in different pain syndromes. In this way, a large data set was created consisting of 910 pain patients. In this data set, four items $(5,11,13,21)$ were positively skewed (range: 1.21 to 2.55 ) and nine items $(1,4,6,13,27,29,35,36,37$ ) showed kurtosis (range: -1.27 to 5.55 ). The weighted least-squares algorithm does not assume a normal distribution of items and this algorithm was used to assess the fit of the various models for which polychoric correlation matrices, obtained by PRELIS, were used. The models were estimated while allowing the latent variables to correlate. Each item was assumed to load only on one factor such that items of the same PASS subscale loaded on the same factor. In addition, residuals of each item were assumed to be uncorrelated. The goodness-of-fit for each factor solution was evaluated using several descriptive criteria: (a) root mean-square error of approximation (RMSEA); (b) the comparative fit index (CFI); (c) the non-normed fit index (NNFI); and (d) expected cross-validation index (ECVI). The RMSEA quantifies the divergence between the data and a proposed model per degree of freedom. Values below 0.05 or lower indicate a close fit, whereas values up to 0.08 represent reasonable errors of approximation. The CFI and NNFI indices measure how much better the model fits as compared to a baseline model, in which the observed variables (items) are assumed to be uncorrelated (i.e., the independence model). For 
the CFI and NNFI, values above 0.90 are considered as indicative of an adequate fit whereas values above 0.95 are indicative of a good to very good fit. The ECVI is a relative measure to compare competing models: the model with the lowest value has the best fit. As the one factor model is a special case of the four-factor and five-factor model, the models can be compared with a likelihood ratio test. More specifically, under the null hypothesis that the special model fits as well as the more general one, the difference between their Chi-square values is itself Chi-square distributed with degrees of freedom equal to the difference between their degrees of freedom.

In order to examine psychometric properties of the PASS-20, the third sample was inappropriate to use as this sample of patients had already been used to construct and validate the PASS-20 as reported previously (McCracken \& Dhingra, 2002). Consequently, only sample one and two were taken into account. As both samples have adequate sample sizes for cross-validation of the PASS-20, analyses were conducted for each sample separately. Confirmatory factor analyses were conducted to examine the goodness-of-fit for the factor structure of the PASS-20 in sample 1 and 2 . The same fit-indices were used to evaluate the goodness-of-fit. Additionally, confirmatory factor analysis was used to investigate the invariance of the factor structure of the PASS-20 among fibromyalgia patients and chronic lowback pain patients. A restrictive model was tested by equating the number of factors, factor loadings, factor correlations, and error variances in both samples. As the fourfactor model and the one-factor model are nested, the Chi-square statistic was used to test whether the four-factor solution fitted significantly better than the one-factor solution. The extent to which scores on the original PASS, the PASS-20, and their subscales are interrelated is examined by computing Pearson correlation coefficients. Convergent validity of the PASS-20 and the original PASS was examined for sample one by computing Pearson correlation coefficients between scores on the PASS (PASS-20 and the original PASS) and scores on the PVAQ, TSK, and PCS. Furthermore, internal consistency reliability (Cronbach's alpha) of the PASS-20 and its subscales was determined.

\section{RESULTS}

\section{Descriptive statistics of the questionnaires}

Descriptive information of the questionnaires is presented in table 4-12. Internal consistency reliability (Cronbach's alpha's) for the measures was good to excellent (i.e., PVAQ; $\alpha=0.87$, TSK; $\alpha=0.80$, PCS; $\alpha=0.92$ ). One remark with regard to table 412 is in order. Chronic low-back pain patients (sample 2) have higher scores on the original PASS, the PASS-20, and their subscales in comparison with the other samples. The most salient differences on these scores were observed between the first sample and the second sample. T-test comparisons between these two samples indicated statistically significant differences between the two samples with respect to 
average scores on the original PASS, the PASS-20, and the subscales ( $\mathrm{p}$-values all below 0.007 ), except for the 'physiological anxiety' subscale.

Table 4-12: Descriptive statistics of the total scores and subscales (only for the PASS) of questionnaires.

\begin{tabular}{|c|c|c|c|c|c|c|}
\hline & \multicolumn{2}{|c|}{ Sample $1(n=398)$} & \multicolumn{2}{|c|}{ Sample $2(n=228)$} & \multicolumn{2}{|c|}{ Sample $3(n=284)$} \\
\hline & Mean & SD & Mean & SD & Mean & SD \\
\hline \multicolumn{7}{|l|}{ Original PASS } \\
\hline Cognitive Anxiety & 21.3 & 10.2 & 23.7 & 11.3 & 22.0 & 11.4 \\
\hline Fear & 12.5 & 9.6 & 18.8 & 10.9 & 16.5 & 10.2 \\
\hline Escape/Avoidance & 18.1 & 8.4 & 25.2 & 9.8 & 23.0 & 10.0 \\
\hline Physiology & 16.6 & 10.8 & 17.0 & 11.8 & 12.6 & 10.7 \\
\hline PASS total & 68.4 & 32.9 & 84.7 & 37.7 & 74.1 & 35.6 \\
\hline \multicolumn{7}{|l|}{ PASS-20 } \\
\hline Cognitive Anxiety & 11.2 & 5.9 & 13.3 & 6.4 & 12.3 & 6.7 \\
\hline Fear & 6.6 & 5.9 & 9.8 & 6.6 & 7.4 & 6.4 \\
\hline Escape/Avoidance & 10.2 & 5.4 & 13.8 & 6.0 & 12.8 & 6.1 \\
\hline Physiology & 9.1 & 5.8 & 9.4 & 6.4 & 6.1 & 5.7 \\
\hline PASS-20 total & 37.1 & 19.2 & 46.4 & 21.5 & 38.6 & 20.4 \\
\hline PVAQ & 39.9 & 12.1 & & & & \\
\hline TSK & 34.2 & 8.2 & & & & \\
\hline PCS & 20.3 & 11.5 & & & & \\
\hline
\end{tabular}

Note: Sample 1 = Dutch fibromyalgia patients, Sample 2 = Dutch chronic low-back pain patients, Sample $3=$ American pain patients with various diagnoses, $\mathrm{PASS}=$ Pain Anxiety Symptoms Scale, $\mathrm{PVAQ}=$ Pain Vigilance and Awareness Questionnaire, TSK = Tampa Scale for Kinesiophobia; PCS = Pain Catastrophizing Scale.

Table 4-13 depicts the goodness-of-fit indices for (a) the four-factor solution proposed by McCracken et al. (1993), (b) the four-factor solution proposed by Larsen et al. (1997), (c) the five-factor structure solution proposed by Larsen et al. (1997), and (d) the one-factor solution. For all tested models, RMSEA values were reasonable (values near to 0.08). The CFI and NNFI were above the acceptable value of 0.90 . Taken together, the goodness-of-fit indices for the four models tested here indicated adequate fit. However, the differences between the chi-squares of each of the proposed models (i.e., four-factor solution proposed by McCracken, and four- and five-factor solutions proposed by Larsen) were statistically significant ( $p<0.001$ for all three models). Further, the ECVI indicated that the five-factor solution proposed by Larsen et al. (1997) provided a slightly better fit compared to the other models. 
Table 4-13: goodness-of-fit indices statistics for various PASS models as obtained by means of confirmatory factor analysis.

\begin{tabular}{lccccc}
\hline & $\chi^{2}(\mathrm{df})$ & $\mathrm{RMSEA}$ & $\mathrm{CFI}$ & $\mathrm{NNFI}$ & $\mathrm{ECVI}$ \\
\hline McCracken (1993) & $5805(738)$ & 0.087 & 0.91 & 0.91 & 6.58 \\
Larsen (1997) (four factor) & $5750(732)$ & 0.087 & 0.91 & 0.91 & 6.52 \\
Larsen (1997) (five factor) & $4664(689)$ & 0.080 & 0.91 & 0.90 & 5.33 \\
One-factor solution & $5994(738)$ & 0.089 & 0.91 & 0.90 & 6.77 \\
\hline PASS-20 (McCracken) & & & & 0.95 & 2.10 \\
\hline Sample 1 (four factor) & $740(164)$ & 0.094 & 0.96 & 0.90 & 2.36 \\
Sample 1 (one factor) & $857(170)$ & 0.100 & 0.91 & 0.98 & 2.48 \\
Sample 2 (four factor) & $472(164)$ & 0.091 & 0.98 & 0.98 & 2.63 \\
Sample 2 (one factor) & $517(170)$ & 0.095 & 0.98 & 0.92 & 2.44 \\
\hline Invariance (four factor) & $1430(374)$ & 0.095 & 0.90 & 0.91 & 2.65 \\
Invariance (one factor) & $1576(380)$ & 0.100 & 0.91 & & \\
\hline
\end{tabular}

Note: RMSEA = Root Mean Square Error of Approximation, CFI = Comparative Fit Index, NNFI = Non-Normed Fit Index, ECVI = Expected Cross-Validation Index. Sample 1 = Dutch fibromyalgia patients, Sample 2 = Dutch chronic low-back pain patients.

One remark with regard to the results presented in table 4-13 needs further addressing. Our confirmatory factor analysis models assumed that each item loaded on one factor only, such that items of the same subscale load on the same factor, and that all residual correlations between items are zero. This means assuming that all item-item correlations can be explained in terms of the factor model with one factor per subscale and one loading per item. The so-called 'modification-indices' computed by LISREL showed that for each model the fit could be improved substantially by allowing residual correlation for two pairs of item (i.e., item 9 and 12 and item 2 and 40) out of all $40^{*} 39 / 2=780$ item-item pairs. When two items have residual positive residual correlation, it means that the correlation between these two items is stronger than the correlations between the remaining items of the scale. The fit indices in table 4-13 are those of the modified models that assumed residual correlation for the two items pairs mentioned above. Allowing these pairs of items to have positive residual correlation may be theoretically justified as items 9 and 12 belong to the same subscale and item 2 and 40 also belong to the same subscale in all tested models. Treating items that load on the same factor as belonging to the same subscale yielded moderate to high correlations (Pearson correlation coefficients ranged from 0.41 to $0.72)$.

\section{Validity and reliability of the PASS-20}

The factor structure of the PASS-20 was investigated by means of confirmatory factor analysis. Table 4-13 presents goodness-of-fit indices for the one-factor and the fourfactor solutions. Except the RMSEA in both samples, the fit indices indicated good to very good fit for both the four-factor solution and the one-factor solution in both samples. The difference between the chi-squares of four-factor solution and the one- 
factor solution was statistically significant in both samples $(\mathrm{p}<0.001$ in both samples), favoring the four-factor solution. In addition, the ECVI has the lowest value for the four-factor solution in both samples, indicating that the four-factor solution provides the best fit. Taken together, although some (unexplained) error variance is present in the factor structure of the PASS-20, the fit of the four-factor solution of the PASS-20 is adequate. Subscales were moderately intercorrelated (i.e., Pearson correlation coefficients ranged from 0.48 to 0.72 ). Furthermore, the factor structure (one-factor and four-factor solutions) of the PASS 20 seemed to be fairly invariant across fibromyalgia patients and chronic low-back pain patients. More specifically, table 4-13 shows the fit indices for the 'invariance' model assuming that factor correlations, factor loadings, and residual variances are the same for both patient samples. The four-factor fitted slightly but significantly better than the onefactor solution $(p<0.001)$. Note that although the factor structure seems to be the same for both samples, the average PASS scores are different (see table 4-12).

Reducing the number of items of a questionnaire may result in a loss of information, which may affect the (internal) validity of the questionnaire. To examine the internal validity of the subscales of the PASS-20, intercorrelations were computed among the subscales of the original 40-item PASS (sample 1: $0.53-0.72$; sample 2: range $0.54-0.75$ ) and among the subscales of the PASS-20 in both the fibromyalgia and chronic low-back pain sample (sample 1: range: $0.58-0.72$; sample 2: range 0.49 - 0.71). The intercorrelations between the subscales of the original 40-item were almost identical to those obtained for the PASS-20, supporting the internal validity of the subscales of the PASS-20. To ensure that the PASS-20 is a good reflection of the original PASS, Pearson correlation coefficients were computed between the original PASS and the PASS-20 subscales for sample 1 and 2 separately. Table 4-14 shows high correlation coefficients, which favor the construct validity. In a similar way, Pearson correlation coefficients were computed between the original PASS and the PASS-20, and pain-related measures (i.e., PVAQ, TSK, and PCS) for sample 1 only. Correlation coefficients with pain-related measures were modest but almost similar for the original PASS and the PASS-20, providing support for the construct validity of the PASS-20 (see table 4-15). In addition, internal consistency reliability (Cronbach's alpha) was estimated for the PASS-20 and the original PASS as well as their subscales in both sample 1 and 2 (see table 4-15). 
Table 4-14: Pearson correlation coefficients of subscales of the original PASS and the 20-item version.

\begin{tabular}{|c|c|c|c|c|c|}
\hline & Cognitive-20 & Fear-20 & Escape-20 & Physiology-20 & PASS-20 total \\
\hline \multicolumn{6}{|c|}{ Original PASS Sample 1} \\
\hline Cognitive Anxiety & 0.94 & 0.74 & 0.56 & 0.66 & 0.87 \\
\hline Fear & 0.70 & 0.95 & 0.55 & 0.56 & 0.83 \\
\hline Escape/Avoidance & 0.62 & 0.63 & 0.93 & 0.49 & 0.79 \\
\hline Physiology & 0.62 & 0.64 & 0.51 & 0.94 & 0.81 \\
\hline PASS total & 0.85 & 0.87 & 0.74 & 0.80 & 0.98 \\
\hline \multicolumn{6}{|c|}{ Original PASS Sample 2} \\
\hline Cognitive Anxiety & 0.94 & 0.77 & 0.62 & 0.69 & 0.89 \\
\hline Fear & 0.69 & 0.95 & 0.51 & 0.67 & 0.84 \\
\hline Escape/Avoidance & 0.66 & 0.63 & 0.92 & 0.54 & 0.81 \\
\hline Physiology & 0.63 & 0.73 & 0.49 & 0.96 & 0.83 \\
\hline PASS total & 0.85 & 0.90 & 0.72 & 0.84 & 0.98 \\
\hline
\end{tabular}

Note: Down: original subscales of the PASS; Across: subscales (abbreviated) of the PASS-20. PASS = Pain Anxiety Symptoms Scale.

Table 4-15: Pearson correlation coefficients of subscales of the PASS-20 and subscales of the original PASS with pain-related measures for sample 1 and internal consistency (Cronbach's alpha) for sample 1 and 2.

\begin{tabular}{|c|c|c|c|c|c|}
\hline & \multirow[t]{2}{*}{ PVAQ } & \multirow[t]{2}{*}{ TSK } & \multirow[t]{2}{*}{ PCS } & \multicolumn{2}{|c|}{ Alpha } \\
\hline & & & & Sample 1 & Sample 2 \\
\hline \multicolumn{6}{|l|}{ Original PASS } \\
\hline Cognitive Anxiety & 0.52 & 0.45 & 0.69 & 0.85 & 0.86 \\
\hline Fear & 0.51 & 0.54 & 0.73 & 0.86 & 0.86 \\
\hline Escape/Avoidance & 0.55 & 0.49 & 0.58 & 0.75 & 0.78 \\
\hline Physiology & 0.42 & 0.41 & 0.58 & 0.86 & 0.87 \\
\hline PASS Total & 0.59 & 0.55 & 0.76 & 0.94 & 0.94 \\
\hline \multicolumn{6}{|l|}{ PASS-20 } \\
\hline Cognitive Anxiety & 0.54 & 0.44 & 0.70 & 0.84 & 0.83 \\
\hline Fear & 0.53 & 0.53 & 0.74 & 0.84 & 0.84 \\
\hline Escape/Avoidance & 0.50 & 0.47 & 0.54 & 0.73 & 0.76 \\
\hline Physiology & 0.40 & 0.37 & 0.56 & 0.74 & 0.79 \\
\hline PASS-20 Total & 0.59 & 0.54 & 0.76 & 0.91 & 0.92 \\
\hline
\end{tabular}

Note: PASS = Pain Anxiety Symptoms Scale; PVAQ = Pain Vigilance and Awareness Questionnaire; TSK = Tampa Scale for Kinesiophobia; PCS = Pain Catastrophizing Scale.

\section{DISCUSSION}

In pain management, several questionnaires are administered to assess different aspects of pain. Determining the psychometric quality of these questionnaires is a necessity. The present study examined psychometric properties of the PASS, a 
measure of pain-related fear, in chronic pain patients. Although the PASS is in many respects psychometrically sound, studies that have investigated the factor structure of the PASS have yielded inconsistent results. The present study aimed to test several factor structures by means of confirmatory factor analysis. The goodness-of-fit of the four-factor structure obtained by McCracken et al. (1993), and the four- and fivefactor structure proposed by Larsen et al. (1997) was adequate and all three models fitted significantly better than a one-factor solution. In all models, two pairs of items had residual correlation. Allowing two items to correlate only serves the purpose of improving the model fit and has no consequences for use of the measure in research and clinical settings. The ECVI, a relative descriptive fit measure that can be used to compare competing models, indicated that the five-factor solution provided by Larsen et al. (1997) was slightly better compared to the other models.

It is not surprising that the goodness-of-fit indices of all tested models of the 40-item PASS did not provide an excellent fit when the results of previously reported exploratory factor analyses are taken into account. That is, factor solutions obtained by exploratory factor analysis accounted for approximately $50 \%$ of the variance and some PASS items did not substantially load on their corresponding factor or had salient double loadings. In testing the different models in the present study, all items were allowed to load only on one factor. Factor loadings were substantial across all tested models (range 0.49 to 0.89 ) but it should be noted that polychoric correlation matrices were used for confirmatory factor analyses, which usually yield higher factor loadings compared to Pearson correlation matrices that have mainly been used in previous studies.

The current study further aimed to examine psychometric properties of the PASS-20, a shortened version of the original PASS containing the same subscales as the original PASS from McCracken et al. (1993). A confirmatory factor analysis was conducted to test the one-factor and the four-factor solutions of the PASS-20 in a sample of fibromyalgia patients and a sample of chronic low-back pain patients. The goodness-of-fit indices of the four-factor solution indicated adequate fit and the fourfactor solution fitted significantly but only slightly better than the one-factor solution. Furthermore, although the fibromyalgia and low-back pain samples differed with regard to the mean scores on the total score and subscale scores, factor correlations, factor loadings, and residual variances of the PASS-20 were found to be invariant across these samples. Thus, the same pain processes, reflected by the subscales of the PASS-20, are tapped in both pain syndromes. Testing invariance of the original PASS across different pain samples was not central to analyses in the present study as sample sizes were relatively small compared to the number of items of the original PASS (e.g., 40 items).

With regard to the construct validity of the PASS-20, McCracken and Dhingra (2002) selected items on the basis of item-total correlations. This way, correlations between the short scales and the original scales were guaranteed. Thus, the present study offers a first attempt to cross-validate the results from their study. In the current study, high correlations were observed between scores on the PASS-20 and 
the original PASS (including the subscales) for both the fibromyalgia and the lowback pain sample, indicating that the PASS-20 is a good reflection of the original PASS. Furthermore, correlations for both the original PASS and the PASS-20 with pain-related measures (i.e., PVAQ, TSK, and PCS) were similar, indicating good convergent validity. Internal consistency reliability was adequate to excellent. It should be noted that an adequate internal consistency observed for the Escape/Avoidance subscale is in line with the notion that escape and avoidance behavior consists of a broad (heterogeneous) range of behaviors. One limitation of the present study was that the PASS-20 was not administered as a separate measure apart from the original PASS. Instead, the responses on the PASS-20 were derived from the original PASS. One cannot exclude that item context effects may have influenced item responses, which may in turn have influenced the psychometric properties assessed in the present study.

Where do we stand with the Pain Anxiety Symptoms Scale now? The results from the present study showed that a five-factor solution of the PASS proposed by Larsen et al. (1997) fitted slightly better than the four-factor solutions proposed by Larsen et al. (1997) and McCracken et al. (1993). However, the validity of the four subscales of the original PASS (McCracken et al., 1993) has been most extensively investigated. For example, regression analyses have shown that pain severity, as measured with the McGill Pain Questionnaire (Melzack, 1975), was best predicted by the PASS physiological anxiety score, and disability and avoidance pain behaviors were best predicted by the PASS escape/avoidance anxiety score. Complaint pain behaviors were best predicted by the PASS fearful appraisal anxiety scores (McCracken et al., 1996). The validity of the physiological anxiety and cognitive anxiety scales of the original PASS is supported by high correlations between respective somatic and cognitive factors of the Cognitive Somatic Anxiety Questionnaire (McCracken et al., 1992; CSAQ: Schwartz et al., 1978). We therefore recommend researchers and clinicians to use the original PASS. The present study has also shown that the PASS-20 is a good reflection of the original PASS. We recommend using the PASS-20 when there is concern about time and amount of effort asked of individuals. However, the validity of the PASS-20 subscales needs to be further investigated. Scores on the subscales of the original PASS can be used when there is interest in assessing specific aspects of pain-related fear (i.e., fearful appraisal of pain, cognitive anxiety, physiological anxiety, escape and avoidance behavior). A total score may be used for screening purposes to identify patients who suffer excessive fear of pain.

The original PASS and the PASS-20 tap four aspects of pain-related fear, which have important implications for treatment. It is important to know whether subtypes of patients can be identified for which treatment can be individually tailored. For example, it is conceivable that individuals whose fear is manifested primarily in the physiological response system may be more responsive to relaxation training than to cognitive restructuring (McCracken et al., 1992). In a similar vein, individuals whose fear is primarily manifested in the fearful appraisal of pain and 
escape and avoidance behavior may benefit from in vivo exposure with behavioral experiments (Vlaeyen et al., 2001; Vlaeyen et al., 2002).

Future research should examine the validity of the subscales of the five-factor solution proposed by Larsen et al. (1997) this factor solution was found to have a slightly better fit compared to the other models tested. Especially the coping scale, which is not included in any other models, should be further restructured and evaluated (Larsen et al., 1997). There is considerable amount of research on gender differences in pain responding. There may not only be important gender differences in coping but also in the perception and conceptualization of the pain experience. Although not central to analyses in the present study, future studies should address invariance of the factor structure across gender in sufficiently large samples for both the original PASS and the PASS-20. In addition, invariance across different cultures should also be investigated. Further, the stability over time (i.e., test-retest reliability) and discriminant validity were not investigated in the present study and warrant investigation in future studies. Some good candidates for assessing discriminant validity of the PASS-20 may be state-trait anxiety, somatization, pain coping, and depressive symptoms. Discriminant validity and convergent validity should preferably be assessed by means of a multitrait-multimethod study (Campbell \& Fiske, 1959). In this kind of study, pain-related fear should be measured with a number of different methods (e.g., physiological measures, behavioral measures and self-report measures) and different measures of the same construct and measures that are not related to the construct are to be included. Finally, future studies should also assess sensitivity to change of both the original PASS and the PASS-20 in the context of treatment outcome.

\section{REFERENCES}

Bergner, M., Bobbitt, R. A., Carter, W. B., \& Gilson, B. S. (1981). The Sickness Impact Profile: development and final revision of a health status measure. Medical. Care, 29, 797-805.

Campbell, D. T., \& Fiske, D. W. (1959). Convergent and discriminant validation by the multitrait-multimethod matrix. Psychological Bulletin, 56, 81-105.

Crombez, G., \& Vlaeyen, J. W. S. (1996a). The Pain Vigilance and Awareness Questionnaire: unpublished authorized Dutch translation.

Crombez, G., \& Vlaeyen, J. W. S. (1996b). The Pain Catastrophizing Scale: unpublished authorized Dutch/Flemish translation.

Goubert, L., Crombez, G., Van Damme, S., Vlaeyen, J. W. S., Bijttebier, P., \& Roelofs, J. (2004). Confirmatory factor analysis of the Tampa Scale for Kinesiophobia: invariant two-factor model across low back pain patients and fibromyalgia patients. Clinical Journal of Pain, 20(2), 103-110.

Jöreskog, K. G, \& Sörbom D. (1999). LISREL 8.30. Chicago IL: Scientific Software International Inc. 
Kopec, J. A., Esdaile, J. M., Abrahamowicz, M., Abenhaim, L., Woodauphinee, S., Lamping, D. L., \& Williams, J. I. (1995). The Quebec Back Pain Disability Scale. Measurement properties. Spine, 20(3), 341-352.

Larsen, D. K., Taylor, S., \& Asmundson, G. J. G. (1997). Exploratory factor analysis of the Pain Anxiety Symptoms Scale in patients with chronic pain complaints. Pain, 69, 27-34.

Lethem, J., Slade, P. D., Troup, J. D. G., \& Bentley, G. (1983). Outline of a fearavoidance model of exaggerated pain perceptions. Behaviour Research and Therapy, 21, 401-408.

McCracken, L. M., Zayfert, C., \& Gross, R. T. (1992). The Pain Anxiety Symptoms Scale: development and validation of a scale to measure fear of pain. Pain, 50, 67-73.

McCracken, L. M., Gross, R. T., Hexum, C. L., \& Semenchuck, E. M. (1993). Factor structure and temporal stability of the pain anxiety symptoms scale. Paper presented at the annual convention for the Society of Behavioral Medicine, San Francisco, CA.

McCracken, L. M., Gross, R. T., Aikens, J., \& Carnrike, C. L. M. (1996). The assessment of anxiety and fear in persons with chronic pain: a comparison of instruments. Behaviour Research and Therapy, 34(11/12), 927-933.

McCracken, L. M. (1997). "Attention" to pain in persons with chronic pain: a behavioural approach. Behavior. Therapy, 28, 271-284.

McCracken, L. M, \& Dhingra, L. (2002). A short version of the Pain Anxiety Symptoms Scale (PASS-20): preliminary Development and Validity. Pain Research and Management, 7, 45-50.

Melzack, R. (1975). The McGill Pain Questionnaire: major properties and scoring methods. Pain, 1, 277-299.

Miller, R. P., Kori, S. H., \& Todd, D. D. (1991). The Tampa Scale. Unpublished Report, Tampa, FL.

Osman, A., Barrios, F. X., Osman, J. R., Schneekloth, R., \& Troutman, J. A. (1994). The pain anxiety symptoms scale: psychometric properties in a community sample. Journal of Behavioral Medicine, 17, 511-522.

Philips, H. C. (1987). Avoidance behaviour and its role in sustaining chronic pain. Behaviour. Research and Therapy, 25, 273-279.

Riley, J. F., Ahern, D. K., \& Follick, M. J. (1988). Chronic pain and functional impairment: assessing beliefs about their relationship. Archives of Physical and Medical Rehabilitation, 69, 579-582.

Roelofs, J. Peters, M.L., McCracken, L. M., \& Vlaeyen, J. W. S. (2003). The pain vigilance and awareness questionnaire (PVAQ): further psychometric evaluation in fibromyalgia and other chronic pain syndromes. Pain, 101, 299-306.

Salén, B. A., Spanfort, E. V., Nygren, A. L., \& Nordemar, R. (1994). The Disability Rating Index: an instrument for the assessment of disability in clinical settings. Journal of Clinical Epidemiology, 47(12), 1423-1434. 
Schwartz, G. E., Davidson, R. J., \& Goleman, D. J. (1978). Patterning of cognitive and somatic processes in the self-regulation of anxiety: effects of meditations versus exercise. Psychosomatic Medicine, 40, 321-328.

Sullivan, M. J. L., Bishop, S. R., \& Pivik, J. (1995). The pain catastrophizing scale: development and validation. Psychological Assessment, 7, 524-532.

Van Damme, S., Crombez, G., Bijtebier, P., Goubert, L., \& Van Houdenhove, B. (2002). A confirmatory factor analysis of the Pain Catastrophizing Scale: invariant factor structure across clinical and non-clinical populations. Pain, 96, 319-324.

Vlaeyen, J. W. S., Kole-Snijders, A. M. J., Boeren, R. G. B., \& Van Eek, H. (1995a). Fear of movement/(re)injury in chronic low back pain and its relation to behavioral performance. Pain, 62, 363-372.

Vlaeyen, J. W. S., Kole-Snijders, A. M. J., Rotteveel, A., Ruesink, R., \& Heuts P. H. T. G. (1995b). The role of fear of movement/(re)injury in pain disability. Journal of Occupational Rehabilitation, 5, 235-252.

Vlaeyen, J. W. S., \& Linton, S. J. (2000). Fear-avoidance and its consequences in chronic musculoskeletal pain: a state of the art. Pain, 85, 317-332.

Vlaeyen, J. W. S., De Jong, J. R., Geilen, M., Heuts, P. H. T. G., \& Van Breukelen, G. (2001). Graded exposure in vivo in the treatment of pain-related fear. A replicated single-case experimental design in four patients with chronic low back pain. Behaviour Research and Therapy, 39, 151-166.

Vlaeyen, J. W. S., De Jong, J. R., Geilen, M., Heuts, P. H. T. G., \& Van Breukelen, G. (2002). The treatment of fear of movement/(re)injury in chronic low back pain: Further evidence on the effectiveness of exposure in vivo. Clinical Journal of Pain, 18(4), 251-261.

Waddell, G., Newton, M., Henderson, I., Somerville, D., \& Main, C. J. (1993). A FearAvoidance Beliefs Questionnaire (FABQ) and the role of fear-avoidance beliefs in chronic low back pain and disability. Pain, 52, 157-168.

Zwick, W. R., \& Velicer, W. F. (1986). Comparison of five rules for determining the number of components to retain. Psychological Bulletin, 99, 432-442. 


\title{
4.4 THE TAMPA SCALE FOR KINESIOPHOBIA: FURTHER EXAMINATION OF PSYCHOMETRIC PROPERTIES IN PATIENTS WITH CHRONIC LOW BACK PAIN AND FIBROMYALGIA*
}

\begin{abstract}
The present study attempted to replicate the robustness of a two-factor model of the Tampa Scale for Kinesiophobia (TSK) in chronic low back pain patients and fibromyalgia patients, by means of confirmatory factor analysis. Construct and predictive validity of the TSK subscales were also examined. Results clearly indicated that a two-factor model fitted best in both pain samples. These two factors were labeled somatic focus, which reflects the belief in underlying and serious medical problems, and activity avoidance, which reflects the belief that activity may result in (re)injury or increased pain. Construct validity of the TSK and its subscales was supported by moderate correlation coefficients with self-report measures of painrelated fear, pain catastrophizing, and disability, predominantly in patients with chronic low back pain. Predictive validity was supported by moderate correlation coefficients with performance on physical performance tests (i.e., lifting tasks, bicycle task) mainly in chronic low back pain patients. Implications of the results are discussed and directions for future research are provided.
\end{abstract}

\footnotetext{
* Roelofs, J., Goubert, L., Peters, M. L., Vlaeyen, J. W. S., \& Crombez, G. The Tampa Scale for Kinesiophobia: further examination of psychometric properties in patients with chronic low back pain and fibromyalgia. (manuscript in press, European Journal of Pain).
} 


\section{INTRODUCTION}

Pain-related fear has been increasingly recognized as an important contributor to the maintenance of (chronic) pain. The importance of pain-related fear has been stressed in the 'fear-avoidance' model of chronic pain (Lethem et al., 1983). In this model, confrontation and avoidance are postulated as two extreme responses to pain-related fear. Confrontation leads to a reduction of fear over time while avoidance of backstressing activities maintains or exacerbates pain-related fear. Based on the fearavoidance model, a cognitive-behavioural oriented model for chronic pain has been proposed (Vlaeyen \& Linton, 2000). According to this model, catastrophic thoughts about pain may lead to an increase of pain-related fear, which is in turn associated with avoidance behaviors and hypervigilance to bodily sensations and pain. Depression and disuse (i.e., a state of inactivity) may evolve, which in turn are associated with decreased pain tolerance and subsequently promote the painful experience. With respect to pain-related fear, research has supported the relation between pain catastrophizing and pain-related fear, pain-related fear and disability, and between pain-related fear and increased body awareness and attentional focus toward pain and noxious body stimuli (McCracken et al., 1992; Vlaeyen et al., 1995a; Vlaeyen et al., 1995b; McCracken et al., 1996; Eccleston et al., 1997; McCracken et al., 1998; Crombez et al., 1999a; Crombez et al., 1999b; Peters et al., 2000; Vlaeyen \& Linton, 2000).

Self-report measures (questionnaires) are an important tool in obtaining information about pain-related fear in chronic pain patients. Several questionnaires of pain-related fear such as the Pain and Impairment Relationship Scale (PAIRS; Riley et al., 1988), the Fear-Avoidance Beliefs Questionnaire (FABQ; Waddell et al., 1993), and the Pain Anxiety Symptoms Scale (PASS; McCracken et al., 1992) have been developed to assess specific aspects of pain-related fear (see for a comparison of instruments McCracken et al., 1996). A more specific measure of pain-related fear, namely fear of movement and (re)injury is tapped by the Tampa Scale for Kinesiophobia (TSK) (Miller et al., 1991). The TSK consists of 17 items intended to assess fear of movement and fear of (re)injury. Respondents are asked to indicate to what extent the items are a true description of the assumed association between movement and (re)injury on a 4-point Likert scale, ranging from strongly disagree to strongly agree. Four items (i.e., items 4, 8, 12,16) are inversely phrased.

Several studies have found support for the construct and predictive validity and reliability (i.e., internal consistency and test-retest reliability) of the TSK (Vlaeyen et al., 1995a; Vlaeyen et al., 1995b; Crombez et al., 1998; Crombez et al., 1999b; Koho et al., 2001; Swinkels-Meewisse et al., 2003). With respect to the factor structure of the TSK, Vlaeyen et al. (1995b) conducted a principal components analysis with oblique rotation on TSK scores derived from 129 patients with chronic low back pain who were admitted to a rehabilitation centre. Based on the $\chi^{2}$ - test for the sufficient number of factors extracted and the interpretability of the factors, a four-factor 
solution accounting for $36 \%$ of the variance was obtained. The factors were labeled harm (items 3, 6, 11), fear of (re)injury (items 1, 9), importance of exercise (items 4, 12, 14), and avoidance of activity (items 2, 10, 13, 15). Five items were excluded as the factor loadings were below 0.40. Clark et al. (1996) conducted a principal components analysis with varimax rotation on TSK scores from 167 male veterans with chronic pain who were admitted to a pain centre. Two factors were identified accounting for $49 \%$ of the variance. The first factor, activity avoidance (TSK-AA), reflected the belief that activity may result in (re)injury or increased pain (items 1, 2, 9, 10, 13, 14, 15, 17) and the second factor, somatic focus (TSK-SF), reflected a belief in underlying and serious medical problems (items 3, 5, 6, 7, 11). In this two-factor model, the four inversely phrased items showed weak associations with the TSK total score and were omitted, thus leaving a total number of 13 items. Geisser et al. (2000) attempted to replicate the two-factor structure obtained by Clark and colleagues. Principal factor analysis with varimax rotation was used on 133 chronic back pain patients who completed a multidisciplinary assessment of their pain. Inspection of the scree plot (Cattell, 1978) and eigenvalues suggested that a two-factor solution, accounting for $69 \%$ of the variance, provided the best fit. One item (item 8 ) was found to have a secondary loading, but the original two-factor structure was retained. The studies from Vlaeyen et al. (1995b), Clark et al. (1996), and Geisser et al. (2000) relied on exploratory factor analysis. In exploratory factor analysis, the empirical data are explored to discover and detect characteristic features and interesting relationships without imposing any definite model on the data. At this point, there is a need to test the goodness-of-fit of the four-factor and two-factor solutions that have been proposed. Confirmatory factor analysis is a useful tool in evaluating the goodness-offit of previously reported factor structures. In confirmatory factor analysis, a model is built based on a priori information about the data structure derived from previous studies that used an exploratory factor analytic approach (see Vlaeyen et al., 1995b; Clark et al., 1996; Geisser et al., 2000). Recently, we investigated the goodness-of-fit of the four-factor solution (Vlaeyen et al., 1995b) and the two-factor solution (Clark et al., 1996) in chronic low back pain patients and fibromyalgia patients by means of confirmatory factor analysis (Goubert et al., 2004). The results showed that for both chronic low back patients and fibromyalgia patients, the two-factor model (Clark et al., 1996) provided a better fit than the four-factor model (Vlaeyen et al., 1995b). Moreover, the two-factor model was invariant across both samples indicating that the same pain processes, reflected by TSK-AA and TSK-SF, are measured in both pain syndromes. A limitation of our previous study was the small sample size of fibromyalgia patients. Further, no attempt was made to investigate the construct and predictive validity of the two TSK subscales.

The present study further investigated psychometric properties of the Dutch version of the TSK in large samples of chronic low back pain (CLBP) patients and fibromyalgia (FM) patients. It should be noted that TSK data from the CLBP and FM samples in this study, have not been used in our previous study (Goubert et al., 2004). First, the goodness-of-fit of the four-factor solution and two-factor solution 
was evaluated by means of confirmatory factor analysis. In line with our previous study, one-factor solutions with and without the inversely phrased items were also tested. We expected that the two-factor model (Clark et al., 1996) would provide the best fit. Second, construct validity (i.e., convergent validity) of the best fitting factor structure of the TSK was assessed by investigating the relationships with other selfreport measures of pain-related concepts such as pain related fear, pain catastrophizing, and disability. For establishing predictive validity, we re-analyzed data from two studies in which a physical performance test was performed in CLBP patients (see Vlaeyen et al., 1999 for details) and FM patients (see Peters et al., 2000 for details). Finally, internal consistency (Cronbach's alpha) of the best fitting factor structure of the TSK was determined.

\section{METHODS}

\section{Participants}

The CLBP sample comprised 225 Dutch low-back pain patients (62\% female) who were referred to the pain unit of the Maastricht University Hospital (The Netherlands). Mean age was 50.0 years $(S D=14.0)$. Mean pain duration was 75 months $(S D=93)$. Mean VAS pain ratings were $63.3 \mathrm{~mm}$. $(S D=15.1)$. The CLBP sample was substantially disabled as measured with the Quebec Back Pain Disability Scale (Kopec et al., 1995). Mean total score on this scale was 61.0 (SD =17.4). The FM sample consisted of 391 predominantly Dutch female patients ( $94.5 \%$ female) who were all member of a patients' association. Mean age was 47.4 years (SD $=10.0)$ and mean pain duration was 159 months $(S D=115)$. No data on current pain was available. FM patients were substantially disabled as measured with the Disability Rating Index (Salén et al., 1994). Mean score on this measure was 59.7 (SD = 14.7). Further, 35\% was working (either part-time or full-time) and 37\% was recipient of disablement insurance benefits. Patients were diagnosed as having fibromyalgia by either the rheumatologist or the general practitioner.

\section{Measures}

The TSK is a 17-item self-report measure of fear of movement and (re)injury. In the present study a Dutch version of the TSK was used (Vlaeyen et al., 1995a). The translation of the English version of the TSK into the Dutch version was done in a state-of-the-art manner that involved back translation and re-translation. CLBP patients and FM patients further completed the Pain Anxiety Symptoms Scale (PASS; McCracken et al., 1992) and the Pain Catastrophizing Scale (PCS; Sullivan et al., 1995). The PASS is a 40-item general measure of fear and anxiety behaviors related to pain (e.g., 'When I feel pain I am afraid something terrible will happen'). Items are rated on a 6-point Likert scale and anchors are labeled 'never' and 'always'. The PCS is a 13-item self-report measure of pain catastrophizing (e.g., 'I keep thinking how badly 
I want the pain to stop'). Items are rated on a 4-point Likert scale and anchors are labeled 'not at all' and 'all the time'.

\section{STATISTICAL ANALYSES}

\section{Confirmatory factor analysis}

The robustness of the four-factor (Vlaeyen et al., 1995b) and two-factor model (Clark et al., 1996) of the TSK was examined by means of confirmatory factor analysis. For this purpose, the statistical package LISREL version 8.30 was used (Jöreskog \& Sörbom, 1999). In line with our previous study (Goubert et al., 2004), one-factor models with and without inversely phrased items were also examined. Thus, the goodness-of-fit of four different models was evaluated. In the CLBP and FM samples, four items were somewhat skewed (range: -1.04 to 1.59) and nine items showed some kurtosis (range: -1.45 to 0.76 ). The weighted least-squares algorithm does not assume a normal distribution of items and this algorithm was used to assess the fit of the various models for which polychoric correlation matrices, obtained by PRELIS, were used. The models were estimated while allowing the latent variables to correlate. Each item was assumed to load only on one factor. In addition, residuals of each item were assumed to be uncorrelated. The goodness-of-fit for each factor solution was evaluated using several descriptive criteria: (a) the Root Mean-Square Error of Approximation (RMSEA); (b) the Non-Normed Fit Index (NNFI); (c) the Comparative Fit Index (CFI); and (d) Expected Cross-Validation Index (ECVI). The RMSEA quantifies the divergence between the data and a proposed model per degree of freedom. Values below 0.05 or lower indicate a close fit, whereas values up to 0.08 represent reasonable errors of approximation. A $90 \%$ confidence interval of the RMSEA point estimate is also provided. The NNFI and CFI indices measure how much better the model fits as compared to a baseline model, in which the observed variables (items) are assumed to be uncorrelated (i.e., the independence model). For the NNFI and CFI, values above 0.90 are considered as indicative of an adequate fit whereas values above 0.95 are indicative of a good to very good fit. The ECVI is a relative measure to compare competing models: the model with the lowest value has the best fit. As the one-factor solution without inversely phrased items is a special case of the two-factor solution (Clark et al., 1996), the models can be compared with a likelihood ratio test. More specifically, under the null hypothesis that the special model fits as well as the more general one, the difference between their Chi-square values is itself Chi-square distributed with degrees of freedom equal to the difference between their degrees of freedom.

\section{Validity and internal consistency}

In line with our previous study, we expected to identify the two-factor model (Clark et al., 1996) as the best fitting factor model. Construct validity (i.e., convergent validity) of this model was assessed by computing Pearson correlation coefficients 
between the TSK and scores on the subscales, and scores on the PASS and the PCS. As the TSK and the PASS are both measures of pain-related fear, scores on the TSK (total and subscale scores) were expected to be more strongly associated with the PASS as compared to the PCS in both pain samples. Second, TSK-AA was hypothesized to have a stronger association with the escape/avoidance subscale of the PASS compared to the TSK-SF subscale. Third, the TSK-AA subscale was expected to be more strongly associated with self-reported disability compared to the TSK-SF subscale in both samples.

To investigate the predictive validity of the TSK subscales, two studies in which data on a physical performance tests were collected in both CLBP (Vlaeyen et al., 1999) and FM patients (Peters et al., 2000), were re-analyzed. In the study by Vlaeyen and colleagues, 31 CLBP completed a lifting task and a stationary bicycle task. In the lifting task, patients were asked to stand up and lift a $5.5 \mathrm{~kg}$ bag with the dominant arm and hold it until pain or physical discomfort urged them to place the bag back on the floor. A similar instruction was given for the stationary bicycle task. In the study by Peters and colleagues, 28 FM patients completed a similar lifting task as in the study by Vlaeyen and colleagues. In both studies, physical performance was operationalised as the maximum duration of lifting or cycling. We expected TSK-AA to be more strongly associated with physical performance compared to TSK-SF in both pain samples. Internal consistency of the TSK total score (without inversely phrased items) and its subscales was determined by means of Cronbach's Alpha.

\section{RESULTS}

\section{Confirmatory factor analysis}

Table 4-16 presents the goodness-of-fit indices for the one-factor solution (model 1), in which all 17 items were included, the four-factor solution (model 2) proposed by Vlaeyen et al. (1995b), the one-factor solution (model 3) without inversely phrased items, and the two-factor solution (model 4) as proposed by Clark et al. (1996). With respect to the goodness-of-fit indices depicted in table 4-16, RMSEA values were reasonable (values below 0.08), except for model 1 in CLBP patients. The NNFI, CFI, and GFI favored the two-factor model in CLBP patients and both the two-factor and four-factor models in the FM sample. The lowest values for ECVI were also found for these models. Since the one-factor solution without inversely phrased items (model 3 ) and the two-factor solution (model 4) are nested, the improvement in fit provided by splitting one factor (model 3) into two factors (model 4) was substantially and statistically significant in CLBP $\left(\Delta \chi^{2}(1)=26, \mathrm{p}<0.001\right)$ and FM patients $\left(\Delta \chi^{2}(1)=47\right.$, $\mathrm{p}<0.001)$. 
Table 4-16: Goodness-of-fit indices for various TSK models obtained by means of confirmatory factor analysis.

\begin{tabular}{lllllll}
\hline & $\chi^{2}(\mathrm{df})$ & RMSEA $(90 \% \mathrm{Cl})$ & NNFI & CFI & GFI & ECVI \\
\hline $\begin{array}{l}\text { Chronic low back pain } \\
(\mathrm{n}=225)\end{array}$ & & & & & & \\
Model 1 & $403(119)$ & $0.100(0.092-0.110)$ & 0.69 & 0.73 & 0.92 & 2.10 \\
Model 2 & $108(48)$ & $0.075(0.056-0.094)$ & 0.85 & 0.89 & 0.97 & 0.75 \\
Model 3 & $145(65)$ & $0.074(0.058-0.090)$ & 0.83 & 0.86 & 0.96 & 0.88 \\
Model 4 & $119(64)$ & $0.062(0.044-0.079)$ & 0.88 & 0.90 & 0.97 & 0.77 \\
Model 4 (Modified) & $108(63)$ & $0.056(0.038-0.074)$ & 0.90 & 0.92 & 0.97 & 0.73 \\
Fibromyalgia ( $\mathrm{n}=391)$ & & & & & & \\
Model 1 & $353(119)$ & $0.071(0.062-0.080)$ & 0.78 & 0.80 & 0.96 & 1.08 \\
Model 2 & $111(48)$ & $0.058(0.044-0.072)$ & 0.88 & 0.91 & 0.98 & 0.44 \\
Model 3 & $200(65)$ & $0.073(0.061-0.084)$ & 0.80 & 0.84 & 0.97 & 0.65 \\
Model 4 & $153(64)$ & $0.060(0.048-0.072)$ & 0.87 & 0.89 & 0.97 & 0.53 \\
Model 4 (Modified) & $96(63)$ & $0.037(0.021-0.051)$ & 0.95 & 0.96 & 0.98 & 0.39 \\
\hline
\end{tabular}

Note: Model 1 = one-factor model (17 items); Model 2 = four-factor model (Vlaeyen et al., 1995b); Model 3: onefactor model (without inversely phrased items); Model 4: two-factor model (Clark et al., 1996). Model 4 (Modified): two-factor model with residual covariance between item 14 and 17. RMSEA = Root Mean Square Error of Approximation, $90 \% \mathrm{Cl}=90 \%$ Confidence interval for RMSEA; NNFI = Non-Normed Fit Index; $\mathrm{CFI}=$ Comparative Fit Index; GFI = Goodness of Fit Index, ECVI = Expected Cross-Validation Index.

One important remark has to be made. Items with identical rating scales may have residual correlation. When items have residual correlation, it means that these items have something in common which is not reflected by the latent construct itself (Byrne, 1989). It is also possible that items represent a unique construct within the latent construct itself. LISREL provides modification indices, which show how much the fit of a model improves when residual correlation among items is considered. When parsimoniously used, allowing items to have residual correlation only serves the purpose of improving the model fit and has no consequences for use of the measure in research and clinical settings. With respect to the four-factor solution (model 2), fit increased substantially when measurement errors between two inversely phrased items (items 4 and 12) were considered in both pain samples. The finding that two inversely phrased items have residual correlation indicates that these items have something in common (i.e., both are inversely formulated), which is not reflected by the remaining item (item 14) that loads on the importance of exercise subscale. As this subscale consists of two inversely phrased items with residual correlation and one positively formulated item, this subscale may represent a methodological artifact rather than a content factor. With respect to the two-factor solution (model 4), fit increased substantially in both pain samples, when allowing for items 14 and 17 to have residual correlation (see table 4-16: model 4 Modified). The improvement in fit provided by the two-factor model with residual correlation between items 14 and 17 (model 4 Modified) and the original two-factor solution (model 4) was statistically significant in CLBP $\left(\Delta \chi^{2}(1)=11, \mathrm{p}<0.001\right)$ and FM patients $\left(\Delta \chi^{2}(1)=57, \mathrm{p}<0.001\right)$. It may be theoretically justified for these items to have residual 
correlation as they load on the same activity avoidance subscale. Figure 4-1 displays factor loadings for the two-factor solution in CLBP patients and FM patients (between parentheses). Taken together, the two-factor solution in which items 14 and 17 have residual correlation provided the best fit in both CLBP patients and FM patients. Mean scores on the subscales and the total score are depicted in table 4-17. It is clear from table 4-17 that CLBP patients have higher mean scores on both subscales (and also on the total score) compared to FM patients.

Table 4-17: Descriptive statistics and internal consistency (Cronbach's alpha) of the TSK and the two subscales.

\begin{tabular}{lcccccc}
\hline & \multicolumn{2}{c}{ Chronic low back pain sample $(\mathrm{n}=225)$} & \multicolumn{2}{c}{ Fibromyalgia sample $(\mathrm{n}=391)$} \\
\hline & Mean & SD & Alpha & Mean & SD & Alpha \\
\hline TSK (total) & 33.8 & 7.6 & 0.81 & 28.2 & 7.1 & 0.79 \\
TSK-AA & 21.4 & 3.6 & 0.76 & 17.9 & 5.0 & 0.72 \\
TSK-SF & 12.4 & 5.2 & 0.72 & 10.4 & 3.3 & 0.70 \\
\hline
\end{tabular}

Note: TSK = Tampa Scale for Kinesiophobia; SF = Somatic Focus; AA = Activity Avoidance; TSK (total) refers to total scores without inversely phrased items.

Figure 4-1: Factor loadings as obtained with confirmatory factor analysis shown for chronic low back pain patients and fibromyalgia patients (between parentheses).

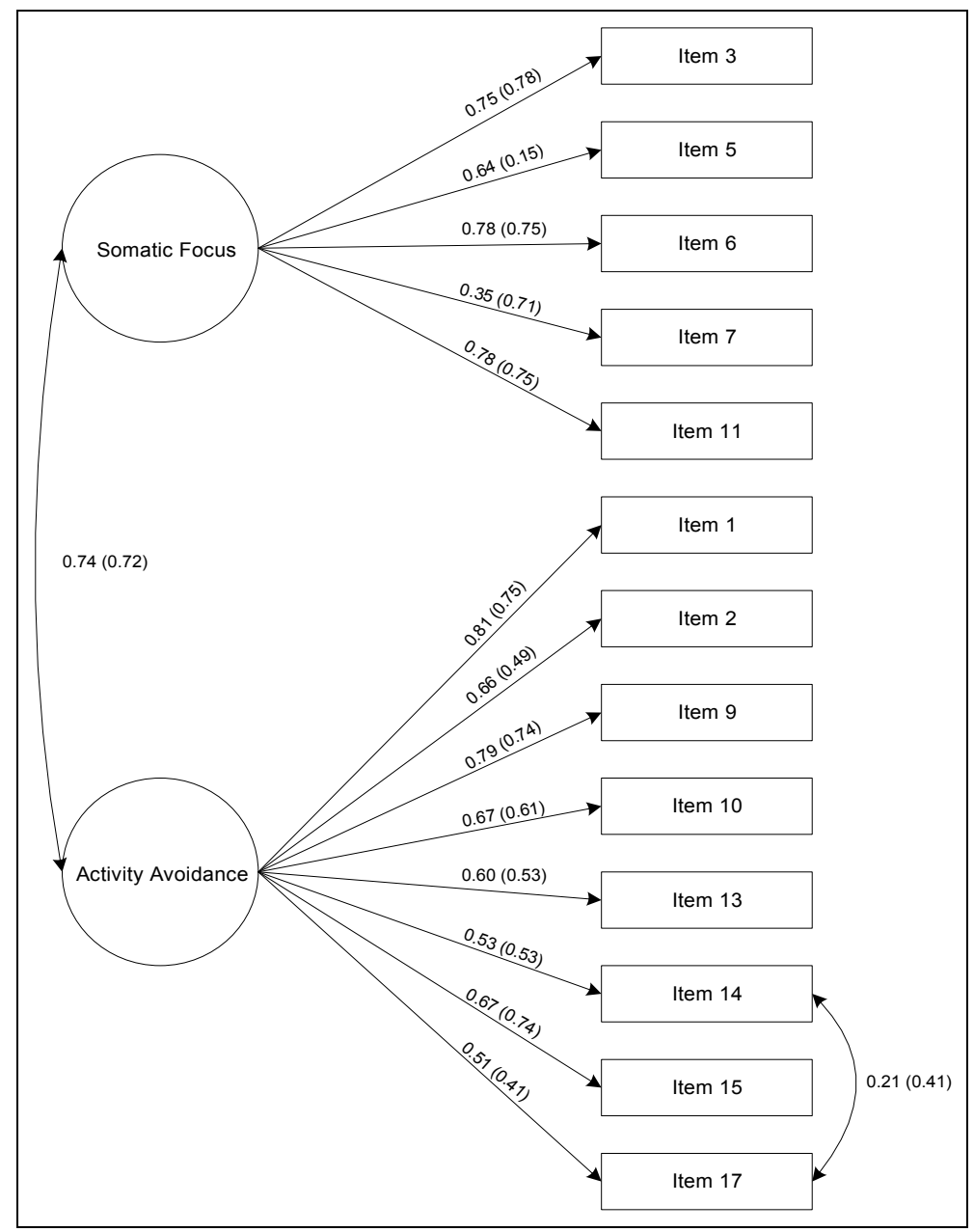




\section{Validity and internal consistency}

Table 4-18 depicts a correlation matrix between the TSK total and subscale scores and scores on the PASS, the PCS, and the Quebec Back Pain Disability Scale (CLBP sample) and the Disability Rating Index (FM sample). We expected scores on the TSK (without inversely phrased items) and its subscales to be more strongly associated with the PASS than with the PCS. For the CLBP sample, TSK total score, TSK-SF, and TSK-AA were significantly stronger associated with the scores on the PASS compared to the PCS $(\mathrm{z}=4.436, \mathrm{p}<0.001 ; \mathrm{z}=4.112, \mathrm{p}<0.001 ; \mathrm{z}=2.988, \mathrm{p}=0.001)$ respectively. For the FM sample, the TSK total score, TSK-SF and TSK-AA subscales were not significantly stronger associated with the PASS compared to the PCS ( $\mathrm{z}=$ $0.940, \mathrm{p}=0.347 ; \mathrm{z}=1.201, \mathrm{p}=0.230 ; \mathrm{z}=0.494, \mathrm{p}=0.621$ ) respectively. We also expected TSK-AA, in comparison to TSK-SF, to be more strongly associated with the PASS escape/avoidance subscale as both the TSK-AA and PASS escape/avoidance scales represent avoidance behaviour related to pain. Compared to TSK-SF, TSK-AA had a significantly stronger association with PASS escape/avoidance subscale in the CLBP $(z=2.629, p=0.009)$ and the FM sample $(z=3.598, p<0.001)$. For measures of disability in CLBP, compared to the TSK-SF, the TSK-AA was significantly stronger associated with scores on the Quebec Back Pain Disability Scale $(z=2.408, p=0.008)$. For fibromyalgia, TSK-AA was not stronger associated with scores on the Disability Rating Index compared to the TSK-SF $(z=1.260, p=0.208)$. Internal consistency reliability (Cronbach's Alpha) was adequate for both subscales and total score of the TSK (see table 4-17).

Table 4-18: Correlation matrix of pain-related measures and their corresponding subscales.

\begin{tabular}{lllllll}
\hline & \multicolumn{2}{l}{ Chronic low back pain $(\mathrm{n}=225)$} & \multicolumn{2}{l}{ Fibromyalgia $(\mathrm{n}=391)$} \\
\hline & TSK-SF & TSK-AA & TSK (total) & TSK-SF & TSK-AA & TSK (total) \\
\hline PASS & $0.548^{*}$ & $0.487^{*}$ & $0.602^{*}$ & $0.465^{*}$ & $0.476^{*}$ & $0.544^{*}$ \\
PASS (fear) & $0.576^{*}$ & $0.459^{*}$ & $0.598^{*}$ & $0.481^{*}$ & $0.409^{*}$ & $0.505^{*}$ \\
PASS (cognitive) & $0.504^{*}$ & $0.420^{*}$ & $0.547^{*}$ & $0.385^{*}$ & $0.383^{*}$ & $0.442^{*}$ \\
PASS (physiology) & $0.472^{*}$ & $0.318^{*}$ & $0.439^{*}$ & $0.374^{*}$ & $0.348^{*}$ & $0.413^{*}$ \\
PASS (escape/avoidance) & $0.349^{*}$ & $0.512^{*}$ & $0.516^{*}$ & $0.325^{*}$ & $0.490^{*}$ & $0.490^{*}$ \\
PCS & $0.303^{*}$ & $0.305^{*}$ & $0.348^{*}$ & $0.428^{*}$ & $0.461^{*}$ & $0.516^{*}$ \\
PCS (rumination) & $0.181^{*}$ & $0.246^{*}$ & $0.255^{*}$ & $0.324^{*}$ & $0.397^{*}$ & $0.424^{*}$ \\
PCS (magnification) & $0.542^{*}$ & $0.425^{*}$ & $0.550^{*}$ & $0.452^{*}$ & $0.398^{*}$ & $0.484^{*}$ \\
PCS (helplessness) & $0.235^{*}$ & $0.229^{*}$ & $0.259^{*}$ & $0.397^{*}$ & $0.438^{*}$ & $0.486^{*}$ \\
Quebec & 0.167 & $0.331^{*}$ & $0.345^{*}$ & - & - & - \\
Disability Rating Index & - & - & - & $0.244^{*}$ & $0.305^{*}$ & $0.324^{*}$ \\
\hline
\end{tabular}

Note: TSK = Tampa Scale for Kinesiophobia; SF = Somatic Focus; AA = Activity Avoidance; TSK (total) refers to $\overline{\text { total }}$ scores without inversely phrased items; PASS = Pain Anxiety Symptoms Scale; PCS = Pain Catastrophizing Scale. ${ }^{*} p<0.01$. 
With respect to the predictive validity of the TSK subscales, table 4-19 depicts Pearson correlation coefficients between the TSK (total and subscale scores) and physical performance tests. Compared to TSK-SF, TSK-AA was more strongly associated with the lifting task and the bicycling task only in CLBP (see z-values in table 4-19), providing support for the predictive validity of the TSK subscales.

Table 4-19: Correlation matrix between physical performance and TSK subscales.

\begin{tabular}{lccccc}
\hline & TSK-SF & TSK-AA & TSK (total) & z-value & p-value \\
\hline CLBP $(n=31)$ & & & & 0.008 \\
\hline Lifting task & -0.103 & $-0.624^{* *}$ & $-0.497^{* *}$ & 2.663 & 0.004 \\
Bicycling task & 0.052 & $-0.543^{* *}$ & $-0.359^{*}$ & 2.849 & 0.290 \\
\hline Fibromyalgia $(\mathrm{n}=28)$ & & & & 1.057 \\
\hline Lifting task & -0.360 & $-0.457^{*}$ & $-0.430^{*}$ & & \\
\hline
\end{tabular}

Note: TSK = Tampa Scale for Kinesiophobia; SF = Somatic Focus; AA = Activity Avoidance; TSK (total) refers to total scores without inversely phrased items; ${ }^{*} p<0.05,{ }^{* *} p<0.01$. A significant $z$-value indicates that, compared to the TSK-SF, TSK-AA is more strongly associated with the corresponding physical performance test.

\section{DISCUSSION}

The present study aimed to replicate the robustness of a two-factor solution of the TSK in CLBP patients and FM patients and to provide further evidence for the construct and predictive validity of the best fitting factor structure. With respect to the results of confirmatory factor analyses, goodness-of-fit indices clearly indicated that the two-factor solution of the TSK (Clark et al., 1996) provided the best fit in both pain syndromes. In this two-factor model, two items (items 14 and 17) had residual correlation. It may be theoretically justified to allow these two items to correlate since both items belong to the same subscale (i.e., activity avoidance). It is important to note that allowing these two items to have residual correlation only serves the purpose of improving the model fit and has no consequences for use of the measure in research and clinical settings. Taken together, the present study provided further evidence for the robustness of a two-factor solution of the TSK.

The four-factor model of the TSK (Vlaeyen et al., 1995b), and the importance of exercise subscale in particular, was difficult to interpret as two inversely formulated items showed a substantial residual correlation and loaded together with one positively phrased item on this subscale. In many handbooks it is suggested to use both positively and inversely formulated items to prevent individuals who complete a questionnaire from giving similar responses to the remaining items after already having answered several items from the questionnaire (i.e., the response set phenomenon) (Maassen, 1991). However, a difficulty with the use of both types of items is that not all individuals who complete the questionnaire are aware of this while answering the questions (items). This way, intercorrelations between inversely phrased items may be higher than their correlations with the other (positively 
phrased) items, which may seriously influence the fit of factor solution. The same holds for positively phrased items. For the TSK, previous studies have found that at least some of the inversely phrased items showed weak associations with the total TSK score (Vlaeyen et al., 1995b; Clark et al., 1996). In addition, our previous study (Goubert et al., 2004) and the present study clearly showed that the best fitting factor model was a model without inversely phrased items. For researchers or clinicians who want to administer questionnaires that comprise inversely phrased items, we suggest to provide careful verbal or written instructions to patients on the presence of both positively and inversely formulated items so that they will be more alert while answering them.

With respect to the construct and predictive validity of the two-factor model, most support was found for the validity of the activity avoidance subscale in the CLBP sample on self-report measures as well as physical performance tasks. Thus, it appears that the TSK subscales represent two different constructs in chronic low back pain patients but that for fibromyalgia patients, both constructs do not have a clear differential effect. The finding of the present study that in the CLBP sample, physical performance tasks were more strongly associated with activity avoidance than with somatic focus, is in line with results from the study by Geisser et al. (2000). In their study, only activity avoidance significantly predicted performance on a behavioural task in which weight was lifted from floor to waist and from waist to shoulder during Progressive Isoinertial Lifting Evaluation (PILE) in chronic back pain patients. Clark et al. (1996) found support for the TSK total score, and to a lesser extent, for scores on both subscales to correlate significantly with multiple measures of perceived impairment and emotional distress. Further, only the somatic focus subscale was significantly associated with self-reported pain. However, individuals with higher TSK scores did not exhibit more limited physical capacities. In future studies, we recommend to assess convergent validity and discriminant validity by means of a multitrait-multimethod study (Campbell \& Fiske, 1959). In this kind of study, kinesiophobia should be measured with a number of different methods (e.g., physiological measures, behavioural measures and self-report measures) and different measures of the same construct and measures that are not related to the construct are to be included.

In sum, results of the present study replicated and extended our previous findings that a two-factor model of the TSK (Clark et al., 1996) provided the best fit in CLBP and FM patients. Compared with our previous study, larger samples of CLBP and FM patients were used. Construct validity (i.e., convergent validity) and predictive validity of the TSK subscales, TSK-AA in particular, was also supported mainly in the CLBP sample. For the researcher and clinician, total scores on the TSK without the inversely phrased items, may be used to obtain a general measure of kinesiophobia, which can be especially useful for screening purposes. Scores on the individual subscales can provide useful information on somatic focus (i.e., a belief in underlying and serious medical problems) and activity avoidance (i.e., the belief that activity may result in (re)injury or increased pain). However, future research should 
be aimed at further establishing the construct validity (i.e., convergent and discriminant validity) and predictive validity of the TSK subscales. Also, cut-off scores on the TSK should be identified by means of receiver operating characteristics curves (ROC-curves) to identify individuals who may be at risk for presenting painrelated fear as tapped by this instrument.

\section{ACKNOWLEDGMENTS}

Liesbet Goubert is Research Assistant of the Fund for Scientific Research - Belgium (FWO).

\section{REFERENCES}

Byrne, B. M. (1989). A primer of LISREL: Basic applications and programming for CFA models. New York: Springer-Verlag.

Campbell, D. T., \& Fiske, D. W. (1959). Convergent and discriminant validation by the multitrait-multimethod matrix. Psychological Bulletin, 56, 81-105.

Cattell, R. B. (1978). The scientific use of factor analysis in behavioural and life sciences. New York: Plenum Press.

Clark, M. E., Kori, S. H., \& Brockel, J. (1996). Kinesiophobia and chronic pain: psychometric characteristics and factor analysis of the Tampa Scale. American Pain Society Abstracts; 77.

Crombez, G., Vervaet, L., Lysens, R., Baeyens, F., \& Eelen, P. (1998). Avoidance and confrontation in painful, back-straining movements in chronic back pain patients. Behavioral Modification, 22, 62-77.

Crombez, G., Eccleston, C., Baeyens, F., Van Houdenhove, B., \& Van den Broeck, A. (1999a). Attention to chronic pain is dependent upon pain-related fear. Journal of Psychosomatic Research, 47, 403-410.

Crombez, G., Vlaeyen, J. W. S., Heuts, P. H. T. G., \& Lysens R. (1999b). Pain-related fear is more disabling than pain itself: evidence on the role of pain-related fear in chronic back pain disability. Pain, 80, 329-339.

Eccleston, C., Crombez, G., Aldrich, S., \& Stannard, C. (1997). Attention and somatic awareness in chronic pain. Pain, 72, 209-215.

Geisser, M. E., Hang, A. J., \& Theisen, M. E. (2000). Activity avoidance and function in persons with chronic back pain. Journal of Occupational Rehabilitation, 10(3), 215-227.

Goubert, L., Crombez, G., Van Damme, S., Vlaeyen, J. W. S., Bijttebier, P., \& Roelofs, J. (2004). Confirmatory factor analysis of the Tampa Scale for Kinesiophobia: invariant two-factor model across low back pain patients and fibromyalgia patients. Clinical Journal of Pain, 20(2), 103-110. 
Jöreskog, K. G., \& Sörbom, D. (1999). LISREL 8.30. Chicago IL: Scientific Software International Inc.

Koho, P., Aho, S., Watson, P., \& Hurri, H. (2001). Assessment of chronic pain behaviour: reliability of the method and its relationship with perceived disability, physical impairment and function. Journal of Rehabilitation and Medicine, 33, 128132.

Kopec, J. A., Esdaile, J. M., Abrahamowicz, M., Abenhaim, L., Woodauphinee, S., Lamping, D. L., \& Williams, J. I. (1995). The Quebec Back Pain Disability Scale. Measurement properties. Spine, 20(3), 341-352.

Lethem, J., Slade, P. D., Troup, J. D. G., \& Bentley, G. (1983). Outline of a fearavoidance model of exaggerated pain perceptions. Behaviour Research and Therapy, 21, 401-408.

Maassen, G. (1991). The use of positively and negatively phrased items and the fit of a factor solution. Quality \& Quantity; 25, 91-101.

McCracken, L. M., Zayfert, C., \& Gross, R. T. (1992). The Pain Anxiety Symptoms Scale: Development and validation of a scale to measure fear of pain. Pain, 50, 6773.

McCracken, L. M., Gross, R. T., Aikens, J., \& Carnrike, C. L. M. (1996). The assessment of anxiety and fear in persons with chronic pain: a comparison of instruments. Behaviour Research and Therapy, 34, 927-933.

McCracken, L. M., Faber, S. D., \& Janeck, A. S. (1998). Pain-related anxiety predicts non-specific physical complaints in persons with chronic pain. Behaviour Research and Therapy, 36, 621-630.

Miller, R. P., Kori, S. H., \& Todd, D. D. (1991). The Tampa Scale. Unpublished report, Tampa, FL.

Peters, M. L., Vlaeyen, J. W. S., \& Van Drunen, C. (2000). Do fibromyalgia patients display hypervigilance for innocuous somatosensory stimuli? Application of a body scanning reaction time paradigm. Pain, 86, 283-292.

Riley, J. F., Ahern, D. K., \& Follick, M. J. (1988). Chronic pain and functional impairment: assessing beliefs about their relationship. Archives of Physical and Medical Rehabilitation, 69, 579-582.

Salén, B. A., Spanfort, E. V., Nygren, A. L., \& Nordemar, R. (1994). The Disability Rating Index: an instrument for the assessment of disability in clinical settings. Journal of Clinical Epidemiology, 47(12), 1423-1434.

Sullivan, M. J. L., Bishop, S. R., \& Pivik, J. (1995). The pain catastrophizing scale: development and validation. Psychological Assessment, 7, 524-532.

Swinkels-Meewisse, I. E. J., Roelofs, J., Verbeek, A. L. M., Oostendorp, R. A. B., \& Vlaeyen, J. W. S. (2003). Fear of movement/(re)injury, disability and participation in acute low back pain. Pain, 105, 371-379.

Vlaeyen, J. W. S., Kole-Snijders, A. M. J., Boeren, R. G. B., \& Van Eek, H. (1995a). Fear of movement/(re)injury in chronic low back pain and its relation to behavioral performance. Pain, 62, 363-372. 
Vlaeyen, J. W. S., Kole-Snijders, A. M. J., Rotteveel, A., Ruesink, R., \& Heuts P. H. T. G. (1995a). The role of fear of movement/(re)injury in pain disability. Journal of Occupational Rehabilitation, 5, 235-252.

Vlaeyen, J. W. S., Seelen, H. A. M., Peters, M. L., De Jong, P., Aretz, E., Beisiegel, E., \& Weber, W. E. J. (1999). Fear of movement/(re)injury and muscular reactivity in chronic low back pain patients: an experimental investigation. Pain, 82, 297-304.

Vlaeyen, J. W. S., \& Linton, S. J. (2000). Fear avoidance and its consequences in chronic musculoskeletal pain: a state of the art. Pain, 85, 317-332.

Waddell, G., Newton, M., Henderson, I., Somerville, D., Main, C. J. (1993). A FearAvoidance Beliefs Questionnaire (FABQ) and the role of fear-avoidance beliefs in chronic low back pain and disability. Pain, 52, 157-168. 


\title{
4.5 THE FEAR OF PAIN QUESTIONNAIRE: FURTHER PSYCHOMETRIC EXAMINATION IN A NON-CLINICAL SAMPLE
}

\begin{abstract}
The present study examined psychometric properties of the Fear of Pain Questionnaire, a measure of pain-related fear, in a non-clinical sample. Factor structure of the FPQ was investigated by means of confirmatory factor analysis. A previously reported three-factor model was confirmed but at least one lower order factor emerged and some items had positive residual correlation. Construct validity of the FPQ was assessed by comparing correlation coefficients with related and unrelated measures. The FPQ and the subscales showed adequate to good construct validity. Moreover, modest correlation coefficients were found between the FPQ and other pain-related measures. Reliability of the FPQ (internal consistency and testretest reliability) was determined. Both the FPQ and its subscales showed good internal consistency and test-retest reliability was moderate to good. Further, normative data was provided. Results of the present study are discussed and directions for future research are provided.
\end{abstract}




\section{INTRODUCTION}

Pain-related fear has been recognized as an important determinant of chronic pain. According to the fear-avoidance model of exaggerated pain (Lethem et al., 1983), the degree of pain-related fear may initiate two extreme responses to pain, namely confrontation and avoidance. Philips (1987) has suggested that chronic pain sufferers may learn to avoid stimuli that are associated with the initiation or exacerbation of their pain symptoms. Based on the work of Lethem et al. (1983) and Philips (1987), a cognitive-behavioral model has been proposed which posits a behavioral mechanism in which pain-related fear contributes to the transition of acute pain becoming chronic pain (see for an overview Vlaeyen \& Linton, 2000). Briefly, if acute pain is interpreted as threatening, pain-related fear may evolve, leading to avoidance behavior and hypervigilance to bodily sensations and pain. A chronic pattern of disability, disuse, and depression is maintained in which depression and disuse are assumed to be associated with decreasing pain tolerance and hence promoting the painful experience, which fuels the cycle of increasing fear and avoidance.

Self-report measures are frequently used to obtain information about painrelated fear in chronic pain patients. Several measures of pain-related such as the Pain and Impairment Relationship Scale (PAIRS; Riley et al., 1988), the FearAvoidance Beliefs Questionnaire (FABQ; Waddell et al., 1993), the Tampa Scale for Kinesiophobia (TSK; Miller et al., 1991), and the Pain Anxiety Symptoms Scale (PASS; McCracken et al., 1992), have been developed aimed at measuring specific aspects of pain-related fear (see for a comparison of instruments McCracken et al., 1996). Although some of these measures have now been modified for use in nonclinical samples, most measures were originally designed to measure pain-related fear in different (chronic) pain samples. Recently, McNeil and Rainwater (1998) developed the Fear of Pain Questionnaire (FPQ) as a measure to quantify painrelated fear not only in (chronic) pain syndromes but also in non-clinical samples.

A small number of studies have investigated psychometric properties of the FPQ. To date, in four subsequent studies McNeil and Rainwater (1998) developed the 30-item FPQ-III. This 30-item FPQ-III (abbreviated as FPQ from here) was presented as the most current, streamlined, and psychometrically stable version. In one of their studies, responses to the FPQ from 275 students were subjected to a principal components analysis with varimax rotation. Five factors had eigenvalues greater then one and the Scree test (Cattell, 1978) identified the presence of either three or five factors. The three-factor solution was selected as the most parsimonious and interpretable one. The factors were labeled 'severe pain', 'minor pain', and 'medical pain' and consisted of ten items each. Each item had a salient loading on the corresponding factor but nine items had secondary loadings. Internal consistency and test-retest reliability of the FPQ and the subscales was good (Cronbach alpha ranged from 0.87 to 0.92 ; test re-rest reliability ranged from 0.69 to 0.76 ). Predictive validity was assessed and supported only for a previous version of the FPQ by using 
the Behavioral Avoidance Test with Video, which is a measure to assess fear-related avoidance/escape behaviors. Normative data were also presented for samples of inpatient chronic pain patients, general medical outpatients, and unselected undergraduates.

Further evidence for the psychometric properties of the FPQ in non-clinical samples was obtained in the study by Osman et al. (2002). In three subsequent studies, the factor structure was examined by means of an exploratory common factor-analytic procedure and confirmatory factor analysis (CFA). In line with the results from McNeil and Rainwater (1998), the exploratory factor analyses showed that each item had a salient loading on its corresponding factor but there were several items with secondary loadings. CFA showed that the three-factor oblique model, in which the latent constructs (i.e., subscales) were allowed to correlate, was the best fitting factor model. However, the fit-indices of this model did not meet the predetermined criteria. Item-parcel analyses (e.g., parcels of two items were created by randomly combining two items within each factor creating three factors containing five parcel-items each) were also conducted. Results of the item-parcel analyses showed that the three-factor oblique model was again the best fitting model, which met all pre-established criteria. Thus, the three-factor solution was confirmed only at the level of item-parcels but not at the level of items. Support for the construct validity was provided by means of CFA in which a three-factor model comprising fear of pain as measured with the FPQ (first factor), the PASS (second factor), and negative affect (third factor) provided the best fit compared to a two-factor solution in which both fear of pain measures were forced to load on one factor and negative affect comprised the second factor or a one-factor solution in which all measures loaded on one factor. Moreover, the relation between the FPQ and PASS scale scores was higher than the correlation between the FPQ and negative affect. Internal consistency of the FPQ and the subscales was almost similar to those reported by McNeil and Rainwater (1998). Criterion-related validity of the FPQ was also examined and showed that only the 'minor pain' subscale was strongly related to pain measures, such as pain severity and pain catastrophizing.

The present study examined psychometric properties of a Dutch version of the FPQ in a non-clinical sample of undergraduates. First, the goodness-of-fit of the three-factor structure of the FPQ was examined by means of confirmatory factor analysis. Second, convergent and discriminant validity of the FPQ was examined by means of correlational analysis of the FPQ with related and unrelated measures. Third, internal consistency and test-retest reliability of the FPQ and the subscales were estimated. Finally, normative data of the FPQ and its subscales was provided. 


\section{METHODS}

\section{Participants}

Two samples were used in the current study. The first sample consisted of 271 firstyear college students ( $17 \%$ male). Mean age was 19.6 years ( $\mathrm{SD}=1.9$ years). The second sample comprised 194 first-year and higher-year college students (22\% male). Mean age was 21.2 years ( $S D=2.5$ years). As expected, mean age in sample two was significantly higher compared to mean age in sample one $(\mathrm{t}(463)=7.84, \mathrm{p}<0.001)$. The FPQ was completed in both samples. It should be noted that individuals in sample two completed the FPQ as well as an additional battery of questionnaires (see measures section) two years after sample one completed the FPQ. There was no overlap of persons between both samples. Data from sample one was used only for confirmatory factor analysis, estimating internal consistency, and for providing normative data.

\section{Measures}

Participants in both samples completed a Dutch version of the Fear of Pain Questionnaire (FPQ; McNeil \& Rainwater, 1998). The FPQ is a 30-item self-report measure of pain-related fear designed to tap fear related to severe pain (e.g., "Breaking your leg"), minor pain (e.g., "Getting a paper-cut on your finger"), and medical pain (e.g., "Receiving an injection in your hip/buttocks"). Items are scored on a 5-point Likert scale ranging from 1 (not at all) to 5 (extreme). FPQ total scores range from 30 to 150. The translation of the English version of the FPQ into the Dutch version was done in a state-of-the-art manner that involved back translation and retranslation.

The Pain Anxiety Symptoms Scale (PASS; McCracken et al., 1992) is a 40-item self-report measure of pain-related fear tapping four domains: fearful appraisal of pain, cognitive anxiety, physiological anxiety, and escape/avoidance behavior. Items are rated on a 6-point Likert scale ranging from 0 (never) to 5 (always). PASS total scores range between 0 and 200. Reliability and validity of the PASS in clinical and non-clinical populations has been well established (McCracken et al., 1993; Osman et al., 1994; Larsen et al. 1997; Roelofs et al., 2004).

The trait version of the State-Trait Anxiety Inventory (STAI-T; Spielberger et al., 1970) is a self-report measure of trait anxiety containing 20 items rated on a 4-point scale ranging from 1 (almost never) to 4 (almost always). Total scores range from 20 to 80. Reliability and validity have been well documented (Kabacoff et al., 1997; Oei et al., 1990).

The Fear of Spiders Questionnaire (FSQ; Szymanski \& O'Donohue, 1995) is a 18item self-report measure of specific anxiety related to spiders. Items are rated on a 8point scale ranging between 0 (fully agree) to 7 (fully disagree). Total scores range from 0 to 126. Reliability and validity of the FSQ are good (Szymanski \& O'Donohue, 1995; Muris \& Merckelbach, 1996). 
The Aggression Questionnaire (AQ; Buss \& Perry, 1992; Meesters et al., 1996) comprises 29 items scored on a 5-point Likert scale ranging from 1 (extremely like me) to 5 (extremely unlike me). Total scores range from 29 to 145 . Reliability and validity of the AQ has been well documented (Buss \& Perry, 1992; Meesters et al., 1996; Morren \& Meesters, 2002).

The Pain Vigilance and Awareness Questionnaire (PVAQ; McCracken, 1997; Crombez \& Vlaeyen, 1998) is a measure of pain vigilance, which consists of 16 items rated on a 6-point scale with anchors of never and always. Total scores range from 0 to 80. The PVAQ is a reliable and valid measure of pain vigilance in pain-free individuals and chronic pain populations (Roelofs et al., 2002; Roelofs et al., 2003).

The Pain Catastrophizing Scale (PCS: Sullivan et al., 1995; Crombez \& Vlaeyen, 1996) is a 13-item self-report measure of pain catastrophizing. Items are rated on a 4point scale ranging from 1 (not at all) to 4 (all the time). Total scores range between 13 and 52. The PCS has been shown to be a reliable and valid measure of pain catastrophizing in pain-free individuals and chronic pain syndromes (Sullivan et al., 1995; Van Damme et al., 2002).

The Zung (Zung, 1965) is a 20-item inventory of depression. Items are rated on a 4-point Likert scale ranging from 1 (none or a little bit of the time) to 4 (most or all of the time). Total scores range from 20 to 80 . The Zung is a reliable and valid measure of depression (Zung, 1965).

For all questionnaires, higher scores reflect higher levels of the underlying person characteristic that the questionnaire presumes to measure. In the present study, total scores on all questionnaires (except for the FPQ) were used to assist in the validation of the FPQ.

\section{STATISTICAL ANALYSIS}

Individuals with more than $10 \%$ missing values were omitted from analyses. For individuals with less than $10 \%$ missing values, imputation was carried out by means of a regression technique that takes the responses of the person with missing values on the remaining items as well as responses from other persons on the item for which a person had missing values into account.

\section{Confirmatory factor analysis}

The goodness-of-fit of the previously reported three-factor solution of the FPQ (McNeil and Rainwater, 1998; Osman et al., 2002) was examined by means of confirmatory factor analysis (LISREL version 8.30; Jöreskog \& Sörbom, 1999). Each item was assumed to load only on one factor such that items of the same FPQ subscale loaded on the same factor (latent construct). Goodness-of-fit of the threefactor model was estimated while latent constructs (subscales) were allowed to correlate. A one-factor solution in which all items load on one latent construct was also examined as total scores on the FPQ are frequently reported in research papers. 
As this one-factor model is a special case of the three-factor model, the models can be compared with a likelihood ratio test. More specifically, under the null hypothesis that the special model fits as well as the more general one, the difference between their Chi-square values is itself Chi-square distributed with degrees of freedom equal to the difference between their degrees of freedom. The Maximum Likelihood algorithm was used to assess the fit of the models. The goodness-of-fit of the threefactor model and the one-factor model was evaluated using several descriptive criteria: (a) Root Mean Square Error of Approximation (RMSEA); (b) the Comparative Fit Index (CFI); the Non-Normed Fit Index (NNFI); and (d) the Expected Cross-Validation Index (ECVI). For the RMSEA, values below 0.05 or lower indicate a close fit, whereas values up to 0.08 represent reasonable errors of approximation. For the CFI and NNFI, values above 0.90 are indicative of an adequate fit whereas values above 0.95 are indicative of a good to very good fit. The ECVI is a relative measure to compare competing models (e.g., one-factor model vs. three-factor model): the model with the lowest value has the best fit. Data from both samples were pooled for the confirmatory factor analyses.

\section{Construct validity, reliability and normative data}

Construct validity of the FPQ was examined in sample two only by computing Pearson correlation coefficients between scores on the FPQ (and its subscales) and scores on the PASS, STAI-T, FSQ, AQ, PCS, PVAQ, and Zung. As the FPQ and the PASS are both measures of pain-related fear, convergent validity would be supported when the correlation between the FPQ and PASS is stronger then the correlation between FPQ and STAI-T (general trait anxiety). It was also expected that the correlation between FPQ and STAI-T is stronger than the correlation between FPQ and FSQ (specific anxiety for spiders). Further, support for discriminant validity would be provided when there is no substantial correlation between FPQ and AQ and between FPQ and Zung. Z-tests were used to compare the correlation coefficients. To decrease the likelihood of spurious findings due to Type I error, alpha was set to 0.01 . Modest correlation coefficients were expected between FPQ and other pain-related measures such as the PCS and the PVAQ.

Internal consistency (Cronbach's alpha) and test-retest reliability was examined in the FPQ total score as well as the subscales. Internal consistency was determined for both samples separately. For test-retest reliability, 46 students who participated in an experiment approximately two months after administration of the questionnaires completed the FPQ for the second time. An intra-class correlation coefficient (ICC) was computed to assess test-retest reliability.

Normative data of the FPQ and the subscales was provided by computing the $25^{\text {th }}, 50^{\text {th }}$, and the $75^{\text {th }}$ percentile scores for males and females separately as well for males and females together. 


\section{RESULTS}

Table 4-20 presents descriptive statistics of the questionnaires in both samples for males and females separately as well as for males and females together. In sample one, significant gender differences (alpha $=0.05$ ) were found between scores on the FPQ $(t[269]=2.75 ; p=0.006)$, the minor pain subscale $(t[269]=2.25 ; p=0.025)$, and the medical pain subscale $(\mathrm{t}[269]=2.61 ; \mathrm{p}=0.010)$. Borderline significant gender differences were found on the severe pain subscale $(\mathrm{t}[269]=1.92 ; \mathrm{p}=0.056)$ in sample one. No statistically significant gender differences on the FPQ and the subscales were found in sample two. Further, significant gender differences were only found on the FSQ $(\mathrm{t}[192]=3.25 ; \mathrm{p}=0.001)$.

Table 4-20: Descriptive statistics of the questionnaires for both samples.

\begin{tabular}{|c|c|c|c|c|c|c|c|}
\hline & \multicolumn{2}{|c|}{ Males $(n=45)$} & \multicolumn{2}{|c|}{ Females $(n=226)$} & \multicolumn{2}{|c|}{ Both $(n=271)$} & \multirow[t]{2}{*}{ Alpha } \\
\hline & Mean & SD & Mean & SD & Mean & SD & \\
\hline \multicolumn{8}{|l|}{ Sample 1} \\
\hline $\mathrm{FPQ}$ & 68.0 & 13.5 & 75.2 & 16.5 & 74.0 & 16.3 & 0.93 \\
\hline FPQ severe & 30.5 & 7.1 & 32.7 & 7.0 & 32.3 & 7.1 & 0.88 \\
\hline FPQ minor & 16.8 & 4.4 & 18.7 & 5.3 & 18.4 & 5.2 & 0.86 \\
\hline FPQ medical & 20.8 & 5.5 & 23.8 & 7.3 & 23.3 & 7.2 & 0.88 \\
\hline Sample 2 & \multicolumn{2}{|c|}{ Males $(n=42)$} & \multicolumn{2}{|c|}{ Females $(n=152)$} & \multicolumn{2}{|c|}{ Both $(n=194)$} & \\
\hline $\mathrm{FPQ}$ & 73.2 & 15.8 & 74.2 & 16.6 & 74.0 & 16.4 & 0.91 \\
\hline FPQ severe & 31.1 & 8.6 & 32.6 & 7.8 & 32.2 & 8.0 & 0.89 \\
\hline FPQ minor & 18.8 & 5.0 & 18.0 & 5.5 & 18.2 & 5.4 & 0.82 \\
\hline FPQ medical & 23.3 & 6.0 & 23.7 & 7.2 & 23.6 & 6.9 & 0.85 \\
\hline PASS & 52.5 & 23.7 & 52.8 & 24.6 & 52.7 & 24.4 & 0.93 \\
\hline PCS & 14.1 & 7.3 & 13.7 & 7.6 & 13.8 & 7.6 & 0.88 \\
\hline PVAQ & 29.2 & 12.1 & 30.3 & 11.1 & 30.0 & 11.3 & 0.87 \\
\hline STAI-T & 34.7 & 7.9 & 36.3 & 9.7 & 36.0 & 9.3 & 0.92 \\
\hline Zung (depression) & 34.1 & 6.0 & 34.6 & 7.1 & 34.5 & 6.8 & 0.82 \\
\hline FSQ & 7.2 & 14.4 & 21.0 & 26.5 & 18.0 & 25.0 & 0.96 \\
\hline$A Q$ & 65.5 & 13.6 & 62.7 & 12.0 & 63.3 & 12.4 & 0.82 \\
\hline
\end{tabular}

Note: $F P Q=$ Fear of Pain Questionnaire, PASS = Pain Anxiety Symptoms Scale, $P C S=$ Pain Catastrophizing Scale, $P V A Q=$ Pain Vigilance and Awareness Questionnaire, STAI-T = trait version of the State-Trait Anxiety Inventory; $A S I=$ Anxiety Sensitivity Index, FSQ = Fear of Spiders Questionnaire, $A Q=$ Aggression Questionnaire.

\section{Confirmatory factor analysis}

Table 4-21 depicts the goodness-of-fit indices for the three-factor model and the onefactor model as obtained by means of confirmatory factor analysis. The fit-indices for the one-factor model and the three-factor model did not meet the pre-established criteria. The three-factor solution did provide a statistically better fit compared to the one-factor model. That is, the difference between the chi-squares of the one-factor model and the three-factor model $(3553-2749=804)$ was statistically significant $(\Delta \mathrm{df}$ 
$=405-402=3$ ). Thus, it should be concluded that, although the three-factor model of the FPQ fitted better then the one-factor solution, fit of both models were poor. Inspection of the so-called 'modification-indices) that are computed by LISREL showed that some items had large positive residual correlation. When items have (positive) residual correlation, it means that the correlation between these items is stronger than the correlations between the remaining items of the scale or subscale. Careful inspection of the modification indices revealed the presence of a lower order factor within the 'medical pain' subscale. This lower order factor comprised four items related to getting an injection (items 8, 11, 14, and 17). Within this 'injection' factor, items 8 and 11 had strong residual correlation. Further, the 'injection' factor was substantially correlated with the 'severe pain' subscale. Within the 'medical pain' subscale, items 26 and 29 had strong residual correlation as they are uniquely related to dental fear. In addition, item 17 (e.g., "receiving an injection in your mouth") was substantially correlated with these dental fear items. Within the 'severe pain' items 3 and 6 had strong residual correlation as they refer to fear associated with breaking an arm or a leg respectively. Within the 'minor pain' subscale, items 4 and 19 had strong residual correlation as both items refer to cutting the tongue while licking an envelope or a paper-cut on your finger respectively. When re-running the three-factor model that is adjusted according to the abovementioned modifications, all fit indices met the predetermined criteria indicating that an adequate to good fit was obtained (see table 4-21 under 'three-factor model modified'). The ECVI also clearly favored the three-factor model including the abovementioned modifications. Moreover, the improvement of fit can be tested statistically by means of the chisquare test. The difference in chi-square between the original three-factor model and the three-factor model modified $(2749$ - $1029=1720)$ was indeed statistically significant $(\Delta \mathrm{df}=402-395=7)$.

Table 4-21: Fit indices of the factor models as obtained by means of CFA $(n=465)$.

\begin{tabular}{lcccccc}
\hline & \multicolumn{2}{c}{ RMSEA } & CFI & NNFI & ECVI & Chi $^{2}(\mathrm{df})$ \\
\hline & Estimate & \multicolumn{1}{c}{$90 \% \mathrm{Cl}$} & & & & \\
\hline One-factor & 0.15 & $0.14-0.16$ & 0.53 & 0.50 & 10.59 & $3553(405)$ \\
Three-factor model oblique & 0.11 & $0.10-0.12$ & 0.72 & 0.70 & 6.20 & $2749(402)$ \\
Three-factor model modified & 0.061 & $0.057-0.065$ & 0.91 & 0.90 & 2.62 & $1029(395)$ \\
\hline
\end{tabular}

Note: RMSEA = Root Mean Square Error of Approximation; CFI = Comparative Fit Index; NNFI = Non-Normed Fit Index; ECVI = Expected Cross-Validation Index.

\section{Construct validity, reliability, and normative data}

With respect to the construct validity of the FPQ (see table 4-22), the correlation between FPQ and PASS was significantly stronger than the correlation between FPQ and STAI-T $(z=2.187, p=0.029)$. The same pattern of results was found for the FPQ severe subscale $(z=2.152, p=0.031)$, but not for FPQ minor $(z=0.905, p=0.366)$ and FPQ medical $(z=1.885, p=0.059)$. Thus, convergent validity of the FPQ and its subscales was partially supported. There was no statistically significant difference 
between the magnitude of the correlation between FPQ and STAI-T and between FPQ and FSQ $(z=1.228, p=0.219)$, indicating no difference in the degree of association between fear of pain and trait anxiety and between fear of pain and a measure of specific fear (i.e., fear of spiders). The same pattern of results was found for the FPQ severe subscale $(z=0.408, p=0.816)$, FPQ minor $(z=1.709, p=0.087)$, and FPQ medical $(z=1.304, p=0.192)$. Further, no substantial correlation was found between FPQ and AQ and between FPQ and Zung, supporting the discriminant validity of the FPQ. Although the FPQ minor subscale showed a significant association with $A Q$, the magnitude of this correlation was quite modest. Similarly, Zung depression scores were significantly but modestly associated with the FPQ minor and FPQ medical subscales.

With respect to reliability, Cronbach's alpha of the FPQ total score and subscales was high indicating good internal consistency (see table 4-20). Test-retest reliability was assessed with an interval of about two months between both administrations. The ICC of the FPQ total score was 0.67 (mean $=76.7, \mathrm{SD}=13.7$ for the first test administration [adm1] and mean $=75.3, \mathrm{SD}=16.7$ for the second test administration [adm2]), indicating reasonable test-retest reliability with an interval of two months. For the FPQ severe pain, FPQ minor pain, and FPQ medical pain subscales, ICC's were 0.43 (mean $=33.6, \mathrm{SD}=6.7$ for $\mathrm{adm} 1$ and mean $=31.7, \mathrm{SD}=7.3$ for $\mathrm{adm} 2), 0.55$ (mean $=19.3, \mathrm{SD}=4.6$ for $\mathrm{adm} 1$ and mean $=19.7, \mathrm{SD}=5.0$ for $\mathrm{adm} 2$ ), and 0.80 (mean $=23.8, \mathrm{SD}=6.0$ for $\operatorname{adm} 1$ and mean $=23.9, \mathrm{SD}=6.9$ for $\operatorname{adm} 2$ ) respectively indicating moderate to good test-retest reliability. Table 4-23 presents normative data of the FPQ and the FPQ subscales.

Table 4-22: Pearson correlation coefficients of the FPQ with related and unrelated measures $(n=194)$.

\begin{tabular}{|c|c|c|c|c|}
\hline & $\mathrm{FPQ}$ & FPQ severe & $\mathrm{FPQ}$ minor & FPQ medical \\
\hline PASS & $0.34^{\star \star}$ & $0.21^{\star \star}$ & $0.29^{\star \star}$ & $0.32^{* *}$ \\
\hline STAI-T & $0.17^{\star}$ & 0.04 & $0.22^{* *}$ & $0.18^{*}$ \\
\hline FSQ & 0.06 & 0.02 & 0.07 & 0.06 \\
\hline$A Q$ & 0.11 & -0.03 & $0.19^{*}$ & 0.13 \\
\hline PCS & $0.37^{\star \star}$ & $0.27^{\star \star}$ & $0.29^{* *}$ & $0.32^{* *}$ \\
\hline PVAQ & $0.28^{* *}$ & $0.15^{*}$ & $0.24^{* *}$ & $0.30^{* *}$ \\
\hline Zung & 0.14 & 0.01 & $0.19^{* *}$ & $0.17^{*}$ \\
\hline
\end{tabular}

Note: $\mathrm{FPQ}=$ Fear of Pain Questionnaire, PASS = Pain Anxiety Symptoms Scale, STAI-T = trait version of the State-Trait Anxiety Inventory, ASI = Anxiety Inventory Index, FSQ = Fear of Spiders Questionnaire, AQ = Aggression Questionnaire, PCS = Pain Catastrophizing Scale, PVAQ = Pain Vigilance and Awareness Questionnaire. 
Table 4-23: Norm scores for the FPQ and its subscales across both samples for males $(n=87)$, females $(n=378)$ and males and females together $(n=465)$.

\begin{tabular}{llccc}
\hline & & Males & Females & Both \\
\hline Percentile 25 & FPQ & 60 & 63 & 63 \\
& FPQ severe & 27 & 28 & 28 \\
& FPQ minor & 14 & 14 & 14 \\
& FPQ medical & 18 & 19 & 19 \\
Percentile 50 & FPQ & 73 & 76 & 76 \\
& FPQ severe & 32 & 34 & 34 \\
& FPQ minor & 17 & 18 & 18 \\
& FPQ medical & 22 & 23 & 22 \\
& FPQ & 81 & 86 & 85 \\
& FPQ severe & 37 & 38 & 38 \\
& FPQ minor & 22 & 22 & 22 \\
& FPQ medical & 26 & 28 & 28 \\
\hline
\end{tabular}

\section{DISCUSSION}

The present study investigated psychometric properties of the Fear of Pain Questionnaire (McNeil \& Rainwater, 1998) in a non-clinical population of undergraduates. The factor structure of the FPQ was examined by means of confirmatory factor analysis. Construct validity of the FPQ and reliability (internal consistency and test-retest reliability) were also assessed. Finally, normative data was provided.

With respect to the factor structure, the previously reported three-factor model comprising FPQ severe, FPQ minor, and FPQ medical, was found to fit substantially and significantly better compared to the one-factor model. However, within the FPQ medical subscale, a lower-order factor consisting of items referring to injection was identified. In addition, some items had strong residual correlation. When two items have residual correlation, it means that the correlation between these items is stronger than the correlations between the remaining items of the subscale. Acknowledging the lower order 'injection' factor and allowing a restricted number of items to have residual correlation, fit improved substantially and significantly. As there are for example four items referring to 'injection' and two items to breaking a leg or an arm, it may be that some of these items are redundant and could be omitted in a shorter version of the FPQ that might tap the three FPQ factors equally well compared to the original FPQ. In this respect, Osman et al. (2002) analyzed a subset of items (parcels) that might be used to develop a short screening version of the FPQ and found adequate fit for this model. The findings from the present study are line with previous studies, which have favored the three-factor model of the FPQ but have also experienced difficulties in establishing the correct 
number of factors to retain (McNeil \& Rainwater, 1998; Osman et al., 2002). Taken together, the results from the confirmatory factor analysis confirmed the three-factor model of the FPQ but it should be kept in mind that at least one lower-order factor is present and that some items have residual correlation.

Construct validity (i.e., convergent and discriminant validity) of the FPQ was supported. FPQ scores were stronger associated with the PASS, another measure of pain-related fear compared to trait anxiety as measured with the STAI-T. For the FPQ subscales, only the FPQ severe pain scale showed the same pattern of results. Thus, convergent validity of the FPQ was partially supported. No substantial association was found between FPQ scores and scores on a measure of aggression (AQ). Only the FPQ minor pain subscale showed a significant but modest correlation with the AQ. Thus, discriminant validity of the FPQ was fairly supported. Further, moderate correlation coefficients were found between the FPQ and other pain-related measures supporting its validity. These results extend the findings on the construct validity of the FPQ reported by McNeil and Rainwater (1998) and Osman et al. (2002). In line with their studies, FPQ total scores showed good construct validity but differential support for construct validity of the subscales was found in the present study. Convergent validity of the FPQ severe pain subscale was strongest compared to the other subscales. FPQ medical pain showed the weakest discriminant validity compared to the other FPQ subscales.

Internal consistency of the FPQ and its subscales was good. Similar values for Cronbach's alpha have previously been reported (McNeil \& Rainwater, 1998; Osman et al. 2002). Test-retest reliability of the FPQ and its subscales over a two months period of time was moderate to good. The FPQ medical pain subscale was most stable across the two months and the FPQ severe pain subscale was least stable. Only one study has addressed the test-retest reliability of this measure in a comparable sample of undergraduates (McNeil \& Rainwater, 1998). In that study, test-retest was assessed over three weeks and correlations ranged from 0.69 to 0.76 . Consistent with our study, they found the FPQ medical pain subscale to be most stable and the FPQ severe pain subscale to be least stable. However, the present study used a substantially longer time interval compared to McNeil and Rainwater (1998). Although the FPQ is considered to be a trait measure, one cannot rule out that changes in fear of pain might have occurred due to the relative large period of time between both test administrations.

In conclusion, the findings of the present study indicate that the FPQ is a reliable and valid measure of pain-related fear in a non-clinical population of undergraduates. Confirmatory factor analysis clearly favored a three-factor solution. However, only a three-factor model in which a lower order was identified and some items were allowed to have residual correlation provided adequate fit. Based on these results, future research could be aimed at shortening the FPQ as some items appear to be redundant. Especially the items referring to receiving an injection may contaminate a measure of pain-related fear as they may reflect a phobia towards blood-injection rather than fear of pain. Future research should also be aimed at 
addressing psychometric properties of the FPQ in clinical populations (e.g., low-back pain, fibromyalgia, whiplash). This way, the contribution of the FPQ to our knowledge and understanding of pain-related fear in chronic pain syndromes could be extended. More specifically, the unique contribution of the FPQ beyond other measures of pain-related fear such as the PASS, the TSK, the PAIRS, and the FABQ should be established.

\section{REFERENCES}

Buss, A. H., \& Perry, M. (1992). The aggression Questionnaire. Journal of Personality and Social Psychology, 63(3), 452-459.

Cattell, R. B. (1978). The scientific use of factor analysis in behavioural and life sciences. New York: Plenum Press.

Crombez, G., \& Vlaeyen, J. W. S. (1998). The Pain Vigilance and Awareness Questionnaire: unpublished Dutch/Flemish translation.

Crombez, G., \& Vlaeyen, J. W. S. (1996). The Pain Catastrophizing Scale: unpublished Dutch/Flemish translation.

Jöreskog, K. G., \& Sörbom, D. (1999). LISREL 8.30. Chicago IL: Scientific software International Inc.

Kabacoff, R. I., Segal, D. L., Hersen, M., \& Van Hasselt, V. B. (1997). Psychometric properties and diagnostic utility of the Beck Anxiety Inventory and the State-Trait Inventory with older adult psychiatric outpatients. Journal of Anxiety Disorders, $11,33-47$.

Lethem, J., Slade, P. D., Troup, J. D. G., \& Bentley, G. (1983). Outline of a fearavoidance model of exaggerated pain perceptions. Behaviour Research and Therapy, 21, 401-408.

McCracken, L. M., Zayfert, C., \& Gross, R. T. (1992). The Pain Anxiety Symptoms Scale: Development and validation of a scale to measure fear of pain. Pain, 50, 6773.

McCracken, L. M., Gross, R. T., Hexum, C. L., \& Semenchunck, E. M. (1993). Factor structure and temporal stability of the Pain Anxiety Symptoms Scale. Paper presented at the annual convention for the Society of Behavioral Medicine, San Francisco, CA.

McCracken, L. M., Gross, R. T., Aikens, J., \& Carnrike, C. L. M. (1996). The assessment of anxiety and fear in persons with chronic pain: A comparison of instruments. Behaviour Research and Therapy, 34(11/12), 927-933.

McCracken, L. M. (1997). "Attention" to pain in persons with chronic pain: A behavioural approach. Behaviour Therapy, 28, 271-284.

McNeil, D. W., \& Rainwater, A. J. (1998). Development of the Fear of Pain Questionnaire-III. Journal of Behavioral Medicine, 21(4), 389-410. 
Meesters, C. M. G., Muris, P., Bosma, H., Schouten, E., \& Beuving, S. (1996). Psychometric evaluation of the Dutch version of the aggression questionnaire. Behaviour Research and Therapy, 34(10), 839-843.

Miller, R. P., Kori, S. H. \& Todd, D. D. (1991). The Tampa Scale. Unpublished report, Tampa, FL.

Morren, M., \& Meesters, C. M. G. (2002). Validation of the Dutch version of the Aggression Questionnaire in Adolescent Male Offenders. Aggressive Behavior, 28, 87-96.

Muris, P., \& Merckelbach, H. (1996). A comparison of two spider fear questionnaires. Journal of Behavioral and Experimental Psychiatry, 27(3), 241-244.

Oei, T. P. S., Evans, L., \& Cook, C. M. (1990). Utility and validity of the State Trait Anxiety Inventory with anxiety disorder patients. British Journal of Clinical Psychology, 29, 429-432.

Osman, A., Breitenstein, J. L., Barrios, F. X., Gutierrez, P. M., \& Kopper, B. A. (2002). The Fear of Pain Questionnaire-III: Further reliability and validity with nonclinical samples. Journal of Behavioral Medicine, 25(2), 155-173.

Osman, A., Barrios, F. X., Osman, J. R., Schneekloth, R., \& Troutman, J. A. (1994). The pain anxiety symptoms scale: psychometric properties in a community sample. Journal of Behavioral Medicine, 17, 511-522.

Philips, H. C. (1987). Avoidance behaviour and its role in sustaining chronic pain. Behaviour Research and Therapy, 25, 273-279.

Riley, J. F., Ahern, D. K., \& Follick, M. J. (1988). Chronic pain and functional impairment: assessing beliefs about their relationship. Archives of Physical and Medical Rehabilitation, 69, 579-582.

Roelofs, J., McCracken, L. M., Peters, M. L., Crombez, G., Van Breukelen, G., \& Vlaeyen, J. W. S. (2004). Psychometric evaluation of the Pain Anxiety Symptoms Scale (PASS) in chronic pain patients. Journal of Behavioral Medicine, 27(2), 167183.

Roelofs, J., Peters, M. L., Muris, P., \& Vlaeyen, J. W. S. (2002). Dutch version of the Pain Vigilance and Awareness Questionnaire: Validity and reliability in a pain-free population. Behaviour Research and Therapy, 40, 1081-1090.

Roelofs, J., Peters, M. L., McCracken, L. M., \& Vlaeyen, J. W. S. (2003). The Pain Vigilance and Awareness Questionnaire (PVAQ): further psychometric evaluation in fibromyalgia and other chronic pain syndromes. Pain, 101, 299-306.

Spielberger, C. D., Gorsuch, R. L., \& Lushene, R. E. (1970). State-trait anxiety inventory. Palo Alto: Consulting Psychologists Press.

Sullivan, M. J. L., Bishop, S. R., \& Pivik, J. (1995). The pain catastrophizing scale: Development and validation. Psychological Assessment, 7, 524-532.

Szymanski, J., \& O'Donohue, W. (1995). Fear of Spiders Questionnaire. Journal of Behaviour Therapy and Experimental Psychiatry, 26, 31-34.

Van Damme, S., Crombez, G., Bijtebier, P., Goubert, L., \& Van Houdenhove, B. (2002). A confirmatory factor analysis of the Pain Catastrophizing Scale: invariant factor structure across clinical and non-clinical populations. Pain, 96, 319-324. 
Vlaeyen, J. W. S., \& Linton. S. J. (2000). Fear-avoidance and its consequences in chronic musculoskeletal pain: a state of the art. Pain, 85, 317-332.

Waddell, G., Newton, M., Henderson, I., Somerville, D., \& Main, C. J. (1993). A FearAvoidance Beliefs Questionnaire (FABQ) and the role of fear-avoidance beliefs in chronic low back pain and disability. Pain, 52, 157-168.

Zung, W. W. K. (1965). A self-rating depression scale. Archives of General Psychiatry, 12, 63-70. 


\section{CHAPTER 5}

General Discussion 

The aim of this thesis was to examine the degree to which hypervigilance (or increased attention to pain) mediates the relation between pain-related fear and the pain experience. A prerequisite to investigating this question is demonstrating a relationship between pain-related fear and attention to pain. In chapter 2, a series of experimental studies on information processing was presented most of which examined selective attentional processing as a function of pain-related fear in pain patients and pain-free individuals. In the following chapter (chapter 3), two studies were presented in which the effects of a manipulation of attention to pain on the pain experience was examined. In addition, the moderating effects of pain-related fear on the relation between attention to pain (manipulated) and the pain experience were also investigated in both studies. The first study involved an experimental study in which pain-free individuals underwent an experimental pain test. In the second study, an experience sampling methodology was used in which chronic low back pain patients were followed for three weeks during which attention to pain was manipulated. This study also allowed for a direct examination of the research question (i.e., the extent to which attention to pain mediates the relation between pain-related fear and pain intensity). In chapter 4, a series of studies was presented aimed at establishing reliability and validity of self-report measures of pain vigilance and pain-related fear. These measures have frequently been used in the studies described in the previous chapters and determining psychometric properties is therefore of great importance. The results from the studies on information processing (chapter 2), on the manipulation of attention to pain (chapter 3), and on psychometric properties of the self-report measures (chapter 4) are subsequently discussed in this chapter. The discussion ends with a conclusion in which the research question is answered and clinical implications are provided.

\section{Information processing of pain-related stimuli: where do we stand now?}

During the past decade, researchers in the field of psychopathology have increasingly relied on cognitive models in accounting for emotional disorders such as several anxiety disorders and depression (Williams et al., 1997). Inspired by Beck's schema theory (Beck, 1976; Beck et al., 1986) and Bower's network theory of the relation between cognition and emotion (Bower, 1981, 1987), biases in attention, memory and interpretation have been identified. In the case of chronic pain, there is good evidence that (chronic) pain patients exhibit an interpretation bias and a memory bias towards pain-related stimuli. However, the existence of selective attentional processing of pain-related stimuli is less clear (Pincus \& Morley, 2001). Two widely used experimental paradigms for investigating selective attentional processing have been the modified Stroop task and the visual dot-probe task, each of which are discussed below.

\section{The modified Stroop task}

Chapter two started with a meta-analysis on five Stroop studies (see chapter 2.1). A meta-analysis differs from a systematic review in that it not only provides an 
overview of studies published in a certain field but also includes a quantitative summary estimate (e.g., a Mean Difference). The general conclusion of the metaanalysis was that pain patients selectively attend to sensory pain words and affective pain words. Meta-regression analysis showed that methodological quality of the individual studies included in the meta-analysis did not influence the estimation of the Mean Differences. The study included in the meta-analysis with the lowest rating of methodological quality (e.g., Pearce \& Morley, 1989) showed relatively high MD estimations on both sensory and affective pain words compared to the other studies (see chapter 2.1). One could argue that this study may have been responsible for the overall significant MD estimations on sensory and affective pain words. However, the sample size of the individual studies rather than the individuals MD was the critical factor in determining the weight of an individual study in the estimation of the overall MD for sensory and affective pain words in the meta-analysis. The results from the meta-analysis were the starting point for further research.

The meta-analysis showed that chronic low back pain patients selectively attend to pain related words as measured on a modified Stroop task compared to pain free controls. A second study was set up to examine whether it was pain itself or pain-related fear that would be associated with this selective attentional processing of pain-related words. The fear-avoidance model postulates that fear of pain would be associated with selective attentional processing. To disentangle the effects of pain and fear of pain on selective attentional processing, pain and fear of pain were experimentally induced in pain-free individuals by means of a factorial design (chapter 2.2). For this study, pain-free individuals were used rather than chronic low back pain patients, as the effect of fear of pain in the absence of pain cannot be investigated in pain patients as they are constantly in pain. Although on theoretical grounds fear of pain was expected to be associated with selective attentional processing, results showed that pain itself, rather than fear of pain, was associated with selective attentional processing. A second experiment was set up to replicate this finding from the first experiment, but proved unsuccessful. Thus, although the first experiment showed that pain was associated with selective attentional processing, this finding could not be replicated in a second experiment. Taken together, this study did not provide evidence for selective attentional processing as a function of either fear of pain or pain itself in pain-free individuals.

A third study examined whether the observed pattern of attentional processing on sensory pain and affective pain words as found in the meta-analysis, could be demonstrated for word categories that match more closely to the fears of chronic low back pain patients. Fear of movement and the possible consequences in terms of injury may be considered a good candidate. In this study, selective attentional processing on movement and injury related words was examined in pain patients and controls (chapter 2.3). Patients were selected on the basis of their scores on the Tampa Scale for Kinesiophobia (TSK; Miller et al., 1991), a measure of fear of movement and (re)injury. All patients completed the modified Stroop task containing words related to movement and injury. The hypothesis that highly fearful 
pain patients would selectively attend to these words was not found in this study. Compared to controls, chronic low back pain patients in general did not display selective attentional processing on movement and injury related words.

A fourth study was set up to examine whether words relevant to the patients' concerns may be associated with selective attentional processing. The relevance of sensory pain words for patients' concerns was rated idiosyncratically. It was expected that pain words rated as highly relevant would be associated with increased Stroop reaction times, especially in high fearful or high pain catastrophizing chronic low back pain patients (chapter 2.4). Word relevance in isolation or in interaction with pain-related fear or pain catastrophizing did not account for Stroop reaction times. A recent Stroop study that used personalized pain words also could not find selective attentional processing on these pain words in chronic pain patients compared to controls. Stroop reaction times were not associated with scores on measures of fear of pain and depression (Andersson \& Haldrup, 2003). Taken together, although the meta-analysis has shown that chronic pain patients selectively attend to sensory and affective pain words, attempts to replicate Stroop effects in chronic pain patients and pain-free individuals appear to be difficult. Moreover, the assumed importance of pain-related fear in selective attentional processing could not be demonstrated in the Stroop studies presented in chapter 2 .

\section{The visual dot-probe task}

The modified Stroop task may be limited as a pure measure of selective attentional processing. As the meaning of pain words may interfere with color naming of the words, the modified Stroop task may be considered a measure of general information processing bias rather than a pure measure of selective attentional processing. Another paradigm for investigating selective attentional processing is the visual dotprobe task. The dot-probe is assumed to represent a more direct test of allocation of visual attention thereby eliminating interpretations of results that are associated with stages of information processing unrelated to attention. In 2000, a study was published examining selective attentional processing in pain free individuals by means of a dot-probe task (Keogh et al., 2000). This study found that high fearful individuals in particular selectively attended to pain words. Using a dot-probe task, Asmundson et al. (1997) found that chronic pain patients low in anxiety sensitivity shifted attention away from stimuli related to pain. No effects on selective attentional processing were found in the group of patients high in anxiety sensitivity. Thus, the dot-probe may be considered a more robust measure of selective attentional processing. The first dot-probe experiment in this thesis (chapter 2.5) attempted to replicate the dot-probe study from Keogh et al. (2000). In the replication study, pain words, social threat words, and positive words were used. Unfortunately, the results from the Keogh et al. study were not replicated. A second dot-probe experiment, also described in chapter 2.5, examined attention to and avoidance of these types of pain words as a function of pain-related fear and presentation time of stimuli. Attention to 
pain was expected in high fearful individuals and at shorter presentation times of pain words while avoidance of pain words was hypothesized in low fearful individuals and at greater presentation times of word stimuli. Avoidance of threat in low fearful individuals may represent a means of regulating anxiety and enabling behavioral organization to continue in ongoing tasks, which is presumably adaptive as long as avoidance does not interfere with the processing of true threat (see Vasey et al., 1996). Results showed no effect of pain-related fear and presentation time of stimuli on attention to and avoidance of pain words in pain-free individuals.

In the last paragraph (chapter 2.6), a study is described in which the role of pain-related fear in selective attentional processing was investigated in chronic low back pain patients and controls by means of two dot-probe tasks. In addition to word stimuli (e.g., sensory pain, affective pain, movement words, injury words, and social threat words), idiosyncratically chosen pictorial stimuli were also included as these stimuli may be more salient than words and may therefore reflect patients' concerns (e.g., possible harmful consequences of movements) more precisely. A recent dotprobe study applying pictorial stimuli in undergraduates, has examined the extent to which the observed selective attentional processing could be attributed to vigilance to threat or to a difficulty to disengage attention from threat (Koster et al., in press). Vigilance to threat is reflected by facilitated responding to congruent threatening trials. In a congruent trial, the emotional stimulus and the dot probe appear both in either the upper or lower location. Difficulty to disengage from threat should result in a delay in reaction times to incongruent threatening trials compared to neutral trials. In the case of an incongruent trial, the emotional stimulus appears in the upper location and the dot probe appears in the lower location or vice versa. The results from the study by Koster and co-workers did not support the notion of vigilance to threat. However, their results clearly showed that participants had difficulty in disengaging attention from threat. In the study presented in chapter 2.6, results from the two dot probe tasks were analyzed by means of the conventional bias index (i.e., comparison of congruent trials with incongruent trials), a comparison of congruent trials with neutral trials (vigilance to threat), and a comparison of incongruent trials with neutral trials (difficulty to disengage from threat). The only significant findings were found on the dot probe task with pictorial stimuli, on which patients and to a lesser degree controls experienced difficulty to disengage from threat pictures. Scores on the Tampa Scale for Kinesiophobia (TSK) were positively associated with this difficulty to disengage from threat only in controls. Thus, the study described in 2.6 successfully replicated the results from Koster and co-workers in a clinical sample. Taken together, the dot-probe task as a general measure of selective attentional processing appears difficult to replicate. However, when one specific component of attentional processing is examined (e.g., disengagement from threat), chronic low back pain patients and to a lesser degree controls, indeed appeared to have difficulty to disengage from threat stimuli. However, the assumed influence of pain-related fear on selective attentional processing in general and on the observed difficulty to disengage was not demonstrated in chronic low back pain patients. 


\section{Future research}

In conclusion, the modified Stroop task and the dot-probe task have not provided robust evidence for selective attentional processing as a function of pain-related fear in either pain-free individuals or chronic low back pain patients. Future studies examining selective attentional processing should preferably use a componential approach. In general, three interrelated components of attention to all forms of threat can be distinguished (e.g., Eysenck, 1992; Mogg \& Bradley, 1998): (1) an initial attentional shift to a threatening stimulus, (2) engagement with a threatening stimulus, and (3) disengagement from a threatening stimulus. The modified Stroop task is a general measure of selective attentional processing by conventionally providing an overall index of attentional deployment by pain-related stimuli, which does not allow for a direct componential examination of selective attentional processing. The dot-probe allows for examining difficulty to disengage from threat. However, initial orienting and engagement with the threatening stimulus cannot be measured with the dot-probe paradigm as the threat stimulus has already been presented when a response to the dot probe has to be made. According to the notion of vigilance for threat, faster response times on congruent trials are expected compared to neutral trials. This would indicate that individuals preferentially hold their attention at the threatening location. It does, however, not show an initial attentional shift to the threatening stimulus or a facilitated engagement with the threat stimulus. When a threatening stimulus and a neutral stimulus are presented simultaneously for half a second, it is possible that more than one shift of attention occurs between both type of stimuli. Alternative methods of measuring initial attentional shift to and engagement with the threatening stimulus are needed. A more directly observable and ecologically valid measure of initial orienting may be eye movements. Eye movements are rapid, naturalistic, and normally automatic in that individuals commonly look at stimuli that attract their attention (Mogg et al., 2000). Thus, future studies could measure the direction and latency of the first eye movement in response to stimulus presentation but it should be noted that measuring eye movement is, like the dot-probe task, a measure of visually oriented attention. Visual attention for words or pictures is only one way of operationalizing selective attentional processing. Further, words or pictures are symbolic representations of the threatening stimuli. Other paradigms such as the primary task paradigm and the body scanning tasks have attempted to measure selective attentional processing more closely related to bodily sensations and pain. In a primary task paradigm, the degradation in patients' task performance is measured when (non-painful) electrocutaneous stimuli are given. Especially patients who are fearful about their pain show decrements in task performance (Crombez et al., 1999; Peters et al., 2002), emphasizing the importance of the threat value of pain (see Eccleston \& Crombez, 1999). In a body-scanning task, (non-painful) electrocutaneous stimuli are given on one or more body locations and have to be detected as fast and as accurately as possible. Peters and co-workers applied a body-scanning task to fibromyalgia patients and controls and found no differences in reaction times 
between both groups. However, within the group of fibromyalgia patients, high pain fearful patients showed faster detection times compared to low pain fearful patients.

Recently, a cueing paradigm has been developed, which examines selective attentional processing closely related to bodily sensations (i.e., electrocutaneous stimulation) in undergraduates (see Van Damme et al., 2002). This study also allowed for a componential analysis of attention, namely engagement with and disengagement from threatening pain targets. In this task, pain targets given to the left forearm and tone targets have to be detected as quickly and as accurately as possible. The target stimuli are preceded by pain cues (the word 'pain'), tone cues (the word 'tone'), or neutral cues (a series of the character ' $X$ '). Results showed that when a cue correctly primed a target, attention was optimally engaged in the identification of the target irrespective of the threatening context of the cue or target. However, when pain was cued and did not occur, there was retardation in disengagement from the pain cue. This retardation was particularly present in individuals high in catastrophic thinking (Van Damme et al., 2002). Obviously, the results from this study need to be replicated in clinical pain samples.

Summarizing, two important dimensions can be postulated along which several paradigms for measuring selective attentional processing can be classified. One dimension is the degree to which a paradigm is able to examine different components or sub-dimensions of selective attentional processing (e.g., initial orienting, engagement with and [difficulty to] disengagement from threat). The second dimension is the degree to which a paradigm measures selective attentional processing of stimuli related to bodily sensations or pain. Figure 5-1 displays the various paradigms along these two dimensions. The modified Stroop paradigm and the dot-probe paradigm make use of word stimuli or pictorial stimuli. These stimuli are symbolic representations of what is threatening for patients and are not closely related to bodily sensations or pain. The primary task paradigm, the body scanning paradigm, and the cueing paradigm all apply (non-painful) electrocutaneous stimuli and are therefore more close related to bodily sensations or pain. The modified Stroop paradigm and the primary task paradigm are general measures of selective attentional processing. The dot-probe task allows for examination of difficulty to disengage from threat and is therefore a more specific measure of selective attentional processing. The body-scanning paradigm is even more specific as this paradigm measures the detection of electrocutaneous stimuli, which may be a reflection of initial orienting attention to threat. The cueing paradigm is perhaps the best paradigm available at this moment for examining selective attentional processing as it is closely related to bodily sensations and allows for a detailed investigation of engagement with and disengagement from threat.

A future paradigm for examining selective attentional processing should combine the ability to examine specific aspects of selective attentional processing and should be closely related to bodily sensations and pain. One potential paradigm could be a dot-probe like scanning task. Following the cueing paradigm, difficulty to disengage from threat can be investigated in chronic low back pain patients by 
giving electrocutaneous stimuli to two positions, namely at a threatening location (e.g., lower part of the back) and at a neutral (non-threatening) location. Analogous to the conventional dot-probe task, a strong electrocutaneous stimulus is given to one of the two locations followed by a second less invasive electrocutaneous stimulus of which the exact location has to be detected by means of a response box. It is important to determine an adequate time interval between the two electrocutaneous stimuli. A time-interval of 500 milliseconds, which is commonly used in conventional dot-probe tasks, may be too short. Especially for the back, giving the first stimulus may lead to adaptation or habituation of the receptors in the lower part of the back making it more difficult to detect the second more invasive stimulus correctly. A second issue is the choice of a neutral location. Some parts of the body, for example the forearm are much more sensitive than the lower part of the back. One could reduce the stimulus intensity for this location but alternative bodily locations should be examined prior to conducting the experiment.

Figure 5-1: Overview of paradigms for examining selective attentional processing along two axes, the degree to which sub-dimensions of selective attentional processing can be examined and the degree to which the paradigm uses stimuli related to bodily sensations or pain.

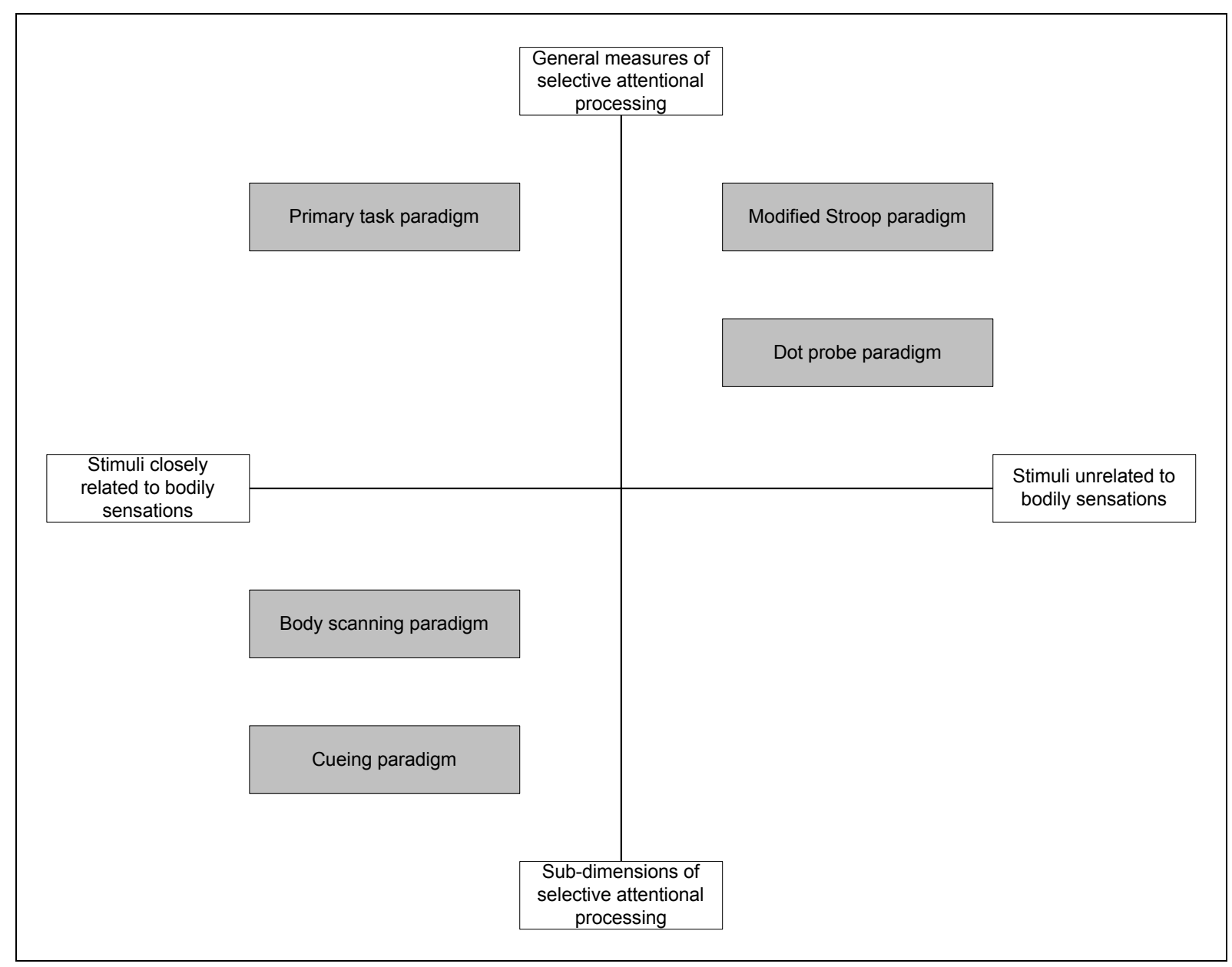




\section{Does a manipulation of attention to pain influence the pain experience?}

In two studies described in chapter 3, attention to pain was manipulated to examine the influence on self-reported pain intensity. The first study investigated the effects of a manipulation of attention to pain (mediator) on the pain perception and to what extent these effects depended on the level of self-reported pain-related fear (see chapter 3.1). More specifically, the effects of attentional focusing and distraction on pain tolerance and pain intensity were examined in female undergraduates who underwent the cold pressor pain test. Pain-related fear as a possible moderator of the effects of attentional focusing and distraction on the pain perception was also examined. Pain-related fear was tested in this study as a moderated as distraction has been found to be ineffective in high fearful individuals as the process of attending to pain in high fearful individuals may be automatic (Hadjistavropoulos et al., 2000). It is possible that high fearful individuals may profit from other strategies such as attentional (or sensory) focusing, which is in line with Leventhal and Everhart's parallel processing model (Leventhal \& Everhart, 1979). According to this model, focusing on sensory aspects of the pain stimuli is beneficial as it prevents the distress schemata from activation. In line with the prediction, high pain fearful females reported greater pain intensity ratings than those low in pain-related fear. A post-hoc analysis showed that distraction produced reduced pain ratings in low fearful individuals while attentional focusing led to reduced pain ratings in high fearful individuals. The finding that distraction may be beneficial for low fearful individuals is in line with previous findings (e.g., Hadjistavropoulos et al., 2000; Heyneman et al., 1990). The finding that high fearful individuals profit from attention focusing is in line with Leventhal and Everhart's parallel processing model (Leventhal \& Everhart, 1979). Thus, this study provided preliminary evidence that depending on the level of pain-related fear, attentional focusing and distraction from pain influence selfreported pain intensity but not pain tolerance. With respect to pain tolerance, a recent study by James and Hardardottir (2002) found increased pain tolerance in individuals low in trait anxiety while individuals high in trait anxiety were least pain tolerant, only in the condition in which no manipulation of attention to pain took place. Unfortunately, pain intensity was not assessed in the James and Hardardottir study.

The second study presented in chapter 3 was the only study in which the mediating role of attention to pain in relation to fear of pain and pain intensity was measured directly. An experience sampling diary study in chronic low back pain patients was conducted, in which patients were followed for a period of three weeks during which they had to complete an electronic diary (palm-top) eight times a day (see chapter 3.2). This study was divided in two sub-studies. In the first sub-study, attention to pain was found to mediate the relation between pain-related fear and pain intensity, but the effects were small and clinically irrelevant. Further, painrelated fear did not moderate the effects of attention to pain on pain intensity. The best conclusion that could be drawn was that pain-related fear and attention to pain independently account for variance in pain intensity. Thus, the main research 
question of this thesis (mediating role of attention to pain in relation to fear of pain and pain intensity) was not supported. The second sub-study attempted to manipulate attention to pain in daily life (attentional focusing on pain versus distraction from pain). No effects of the manipulation in isolation or in interaction with pain-related fear as a trait characteristic (TSK) on pain intensity was found. To date, only one study has examined the effects of a manipulation of attentional focusing on self-reported pain intensity in a clinical pain sample (Fors et al., 2002). Distraction from pain (patients were instructed to visualize beautiful, natural settings on nice summer days) administered daily on a videotape reduced pain ratings of fibromyalgia patients during the 28-day study period. Attentional focusing (patients were instructed to visualize their own pain-alleviating systems by showing how endorphins may reduce levels of pain on a videotape) did not differ from the control group in which no instructions were given. It is important to note that the manipulation check proved unsuccessful in our study. The failure of the manipulation check to be successful stresses the difficulty with which attention to pain can be manipulated in daily life. As a consequence, this study does not provide the exclusive answer to the question whether attention to pain mediates the relation between pain-related fear and pain intensity.

\section{Future research}

One difficulty with assessing the influence of a distraction from pain manipulation on the pain perception is that individuals are inquired about the experience of pain and are thus asked to attend to their pain thereby possibly counteracting and confounding the impact of distraction (Johnson and Petrie, 1997; Leventhal, 1992). Future studies applying a distraction manipulation could use alternative outcome measures such as physical performance. In addition to self-reported physical performance, objective measures such as advanced automatic activity monitors should be used (Bussman et al., 1998). A quite robust measure of activity levels in daily life consists of the quantification of energy expenditure, for example with the use the doubly labeled water technique (Westerterp et al., 1995). Energy expenditure may be calculated by analyzing the excretion of isotopes in urine samples during a number of consecutive days. This method has not been used in (chronic) pain patients but has the disadvantage of being quite expensive (Vlaeyen \& Linton, 2000).

\section{Self-report measures of pain vigilance and pain-related fear}

In several studies reported in this thesis, vigilance to pain and pain-related fear were measured with self-report measures. Determining reliability and validity of these measures is therefore of paramount importance. A series of studies was presented in chapter 4 aimed at determining psychometric properties of several measures of pain vigilance and pain-related fear. 


\section{Pain vigilance}

The Pain Vigilance and Awareness Questionnaire (PVAQ) has been developed to assess vigilance to pain (McCracken, 1997). The Pain Vigilance and Awareness Questionnaire taps two aspects of pain vigilance in pain-free individuals (see chapter 4.1 ) as well as in patients with fibromyalgia and other chronic pain syndromes (see chapter 4.2), namely attention to pain and attention to changes in pain. Compared to the attention to changes in pain subscale, the attention to pain subscale was most profoundly associated with self-report measures of pain catastrophizing and painrelated fear. With respect to the measurement of pain vigilance in daily life, the diary study described in chapter 3 included two items representing each of the two subscales. Moderate associations were found between the attention to pain item and items reflecting pain-related fear, pain catastrophizing, and pain intensity. However, no clinically relevant associations were found between these items and the attention to changes in pain item. One could inquiry about the clinical utility of both subscales. Individuals who constantly scan their body for pain signals may become fearful for pain predisposing them for developing chronic manifestations of pain. In contrast, in the absence of a constant scanning, attending only to changes in pain may be adaptive and useful for some pain patients to get or retain control of their pain. These individuals may engage in activities in daily life according to the changes in pain intensity they experienced. One may speculate that individuals who recover from an acute phase of back pain may also have a low score on the attention to pain scale but may have a high score on the attention to changes in pain subscale.

\section{Pain-related fear}

At present, several measures of pain-related fear have been developed aimed to measure specific aspects of pain-related fear. Three measures of pain-related fear were used throughout this thesis, namely the Pain Anxiety Symptoms Scale, the Tampa Scale for Kinesiophobia, and the Fear of Pain Questionnaire. The Pain Anxiety Symptoms Scale (PASS; McCracken, 1992; see 4.3) has been developed as a general measure of anxiety and fear in individuals with various chronic pain conditions. The factor structure of the PASS was not transparent but the original four-factor model may be considered most appropriate. In this four-factor model, subscales were labeled fearful appraisal of pain, cognitive anxiety, physiological anxiety, and escape and avoidance behavior. Validity and reliability of this fourfactor model was supported. Recently, a shortened version of the original PASS has been developed (McCracken \& Dhingra, 2002). This shortened version was also tested in chapter 4.3 and appeared to be a good reflection of the original PASS.

The Tampa Scale for Kinesiophobia (TSK; Miller et al., 1991; see 4.4) is a measure of fear of movement and (re)injury. This measure has been extensively used in chronic low back pain patients to assess levels of fear of movement and (re)injury. In line with previous studies (Clark et al., 1996; Goubert et al., 2004), confirmatory factor analyses showed the presence of two factors (e.g., 'activity avoidance' and 'somatic focus'). Reliability (e.g., internal consistency) of both subscales was good. 
The construct validity and predictive validity of these two subscales were supported. However, the construct validity and predictive validity was most strongly supported in chronic low back pain patients and to a lesser degree in fibromyalgia patients. Thus, the TSK as a measure of fear of movement and (re)injury may be a more sensitive measure in chronic low back pain patients compared to fibromyalgia patients.

The Fear of Pain Questionnaire (Rainwater \& McNeil, 1998; see chapter 4.5) is a general measure of pain-related fear, which is especially suitable for use in nonclinical populations, as it does not assume respondents to have experienced pain or to be in pain at the moment of completing the items. Previous reports on the factor structure of the FPQ have supported a three-factor solution but difficulties in establishing the correct number of factors to retain have also been reported. In the study described in chapter 4.5 , the three-factor structure of the FPQ was confirmed but results also indicated that the three-factor model was not entirely transparent. That is, a lower order factor emerged within one of the subscales and some pairs of items had strong residual correlation. Despite these minor limitations, construct validity of the original three-factor model of the FPQ was sufficient and reliability (e.g., test-retest and internal consistency) was moderate to good.

An important question that remains to be answered is what measure should be used for what patient. The PASS can be used as a measure of general anxiety and fear in different pain samples. The shortened version may be a good alternative when there is concern about the time and amount of effort asked of individuals. The TSK is especially useful as a measure of fear of movement and (re)injury in chronic low back pain patients and perhaps other musculoskeletal disorders but may be limited for use in fibromyalgia patients. The TSK has shown to be of use in patients with acute low back pain and osteoarthritis (Swinkels-Meewisse et al., 2003; Heuts et al., submitted). The FPQ is especially useful for assessing fear of pain in pain-free individuals. The application of the FPQ to chronic pain samples beyond other measures of pain-related fear should be established.

\section{Future research}

Most self-report measures of pain vigilance and pain-related fear make use of inversely phrased items. In examining the factor structure, these items do not load substantially on their corresponding factor or the inversely phrased items may even group together on one factor providing a methodological artifact rather than a content factor. Although the use of inversely phrased items is recommended in many textbooks to prevent the response set phenomenon (see Maassen, 1991), not all respondents are aware of the presence of these items. Researchers and clinicians who want to administer questionnaires that comprise inversely phrased items should provide careful verbal and written instruction to patients on the presence of inversely phrased items so that respondents will be more alert while answering them.

Several measures of pain-related fear have now been developed, each of which has a (slightly) different focus of content. In addition to the PASS, TSK, and 
FPQ that are discussed in this thesis, the Pain and Impairment Relationship Scale (PAIRS; Riley et al., 1988) has been developed to measure chronic pain patients' attitude concerning activities and pain and the Fear-Avoidance Beliefs Questionnaire (FABQ; Waddell et al., 1993) has been developed to measure patients' beliefs about how work and physical activity may affect their low back pain. Future research could examine to what extent these different concepts exists within the broader framework of pain-related fear. One strategy is to subject patients' responses to all individual items of all measures to a factor analysis. Factor analysis (FA) is a multivariate statistical technique for determining a set of underlying factors that appear to be driving the measurements that are being made with the original items. Two alternative multivariate techniques are multi-dimensional scaling (MDS) and hierarchical cluster analysis (HCA). MDS is aimed at discovering the latent structure of a data pool, when the degree of similarity between the items is known. To obtain the degree of similarity with respect to content of items, all individual items have to be clustered into categories based on whatever criteria an individual believes are relevant. The frequency of occurrence of two items in the same group can subsequently be calculated and can be viewed as a measure of the degree of similarity between items. The result is a multidimensional representation of the items in a geometrical configuration of points. In this configuration, items with greater similarity are put closer to each other. The similarity matrix can be converted into a distance matrix and subsequently submitted to HCA, which is aimed at grouping items with a relatively high degree of similarity. Thus, even though there are similarities in the type of research questions to which FA and MDS can be applied to, these procedures are fundamentally different methods. Most importantly, FA requires subjects to rate all items of all measures and provides an indication of underlying factors "in practice". MDS requires subjects to assess similarities between items at a higher level of abstraction and provides an indication of underlying theoretical dimensions. Future research should examine to what extent the factors obtained from factor analysis are comparable to the theoretical dimensions obtained from MDS.

Another important issue that should be taken into account in future research is the responsiveness of the measures. For example, if the TSK is considered an instrument for evaluation, the concern for validity must be extended beyond the construct itself to a discussion of the responsiveness of the instrument, i.e., the ability to detect change over time. One way of looking at responsiveness is to consider it a way of discriminating between those who have changed and those who have not. Responsiveness can be described in terms of sensitivity and specificity. By setting different cut-off points, a ROC curve can be plotted to quantify this property. Future research could examine cut-off scores of measures of pain-related fear (e.g., PASS, TSK) in relation to treatment. Recently, a cognitive-behavioral treatment program with in vivo exposure has been developed to treat chronic low back pain patients. One question is whether highly fearful patients in particular would profit most from this treatment or whether the treatment may be beneficial for all patients. This has 
raised the question whether pain patients could be classified as either high or low fearful based on the TSK score. Based on clinical observations, a score below 40 is considered low fearful while scores above this cut-off point is considered high fearful. However, empirical research has not yet tested the adequacy of this cut-off point. The challenge in this research would be to find a dichotomous criterion. One possibility would be to ask chronic low back pain patients to lift a shopping bag with a certain weight. The weight of the bag should be chosen in a way that some individuals would lift the bag while others would not. An appropriate criterion should be a good reflection of physical activity in daily life. The question is then to what extent a cut-off score on the TSK obtained from a certain criterion generalizes to daily life of patients.

\section{CONCLUSION AND CLINICAL IMPLICATIONS}

\section{Does attention to pain mediate the relation between pain-related fear and pain intensity?}

The research question in this thesis was the degree to which attention to pain mediates the relation between pain-related fear and the pain experience in chronic low back pain. A prerequisite in a mediation model is demonstrating a relation between the independent variable (pain-related fear) and the mediator (attention to pain). Self-report measures of pain-related fear and pain vigilance show a substantial association (see chapter 4.1 and 4.2). In a similar way, responses to items representing pain-related fear and pain vigilance in the diary study also yielded robust associations (see chapter 3.2). However, examining the relation between pain-related fear and pain vigilance in an experimental setting (e.g., Stroop task or dot-probe task) yielded no robust effects of selective attentional processing as a function of painrelated fear. Chronic low back pain patients did appear to have difficulty to disengage attention from threat, but this effect was not dependent on the level of pain-related fear in chronic low back pain patients. Thus, there appears to be a discrepancy between data obtained from self-report measures (e.g., questionnaires and items from diary study) that support the association between pain-related fear and pain vigilance, and experimental studies that have largely failed to find selective attentional processing as a function of pain-related fear. The suitability of a modified Stroop task for measuring selective attentional processing in chronic low back pain patients can be doubted as Stroop effects appear difficult to replicate. The same holds for the dot-probe task but this task allows for a more detailed analysis of attentional components (e.g., disengagement from threat), which might be a promising approach for future research. The experimental studies presented in chapter 2 , originated out of the cognitive approach of psychopathology. Stimuli used in these tasks are threatening and neutral words or pictures. These stimuli may not adequately represent patients' bodily sensations and pain and may therefore insufficiently capture attentional processes. Alternative paradigms such as the body-scanning task 
and the primary task paradigm are more closely related to bodily sensations and pain that patients experience and may therefore be more sensitive measures for examining selective attentional processing. The rationale for further examining the usefulness of the modified Stroop task and the visual dot-probe task in the present thesis was derived from the meta-analysis that showed that chronic low back pain patients selectively attend to sensory and affective pain words and from a dot-probe study conducted by Keogh and colleagues (2001), which showed selective attentional processing depended on the level of fear of pain in pain-free individuals. A methodological issue may arise from the use of self-report measures in examining the relation between pain-related fear and pain vigilance. It is possible that relations between these construct may be artificially high due to the "shared methods" phenomenon. That is, patients may give a more or less consistent score (either high or low) on each item as long as it is related to pain, which may lead to artificially high associations between pain-related constructs.

The most elegant study that directly addresses the research question is the diary study (see chapter 3.2). This study found no clinical significant mediation effect of attention to pain in the relation between pain-related fear and pain intensity. Instead, pain intensity appeared to be influenced independently by pain-related fear and pain vigilance. As was the case with self-report measures, items reflecting pain vigilance, pain-related fear, and pain intensity in the diary study were all rated by means of a seven-point Likert scale. The "shared methods" phenomenon could also have attributed to the associations found between these construct, possibly leading to inflated associations. A manipulation of attentional focus proved to be unsuccessful and did not influence pain intensity. The effect of the manipulation did not depend on the level of pain-related fear. Although major efforts were undertaken to manipulate attentional focus, it still appears difficult to accomplish a manipulation of attentional focusing in daily life of patients with chronic low back pain. Turning back to the additional route proposed in the introduction of this thesis, there is poor evidence for this additional link. The fear-avoidance model is in essence a vicious cycle in which all processes (e.g., pain catastrophizing, pain-related fear, pain vigilance, avoidance behavior, and pain experience) may occur at the same time. This may be particularly pertinent for pain-related fear and pain vigilance. An increase of the level of pain-related fear is directly accompanied by an increase in pain vigilance. Both pain-related fear and pain vigilance independently influence pain intensity. Figure 5-2 presents the fear-avoidance model in which the relations between painrelated fear and hypervigilance are represented by a double arrow. Both pain-related fear and hypervigilance influence pain intensity. The possibility that the pain experience may also influence pain-related fear and hypervigilance directly remains to be determined. 
Figure 5-2: Modified fear-avoidance model of chronic low back pain.

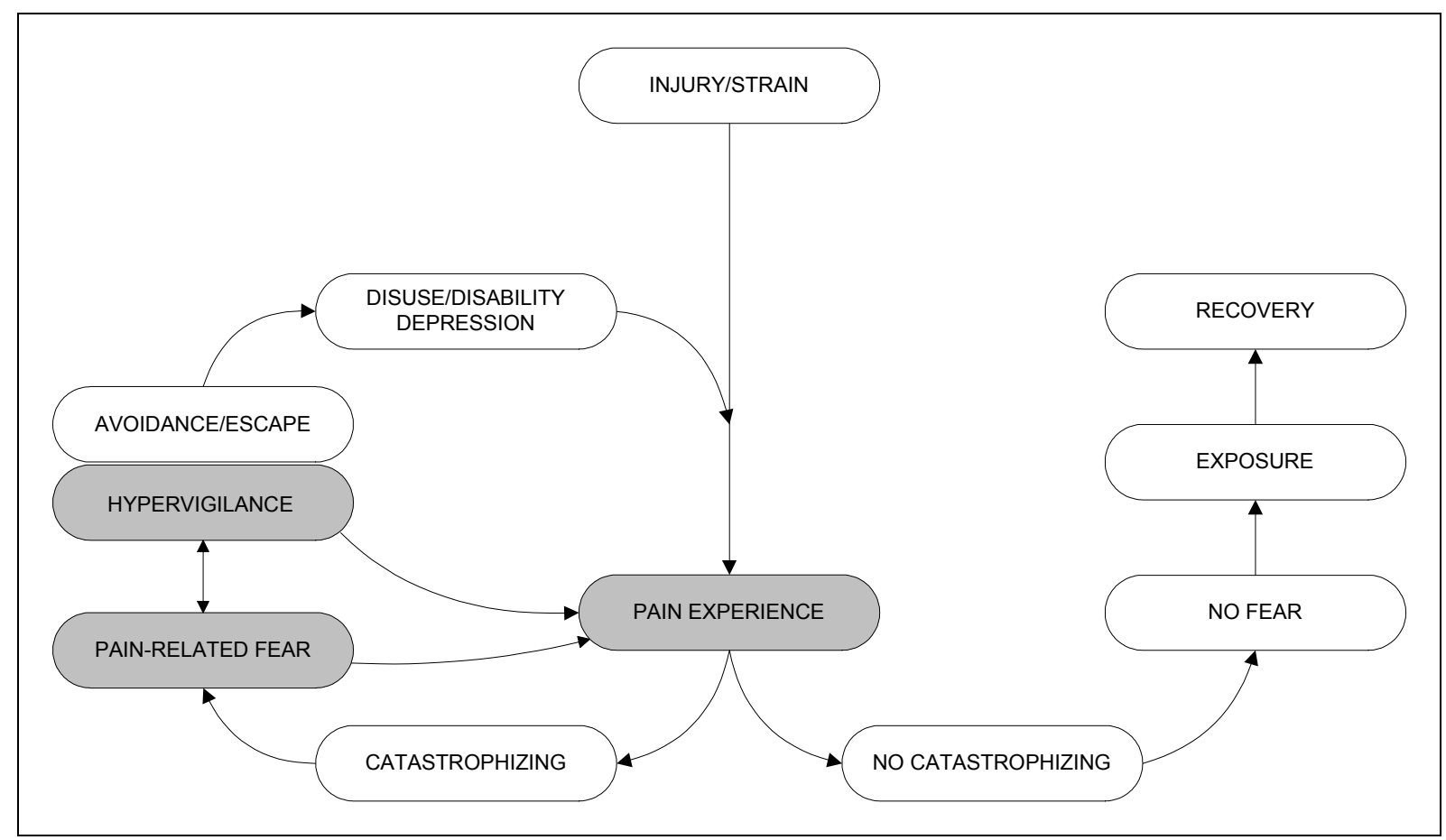

\section{Clinical implications}

The implications of the results of the studies described in this thesis for clinical practice are limited. Distraction may be useful for individuals low in pain-related fear (see chapter 3.1). This is in line with previous studies showing that distraction only works for patients low in pain-related fear (Hadjistavropoulos et al., 2000). In a similar vein, Heyneman et al. (1990) showed that distraction was most beneficial for non-catastrophizing individuals. Distraction was less useful for catastrophizing individuals. Patients who are high in pain-related fear may profit from focusing on sensory aspects of the pain experience.

At present, the efficacy of cognitive-behavioral treatment with in vivo exposure for reducing pain-related fear in chronic low back pain patients has been tested in several studies mainly conducted in our research group (Vlaeyen et al., 2001; Vlaeyen et al., 2002a; Vlaeyen et al., 2002b, see for an overview Roelofs et al., 2002). These studies have shown that this treatment not only reduced levels of painrelated fear, but also levels of pain vigilance and increased physical activity levels. Importantly, these improvements were maintained at one-year follow-up.

\section{References}

Andersson, G., \& Haldrup, D. (2003). Personalized pain words and Stroop interference in chronic pain patients. European Journal of Pain, 7, 431-438. 
Asmundson, G., Kuperos, J., \& Norton, G. (1997). Do patients with chronic pain selectively attend to pain-related information? Preliminary evidence for the mediating role of fear. Pain, 72, 27-32.

Beck, A. T. (1976). Cognitive therapy and the emotional disorders. New York: International University Press.

Beck, A. T., Emery, G., \& Greenberg, R. C. (1986). Anxiety disorders and phobias: A cognitive perspective. New York: Basic Books.

Bower, G. H. (1981). Mood and memory. American Psychologist, 36, 129-148.

Bower, G. H. (1987). Commentary on mood and memory. Behavioural Research and Therapy, 25, 443-456.

Bussman, J. B. J., Van de Laar, Y. M., Neleman, M. P., \& Stam, H. J. (1998). Ambulatory accelerometry to quantify motor behaviour in patients after failed back surgery: a validation study. Pain, 74, 153-161.

Crombez, G., Eccleston, C., Baeyens, F., Van Houdenhove, B., \& Van den Broeck, A. (1999). Attention to chronic pain is dependent upon pain-related fear. Journal of Psychosomatic research, 47, 403-410.

Eccleston, C., \& Crombez, G. (1999). Pain demands attention: a cognitive-affective model on the interruptive function of pain. Psychological Bulletin, 125, 356-366.

Eysenck, M. W. (1992). Anxiety: the cognitive perspective. Hillsdale: Lawrence Erlbaum Associates.

Fors, E. A., Sexton, H., \& Götestam, K. G. (2002). The effect of guided imagery and amitriptyline on daily fibromyalgia pain: a prospective, randomized, controlled trial. Journal of Psychiatric Research, 36, 179-187.

Hadjistavropoulos, H. D., Hadjistavropoulos, T., \& Quine, A. (2000). Health anxiety moderates the effects of distraction versus attention to pain. Behaviour Research and Therapy, 38, 425-438.

Heyneman, N. E., Fremouw, W. J., Gano, D., Kirkland, F., \& Heiden, L. (1990). Individual differences and the effectiveness of different coping strategies for pain. Cognitive Therapy and Research, 14(1), 63-77.

James, J. E., \& Hardardottir, D. (2002). Influence of attention focus and trait anxiety on tolerance of acute pain. British Journal of Health Psychology, 7, 149-162.

Johnson, M. H., \& Petrie, S. M. (1997). The effects of distraction on exercise and coldpressor tolerance for chronic low back pain sufferers. Pain, 69, 43-48.

Keogh, E., Ellery, D., Hunt, C., \& Hannent, I. (2000). Selective attentional bias for pain-related stimuli amongst pain fearful individuals. Pain, 91, 91-100.

Koster, E., Crombez, G., Verschuere, B., \& De Houwer, J. Selective attention to threat in the dot probe paradigm: differentiating vigilance and difficulty to disengage. Behaviour Research and Therapy (in press).

Leventhal, H. (1992). I know distraction works even though it doesn't. Health Psychology, 11, 208-209.

Leventhal, H., \& Everhart, D. (1979). Emotion, pain, and physical illness. In Izard CE (Ed.), Emotions in personality and psychopathology. Plenum Press, New York, pp. 263-299. 
McCracken, L. M. (1997). "Attention" to pain in persons with chronic pain: A behavioral approach. Behavior Therapy, 28(2), 271-284.

Maassen, G. (1991). The use of positively and negatively phrased items and the fit of a factor solution. Quality \& Quantity; 25, 91-101.

Miller, R. P., Kori, S. H., \& Todd, D. D. (1991). The Tampa Scale. Unpublished report. Tampa: FL.

Mogg, K., \& Bradley, B. P. (1998). A cognitive-motivational analysis of anxiety. Behaviour Research and Therapy, 36, 809-848.

Mogg, K., Millar, N., \& Bradley, B. P. (2000). Biases in eye movements to threatening facial expressions in generalized anxiety disorder and depressive disorder. Journal of Abnormal Psychology, 109(4), 695-704.

Pearce, J., \& Morley, S. (1989). An experimental investigation of the construct validity of the McGill Questionnaire. Pain, 39, 115-121.

Peters, M. L., Vlaeyen, J. W. S., \& Kunnen, A. M. W. (2002). Is pain-related fear a predictor of somatosensory hypervigilance in chronic low back pain patients? Behaviour Research and Therapy, 40, 85-103.

Pincus, T., \& Morley, S. (2001). Cognitive processing in chronic pain: a review and integration. Psychological Bulletin, 127, 599-617.

Riley, J. F., Ahern, D. K., \& Follick, M. J. (1988). Chronic pain and functional impairment: assessing beliefs about their relationship. Archives of Physical and Medical Rehabilitation, 69, 579-582.

Roelofs, J., Boissevain, M. D., Peters, M. L., De Jong, J. R., \& Vlaeyen, J. W. S. (2002). Psychological treatments for chronic low back pain: past, present and beyond. Pain Reviews, 9, 29-40.

Swinkels-Meewisse, I. E. J., Roelofs, J., Verbeek, A. L. M., Oostendorp, R. A. B., \& Vlaeyen, J. W. S. (2003). Fear of movement/(re)injury, disability and participation in acute low back pain. Pain, 105, 371-379.

Van Damme, S., Crombez, G., \& Eccleston, C. (2002). Retarded disengagement from pain cues: the effects of pain catastrophizing and pain expectancy. Pain, 100, 111118.

Vasey, M. W., El-Hag, N., \& Daleiden, E. L. (1996). Anxiety and the processing of emotionally threatening stimuli: distinctive patterns of selective attention among high- and low-test-anxious children. Child Development, 67, 1173-1185.

Westerterp, K. R., Wouters, L., \& Van Marken Lichtenbelt, W. D. (1995). The Maastricht protocol for the measurement of body composition and energy expenditure with labeled water. Obesitas Research, 3(1, Suppl 1), 49-57.

Vlaeyen, J. W. S., \& Linton, S. J. (2000). Fear-avoidance and its consequences in chronic musculoskeletal pain: a state of the art. Pain 85, 317-332.

Vlaeyen, J. W. S., De Jong, J. R., Geilen, M., Heuts, P. H. T. G., \& Van Breukelen, G. (2001). Graded exposure in vivo in the treatment of pain-related fear. A replicated single-case experimental design in four patients with chronic low back pain. Behaviour Research and Therapy, 39, 151-166. 
Vlaeyen, J. W. S., De Jong, J. R., Geilen, M., Heuts, P. H. T. G., \& Van Breukelen, G. (2002a). The treatment of fear of movement/(re)injury in chronic low back pain: exposure in vivo versus graded activity. A replicated single-case experimental cross-over design. Clinical Journal of Pain, 18, 251-261.

Vlaeyen, J. W. S., De Jong, J. R., Onghena, P., Kerkhoffs-Hanssen, M., \& KoleSnijders, A. M. J. (2002b). Can pain-related fear be reduced? The application of cognitive-behavioral exposure in vivo. Pain Research and Management, 7, 144-153.

Waddell, G., Newton, M., Henderson, I., Somerville, D., \& Main, C. (1993). A FearAvoidance Beliefs Questionnaire (FABQ) and the role of fear-avoidance beliefs in chronic low back pain and disability. Pain, 52, 157-168.

Williams, J. M. G., \& Watts, F. N., MacLeod, C., \& Mathews, A. (1997). Cognitive psychology and the emotional disorders (2 ${ }^{\text {nd }}$ Edition). Chichester: John Wiley \& Sons. 


\section{SUMMARY}

In most western industrialized countries, non-specific low back pain is a common disease. The personal burden of low back pain is heavy and low back pain is associated with high societal costs. The identification of mechanisms underlying the process of recovery of back pain is therefore of great importance. The 'fearavoidance' model has been proposed as a good candidate to explain why some individuals do and others do not recover from an acute pain incident. More specifically, individuals who catastrophize about the experience of an acute pain incident may subsequently become fearful of their pain. Pain-related fear may lead to avoidance behavior and hypervigilance to bodily sensations and pain, which maintains a chronic pattern of disability, disuse and depression. Depression and disuse are in turn associated with decreasing pain tolerance and hence promote the painful experience, leading to increased fear and avoidance. Thus, a vicious cycle is created in which an acute (low back) pain incident eventually becomes chronic low back pain. In contrast, non-catastrophizing individuals experience little pain-related fear and are more likely to rapidly confront daily activities, leading to fast recovery. Hypervigilance, or (increased) attention to bodily sensations and pain, may play an important role in the maintenance of chronic low back pain. The research question in this thesis was to what extent hypervigilance (or attention to pain) may act as a mediator in the relation between pain-related fear and the pain experience.

Chapter 1 provided a theoretical introduction to the subject of the thesis. An overview of pain theories was presented of which the fear-avoidance model of chronic low back pain briefly outlined in the previous section was discussed in more detail. Thereafter, an in depth discussion of the concept of hypervigilance in the maintenance of chronic low back pain was presented. The introductory chapter concluded with an outline of the thesis and a presentation of the research question, which was addressed in subsequent chapters.

Chapter 2 presented a series of experimental studies in which the relation between pain-related fear and attention to pain was examined. Demonstrating a relationship between pain-related fear and attention to pain is a prerequisite for attention to pain being a mediator in the relation between pain-related fear and the pain experience. Researchers in the field of psychopathology have increasingly relied on cognitive tasks such as the modified Stroop task and the visual dot-probe task in examining selective attentional processing as a function of anxiety in several emotional disorders. In the field of chronic pain, relatively few studies have applied these cognitive tasks in examining selective attentional processing. Chapter 2 started with a meta-analysis on five studies examining selective attentional processing by means of the modified Stroop task in chronic (low back) pain patients (chapter 2.1). Results from the meta-analysis showed that patients selectively attended to sensory and affective pain words and these results were taken as a starting point for further 
extending and refining of the modified Stroop task as a measure of selective attentional processing. Chapter 2.2 described an experimental study that investigated whether fear of pain or pain itself was associated with selective attentional processing in pain free individuals. In line with studies examining selective attentional processing in emotional disorders, fear of pain rather than pain itself was hypothesized to be associated with selective attentional processing. Results showed that neither fear of pain nor pain was associated with selective attentional processing. Chapter 2.3 presented a study that examined whether selective attentional processing could be demonstrated on word categories that match more closely to the fears of chronic low back pain patients, namely fear of movement and injury. More specifically, selective attentional processing of words related to movement and injury was expected especially in high fearful chronic low back pain patients. Results showed no selective attentional processing on these words as a function of painrelated fear. In chapter 2.4, selective attentional processing on sensory pain words was examined in chronic low back pain patients. Patients rated the degree to which these sensory pain words were relevant to their concerns. Selective attentional processing was hypothesized to be present on words rated as highly relevant for patients' concerns in high fearful chronic low back pain patients, but results did not confirm this hypothesis.

In chapter 2.5, a visual dot-probe study was described which attempted to replicate a previous dot-probe study that found selective attentional processing of pain words as a function of pain-related fear in pain-free individuals. No bias was found on social threat and positive words. Unfortunately, the results from the previous dot-probe study were not replicated in the study described in chapter 2.5. A second study was set up in which selective attentional processing and avoidance of pain words was examined as a function of pain-related fear and presentation time of stimuli. Attention to pain was expected in high fearful individuals and at shorter presentation times of word stimuli. Avoidance of pain words was hypothesized in low fearful individuals at greater presentation times of word stimuli. Results showed no effect of pain-related fear and presentation time of word stimuli on attention to and avoidance of pain words in pain-free individuals. Chapter 2.6 examined selective attentional processing in chronic low back pain patients and a control group by means of two dot-probe studies applying word and pictorial stimuli. Results provided no evidence for selective attentional processing as a function of painrelated fear in chronic low back pain patients. However, in analyzing data from dotprobe tasks, researchers have largely relied on the computation of a bias index, which is a general measure of selective attentional processing. The bias index does not take neutral trials (i.e., fillers) into account. When neutral trials were compared to trials in which a threatening stimuli appears, chronic low back pain patients and to a lesser degree controls, appeared to have difficulty to disengage from threat only on the pictorial dot-probe task. Pain-related fear was positively associated with this difficulty to disengage from threat only in controls. 
Chapter 3 presented two studies in which attention to pain was manipulated to examine the influence on the pain experience. Chapter 3.1 described a study, which investigated the influence of attentional focusing and distraction on selfreported pain intensity and pain tolerance in pain-free female individuals who underwent a cold-pressor pain test. As expected, high pain fearful females reported greater pain intensity ratings than those low in pain-related fear. Distraction produced reduced pain intensity ratings in low fearful females while attentional focusing led to reduced pain intensity ratings in high fearful females. These effects were not found for pain tolerance. In chapter 3.2, a diary study was presented in which chronic low back pain patients were followed for a period of three weeks and information with respect to pain-related fear, attention to pain, and pain intensity were collected eight times a day. In the first week only temporal relations between these constructs were examined allowing for a direct test of mediation of attention to pain in the relation between pain-related fear and pain intensity. Although attention to pain was a statistically significant mediator of the relation between pain-related fear and pain intensity, the effects were small and clinically irrelevant. In the remaining two weeks, attention to pain was manipulated (i.e., attentional focusing versus distraction) to examine the influence on pain intensity. No effect of the manipulation in isolation or in interaction with pain-related fear as a trait characteristic on pain intensity was found. Importantly, the manipulation check proved generally unsuccessful.

Chapter 4 presented a series of studies aimed at establishing reliability and validity of self-report measures of pain vigilance and pain-related fear that have been used in this thesis. Psychometric properties of the Pain Vigilance and Awareness Questionnaire (PVAQ) have been examined in pain-free individuals (chapter 4.1) as well as in fibromyalgia and other chronic pain syndromes (chapter 4.2). A two-factor model of the PVAQ has been found in both studies representing 'attention to pain' and 'attention to changes in pain'. The PVAQ showed good internal consistency and fair test-retest reliability. Construct validity of the PVAQ was also supported. With respect to the measurement of pain-related fear, psychometric properties of the Pain Anxiety Symptoms Scale (PASS), the Tampa Scale for Kinesiophobia (TSK), and the Fear of Pain Questionnaire (FPQ) were examined. With regard to the PASS (chapter 4.3), no transparent factor structure was present but the original four-factor model may be considered most appropriate in individuals with various chronic pain conditions. Factors were labeled fearful appraisal of pain, cognitive anxiety, physiological anxiety, and escape and avoidance behavior. Internal consistency of this four-factor model was adequate to good and construct validity was supported. In this chapter, psychometric properties of a shortened version of the PASS, i.e., the PASS-20, were also tested. Internal consistency was good and construct validity was supported, indicating that the PASS-20 is a good reflection of the original PASS. With respect to the TSK (chapter 4.4), a two-factor model has been identified in chronic low back pain patients and fibromyalgia patients. The two factors represented 'activity avoidance' and 'somatic focus'. Internal consistency was good and construct 
validity and predictive validity was supported especially in chronic low back pain patients. The FPQ is especially useful for non-clinical populations as respondents do not necessarily have to be in pain for completing the measure (chapter 4.5). Although a previously reported three-factor model could be replicated, results indicated that the three-factor model was not entirely transparent as a lower order factor emerged and some items had strong residual correlation. Despite these minor limitations, reliability (i.e., test-retest and internal consistency) was moderate to good and construct validity was supported.

Chapter 5 presented a discussion of the results obtained in the previous chapters. Of each chapter, results were briefly summarized and major points of discussion were described. Furthermore, suggestions for further research were provided. Studies examining selective attentional processing by means of the modified Stroop task and the visual dot-probe task (see chapter 2) were put in a broader perspective by comparing these tasks to other tasks that have been used to measure selective attention for bodily sensations and pain in patients with various pain conditions. Two dimensions were proposed along which these tasks could be classified. These dimensions were a) the degree to which a task is able to examine sub-dimensions of attentional processing and $b$ ) the degree to which a task measures selective attentional processing on stimuli related to bodily sensations or pain. For the manipulation of attention to pain (see chapter 3), alternative outcome measures such as the level of physical performance were considered as inquiring individuals to attend to their pain may confound the impact of a distraction manipulation. For the self-report measures (see chapter 4), several measures of pain-related fear have been developed and the extent to which these measures indeed represent different concepts within the broader framework of pain-related fear and the extent of responsiveness of these measures was considered as important issues for further research. Finally, in the light of the research question, chapter 5 concluded that there was poor evidence for attention to pain to mediate the relation between pain-related fear and pain intensity and that clinical implications of the results were limited. 


\section{SAMENVATTING}

Non-specifieke lage rupgijn is een veel voorkomende aandoening in de meeste Westerse geïndustrialiseerde landen. Lage rugpijn gaat gepaard met een hoge lijdensdruk en heeft hoge maatschappelijke kosten tot gevolg. Het is derhalve van groot belang dat mechanismen die ten grondslag liggen aan het herstel van lage rugpijn worden opgehelderd. Het vrees-vermijdingsmodel biedt een verklaring voor de vraag waarom sommige individuen wel en andere individuen niet herstellen van een acuut pijnincident. Individuen die zich kenmerken door catastrofale gedachten over de ervaren pijn kunnen als gevolg daarvan angstig worden voor de pijn. Pijngerelateerde vrees kan leiden tot vermijdingsgedrag en hypervigilantie voor lichamelijke signalen en pijn, waarmee een chronisch patroon van beperkingen, disuse en depressie kan worden geïnduceerd. Depressie en disuse zijn op hun beurt geassocieerd met een verminderde tolerantie voor pijn, wat de pijnervaring bevordert. Op deze manier wordt een vicieuze cirkel gecreëerd waarin een acuut pijnincident (lage rugpijn) uiteindelijk chronisch lage rugpijn kan worden. Individuen die geen catastrofale gedachten hebben zullen weinig angst ervaren voor de pijn en zullen sneller de dagelijkse activiteiten oppakken, waarmee herstel wordt bespoedigd. Hypervigilantie, of (verhoogde) aandacht voor lichamelijke signalen en pijn wordt verondersteld een belangrijke rol te spelen in de instandhouding van chronisch lage rugpijn. De onderzoeksvraag die centraal staat in dit proefschrift is in hoeverre aandacht voor pijn een mediator is in de relatie tussen angst voor pijn en de pijnervaring.

Hoofdstuk 1 gaf een theoretische inleiding over het onderwerp van dit proefschrift. Er werd een overzicht gegeven van pijntheorieën, waarbij het vreesvermijdingsmodel, zoals kort beschreven in de voorgaande alinea, in meer detail besproken werd. Vervolgens werd de rol van hypervigilantie in de instandhouding van chronische pijn nader toegelicht. Het eerste hoofdstuk werd afgesloten met een uiteenzetting van de structuur van het proefschrift en de introductie van de onderzoeksvraag.

Hoofdstuk 2 beschreef een reeks experimentele studies waarin de relatie tussen angst voor pijn en aandacht voor pijn onderzocht werd. Als aandacht voor pijn een mediator is in de relatie tussen angst voor pijn en de pijnervaring, dan is een voorwaarde voor mediatie de aanwezigheid van een relatie tussen angst voor pijn en aandacht voor pijn. Onderzoek op het gebied van psychopathologie, en de relatie tussen angst en selectieve aandacht in het bijzonder, heeft veelvuldig gebruik gemaakt van cognitieve taken zoals de emotionele Stroop taak en de visuele dotprobe taak. Er waren weinig Stroop studies en dot-probe studies uitgevoerd naar selectieve aandacht als functie van angst bij chronische pijn. Hoofdstuk 2 startte met een meta-analyse van vijf studies waarin selectieve aandacht bij chronische pijn patiënten werd onderzocht met behulp van een emotionele Stroop taak (hoofdstuk 
2.1). De resultaten van de meta-analyse lieten zien dat patiënten selectief aandacht schenken aan zowel sensorische als affectieve pijnwoorden. Deze resultaten werden als vertrekpunt genomen voor het verder uitwerken en verfijnen van de emotionele Stroop taak als een maat voor selectieve aandacht. Hoofdstuk 2.2 beschreef een experimentele studie waarin werd nagegaan of angst voor pijn dan wel pijn zelf samenhing met selectieve aandacht in pijnvrije individuen. In overeenstemming met studies waarin selectieve aandacht gemeten werd bij emotionele stoornissen, werd angst voor pijn en niet pijn zelf verondersteld samen te hangen met selectieve aandacht. De resultaten lieten zien dat selectieve aandacht niet samenhing met angst voor pijn en ook niet met pijn zelf. Hoofdstuk 2.3 beschreef een studie waarin selectieve aandacht werd onderzocht voor woordcategorieën die mogelijk representatiever zijn voor datgene waar chronisch lage rugpijn patiënten bang voor zijn, namelijk woorden gerelateerd aan beweging en letsel. Selectieve aandacht voor deze woordcategorieën werd verwacht in met name hoog angstige pijnpatiënten. Resultaten lieten geen selectieve aandacht zien als functie van angst voor pijn. In hoofdstuk 2.4 werd een studie beschreven waarin selectieve aandacht voor sensorisch pijnwoorden werd onderzocht. Patiënten gaven aan in hoeverre de woorden relevant waren voor de pijn die zij ervaarden. Verwacht werd dat selectieve aandacht zou optreden op relevante pijnwoorden in met name hoog angstige patiënten, maar deze verwachting werd niet door de resultaten bevestigd.

In hoofdstuk 2.5 werd een visuele dot-probe studie beschreven bestaande uit een replicatie van een eerdere studie waarin selectieve aandacht voor pijn woorden werd gevonden als functie van angst voor pijn in pijnvrije individuen. Er werd geen vertekening in de aandacht gevonden voor sociaal bedreigende woorden en positieve woorden. De studie beschreven in hoofdstuk 2.5 kon de eerdere bevindingen niet repliceren. Een tweede studie werd opgezet waarin selectieve aandacht en vermijding van pijnwoorden werd onderzocht als functie van angst voor pijn en aanbiedingstijd van stimuli. Aandacht voor pijn woorden werd verwacht in hoog angstige individuen en bij korte aanbiedingstijden, terwijl vermijding van pijn woorden verwacht werd in laag angstige individuen en bij langere aanbiedingstijden. De resultaten lieten geen effecten van angst voor pijn en aanbiedingstijd van pijn woorden zien op aandacht voor of vermijding van pijn woorden in pijnvrije individuen. In hoofdstuk 2.6 werd een studie beschreven waarin selectieve aandacht in chronisch lage rugpijn patiënten en een controlegroep werd onderzocht met behulp van twee dot-probe taken, namelijk met woorden en plaatjes. Voor beide taken werd geen ondersteuning gevonden voor selectieve aandacht als functie van angst voor pijn. Echter, in de analyse van data verkregen uit dot-probe studies werd veelal gebruik gemaakt van de bias-index. Deze index is een algemene maat voor selectieve aandacht. De bias-index neemt in haar berekening niet de neutrale trials (fillers) mee. Wanneer neutrale trials vergeleken werden met bedreigende trials, dan bleken chronisch lage rugpijnpatiënten en in mindere mate controles moeite te hebben zich los te maken van de dreiging. Dit werd alleen gevonden voor de dot-probe taak met plaatjes. Angst voor pijn hing positief samen 
met deze moeite zich los te maken van de dreiging in controles, maar niet in chronisch lage rugpijn patiënten.

Hoofdstuk 3 beschreef twee studies waarin aandacht voor pijn gemanipuleerd werd en de invloed van deze manipulatie op de pijnervaring onderzocht werd. Hoofdstuk 3.1 beschreef een studie waarin de invloed van een manipulatie van aandacht naar de pijn toe en van de pijn af (distractie) op pijnintensiteit en pijn tolerantie werd onderzocht in vrouwelijke pijnvrije individuen die een cold-pressor pijn test ondergingen. In overeenstemming met de verwachting bleken hoog angstige individuen een hogere pijnintensiteit te ervaren in vergelijking met laag angstige individuen. Distractie leidde tot een lagere pijnintensiteit bij laag angstige vrouwen terwijl het richten van de aandacht op de pijn tot een lagere pijnintensiteit bij hoog angstige vrouwen leidde. Deze effecten van de manipulatie werden niet gevonden voor pijn tolerantie. In hoofdstuk 3.2 werd een dagboekstudie beschreven bij chronisch lage rugpijn patiënten die voor een periode van drie weken gevolgd werden. Informatie met betrekking tot pijn-gerelateerde constructen als angst voor pijn, aandacht voor pijn en pijnintensiteit werd verzameld middels een palmtop computer dat acht keer per dag ingevuld diende te worden. In de eerste week werden temporele relaties tussen de constructen vastgesteld en kon mediatie van aandacht voor pijn in de relatie tussen angst voor pijn en pijnintensiteit worden onderzocht. Hoewel aandacht voor pijn in statistisch opzicht een mediator was bleek het effect klein en klinisch niet relevant te zijn. In de resterende twee weken werd aandacht voor pijn gemanipuleerd (aandacht op pijn richten versus distractie) en werd nagegaan wat de invloed van deze manipulatie was op pijnintensiteit. Er werd geen effect van de manipulatie zelf gevonden op pijnintensiteit, ook niet in interactie met angst voor pijn (TSK). De manipulatie-check bleek in het algemeen niet succesvol.

Hoofdstuk 4 beschreef een serie studies waarin de betrouwbaarheid en validiteit van zelf-rapportage maten van aandacht voor pijn (vigilantie) en angst voor pijn, die in diverse studies beschreven in dit proefschrift gebruikt waren. Psychometrische eigenschappen van de Pain Vigilance and Awareness Questionnaire (PVAQ) werden onderzocht in pijnvrije individuen (hoofdstuk 4.1) en in patiënten met fibromyalgie en ander chronische pijn syndromen (hoofdstuk 4.2). De PVAQ onderscheidde zich in twee factoren namelijk aandacht voor pijn en aandacht voor veranderingen in pijn. Deze structuur werd teruggevonden zowel bij gezonden (hoofdstuk 4.1) als bij patiënten (hoofdstuk 4.2). De PVAQ had een goede interne consistentie and een redelijke test-hertest. Construct validiteit werd tevens ondersteund. Met betrekking tot het meten van angst voor pijn werden de Pain Anxiety Symptoms Scale (PASS), de Tampa Scale for Kinesiophobia (TSK) en de Fear of Pain Questionnaire (FPQ) onderzocht. Voor de PASS bleek, ondanks de ondoorzichtige factorstructuur, het originele vier factoren model het beste te passen bij individuen met verschillende pijn syndromen. Factoren waren angstige beoordeling van pijn, cognitieve angst, fysiologische angst en vermijdingsgedrag. Interne consistentie van het vier factoren model was goed en de construct validiteit 
werd ondersteund. In hoofdstuk 4.3 werd tevens psychometrische kenmerken van een verkorte versie van de PASS, de PASS-20, onderzocht. Interne consistentie was goed en construct validiteit werd tevens ondersteund. De PASS-20 is een goede afspiegeling van de oorspronkelijke PASS. Voor de TSK (hoofstuk 4.4) werd een twee factoren model gevonden in lage rugpijn patiënten en patiënten met fibromyalgie. Deze twee factoren waren vermijding van activiteiten en somatische focus. Interne consistentie was goed en construct validiteit en predictieve validiteit werden ondersteund voornamelijk in lage rugpijn patiënten. De FPQ is een bruikbaar instrument om angst voor pijn te kwantificeren in niet-klinische populaties (hoofdstuk 4.5). Individuen hoeven niet noodzakelijkerwijs pijn te ervaren om de items te beantwoorden. Een eerder gevonden drie factoren model kon worden gerepliceerd, maar de resultaten lieten zien dat er waarschijnlijk een lagere orde factor aanwezig was en dat verschillende items residuele variantie hadden. Ondanks deze kleine beperkingen bleek de betrouwbaarheid (interne consistentie en testhertest) matig tot goed te zijn en werd de construct validiteit ondersteund.

Hoofstuk 5 bestond uit een discussie van de resultaten verkregen uit de voorgaande hoofdstukken. Van elk hoofdstuk werden de resultaten kort samengevat en werden de belangrijkste punten voor discussie beschreven. Verder werden suggesties voor toekomstig onderzoek gegeven. Studies waarin selectieve aandacht gemeten werd met behulp van een emotionele Stroop taak of een visuele dot-probe taak (zie hoofdstuk 2) werden in een breder perspectief geplaatst door de vergelijking te maken met andere taken die (selectieve) aandacht voor lichamelijke signalen of pijn meten in individuen met verschillende pijn syndromen. Twee dimensies werden voorgesteld waar deze aandachtstaken in ondergebracht konden worden, namelijk a) de mate waarin een taak in staat is om sub-dimensies van aandacht te meten en $b$ ) de mate waarin een taak selectieve aandacht meet voor stimuli gerelateerd aan lichamelijke signalen of pijn. Met betrekking tot de manipulatie van aandacht voor pijn (zie hoofdstuk 3), kan gebruik gemaakt worden van andere uitkomstmaten dan pijnintensiteit zoals bijvoorbeeld de mate van fysieke activiteit aangezien mensen vragen naar de ervaren pijnintensiteit de mogelijke effecten van ene distractie manipulatie kunnen vertekenen. Met betrekking tot de zelf-rapportage vragenlijsten (zie hoofstuk 4), zijn er verschillende maten ontwikkeld. De mate waarin deze vragenlijsten verschillende concepten representeren binnen het brede kader van angst voor pijn alsmede de responsiviteit van de vragenlijsten dienen in vervolgonderzoek aandacht te krijgen. Tenslotte, ten aanzien van de vraagstelling werd hoofdstuk 5 besloten met de conclusie dat er weinig bewijs is dat aandacht voor pijn de relatie tussen angst voor pijn en pijn medieert en dat de klinische implicaties beperkt zijn. 


\section{DANKWOORD}

Op deze plaats wil ik mijn dank betuigen aan een aantal mensen die mij op de één of andere wijze geholpen hebben bij het tot stand komen van dit proefschrift. Allereerst wil ik mijn dank uitspreken naar mijn beide begeleiders, en co-promotoren, Madelon Peters en Johan Vlaeyen en mijn promotor Marcel van den Hout.

Madelon, ik leerde je tijdens mijn studie Geestelijke Gezondheidkunde al kennen. Je was namelijk, naast Gerben ter Riet, mijn tweede begeleider bij mijn onderzoeksstage dat over placebo en pijn ging. Toen lag mijn interesse al op het gebied van pijn en toen jij me tipte over een nieuw promotieonderzoek op het gebied van pijn waar je nog een geschikte kandidaat voor zocht reageerde ik zonder aarzeling. Niet alleen het onderwerp sprak me aan, ook het feit dat jij mijn begeleider zou worden op dit project gaf voor mij de doorslag. Al tijdens mijn onderzoeksstage viel me je wetenschappelijke gedrevenheid op en de enthousiaste wijze waarop je deze gedrevenheid op mij kon overbrengen. Deze gedrevenheid nam bij mij zijn toevlucht in het schrijven van wetenschappelijk artikelen. Ik herinner me het moment waarop er twee manuscripten van mij op je bureau lagen en ik alweer een derde klaar had om aan jouw te geven. Ik voelde toen toch enige terughoudendheid omdat je het al zo druk had. Maar toch vond je dan tijd om mijn werk op korte termijn te lezen en van bruikbaar commentaar te voorzien. Madelon, ik heb veel waardering voor je, niet alleen als collega, ook als persoon. Ik heb veel van je geleerd en hoop in de toekomst af en toe nog eens met je te kunnen samenwerken.

Johan, in mijn eigen beleving heb ik je altijd als mijn tweede begeleider beschouwd. Maar eigenlijk was je altijd even betrokken bij mijn onderzoek als Madelon. Ik heb je leren kennen als een hardwerkende wetenschapper boordevol interessante ideeën. Deze ideeën kwamen dan naar voren als ik met je aan tafel zat om een opzet van een nieuwe studie door te spreken of een artikel dat ik geschreven had. Het lukte je ook prima om de wetenschappelijke publicatie stroom bij te houden. Met enige regelmaat bracht je me een artikel aan m'n bureau wat relevant was voor mijn onderzoek. Ik heb heel fijn met je samengewerkt en je bescheidenheid en hartelijke uitstraling heb ik bijzonder gewaardeerd. Je hebt inmiddels een grote club mensen om je heen verzameld waarmee je onderzoek doet. Maar niet alleen in Maastricht, ook internationaal ben je een grootheid. Als we pijncongressen bezoeken dan wordt meermaals verwezen naar "Johan and his group" en in de wandelgangen wordt zelfs gesproken over "The Maastricht maffia". En dan was er nog het ongelooflijke verhaal over één van je schapen dat je in Praag had verteld tijdens een diner. Ik zal hier verder maar niet over uitwijden. Johan, ik wil je bedanken voor de fijne en goede samenwerking en ik hoop dat we in de toekomst nog eens samen onderzoek kunnen doen. 
Marcel, jouw rol als promotor kwam eigenlijk pas goed tot zijn recht op het moment dat het proefschrift in grote lijnen klaar was. En dat was ook prima, want ik had per slot van rekening twee uitstekende begeleiders. Toch herinnerde ik me mijn eerste artikel dat ik geschreven had en dat jij toen als beoogd promotor had bekeken. Ik kreeg een diskette van je met daarop een relatief onschadelijk virus en een document met daarin puntsgewijs een aantal opmerkingen waar ik veel aan had. We hebben nu zo naar het einde toe een aantal keren afgesproken en elke keer als ik bij je binnenkwam wist je me weer te boeien met de schat aan kennis die je bezit. Zonder speurwerk trek je dan een proefschrift uit de kast om de resultaten die daarin staan naast de mijne te leggen en vervolgens de discussie aan te gaan. Interessant en leerzaam. Marcel, ik wil je hartelijk bedanken voor de fijne samenwerking.

Het zou wat te ver voeren om nu alle mensen waarmee ik heb mogen samenwerken persoonlijk te bedanken. Dit is al een vrij omvangrijk proefschrift en het zou daarmee alleen maar nog langer worden. Toch zijn er een aantal mensen die ik in het bijzonder wil bedanken. Rosanne Janssen, jij was (en bent) er altijd voor mij. Ik denk dat niemand zich een betere vriendin kan toewensen als iemand zoals jij. Je hebt me ook nog eens ontzettend goed geholpen met de lay-out van dit proefschrift. Ik ben je veel dank verschuldigd en ik ben bijzonder vereerd dat jij paranimf bent. Ruud Houben, wij zijn tegelijkertijd begonnen als pijnonderzoekers in januari van het jaar 2000. Ik herinner me de pijncongressen waar we naar toe gingen en natuurlijk de EPP-cursussen waar we tot diep in de nacht allerlei onderwerpen de revue lieten passeren. Ik vind het dan ook ontzettend fijn dat jij paranimf bent. Peter Muris, alias Merv King, ik heb veel van je geleerd. Niet alleen op wetenschappelijk vlak, maar ook wat betreft tafeltennis en darten. Ik herinner me nog dat we een weekend lang op de Universiteit hebben gezeten om gezamenlijk te werken aan een hoofdstuk over depressie. Wie is er tegenwoordig nog zo gek te krijgen om dat te doen. Wij dus. Zo zijn wij. Je hebt altijd een inspirerende invloed op me gehad. Je bent nu hoogleraar geworden aan de Erasmus Universiteit in Rotterdam waarmee ik je ontzettend veel succes en geluk wens. Ik zal je inspiratie missen. Erik Schouten, ik wil je bedanken voor je statistische adviezen. Ik ben iemand die alles zelf wil kunnen, ook complexe statistische technieken als bevestigende factor analyse en multi-level analyse. In het begin liep ik dan wel eens tegen statistische problemen aan en dan kwam ik bij je langs. Elke keer opnieuw wist je met je heldere uitleg deze problemen als sneeuw voor de zon te laten verdwijnen. Ik kon ook altijd bij je terecht voor een potje tafeltennis of als ik trek had voor een cup-a-soup. Erik bedankt!

Verder wil ik alle collega $\mathrm{AiO}^{\prime}$ s en OiO's van DMKEP bedanken voor de steun en gezelligheid die ik van jullie heb mogen ontvangen. Tafeltennissen, darten of gewoon even binnenlopen, het kon allemaal. We zijn een leuk team samen en dat moeten we koesteren. Eén ding moet me toch van het hart. Ik ben nog nooit naar de $\mathrm{AiO}$ etentjes toe geweest en nu ik geen $\mathrm{AiO}$ meer ben mag ik natuurlijk ook niet meer 
komen. Als ik het op de een of andere manier kan goedmaken met jullie dan hoor ik dat uiteraard graag.

De dames van het secretariaat wil ik bedanken voor de hulp, de ondersteuning en de koekjes, dropjes en pepermuntjes die jullie met me hebben gedeeld de afgelopen jaren. En dan hadden we nog de bloktoetsen. Chantal van Wunnik, elke keer als er weer een bloktoets was geweest van één van mijn blokken dan kwam ik weer naar je toe met een doos vol toetsen en de vraag of je ze uit elkaar wilde halen en wilde sorteren en, als ze nagekeken waren, weer in elkaar wilde zetten. Dat lijkt me geen leuke klus en wat je zelf niet leuk vindt, moet je een ander ook niet vragen. Maar, elke keer ging je gewoon vol frisse moed aan de slag en klaarde je de klus.

Verder wil ik alle andere collega's van DMKEP danken voor de fijne contacten. Ik heb het ontzettend naar de zin gehad (en nog steeds) met jullie allemaal.

Ik wil op deze plaats ook alle studenten en patiënten die hebben meegewerkt aan de dataverzameling hartelijk danken. Zonder jullie was dit onderzoek niet mogelijk geweest. En dat geldt natuurlijk ook voor de studenten die hun onderzoeksstage bij mij hebben doorlopen en meegewerkt hebben aan de dataverzameling. In het bijzonder wil ik Marianne van der Zijden, Frans Thielen, Thijs Fassaert, Judith Deutz en Conny Spijker danken voor hun bijdrage.

Last but not least wil ik mijn familie bedanken. Mijn ouders Wim en Ingrid en mijn zus(je) Dorothy, jullie waren er altijd voor mij. Jullie leefden heel erg mee en wisten precies waar ik mee bezig was. Hoewel ik nooit echt een dip heb gehad, waren er best wel eens momenten dat ik even opzag tegen datgene wat er nog moest gebeuren. Even een telefoontje naar het thuisfront en ik kon er weer tegen. En als ik dan eens in de zoveel tijd weer eens een weekendje naar Zeeland ging dan werd ik altijd verwend. Heerlijke zelfgemaakte soep stond dan klaar bij binnenkomst en ik hoefde natuurlijk niet te koken. Heerlijk, ik kom er graag.

Jeffrey Roelofs 


\section{ABOUt THE AUTHOR}

Jeffrey Roelofs was born on January 14, 1976 in Oosterland, the Netherlands. From 1988 until 1995, he went to High School (HAVO and Atheneum) at the Regionale Scholengemeenschap Professor Zeeman in Zierikzee. In 1995, he started his study Health Sciences at Maastricht University. He specialized in Mental Health Sciences and epidemiology and graduated in December of 1999. During this period, he also followed lessons in band conducting from Jo Conjaerts at Maastricht Conservatory. From January 2000 until August 2003 he was Ph.D. student at the Department of Medical, Clinical, and Experimental Psychology of Maastricht University. During this period, he carried out the studies included in this thesis. Since August 2003, he is assistant professor at the Department of Medical, Clinical, and Experimental Psychology at Maastricht University. 


\section{Publications}

Roelofs, J., Ter Riet, G., Peters, M. L., Kessels, A. G. H., Reulen, J. P. H., \& Menheere, P. P. C. A. (2000). Expectations of analgesia do not affect spinal nociceptive R-III reflex activity: an experimental study into the mechanism of placebo-induced analgesia. Pain, 89, 75-80.

Roelofs, J. Het werkingsmechanisme van placebo's bij pijnbestrijding. (2000). De Psycholoog, 12, 554-557.

Roelofs, J. De rol van endorfines in placebo analgesie. (2001). Nederlands Tijdschrift voor de Psychologie, 56, 69-74.

Peters, M. L., Roelofs, J., \& Vlaeyen, J. W. S. (2001). Pijngerelateerde vrees en hypervigilantie bij chronische pijnpatiënten. Nederlands Tijdschrift voor de Psychologie, 56, 197-207.

Vlaeyen, J. W. S., Peters, M. L., Roelofs, J., De Jong, J., Sieben, J., Houben, R., Verbunt, J., \& Lamoth, C. (2002). Serie onderzoek en psychotherapie: catastrofale misinterpretaties. Vrees voor beweging, letsel en pijn bij lage-rugpijn. Psychotherapie, 28 (3), 205-222.

Roelofs, J., Peters, M. L., Muris, P., \& Vlaeyen, J. W. S. (2002). Dutch version of the Pain Vigilance and Awareness Questionnaire: validity and reliability in a pain-free population. Behaviour Research and Therapy, 40, 1081-1090.

Roelofs, J., Peters, M. L. Zeegers, M. P. A., \& Vlaeyen, J. W. S. (2002). The modified Stroop paradigm as a measure of selective attention towards pain-related stimuli among chronic pain patients: a meta-analysis. European Journal of Pain, 6, 273-281.

Roelofs, J., Peters, M. L. \& Vlaeyen, J. W. S. (2002). Selective attention for painrelated information in healthy individuals: the role of pain and fear. European Journal of Pain, 6, 331-339.

Roelofs, J., \& Claes, S. J. (2002). Hedendaagse biologische visies op depressie. De rol van monoamines, HPA-as-hyperactiviteit en genetische factoren. De Psycholoog, 12, 650-655.

Roelofs, J., Boissevain, M. D., Peters, M. L., De Jong, J. R., \& Vlaeyen, J. W. S. (2002). Psychological treatments for chronic low back pain: past, present, and beyond. Pain Reviews, 9(1), 29-40. 
Roelofs, J., Peters, M. L., McCracken, L., \& Vlaeyen, J. W. S. (2003). The Pain Vigilance and Awareness Questionnaire (PVAQ): further psychometric evaluation in fibromyalgia and other chronic pain syndromes. Pain, 101, 299-306.

Roelofs, J., Peters, M. L., \& Vlaeyen, J. W. S. (2003). The modified Stroop paradigm as a measure of selective attention towards pain-related information in patients with chronic low back pain. Psychological Reports, 92, 707-715.

Roelofs, J., Peters, M. L., Van der Zijden,M., Thielen, F. G. J. M., \& Vlaeyen, J. W. S. (2003). Selective attention and avoidance of pain-related stimuli: a dot-probe evaluation in a pain-free population. The Journal of Pain, 4(6), 322-328.

Swinkels-Meewisse, I. E. J., Roelofs, J., Verbeek, A., Oostendorp, R., \& Vlaeyen, J. W. S. (2003). Fear of movement/(re)injury, disability and participation in acute low back pain. Pain, 105, 371-379.

Goubert, L, Crombez, G., Van Damme, S., Vlaeyen, J. W. S., Bijttebier, P., \& Roelofs, J. (2004). Confirmatory factor analysis of the Tampa Scale for Kinesiophobia: invariant two-factor model across low back pain patients and fibromyalgia patients. Clinical Journal of Pain, 20(2), 103-110.

Roelofs, J., McCracken, L., Peters, M. L., Crombez, G., Van Breukelen, G., \& Vlaeyen, J. W. S. (2004). Psychometric evaluation of the Pain Anxiety Symptoms Scale (PASS) in chronic pain patients. Journal of Behavioral Medicine, 27(2), 167-183.

Roelofs, J., \& Muris, P. (in press). Psychological treatments for depression. In: Griez (Ed.), Mood Disorders: Clinical Management and Research Issues.

Roelofs, J., Peters, M. L., Vlaeyen, J. W. S., Goubert, L., \& Crombez, G. (in press). The Tampa Scale for Kinesiophobia: Further examination of psychometric properties in patients with chronic low back pain and fibromyalgia. European Journal of Pain.

Roelofs, J., Peters, M. L., Van der Zijden, M., Vlaeyen, J. W. S. (in press). Does fear of pain moderate the effects of sensory focusing and distraction on cold pressor pain in pain free individuals? The Journal of Pain.

Arntz, A., \& Roelofs, J. (in press). Cognitieve theorieën. In: H. Van der Molen, S. Perreijn, \& M. A. Van den Hout (Eds), Klinische psychologie. Theorieën en psychopathologie. 
Heuts, P. H. T. G., Vlaeyen, J. W. S., Roelofs, J., de Bie, R. A., Aretz, K., van Weel, C., \& Van Schayck, O. C. P. (in press). Pain-related fear and daily functioning in patients with osteoarthritis. Pain.

Swinkels-Meewisse, I. E. J., Roelofs, J., Verbeek, A. L. M., Vlaeyen, J. W. S., \& Oostendorp, R. A. B. (2004). Statistics and pain-related fear measures in acute low back pain. Manual Therapy, 9, 47-48.

Van Damme, S., Crombez, G., Eccleston, C., \& Roelofs, J. (in press). The role of hypervigilance in the experience of pain. In: G. Asmundson, G. Crombez, J. W. S. Vlaeyen (Eds.), Understanding and treating fear of pain.

\section{Articles submitted}

Roelofs, J., Crombez, G., Peters, M. L., Vlaeyen, J. W. S., \& Verschuere, B. An examination of word relevance in a modified Stroop task in patients with chronic low back pain.

Roelofs, J., Peters, M. L., Vlaeyen, J. W. S., Patijn, J., \& Schouten, E. G. W. Electronic diary assessment of pain-related fear, attention to pain, and pain intensity in chronic low back pain patients.

Roelofs, J., Peters, M. L., Fassaert, T. Vlaeyen, J. W. S. The role of fear of movement and (re)injury in selective attentional processing in chronic low back pain patients.

Roelofs, J., Verbraak, M., Keijsers, G. P. J., de Bruin, M. B. N., \& Schmidt, A. J. M. Psychometric properties of a Dutch version of the Maslach Burnout Inventory General Survey (MBI-DV) in individuals with and without clinical burnout.

Muris, P, Roelofs, J., Meesters, C., \& Boomsma, P. Rumination and worry in nonclinical adolescents.

Swinkels-Meewisse, I. E. J., Roelofs, J., Verbeek, A. L. M., Oostendorp, R. A. B., \& Vlaeyen, J. W. S. Fear-avoidance beliefs, disability, and participation in workers and non-workers with acute low back pain.

Swinkels-Meewisse, I. E. J., Roelofs, J., Verbeek, A. L. M., Oostendorp, R. A. B., \& Vlaeyen, J. W. S. Fear of movement/(re)injury and participation in the transition from acute to chronic low back pain: a prospective study. 